Florida International University FIU Digital Commons

7-21-1999

\title{
The exchange of carbon, nitrogen, and phosphorus in dwarf and fringe mangroves of the oligotrophic southern everglades
}

Stephen Edwards Davis III

Florida International University

DOI: $10.25148 /$ etd.FI14062214

Follow this and additional works at: https://digitalcommons.fiu.edu/etd

Part of the Biology Commons

\section{Recommended Citation}

Davis, Stephen Edwards III, "The exchange of carbon, nitrogen, and phosphorus in dwarf and fringe mangroves of the oligotrophic southern everglades" (1999). FIU Electronic Theses and Dissertations. 3012.

https://digitalcommons.fiu.edu/etd/3012 


\section{FLORIDA INTERNATIONAL UNIVERSITY}

Miami, Florida

\section{THE EXCHANGE OF CARBON, NITROGEN, AND PHOSPHORUS \\ IN DWARF AND FRINGE MANGROVES OF THE OLIGOTROPHIC SOUTHERN EVERGLADES}

A dissertation submitted in partial fulfillment of the requirements for the degree of

DOCTOR OF PHILOSOPHY

in

BIOLOGY

by

Stephen Edward Davis, III 
To: Dean Arthur W. Herriott

College of Arts and Sciences

This dissertation, written by Stephen Edward Davis, III, and entitled The Exchange of Carbon, Nitrogen, and Phosphorus in Dwarf and Fringe Mangroves of the Oligotrophic Southern Everglades, having been approved in respect to style and intellectual content, is referred to you for judgement.

We have read this dissertation and recommend that it be approved.

John Day

James Fourqurean

Rudolf Jaffe

Ronald Jones

Daniel Childers, Major Professor

Date of Defense: July 21, 1999

The dissertation of Stephen Edward Davis, III is approved.

Dean Arthur W. Herriott College of Arts and Sciences

Dean Richard L. Campbell Division of Graduate Studies

Florida International University, 1999 


\section{DEDICATION}

I dedicate this dissertation and the work that led to the production of it to my mother, father, and grandfather. Had it not been for the patience, love, and continuous support of my mother and father, I never would have completed my undergraduate degree. Thank you for always helping me in times of trouble and pushing me to strive for more. Early in my life, my grandfather, a self-educated naturalist, instilled upon me a love of nature and a desire to understand it. It is because of him that I chose to learn more about the inner-workings of nature. My goal is to teach and inspire others to do the same. 


\section{ACKNOWLEDGMENTS}

I would like to thank my committee members for their guidance and support throughout my stay at FIU. Although they came from somewhat different academic backgrounds (geochemistry, microbiology, oceanography, and ecology), I truly feel that I benefited from the diversity in ideas and questions they offered. I am especially grateful to Dr. Daniel Childers for giving me the opportunity to work with such an incredible group of people and for setting a wonderful example of what a major professor should be.

I am indebted to Dr. Ronald Jones and numerous technicians at the Southeast Environmental Research Center for analytical support. Damon Rondeau, Jenny Davis, Mike Korvela, Nick Oehm, and many others from the Ecosystems Lab at FIU were all helpful in conducting field and lab work. I am also indebted to the assistance provided by Steve Kelly, Dave Rudnick, Fred Sklar (South Florida Water Management District), John Day, Carlos Corronado-Molina, Brian Perez, Enrique Reyes, and Martha Sutula (Lousiana State University) throughout my four years on this project. It has been a pleasure working with each of you. The South Florida Water Management District, through a subcontract with Louisiana State University, funded much of this work. The Tropical Biology Program at FIU supported much of the leaf decomposition work.

Finally, I would like to thank my wife for providing ideas and insight and for helping me to maintain focus throughout this process. Because of her, I have learned more about myself in the last three years than the previous twenty-five combined. 
THE EXCHANGE OF CARBON, NITROGEN, AND PHOSPHORUS

IN DWARF AND FRINGE MANGROVES OF THE

OLIGOTROPHIC SOUTHERN EVERGLADES

by

\author{
Stephen Edward Davis, III \\ Florida International University, 1999 \\ Miami, Florida \\ Professor Daniel Childers, Major Professor
}

Water management has altered both the natural timing and volume of freshwater delivered to Everglades National Park. This is especially true for Taylor Slough and the C-111 basin, as hypersaline events in Florida Bay have been linked to reduced freshwater flow in this area. In light of recent efforts to restore historical flows to the eastern Everglades, an understanding of the impact of this hydrologic shift is needed in order to predict the trajectory of restoration. I conducted a study to assess the importance of season, water chemistry, and hydrologic conditions on the exchange of nutrients in dwarf and fringe mangrove wetlands along Taylor Slough. I also performed mangrove leaf decomposition studies to determine the contribution of biotic and abiotic processes to mass loss, the effect of salinity and season on degradation rates, and the importance of this litter component as a rapid source of nutrients. 
Dwarf mangrove wetlands consistently imported total nutrients $(\mathrm{C}, \mathrm{N}$, and $\mathrm{P})$ and released $\mathrm{NO}_{2}{ }^{-}+\mathrm{NO}_{3}{ }^{-}$, with enhanced release during the dry season. Ammonium flux shifted from uptake to release over the study period. Dissolved phosphate activity was difficult to discern in either wetland, as concentrations were often below detection limits. Fluxes of dissolved inorganic nitrogen in the fringe wetland were positively related to DIN concentrations. The opposite was found for total nitrogen in the fringe wetland. A dynamic budget revealed a net annual export of TN to Florida Bay that was highest during the wet season. Simulated increases and decreases in freshwater flow yielded reduced exports of TN to Florida Bay as a result of changes in subsystem and water flux characteristics. Finally, abiotic processes yielded substantial nutrient and mass losses from senesced leaves with little influence of salinity. Dwarf mangrove leaf litter appeared to be a considerable source of nutrients to the water column of this highly oligotrophic wetland. To summarize, nutrient dynamics at the subsystem level were sensitive to short-term changes in hydrologic and seasonal conditions. These findings suggest that increased freshwater flow has the potential to lead to long-term, system-level changes that may reach as far as eastern Florida Bay. 


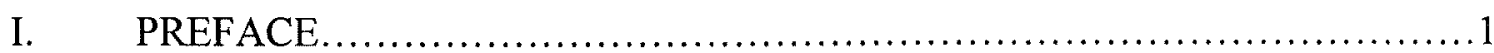

II. AN ENCLOSURE TECHNIQUE FOR QUANTIFYING WETLAND-WATER COLUMN EXCHANGE OF NUTRIENTS IN NON-TIDAL DWARF

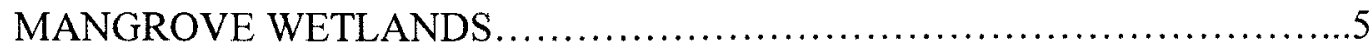

Abstract..................................................................... 5



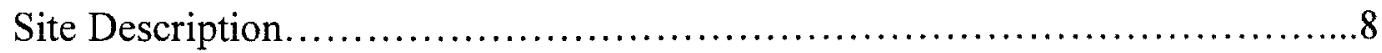

Materials and Methods.................................................... 12

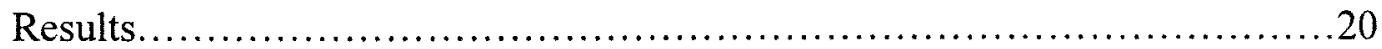

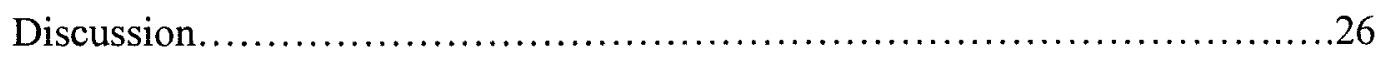

III. FACTORS AFFECTING THE CONCENTRATION AND FLUX OF CARBON, NITROGEN, AND PHOSPHORUS IN A NON-TIDAL DWARF MANGROVE

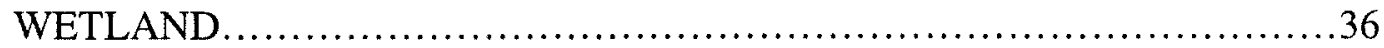

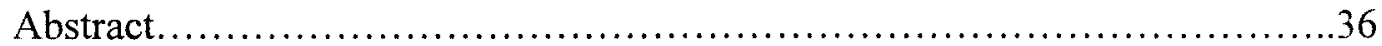

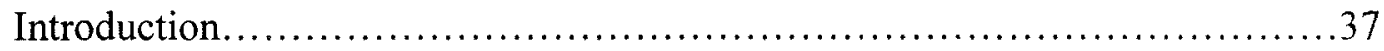

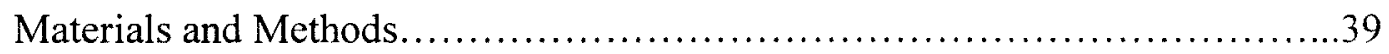

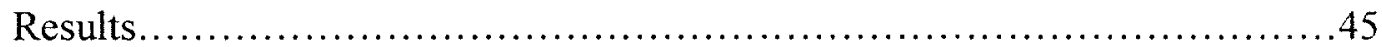

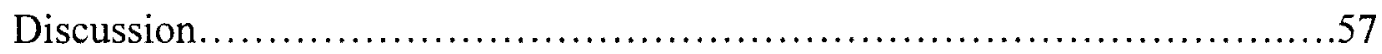

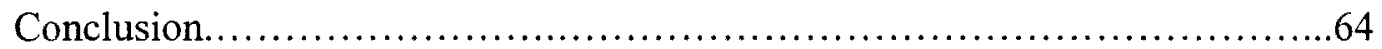

IV. FACTORS AFFECTING THE CONCENTRATION AND FLUX OF NUTRIENTS IN A SOUTHERN EVERLGADES FRINGE MANGROVE WETLAND - AN APPLICATION OF A NEW FLOW-THROUGH FLUME

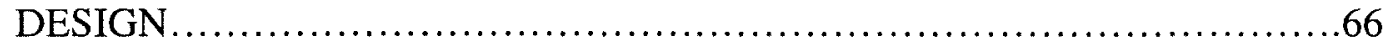

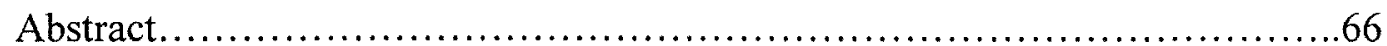

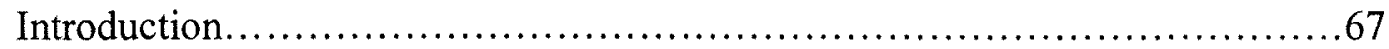

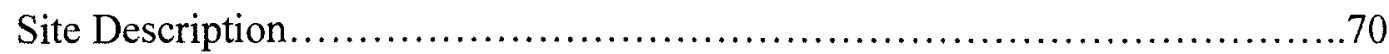

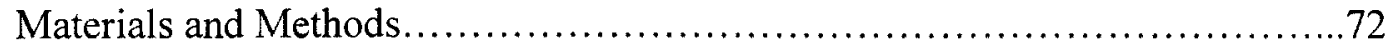

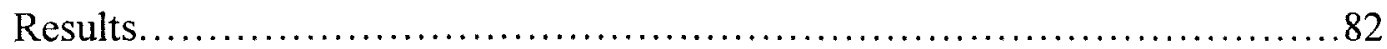

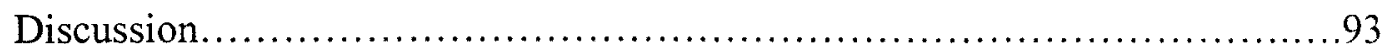

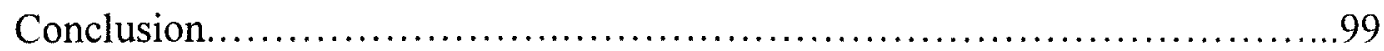

V. BIOITC AND ABIOTIC CONTROLS ON MASS AND NUTRIENT LOSS FROM DWARF RED MANGROVE LEAF LITTER DURING THE EARLY

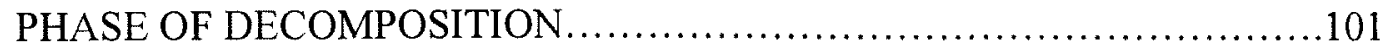

Abstract................................................................. 101

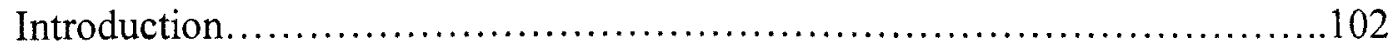

Site Description....................................................... 104

Materials and Methods................................................. 105 




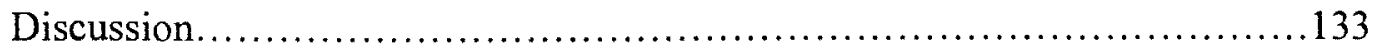

Conclusion........................................................... 140

VI. EXPLORING THE EFFECTS OF AN ALTERED HYDROLOGIC REGIME ON THE SUBSYSTEM EXCHANGE OF NITROGEN IN THE SOUTHERN EVERGLADES SALINITY TRANSITION ZONE THROUGH THE USE OF A DYNAMIC BUDGET .................................................143 Abstract ................................................................ 143

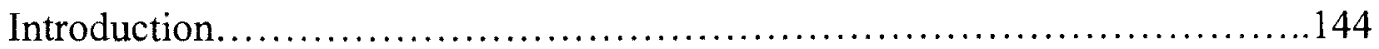

Materials and Methods................................................ 146

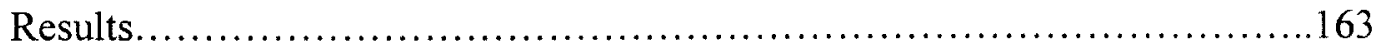

Discussion........................................................ 174

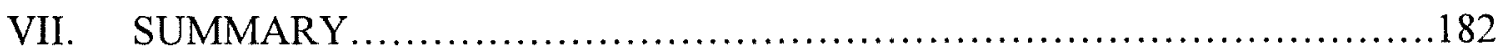

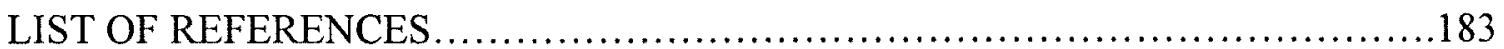

SOURCES OF UNPUBLISHED MATERIALS.................................192

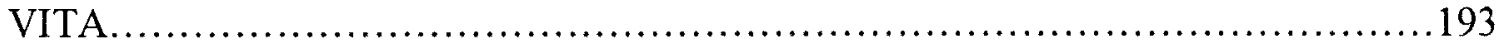




\section{LIST OF TABLES}

TABLE

PAGE

2.1- Regression results of Year 1 fluxes from dwarf mangrove enclosures. $18-19$

2.2- Comparison of dissolved inorganic nitrogen fluxes in different mangrove sites......30

3.1- List of dates and hydrologic information for each sampling of the dwarf mangrove island enclosures

3.2- ANOVA results of concentration vs. Year and concentration vs. season at dwarf mangrove site.

3.3- ANOVA results of flux vs. Year and flux vs. season at dwarf mangrove site.........55

3.4- Regression results of flux vs. salinity, temperature, and concentration at dwarf mangrove site....

4.1- List of dates and hydrologic information for each sampling of the fringe mangrove flumes.

4.2- Flux equations used in flume study .78

4.3- ANOVA results of concentration vs, season and concentration vs. direction of flow at fringe mangrove site.

4.4- Average net areal fluxes and estimated annual fluxes of nutrients in the Taylor River fringe mangrove site.

5.1- Treatment means for percent dry mass remaining in dwarf mangrove leaves......115

5.2- Water treatment and collection day treatment means for percent dry mass remaining in dwarf mangrove leaves. 116

5.3- Percentage of mass loss from various tree species attributed to leaching. .134

6.1- Sources of calibration and validation data for total nitrogen budget 152

6.2- List of model components, units, values, and equations $157-158$

6.3- Description of the four model exercises. 165

6.4- Comparison of modeled total nitrogen exchange between the salinity transition zone and Florida Bay with actual values. 


\section{LIST OF FIGURES}

FIGURE

PAGE

1.1- Map of the southern Everglades and aerial photo of Taylor Slough salinity transition

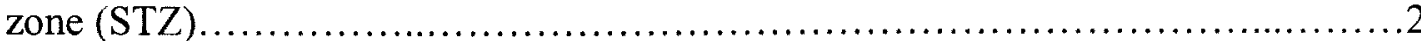

2.1 - Map of the southern Everglades and aerial photo of Taylor River and Little Madeira Bay highlighting the Buttonwood Ridge and dwarf mangrove site.....................9

2.2- Plot of daily salinity at the mouth of Taylor River and mean salinity at dwarf site

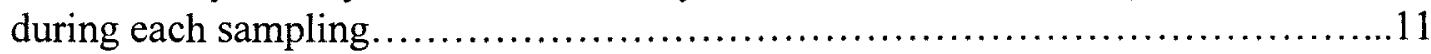

2.3- Illustration and photo of dwarf mangrove enclosures..........................13

2.4- Normalized flux of TOC in each enclosure during Jan. $97 \ldots \ldots \ldots \ldots \ldots \ldots \ldots \ldots \ldots 17$

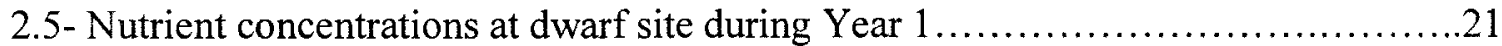

2.6- Year 1 net areal fluxes of nutrients in dwarf mangrove wetland ...................24

2.7- Regression plots of nitrate+nitrite flux vs. concentration and ammonium flux vs. temperature in dwarf mangrove enclosures.....................................25

3.1- Year 1 and 2 nutrient concentrations at dwarf site............................46

3.2- DIN:DIP and TN:TP ratios in surface water at dwarf site......................49

3.3- Correlation matrix of salinity, temperature, and nutrients at dwarf site.............51

3.4- Significant net areal fluxes of nutrients in each enclosure (Years 1 and 2).........52

3.5- Average net areal fluxes of nutrients in island enclosures and control chambers at



3.6- Estimated annual fluxes of nutrients in Taylor Slough dwarf mangrove............59

4.1- Map of southern Everglades and aerial photo of Taylor River and Little Madeira Bay highlighting the Buttonwood Ridge and fringe mangrove site $\ldots \ldots \ldots \ldots \ldots \ldots \ldots \ldots 71$

4.2- Illustration of in-channel flumes employed at fringe mangrove site...............73

4.3- Cross-sectional calibration illustration and data............................... 79

4.4- Year 1 and 2 nutrient concentrations at fringe mangrove site $\ldots \ldots \ldots \ldots \ldots \ldots \ldots \ldots 3$ 
4.5- Pie charts showing the breakdown of significant fluxes measured in the flume study

4.6- Significant fluxes of nutrients measured in the fringe mangrove

4.7- Regression relationships between dissolved inorganic nitrogen flux and concentration at the fringe mangrove site.

4.8- Time-series plots of nutrient concentration change in lower Taylor River

5.1 - a) Illustration of leaf decomposition experimental unit, and b) leaf measurements used along with initial wet weight to predict initial dry weight ................... 106

5.2- Multiple regression and ANOVA output for initial dry weight prediction..... 108

5.3- Experimental design for leaf decomposition experiment.

5.4- Percentage of dry mass remaining over time as a function of a) water treatment level and b) salinity.

5.5- Regression plots of percent dry mass remaining over time.

5.6- Initial concentrations of nutrients in mangrove leaves.

5.7- Box plots showing the effect of salinity and collection day on leaf carbon content in each water treatment level.

5.8- Change in absolute and relative leaf carbon content over time.

5.9- Change in absolute and relative leaf nitrogen content over time.

5.10- Box plots showing the effect of salinity and collection day on leaf phosphorus content in each water treatment level...

5.11- Change in absolute and relative leaf phosphorus content over time

5.12- Initial and final concentrations of nutrients in control bottles.

5.13- Regression plots of water nutrient concentration change over time....

5.14- Salinity and collection day effects on carbon, nitrogen, and phosphorus content of water in incubation bottles.

5.15- Changes in $\mathrm{C}: \mathrm{N}, \mathrm{N}: \mathrm{P}$, and $\mathrm{C}: \mathrm{P}$ ratios in incubation water over time 
5.16- Contribution of carbon to mass loss from mangrove leaves over time.

6.1- a) Map of southern Everglades, b) aerial photo of Taylor Slough salinity transition zone (STZ), and c) conceptualized illustration of water and nutrient sources as a function of season

6.2- Water flux (black) and salinity (gray) data at the mouth of Taylor River....

6.3- Regression relationships between salinity and total nitrogen concentrations at a) the mouth of Taylor River, b) the dwarf site, and c) at the fringe site

6.4- Regression relationships between total nitrogen concentration and flux at the dwarf and fringe mangrove sites.

6.5- Illustration of total nitrogen budget using STELLA symbols....

6.6- Regression relationships between fringe mangrove water level and water flux when flow was toward the south and north.

6.7- Hypothesized relationships between wetland area and water level in each mangrove subsystem.

6.8- Daily values of wetland area (black) and water level (gray) in the a) dwarf and b) fringe subsystem.

6.9- Comparison of modeled total nitrogen concentrations in the dwarf (black) and fringe (dark gray) subsystems with actual concentrations at the mouth of Taylor River (light gray)

6.10- Daily net areal and total fluxes of total nitrogen in the dwarf (black) and fringe (gray) subsystems.

6.11- Validation of modeled total nitrogen exchange between the salinity transition zone and Florida Bay

6.12- Validation of modeled net areal fluxes of total nitrogen in the dwarf mangrove subsystem....

6.13- Model output from exercises 1 and 2 ....

6.14- Model output from exercises 3 and 4 


\section{Chapter 1:}

\section{Preface}

The mangroves of the Everglades and Florida Bay are characterized by different growth forms that are a function of local environmental, hydrologic, and geomorphologic conditions (Lugo and Snedaker 1974; Cintron et al. 1985; Twilley 1998). These conditions not only affect mangrove structure and productivity but also the species composition of the forest (Thom 1967; McKee 1993; Chen and Twilley 1998). Between the freshwater marshes of the southern Everglades and northeast Florida Bay lies a vast area $(\approx 6,000$ ha) of dwarf $(1-1.5 \mathrm{~m}$ in height) red mangrove (Rhizophora mangle L.) wetland (Figure 1.1). This is a low nutrient environment with extremely low primary productivity and little to no tidal influence (Lugo and Snedaker 1974; Cintron et al. 1985). Fringe mangroves, which are more productive and nutrient rich than the dwarf systems, occupy the land-sea interface of this region and are flushed on a more regular basis (Lugo and Snedaker 1974; Cintron et al. 1985; Figure 1.1). The red mangrove is also the predominant species in these wetlands. Together, these two mangrove wetland types make up a substantial portion of what is currently referred to as the salinity transition zone (STZ) of the southern Everglades (Figure 1.1).

The STZ of the southern Everglades is loosely defined as the area of wetland from the northernmost extent of salinity penetration to the interface of the mainland and Florida Bay. Since the influence of tide in this area of the Everglades is negligible, season (wet v. dry) is believed to be the most important factor driving the annual salinity and nutrient profiles through the STZ. However, water management practices, dating back to the early to mid-1900's, have altered both the natural timing and volume of 


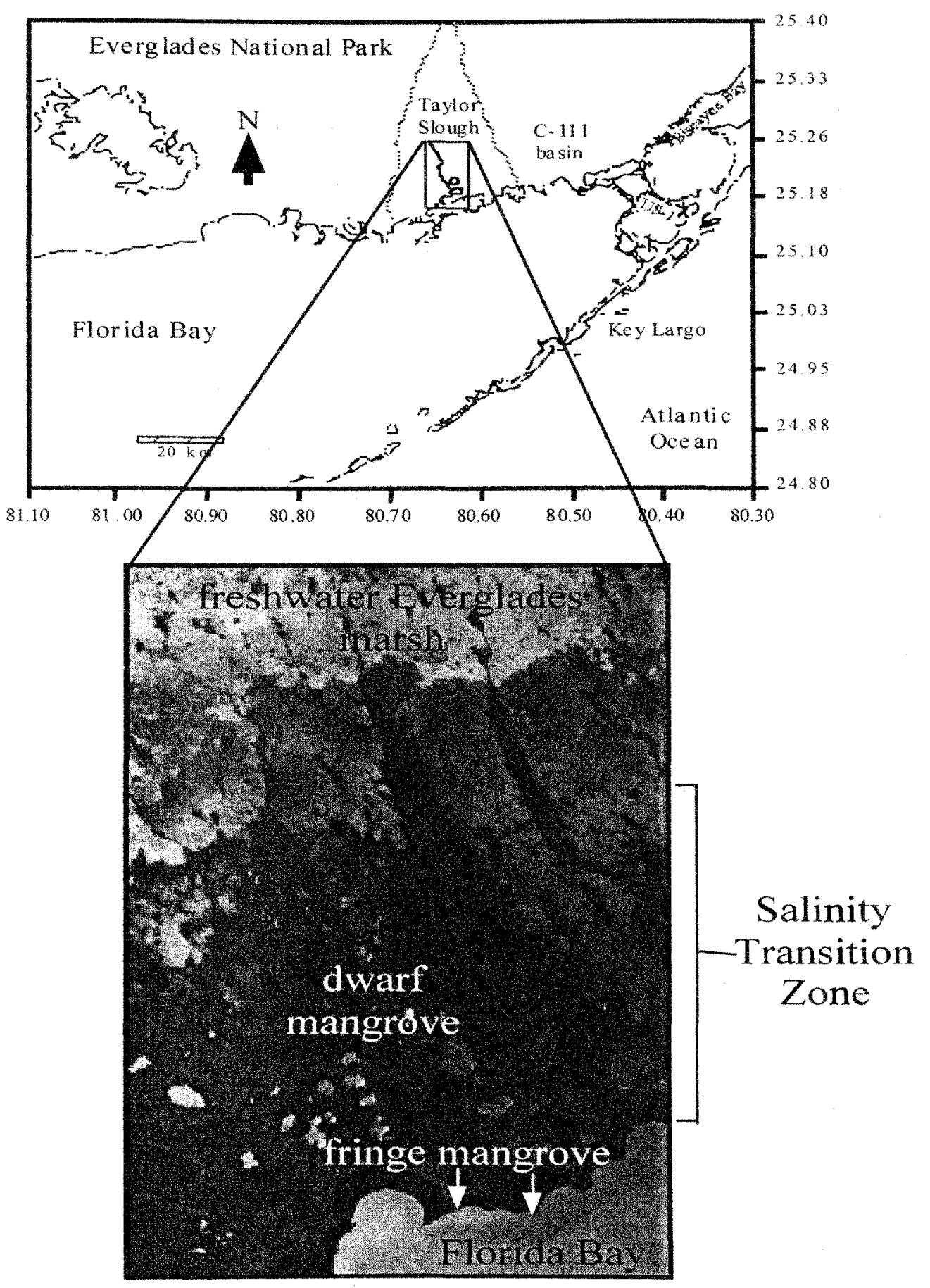

Figure 1.1 - Map of southern Everglades and Florida Bay (top) along with aerial photo of the Taylor Slough salinity transition zone (STZ; bottom) highlighting the locations of dwarf and fringe mangrove wetlands. 
freshwater flowing from the Everglades into Florida Bay. In fact, it has been speculated that past reductions in freshwater flow led to the expansion of the STZ and, thus, to an increase in areal coverage of mangrove wetlands (Ball 1980; Odum et al. 1982). While these structural changes developed over a relatively long time scale (20-50 years), changes in nutrient dynamics may have been evident on much smaller time scales (1-2 years). Given the current efforts to restore the historical freshwater flows back to the southern Everglades, an understanding of the short-term effects on whole-system nutrient dynamics is necessary in order to predict the trajectory of ecosystem change.

Therefore, I conducted a number of studies to determine the effects of season and surface water salinity on the exchange of carbon $(\mathrm{C})$, nitrogen $(\mathrm{N})$, and phosphorus $(\mathrm{P})$ in dwarf and fringe mangrove wetlands of the oligotrophic southern Everglades. Both of these factors pertain to freshwater flow and were expected to vary throughout the course of the two-year study. First, I performed studies of wetland-water column exchange of C, $\mathrm{N}$, and $\mathrm{P}$ in each wetland type during both the wet and dry season (Chapter 2-4). The flux data generated from these "black box" studies were then related to surface water temperature and salinity as well as season in order to account for flux variability. Next, I performed an experiment to estimate the contribution of mangrove leaf litter to water column nutrients $(\mathrm{C}, \mathrm{N}$, and $\mathrm{P})$ and the effect of salinity on the processes (biotic and abiotic) that regulate the release of these nutrients (Chapter 5). Of the numerous processes regulating the wetland-water column exchanges of nutrients, leaf litter decomposition was expected to be one of the most important and easiest to quantify.

Finally, synthesizing flux data from the dwarf and fringe subsystems as well as from daily water sampling, I developed a dynamic budget for total nitrogen in the STZ of 
Taylor Slough, Everglades National Park (Chapter 6). This budget accounted for the daily exchange of total nitrogen within and between the dwarf and fringe subsystems as well as between the STZ and Florida Bay, as a function of seasonal hydrology. Using this budget, I also performed a series of exercises to determine the likely outcome of changing freshwater flows during the wet and dry season. The results of these exercises as well as the results of this research are an important first step in understanding how past and future water management activities will affect ecological pattern and process in the southern Everglades. 


\section{Chapter 2:}

\section{An enclosure technique for quantifying wetland-water column exchange of nutrients in non-tidal dwarf mangrove wetlands}

\section{Abstract}

Few studies of wetland-water column exchange of nutrients exist in the mangrove literature, especially for dwarf mangrove systems. I developed and implemented an enclosure technique to quantify the exchanges of carbon, nitrogen, and phosphorus in a non-tidal, dwarf mangrove wetland along Taylor River, Everglades National Park. Four, quarterly samplings of triplicate, dwarf mangrove island enclosures were conducted from August 1996 (early wet season) to May 1997 (late dry season). Simple linear regression techniques were used to determine net areal fluxes of nutrients in each enclosure, for each sampling. Significant fluxes were measured for all constituents except soluble reactive phosphorus. Results indicated that nitrate + nitrite was consistently exported throughout the year, however this export was significantly greater during dry season compared to wet season samplings. Ammonium flux displayed a different seasonal pattern with export shifting to import as water temperature decreased. The other constituents did not show a noticeable seasonal effect. This wetland was a source of dissolved organic carbon and a sink for total nutrients (organic carbon, nitrogen, and phosphorus) for much of the year. Comparisons with mangrove flux studies from across the tropics indicate: 1) that this non-tidal, oligotrophic dwarf system appears to cycle nitrogen differently than other more productive systems, and 2) this technique provides flux results similar in magnitude to those generated by mangrove benthic flux studies. I believe that this technique has many 
potential applications in both dwarf mangrove and other functionally similar wetland systems and can be used to address many questions of ecological interest.

\section{Introduction}

Dwarf mangroves are one of the four mangrove forest types commonly found in the neo-tropics (Cintron et al. 1985). These forests are characterized by low productivity, are typically dominated by a single species, and rarely attain canopy heights greater than $1.5 \mathrm{~m}$ (Lugo and Snedaker 1974; Cintron et al. 1985). It has been speculated that a number of factors, including soil salinity, degree of soil saturation, soil compactness, and nutrient availability contribute to the stature of these forests (Davis 1940; Egler 1952; Craighead 1971; Lugo and Snedaker 1974; Lin and Sternberg 1992). However, recent experimental evidence suggests that nutrient availability (i.e. phosphorus) may be the most important factor controlling dwarf mangrove production, especially in carbonatedominated systems (Feller 1995; Koch 1997).

Along the southeastern tip of Florida, the red mangrove (Rhizophora mangle L.) is the dominant species in most dwarf mangrove systems. Dwarf red mangrovedominated wetlands cover approximately 6,000 ha between the southern freshwater Everglades marshes and the coastal fringe mangrove systems that line the perimeter of southern Biscayne Bay and eastern Florida Bay (Lin and Sternberg 1992). This region is characterized by calcareous marl soils with little or no tidal influence (Davis 1940; Egler 1952) and, like the freshwater Everglades marshes and Florida Bay, is highly

oligotrophic. While these mangrove wetlands may be an important structural component 
of the vegetated landscape of this region, little is known about their functional role as potential sources, sinks or transformers of nutrients.

Over the last 30 years, there have been a number of studies addressing such issues in temperate estuarine wetlands. For the most part, these studies emphasized one or two equally important processes: the vertical flux of energy and nutrients between a wetland and the overlying water column, or the horizontal advection of energy and nutrients between the wetland and the adjacent tidal creek or coastal system. Early estuarine exchange studies were more concerned with testing the hypothesis that the wetlands are sources of organic matter (energy) to adjacent coastal systems (reviews by Nixon 1980; Childers et al. 1999). However, as the results of these studies became more ambiguous, there was a movement to look more closely at marsh-water column or marsh-tidal creek interactions (Wolaver et al. 1983; Wolaver and Spurrier 1988; Whiting and Childers 1989; Childers and Day 1990; Childers 1994).

Aside from the pioneering works of Golley et al. (1962) and Odum and Heald (1972), it has been only in the last 10-15 years that tropical, mangrove-dominated estuaries have been the setting for this type of ecosystem-level research. Adapting many of the techniques developed in temperate salt marsh systems, investigators of recent mangrove studies have shown that tidally-driven mangrove wetlands can effectively serve as sinks for total suspended solids (Rivera-Monroy et al. 1995) and dissolved inorganic nitrogen (Kristensen et al. 1988; Rivera-Monroy et al. 1995). Tidally influenced mangrove systems also appear to be net sources of organic carbon to adjacent coastal systems (Twilley 1985; Lee 1990), even though the mangrove soils may serve as an efficient sink for dissolved organic carbon (Boto et al. 1989). 
My goal was to develop and implement a portable, meso-scale, in situ technique for quantifying wetland-water column interactions in a non-tidal dwarf mangrove system. The site chosen for this study was a dwarf red mangrove wetland along the Taylor River mangrove system in Everglades National Park. Specifically, I wanted to quantify the exchange of carbon (total and dissolved organic carbon), nitrogen (nitrate+nitrite, ammonium, and total nitrogen), and phosphorus (soluble reactive and total phosphorus) between the dwarf mangrove wetland and the overlying water column. I also sought to explain some of the seasonal variability in the patterns of these exchanges with factors such as surface water salinity, temperature, and ambient nutrient concentration data. In this paper I demonstrate the efficacy of this new method with data from four quarterly flux samplings.

\section{Site Description}

Taylor Slough is the primary natural drainage for freshwater in the southern Everglades, second only to Shark River Slough in all of Everglades National Park. It is located in the southeast corner of Everglades National Park and feeds numerous mangrove creeks that empty into northeastern Florida Bay. One of the most significant of these channels, in terms of freshwater input into Florida Bay, is Taylor River (Figure 2.1). Taylor River is a fairly small channel (approximately $10 \mathrm{~m}$ wide and $1-2 \mathrm{~m}$ deep) that links a number of small, shallow ponds along the north-south gradient of the mangrove salinity transition zone of the southern Everglades. Although it empties into Florida Bay, via Little Madeira Bay (Figure 2.1), Taylor River is not significantly affected by tides. In fact, the direction and velocity of water flow in Taylor River is 


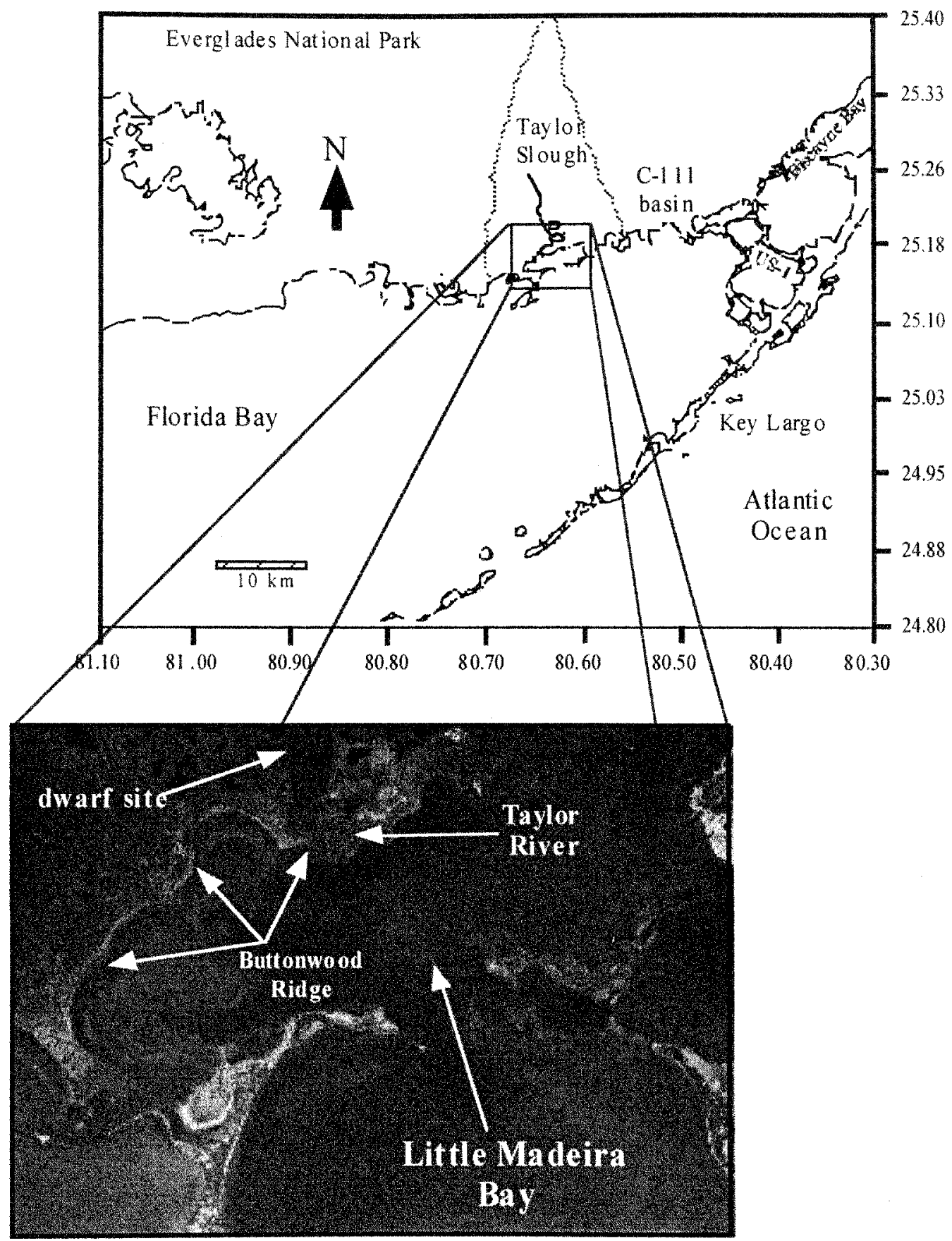

Figure 2.1 - Map of southern Everglades (Taylor Slough), Florida Bay and upper Florida Keys. Enlargement is an aerial photograph of Little Madeira Bay and Taylor River with dwarf mangrove site highlighted. 
driven mostly by the interaction of precipitation, upland runoff, and wind. The result is a clear seasonal salinity pattern that is illustrated in a plot of daily salinity data at the mouth of Taylor River (Figure 2.2).

During a typical wet season (June-November), high precipitation produces a net southerly flow of water from Taylor Slough into Taylor River, which leads to freshwateroligohaline conditions throughout much of the wet season. As the dry season progresses, high evaporation in the Everglades marshes combined with a reduced freshwater head and decreased precipitation result in a hydraulic head in the opposite direction. This yields increased salinity throughout the mangrove zone, the maximum of which is typically set by the salinity of Florida Bay (Figure 2.2). However, during extremely dry years, high evapotranspiration in this shallow wetland combined with no precipitation and reduced freshwater flow can produce surface water salinity in excess of 50\%o (McIvor et al. 1994). Short-term variability (daily to weekly fluctuations) in Taylor River salinity is often driven by wind forcing that is most pronounced during seasonal transitions (personal observation).

Three mangrove forest types characterize the salinity transition zone of Taylor River. A red mangrove-dominated, fringe forest lines the lower stretch of Taylor River as well as the shoreline of Little Madeira Bay. Behind this fringe forest is a black (Avicennia germinans L.) and white (Laguncularia racemosa L. Gaertn.) mangrovedominated basin forest. This band of vegetation runs parallel to Florida Bay along the Buttonwood Ridge and is roughly 0.5 to $1 \mathrm{~km}$ wide (Figure 2.1 ). The remaining mangrove area in between these two forest types and the freshwater Everglades marshes, is dominated by a continuous stand of dwarf red mangrove. Within this zone, there are 


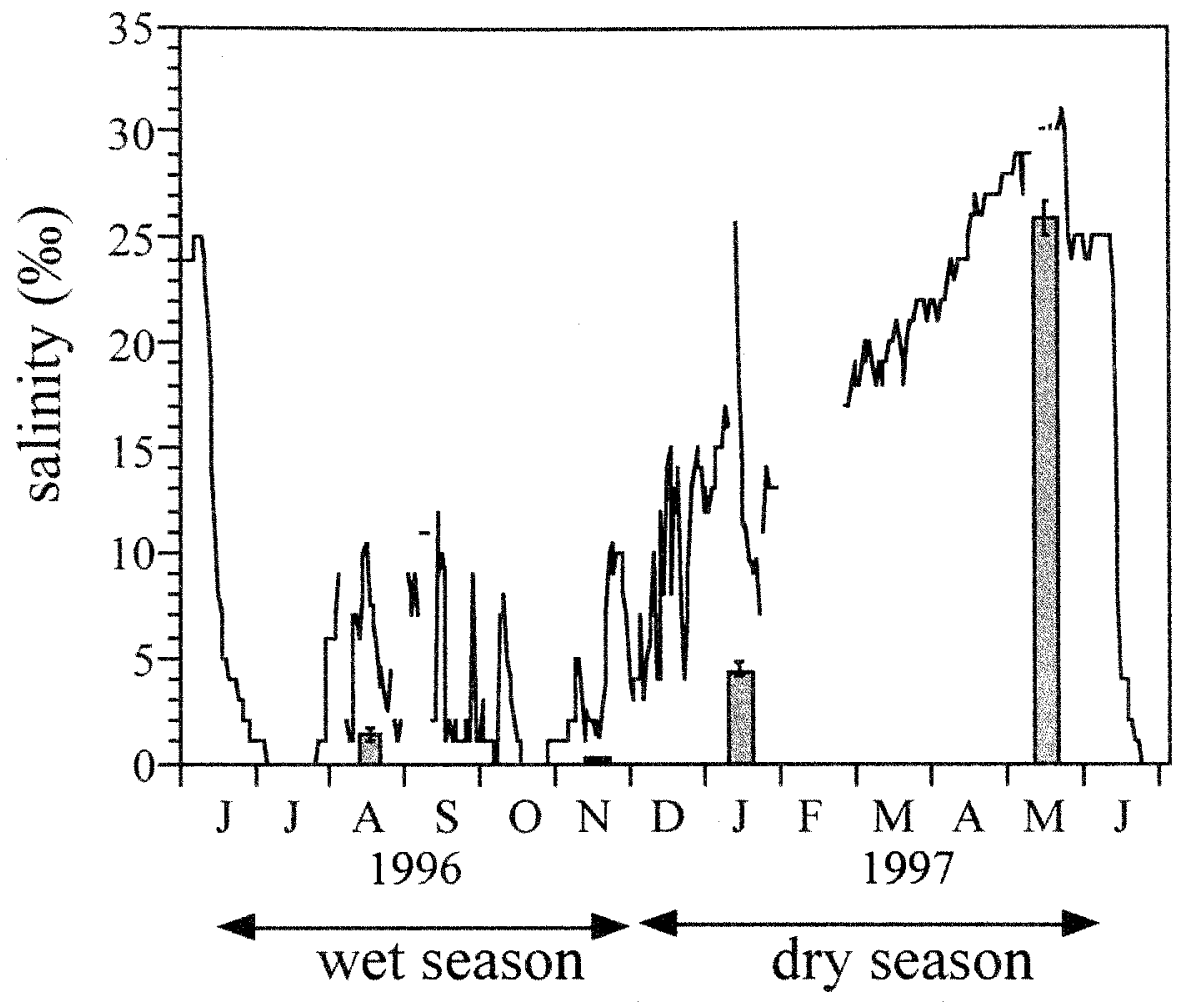

Figure 2.2- Plot of daily averages of salinity (\%o) at the mouth of Taylor River from May 1996 - June 1997 and average salinity \pm standard deviation in the dwarf site during the four sampling periods (histogram bars). The salinity was $0 \%$ for the entire duration of the November 1996 sampling. 
numerous isolated dwarf mangrove islands of varying size (1-10m in diameter) residing in the deeper $(0.5-1 \mathrm{~m})$ areas of the slough. These islands are found on peat mounds with 0.1-0.5m in relief from the bottom of the basin (see enclosure cross-section; Figure 2.3). The hydrology of the dwarf zone in Taylor River is characterized mostly by sheetflow with low current velocities (usually $<1 \mathrm{~cm} \mathrm{~s}^{-1}$ ), and the wetland is perennially inundated. The enclosure study was conducted in this type of dwarf mangrove, approximately $5 \mathrm{~km}$ north of Florida Bay (Figure 2.1).

\section{Materials and Methods}

I constructed circular enclosures around three small $(2.5-4 \mathrm{~m}$ in diameter $)$ dwarf red mangrove islands as shown in Figure 2.3. Island selection was based on accessibility, structural similarity, and proximity to one another, as all sampling was conducted from a kayak. Each enclosure was composed of supports, walls, and attachments. For the supports, aluminum fence posts were set into the mangrove peat at $2 \mathrm{~m}$ intervals around each island and left in place for the duration of the study. The walls and attachments were constructed of a single piece of 6 mil, clear plastic film pre-fabricated with rows of shower curtain rings. Each wall also had a medium-weight chain installed along the bottom to hold it flush against the soil surface. During deployment, the walls were attached to the poles with the rings and the weight of the chain held the wall to the soil surface. At the conclusion of each sampling, the walls were removed in order to prevent shading and isolation effects.

Before the first sampling, I conducted intensive surveys of the microtopography

of each island and established permanent water level meters adjacent to each island. An 
a.

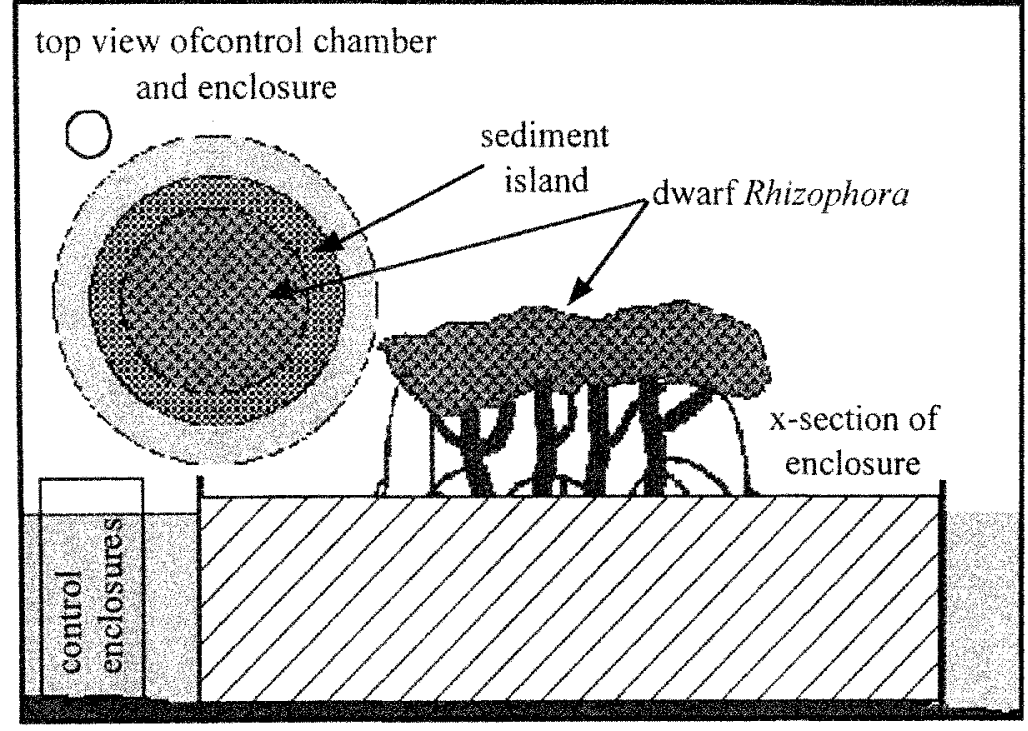

b.

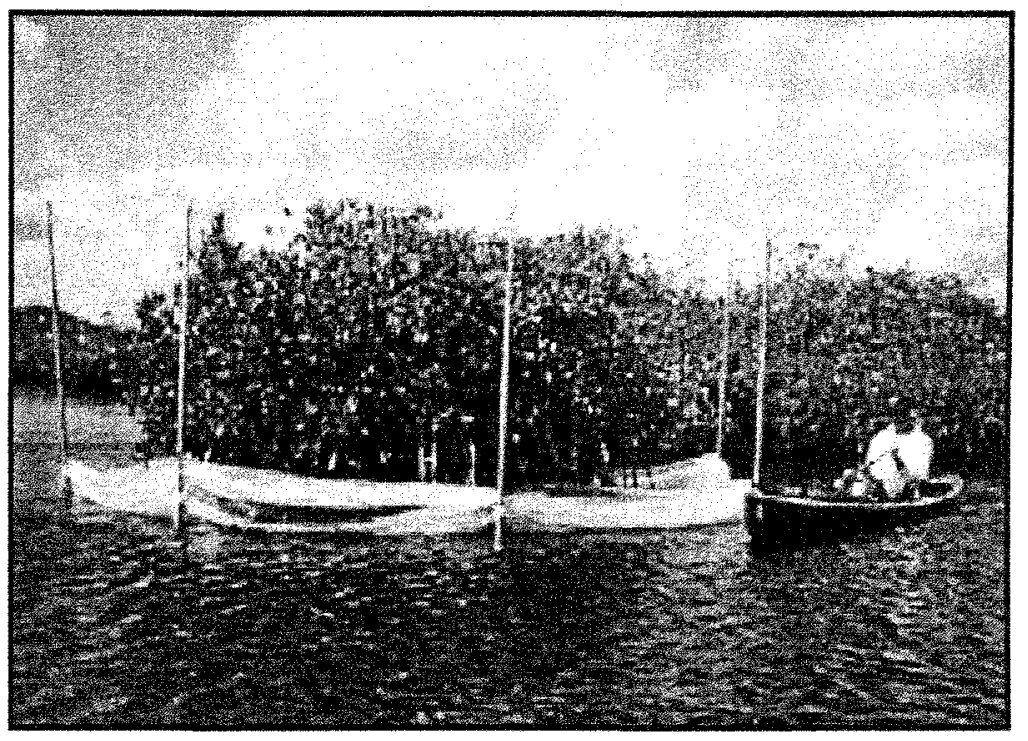

Figure 2.3- a) Illustration of top and cross-sectional views of a dwarf mangrove island enclosure. b) Picture of one of three mangrove enclosures used in Taylor River. All work was conducted from a kayak to reduce soil and prop root community disturbance. 
estimation of the volume of prop roots on each island was then made using data from measured samples. Specifically, I took a prop root census and measured the diameter and length of root submerged from a random sample of 30 prop roots at each island. Assuming that each prop root was a cylinder, the average volume of cylinder (root) submerged was estimated from sample data from each island. The total volume of prop root submerged was then calculated as the product of the average volume of root submerged and the total number of submerged prop roots at each island, at a known water level. I also assumed that the change in volume of each cylinder submerged was a linear function of change in water level. Considering that the range of water level variation during the course of this study was less than $7 \mathrm{~cm}$, I felt this was a safe assumption. Going on these assumptions, a linear model was generated whereby I could estimate the volume of water inside each enclosure and the volume of prop roots submerged from the water level data at a given sampling. Finally, survey data were also used to estimate mangrove island surface area. These values were used to normalize fluxes to a per $\mathrm{m}^{2}$ surface area of wetland.

\section{Enclosure sampling}

I conducted quarterly samplings of the dwarf mangrove enclosures so as to include two wet season (August 96-early wet season and November 96-late wet season) and two dry season (January 97-early dry season and May 97-late dry season) samplings. All fieldwork (i.e. deployment, sampling, and takedown) was conducted from a small boat to reduce soil and prop root community disturbance. At the onset of each sampling, water samples were collected next to each island immediately before the walls were 
lowered into position. Beginning one hour after the walls were lowered, temperature, salinity, and water level were measured and water samples were collected hourly for six hours.

Water samples were taken from inside each of the enclosures at mid-depth using a Nalgene hand pump and side-arm flask, which was connected to a sample tube with a sample diffuser on the end. The sample diffuser was made from a $0.3 \mathrm{~m}$ section of rigid HDPE tubing (1.25cm I.D.) that was sealed at one end and had numerous holes along its length. The purposes of the sample diffuser were 1) to reduce soil or prop root community disturbance, and 2) to allow for the collection of a more integrated water sample. Samples were also collected just outside each enclosure using the same procedures to monitor ambient concentrations of all constituents.

\section{Nutrient analyses}

Immediately after collection, a portion of each water sample was filtered (Whatman $\mathrm{GF} / \mathrm{F}$ ) in the field. Filtered samples were stored frozen and unfiltered samples were kept at $4^{\circ} \mathrm{C}$ until analyzed for nutrient content. Hourly salinity and temperature measurements were made with an analog S-C-T meter (YSI Model 33).

All nutrient analyses were performed at the Southeast Environmental Research Center (SERC) laboratory at Florida International University. Unfiltered water samples were analyzed for total phosphorus (TP) according to a modification of the dry ashing, acid-hydrolysis technique (Solorzano and Sharp, 1980), total nitrogen (TN) using an Antec $7000 \mathrm{~N}$ total nitrogen analyzer, and total organic carbon (TOC) using a hot platinum catalyst, direct injection analyzer (Shimadzu model TOC-5000). Filtered water 
samples were analyzed for soluble reactive phosphorus (SRP), ammonium $\left(\mathrm{NH}_{4}{ }^{+}\right)$, nitrate+nitrite $\left(\mathrm{NO}_{3}{ }^{-}+\mathrm{NO}_{2}{ }^{-}\right)$, and nitrite $\left(\mathrm{NO}_{2}{ }^{-}\right)$on a four-channel auto-analyzer (Alpkem model RFA 300), and for dissolved organic carbon (DOC) using the same method listed above for TOC.

\section{Calculation of fluxes}

Net areal fluxes for a given sampling were calculated by regressing concentration change, normalized for enclosure water volume and wetland area, from each interval versus sampling time $(\mathrm{h})$. Normalized concentration change values were calculated as the product of the difference between the initial concentration $(\mu \mathrm{M})$ and concentration at interval $=x$ and the volume of the enclosure (V) at interval $=x$, divided by the mangrove island area (A; see equation 1 below). For each replicate enclosure, normalized fluxes of a given constituent from all intervals were then regressed against sampling time using StatView 5 (SAS Institute, Inc., Cary, NC). Refer to Figure 2.4 for example of normalized flux regressions for each enclosure. Significant slopes (ANOVA, $p<0.1$ ) generated from this procedure indicated a flux of a given constituent in a single enclosure. Furthermore, the slopes of these models were considered the net areal fluxes for each enclosure (Table 2.1). An alpha level of 0.1 was chosen for the regression analyses to compensate for the small sample size ( $n=6$, for each enclosure) and the high level of variability expected with this in situ study. Standard deviations and averages of net areal flux were calculated when more than one enclosure showed a flux for a given constituent. If only one enclosure showed a flux of a given constituent, then that value 

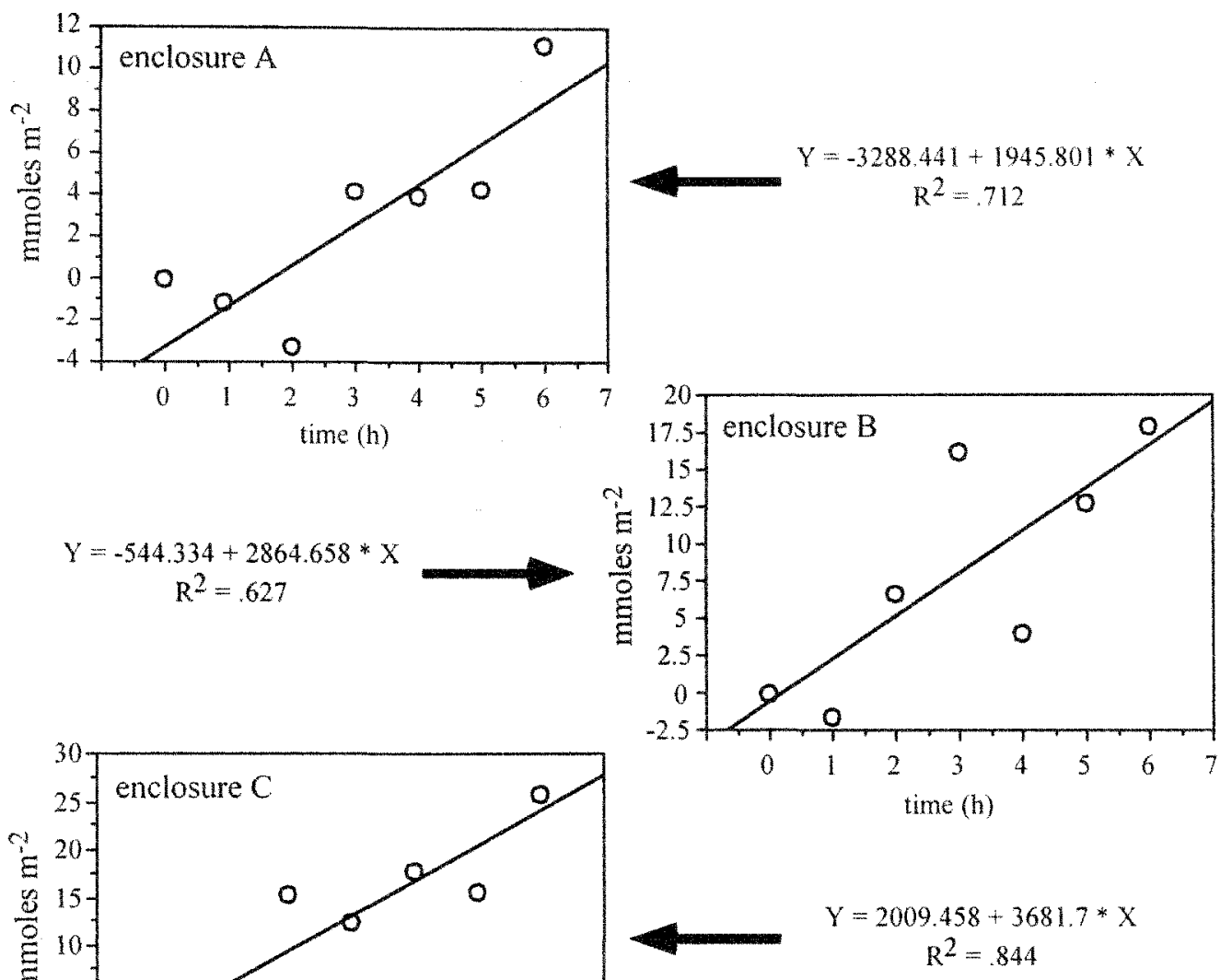

Figure 2.4- An example of net areal flux determination used in this study. Regressions of normalized TOC flux versus time (h) in each enclosure during the January 1997 sampling. Significant slopes $(\mathrm{p}<0.1)$ were used as the net areal flux. Positive slopes, as in this instance, indicated an uptake by the wetland while negative slopes signified an export from the wetland to the water column. 
Table 2.1 - Table showing slope (slope = net areal flux), p-value, and r-squared from each regression of normalized flux versus sampling time in all enclosure samplings. Positive slopes indicate nutrient uptake by the mangrove wetland and negative slopes indicate nutrient export from the wetland to the overlying water column. $\mathrm{nf}=$ no flux measured.

\begin{tabular}{|c|c|c|c|c|c|c|c|c|c|c|}
\hline \multirow[b]{2}{*}{ sampling } & \multirow[b]{2}{*}{ rep. } & \multicolumn{3}{|c|}{ nitrate + nitrite } & \multicolumn{3}{|c|}{ ammonium } & \multicolumn{3}{|c|}{ total nitrogen } \\
\hline & & slope & $\mathrm{p}$-value & $\mathrm{R}^{2}$ & slope & $\mathrm{p}$-value & $\mathrm{R}^{2}$ & slope & $\mathrm{p}$-value & $\mathrm{R}^{2}$ \\
\hline \multirow[t]{3}{*}{ Aug.96 } & $\mathrm{A}$ & -12.87 & 0.006 & 0.81 & -13.19 & 0.075 & 0.50 & 349.81 & 0.021 & 0.69 \\
\hline & B & -12.32 & 0.088 & 0.47 & -12.99 & 0.036 & 0.62 & 317.58 & 0.072 & 0.51 \\
\hline & $\mathrm{C}$ & -16.64 & 0.013 & 0.74 & -17.17 & 0.043 & 0.59 & 380.20 & 0.050 & 0.57 \\
\hline \multirow[t]{3}{*}{ Nov. 96} & $\mathrm{~A}$ & -22.52 & 0.077 & 0.50 & 8.36 & 0.071 & 0.51 & 79.24 & 0.006 & 0.81 \\
\hline & B & -18.78 & 0.043 & 0.59 & 8.15 & 0.065 & 0.53 & 142.23 & 0.022 & 0.68 \\
\hline & $\mathrm{C}$ & -10.21 & 0.093 & 0.46 & 8.30 & 0.092 & 0.46 & 157.00 & 0.076 & 0.50 \\
\hline \multirow[t]{3}{*}{ Jan. 97} & A & -78.96 & 0.079 & 0.49 & 29.42 & 0.057 & 0.55 & 293.15 & 0.005 & 0.83 \\
\hline & B & -141.07 & 0.0003 & 0.94 & 14.95 & 0.060 & 0.54 & 278.87 & 0.027 & 0.66 \\
\hline & $\mathrm{C}$ & -76.94 & 0.031 & 0.64 & 34.50 & 0.017 & 0.72 & 307.70 & 0.031 & 0.64 \\
\hline \multirow[t]{3}{*}{ May. 97} & A & -41.74 & 0.024 & 0.67 & -42.44 & 0.073 & 0.51 & $\mathrm{nf}$ & - & - \\
\hline & $\mathrm{B}$ & -49.61 & 0.081 & 0.49 & -27.94 & 0.0003 & 0.94 & -135.74 & 0.014 & 0.73 \\
\hline & $\mathrm{C}$ & -42.60 & 0.088 & 0.47 & -19.90 & 0.074 & 0.50 & $\mathrm{nf}$ & - & - \\
\hline
\end{tabular}


Table 2.1- continued from previous page

\begin{tabular}{|c|c|c|c|c|c|c|c|c|c|c|c|c|c|}
\hline \multirow{2}{*}{\multicolumn{2}{|c|}{ rep }} & \multicolumn{3}{|c|}{ reactive phosphorus } & \multicolumn{3}{|c|}{ total phosphorus } & \multicolumn{3}{|c|}{ dissolved organic carbon } & \multicolumn{3}{|c|}{ total organic carbon } \\
\hline & & slope & $\mathrm{p}$-value & $\mathrm{R}^{2}$ & slope & $\mathrm{p}$-value & $\mathrm{R}^{2}$ & slope & p-value & $\mathrm{R}^{2}$ & slope & $\mathrm{p}$-value & $\mathrm{R}^{2}$ \\
\hline \multirow[t]{3}{*}{ Aug.96 } & $\mathrm{A}$ & $\mathrm{nf}$ & - & - & 2.97 & 0.070 & 0.51 & $\mathrm{nf}$ & - & - & 3369.64 & 0.047 & 0.58 \\
\hline & $\mathrm{B}$ & $\mathrm{nf}$ & - & - & 2.51 & 0.098 & 0.45 & 4730.24 & 0.014 & 0.73 & 3865.17 & 0.026 & 0.66 \\
\hline & $\mathrm{C}$ & -2.00 & 0.007 & 0.80 & 2.89 & 0.097 & 0.45 & $\mathrm{nf}$ & - & - & 4681.94 & 0.059 & 0.54 \\
\hline \multirow[t]{3}{*}{ Nov. 96} & A & $\mathrm{nf}$ & - & - & -1.02 & 0.034 & 0.63 & -6629.84 & 0.042 & 0.60 & -3547.87 & 0.042 & 0.60 \\
\hline & $\mathrm{B}$ & $\mathrm{nf}$ & - & - & -6.07 & 0.055 & 0.56 & -7246.51 & 0.066 & 0.52 & -3359.56 & 0.001 & 0.90 \\
\hline & $\mathrm{C}$ & 0.57 & 0.089 & 0.47 & -3.94 & 0.048 & 0.58 & -3050.03 & 0.013 & 0.74 & $\mathrm{nf}$ & - & - \\
\hline \multirow[t]{3}{*}{ Jan. 97} & A & $\mathrm{nf}$ & - & - & $\mathrm{nf}$ & - & - & 1728.74 & 0.090 & 0.47 & 1945.80 & 0.017 & 0.71 \\
\hline & $\mathrm{B}$ & $\mathrm{nf}$ & - & - & $\mathrm{nf}$ & - & - & $\mathrm{nf}$ & - & - & 2864.66 & 0.034 & 0.63 \\
\hline & $\mathrm{C}$ & $\mathrm{nf}$ & - & - & $\mathrm{nf}$ & - & - & $\mathrm{nf}$ & - & - & 3681.70 & 0.004 & 0.84 \\
\hline \multirow[t]{3}{*}{ May. 97} & A & -1.28 & 0.046 & 0.58 & 3.45 & 0.012 & 0.75 & -4138.76 & 0.036 & 0.62 & 4440.99 & 0.009 & 0.78 \\
\hline & $\mathrm{B}$ & $\mathrm{nf}$ & - & - & 2.16 & 0.0780 & 0.49 & -2419.22 & 0.003 & 0.86 & 3590.17 & 0.033 & 0.63 \\
\hline & $\mathrm{C}$ & $\mathrm{nf}$ & - & - & 3.11 & 0.064 & 0.53 & -3442.22 & 0.059 & 0.54 & 7286.50 & 0.080 & 0.49 \\
\hline
\end{tabular}


was used as the overall net areal flux for that constituent. One-sample t-tests were used to determine if replicate net areal fluxes were significantly $(p<0.05)$ different from zero. Equation 1

$$
\text { normalized flux }\left(\mu \text { moles } \mathrm{m}^{-2}\right)=\frac{\left.[\mathrm{X}]_{\text {initial }}-[\mathrm{X}]_{\mathrm{x}}\right] \times \mathrm{V}_{\mathrm{x}}}{\mathrm{A}}
$$

\section{Results}

Nutrient concentration data

Average salinity in the surface water ranged from $0 \%$ in Nov. 96 (late wet season) to 27\% in May 97 (late dry season; Figure 2.2). Mean surface water temperature varied from a high of $34.5^{\circ} \mathrm{C}$ in Aug. 96 to a low of $17^{\circ} \mathrm{C}$ in Jan. 97 . Ambient nutrient concentrations displayed a high degree of variability among the different samplings (Figure 2.5). Nitrate+nitrite concentrations were relatively low during the wet season (1$2 \mu \mathrm{M})$ and higher and more variable during the dry season $(0.5-5 \mu \mathrm{M})$. I observed a similar pattern for $\mathrm{NH}_{4}{ }^{+}$concentrations, however Aug. 96 concentrations of $\mathrm{NH}_{4}{ }^{+}$were nearly as high as those measured in Jan. 97. Total nitrogen showed a very strong seasonal trend, with the highest concentrations in the early wet season (median $=88 \mu \mathrm{M}$ in Aug. 96) followed by a significant decline as the wet season progressed into the dry season (median $=52 \mu \mathrm{M}$ in May 97; Figure 2.5). The percentage of total nitrogen that was in the dissolved inorganic form was around 6\% for much of the year (Aug. and Nov. 96 and May 97). However, during Jan. 97, $\mathrm{DIN}\left(\mathrm{NO}_{3}{ }^{-}+\mathrm{NO}_{2}{ }^{-}\right.$and $\left.\mathrm{NH}_{4}{ }^{+}\right)$was consistently $15 \%$ or more of the total nitrogen in the surface water of this dwarf mangrove site. 



Figure 2.5- Box-and-whisker plots of ambient water column nutrient concentrations at Taylor River dwarf mangrove site during each sampling. For each plot, the center line marks the median, the notches indicate the $95 \%$ confidence interval about the median, the bottom and top line of each box represent the $25^{\text {th }}$ and $75^{\text {th }}$ percentiles, and the bottom and top line of the whiskers indicate the $10^{\text {th }}$ and $90^{\text {th }}$ percentiles, respectively. Letters represent significant differences between samplings (ANOVA, $<<0.05$ ). Asterisks on TOC/DOC plots represent a significant difference between TOC and DOC concentrations for a given sampling period (paired t-test, $\mathrm{p}<0.05$ ). 
Soluble reactive phosphorus (a.k.a. reactive phosphorus) concentrations were low and quite variable during all samplings. In fact, I collected several samples that were at or below the limits of detection $(<0.01 \mu \mathrm{M})$ and a few that were over an order of magnitude higher than this (Figure 2.5). The majority of the samples were within this range of SRP concentration. This wide range of SRP concentration seems to be characteristic of other mangrove systems as well (Nixon et al. 1984; Boto and Wellington 1988). Soluble reactive phosphorus was typically $5-10 \%$ of TP in the surface waters of Taylor River except in Aug. 96, when over 25\% of TP was SRP (Figure 2.5).

The organic carbon content (TOC and DOC) of the water in this zone also showed a strong effect of season (Figure 2.5). Total organic carbon and DOC concentrations declined significantly from a high of about $1.45 \mathrm{mM}$ in the early wet season (Aug. 96) to approximately $1.05 \mathrm{mM}$ in the late dry season (May 97). Roughly $95 \%$ of the TOC in Taylor River was in the dissolved form (DOC). Only in Nov. 96 and Jan. 97 did I observe a noticeable difference between TOC and DOC concentrations (Figure 2.5). This characteristic reflected the relative absence of particulate material in this carbonate setting.

\section{$\underline{\text { Flux results }}$}

Regression analyses revealed fluxes of all constituents with R-squared values ranging from 0.45 to 0.94 (Table 2.1). At least one flux was recorded for each constituent during every sampling except January 1996, when neither TP nor SRP displayed a measurable flux (Table 2.1). Overall, SRP exhibited the fewest instances of net areal flux (Table 2.1). Moreover, significant net areal fluxes were observed for all 
constituents except SRP, and $\mathrm{NO}_{3}{ }^{-}+\mathrm{NO}_{2}{ }^{-}, \mathrm{NH}_{4}{ }^{+}$and TOC yielded significant fluxes during all four samplings (Table 2.1; Figure 2.6). Total nitrogen fluxes were significant during three of the four samplings, and TP and DOC fluxes were significant during two samplings (Figure 2.6).

There was a significant export of $\mathrm{NO}_{3}{ }^{-}+\mathrm{NO}_{2}{ }^{-}$from the dwarf mangrove wetland in all four sampling periods (Figure 2.6). This export was significantly greater in the dry season than it was during the wet season (ANOVA, $\mathrm{p}=0.0047$ ). In addition, ambient concentrations of $\mathrm{NO}_{3}^{-}+\mathrm{NO}_{2}^{-}$were higher and more variable during the months in which I measured the highest export of this constituent (Figures 2.5 and 2.6). This resulted in a significant nonlinear relationship between the concentration and flux of $\mathrm{NO}_{3}{ }^{+}+\mathrm{NO}_{2}{ }^{-}$ (Figure 2.7a). Ammonium flux shifted from export to uptake and then back to export over the course of this study (Figure 2.6). This pattern showed a rather strong negative relationship with mean surface water temperature during each sampling (Figure $2.7 \mathrm{~b}$ ). Total nitrogen was imported by the dwarf mangrove wetland during the Aug. 96 sampling, in contrast to the large exports of $\mathrm{NO}_{3}{ }^{-}+\mathrm{NO}_{2}{ }^{-}$and $\mathrm{NH}_{4}{ }^{+}$(Table 2.1; Figure 2.6). I also measured uptake of TN during the Nov. 96 and Jan. 97 samplings (Figure 2.6).

I observed no significant flux of SRP in this study. The inability of us to measure SRP flux was probably the result of low concentrations $(<0.05 \mu \mathrm{M})$ making it difficult to detect significant changes over time. However, there were fairly large uptakes of TP during Aug. $96\left(11.29 \pm 3.76 \mu\right.$ moles $\left.\mathrm{m}^{-2} \mathrm{hr}^{-1}\right)$ and May $97\left(7.79 \pm 3.05 \mu\right.$ moles $\left.\mathrm{m}^{-2} \mathrm{hr}^{-1}\right)$. The large uptake in Aug. 96 may have also included a substantial import of SRP, as the percentage of TP that was soluble reactive was over 25\% at this time (Figure 2.5). 

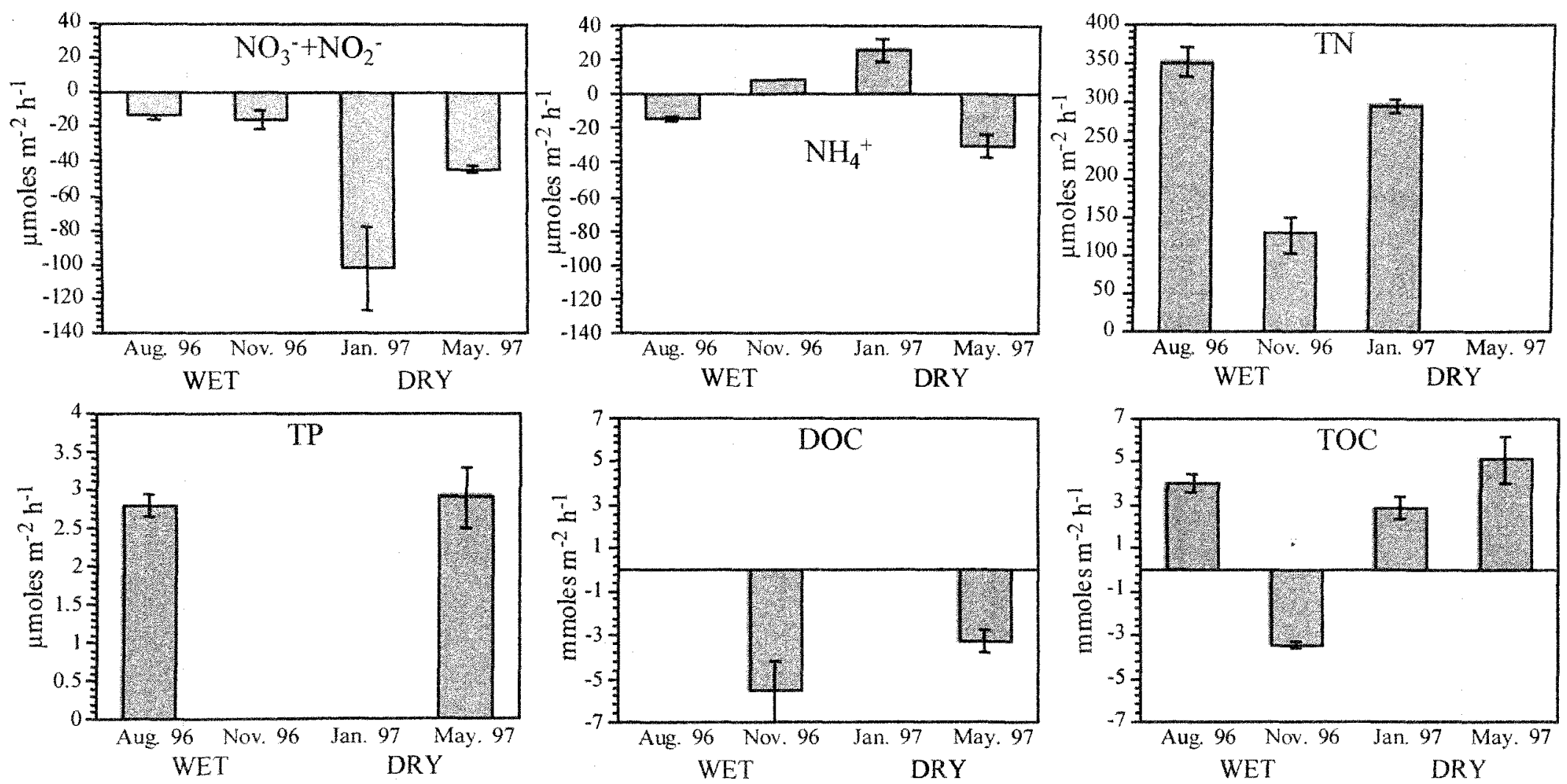

Figure 2.6- Bar charts showing significant net areal fluxes measured over the course of this study. Error bars represent standard errors of the means when more than one enclosure displayed a flux of a given constituent. Positive values indicate an uptake by the wetland and negative values signify an export to the water column. Soluble reactive phosphorus flux was not significant during this study. 

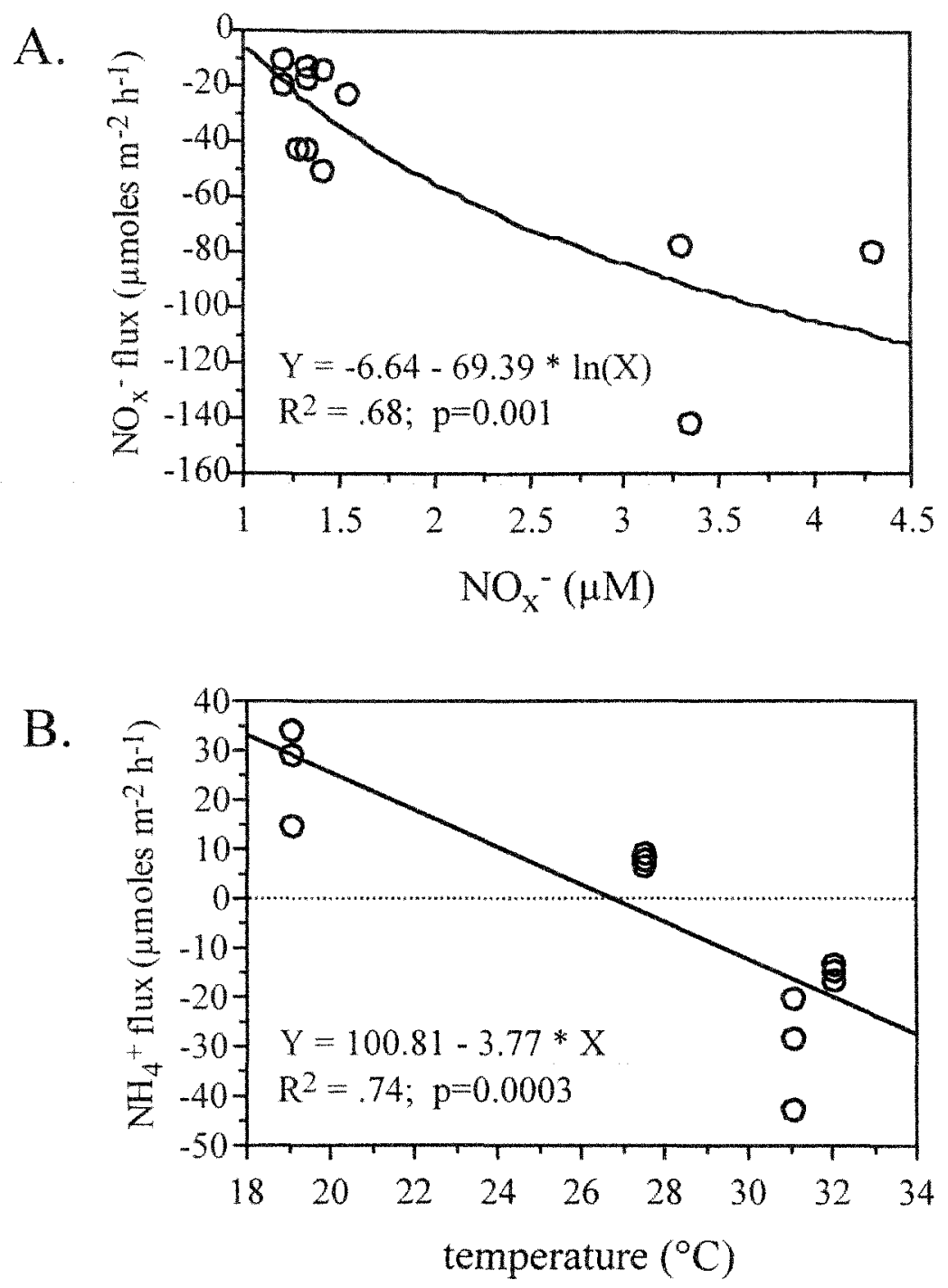

Figure 2.7-a) Regression plot of nitrate + nitrite flux ( $\mu$ moles $\left.\mathrm{m}^{-2} \mathrm{~h}^{-1}\right)$ measured in dwarf mangrove enclosures versus ambient concentrations $(\mu \mathrm{M})$. b) Regression plot of ammonium flux ( $\mu$ moles $\left.\mathrm{m}^{-2} \mathrm{~h}^{-1}\right)$ measured in dwarf mangrove island enclosures versus ambient water temperature $\left({ }^{\circ} \mathrm{C}\right)$. 
Although the concentrations of TOC and DOC were very similar in this system and followed a similar seasonal pattern, I found different flux patterns exhibited by these two constituents (Figures 2.5 and 2.6). Total organic carbon was imported during Aug. 96, Jan. 97 and May 97 and DOC was exported during Nov. 96 (Figure 2.6). Dissolved organic carbon was also exported during the Nov. 96 sampling, but was exported in May 97 as well, in contrast to TOC at that time (Figure 2.6). The other two samplings yielded non-significant fluxes for DOC (Figure 2.6).

\section{Discussion}

I have presented a new method that successfully measured systems-level fluxes in a dwarf mangrove wetland. The magnitude of the fluxes measured in the dwarf system of Taylor River suggested a relatively high metabolism for such an oligotrophic system, which structurally appears to be in a near steady state. Unfortunately, there are few, if any flux studies conducted in non-tidal dwarf mangrove systems to corroborate this observation. Nevertheless, it is possible to make approximate comparisons of this new method with other mangrove flux studies across the tropics. The majority of these have been studies of tidal exchange of detritus or "outwelling" investigations (Twilley 1985; Woodroffe 1985; Boto and Wellington 1988; Lee 1990; Childers et al. 1999). The trend that has emerged from most of these studies (as suggested by Twilley 1988 and later reviewed by Lee 1995) is that mangrove wetlands tend to export organic matter. In spite of the fact that most all of these outwelling studies were conducted in tidal systems, the hypothesis should still apply to a non-tidal system such as this. While the dwarf mangroves in Taylor Slough are not flushed by daily tides, they are seasonally flushed by 
upland runoff fueled by precipitation and wind events and, like all other mangroves, produce a continuous crop of litter.

The significant fluxes I observed for TOC, DOC, TN and TP in Taylor River neither supported nor refuted the outwelling hypothesis. Although there was an export of DOC and TP part of the year, there was also significant uptake of TOC, TN and TP for much of the rest of the year. Since I used an enclosure technique to determine these fluxes, it is difficult to comment directly on the fate and transport of nutrients in this system. Therefore, I related the patterns in observed fluxes to the seasonal hydrology of Taylor River/Slough in order to speculate on the most likely fate of these nutrients.

The dwarf mangrove wetlands of Taylor Slough essentially function as a basin system during the dry season. During this time, net evapotranspiration (ET) likely exceeds freshwater input to the system, as little to no upland runoff or direct precipitation leads to increased residence times. This produces a net movement, albeit a weak one, of high salinity water from Florida Bay towards the dwarf mangrove wetlands. This trend was shown at the mouth of Taylor River during the dry season of 1997 (Figure 2.2). Therefore, Florida Bay inputs, ET, and internal cycling are expected to be the dominant mechanisms controlling the concentration and flux of nutrients in the dwarf mangroves. The wet season, on the other hand, is usually characterized by a strong net southerly movement of fresh water through the dwarf mangroves towards Florida Bay. This phenomenon was illustrated in the daily, surface water salinity data from July through November 1996 at the mouth of Taylor River (Figure 2.2). During the wet season, bay inputs are essentially cut off, as freshwater input from upland runoff sweeps through the dwarf mangrove wetlands of Taylor Slough. This also reduces the relative influences of 
internal recycling and ET in controlling nutrient dynamics. Therefore, I concluded that nutrients exported from the dwarf mangrove wetland during the dry season were recycled within the system, while wet season exports were advected downstream towards Florida Bay.

With this in mind, this wetland was a source of organic carbon (TOC and DOC) to downstream systems during the late wet season (Nov. 96). This event coincided with the lowest salinity recorded in this study $(0 \%)$ and with a consistently low period of salinity at the mouth of Taylor River (Figure 2.2), further supporting the idea that this material was exported downstream. The dwarf system also appeared to be a wet season source of DIN to downstream systems (Figure 2.6). All other nutrients, except SRP, were imported by the mangrove wetland during the wet season. Total phosphorus and organic carbon were imported in Aug. 96 and total nitrogen was imported in both Aug. and Nov. 96. During the dry season, with Florida Bay as the major source of nutrients, the dwarf wetland also imported TOC (entire dry season), TN (early dry season), and TP (late dry season) and exported DIN.

The processes involved with these exchanges and transformations are numerous, however, I will discuss a few potentially important processes that may explain some of my findings. First, leaching of mangrove leaf litter can account for large effluxes of dissolved organic carbon, nitrogen, and phosphorus to the water column (Fell and Master 1980; Tam et al. 1990; Chale 1993; Steinke et al. 1993). This abiotic process contributes a great deal to the tea colored water common in many mangroves. A study has shown that this mangrove leachate, especially from $R$. mangle leaves, is quite labile and is rapidly and efficiently utilized when concentrations are low (Benner et al. 1986). In the 
dwarf system, I found consistent uptake of TOC, TN, and TP. Since particulate loads and dissolved inorganic concentrations are low in this system, I figured that these fractions were mostly labile dissolved organic material of mangrove origin.

My data also suggest an importance of nitrogen transformation in this system. Nitrate + nitrite export in the dwarf wetland during the late wet and early dry season was coupled with ammonium import (Figure 2.6). From this, I concluded that $\mathrm{NO}_{3}{ }^{-}+\mathrm{NO}_{2}{ }^{-}$ accumulation coupled with $\mathrm{NH}_{4}{ }^{+}$loss was indicative of nitrogen transformation from a reduced form to an oxidized form. The consistent export of $\mathrm{NO}_{3}{ }^{-}+\mathrm{NO}_{2}{ }^{-}$in this dwarf mangrove indicated that nitrification rates exceeded denitrification rates, at least during daylight hours. Furthermore, the fluxes of both DIN constituents were temperature or concentration dependent (Figure 2.7). This pattern goes against evidence from many estuarine wetlands that show an uptake of dissolved oxidized inorganic forms of nitrogen and export dissolved and particulate reduced forms (Nixon 1980).

\section{Method comparison}

I compared nitrogen fluxes measured using this technique to four other in situ mangrove flux methods in attempt to explain this latter phenomenon. I also sought to compare the effectiveness in measuring nitrogen flux using this method with the methods used in the other studies, at different spatial scales. These studies all focused primarily on DIN $\left(\mathrm{NO}_{3}{ }^{-}+\mathrm{NO}_{2}{ }^{-}\right.$and $\left.\mathrm{NH}_{4}{ }^{+}\right)$and were conducted in a variety of mangrove settings throughout the tropics (Table 2.2). I also included DIN data from a benthic flux study conducted at a nearby site in Taylor River (Table 2.2; Rudnick unpublished data). The method used to determine nutrient flux reflected both the spatial scale of the questions of 
Table 2.2- Comparison of this and other studies using different methods to quantify DIN fluxes in mangrove systems across the tropics. Annual fluxes of $\mathrm{NH}_{4}{ }^{+}$and $\mathrm{NO}_{\mathrm{x}}{ }^{-}$were taken directly from the literature or estimated from reported fluxes. A positive flux indicates an uptake by the wetland, whereas a negative flux indicates an export from the wetland to the overlying water column.

\begin{tabular}{cccccc} 
System attributes & Coral Creek $^{\mathrm{a}}$ & Estero Pargo $^{\mathrm{b}}$ & Ao Nam Bor & Taylor River $^{\mathrm{d}}$ & this study $^{\mathrm{c}}$ \\
flux method & creek flux & flume & benthic flux & benthic flux & enclsoure \\
trees in experimental unit & yes & yes & no & no & yes \\
spatial scale of interest & whole & fringe & intertidal & sudtidal & dwarf \\
& estuary & wetland & sediments & sediments & wetland \\
tidal range (m) & 2.5 & 0.5 & 2.0 & 0 & 0 \\
$\%$ of day site is inundated & 100 & 90 & 17 & 100 & 100 \\
depth range $(\mathrm{m})$ & $6-8$ & $0-0.5$ & $0-1$ & $0.5-1$ & $0.1-0.5$ \\
$\mathrm{NH}_{4}{ }^{+}$concentration range $(\mu \mathrm{M})$ & $0.1-1.0$ & $1.1-51.7$ & $0.1-2.8$ & $0.1-5.1$ & $0.2-5.5$ \\
$\mathrm{NH}_{4}{ }^{+}$annual flux estimate $\left(\mathrm{g} \mathrm{m}^{-2} \mathrm{yr}^{-1}\right)$ & 0.15 & 0.53 & 6.83 & 3.28 & -0.36 \\
$\mathrm{NO}_{\mathrm{x}}{ }^{-}$concentration range $(\mu \mathrm{M})$ & $0.1-0.6$ & $0.2-4.9$ & $0.3-0.5$ & $0.1-3.2$ & $0.3-5.4$ \\
$\mathrm{NO}_{\mathrm{x}}{ }^{-}$annual flux estimate $\left(\mathrm{g} \mathrm{m}^{-2} \mathrm{yr}^{-1}\right)$ & -0.03 & 0.08 & 4.51 & 1.2 & -5.35 \\
\hline
\end{tabular}

${ }^{a}$ Boto and Wellington 1988; Daytime sampling was conducted every 1-2 months over full tidal cycles for a period of 16 months.

${ }^{b}$ Rivera-Monroy et al. 1995; Flume sampling was conducted over one full tidal cycle per month, for 11 months.

${ }^{c}$ Kristensen et al. 1988; Replicate light and dark benthic chambers were incubated for 1-1.5 hr. Only light chamber data are used here.

d Rudnick unpublished data; Replicate light and dark benthic chambers were incubated for approximately 5-6 hr. Only light chamber flux data were used in this table. 
interest and the hydrodynamics at each of these sites. For example, Boto and Wellington (1988) used a typical Eulerian approach to determine whole estuary nutrient fluxes in Coral Creek, a macro-tidal creek with no upland source of freshwater, while RiveraMonroy et al. (1995) used a flow-through flume to quantify nutrient exchange in a tidally flooded fringe mangrove wetland (Table 2.2). Furthermore, there was a range of water residence times and degrees of isolation of the experimental units (wetland) among these studies.

Short water residence times with no isolation of the system characterized Boto and Wellington's (1988) creek flux study in Australia. They sampled a single point every $0.5 \mathrm{hr}$ for entire tidal cycles (Boto and Wellington 1988). The Mexican flume study of Rivera-Monroy et al. (1995), on the other hand, involved the partial isolation of the wetland. This method limits dispersion by allowing for only a bi-directional flow of water. Here, water residence times were probably an order of magnitude longer, as the water flowing through the flume was flood or ebb driven. They collected samples at both ends of the flume every two hours over the course of a tidal cycle (Rivera-Monroy et al. 1995). Kristensen et al. (1988) used benthic chambers to monitor DIN flux in a mangrove swamp in Thailand. These chambers completely isolated an area of subtidal sediment, without mangrove vegetation, and were sampled at the beginning and end of a 1-1.5hr incubation (Kristensen et al. 1988). Finally, as a comparison of flux results in the Taylor River dwarf mangrove system, I used data from a similar benthic chamber study conducted in a shallow mangrove pond with a long residence time, approximately $2 \mathrm{~km}$ south of the dwarf enclosure site. This study was conducted during the same four sampling periods as my enclosure study (Table 2.2). 
Estimated annual fluxes for $\mathrm{NH}_{4}{ }^{+}$and $\mathrm{NO}_{3}{ }^{-}+\mathrm{NO}_{2}{ }^{-}$(shown in Table 2.2) were either taken directly from the literature or estimated from published flux data. The lowest values for both of these constituents were measured in Coral Creek where there was a small import of $\mathrm{NH}_{4}{ }^{+}\left(0.15 \mathrm{~g} \mathrm{~m}^{-2} \mathrm{yr}^{-1}\right)$ and an even smaller export of $\mathrm{NO}_{3}{ }^{-}+\mathrm{NO}_{2}^{-}(-0.03 \mathrm{~g}$ $\left.\mathrm{m}^{-2} \mathrm{yr}^{-1}\right)$. There was also no apparent seasonality to the whole estuarine fluxes of either constituent (Boto and Wellington 1988; Table 2.2). This system is characterized by low concentrations of dissolved inorganic nutrients and the authors suggested that it appeared to be fairly well balanced in terms of input and output of these constituents (Boto and Wellington 1988). Similarly, ammonium flux in the Taylor River dwarf system was balanced by intra-annual shifts from export to import that appeared to be related to temperature (Figures 2.6 and 2.7b). Rivera-Monroy et al. (1995) found higher imports of both DIN constituents in Estero Pargo (Table 2.2). This fringe wetland was not balanced like the Coral Creek system, as the investigators found significant uptake of $\mathrm{NH}_{4}{ }^{+}$and $\mathrm{NO}_{3}{ }^{-}+\mathrm{NO}_{2}{ }^{-}$in over $70 \%$ of the full tidal cycles monitored (Rivera-Monroy et al. 1995). Although the two benthic chamber studies were conducted in dissimilar mangrove systems, both found much greater uptake of $\mathrm{NH}_{4}{ }^{+}$and $\mathrm{NO}_{3}{ }^{-}+\mathrm{NO}_{2}{ }^{-}$and had similar estimated annual fluxes for both DIN constituents (Table 2.2; Kristensen et al. 1988; Rudnick unpublished data). My flux results for $\mathrm{NO}_{3}{ }^{\circ}+\mathrm{NO}_{2}{ }^{-}$were similar in magnitude only to the benthic flux studies, and different from them all in that I found nothing but $\mathrm{NO}_{3}{ }^{-}+\mathrm{NO}_{2}{ }^{-}$export (Table 2.1).

I believe that these differences can be attributed to a few things. First, methodologically speaking, the flume and creek flux techniques operate on much different physical levels than the rest. These methods are not only dependent on 
concentration to quantify constituent flux but also the movement or flux of water. The interaction of these two factors can make it difficult to discern the influence of the wetland from the variability in the concentration of the water coming into the flume. Variability in current velocity can also affect the magnitude of constituent flux. For instance, high water fluxes can often magnify constituent fluxes, and vice versa. Also, in tidal systems, there is a regular diurnal or semidiurnal shift in the direction of water movement. This shift in direction can result in the repeated delivery of the same parcels of water past a given sampling point, which may confound the quantification of the actual wetland effect. Enclosure studies are different in that they monitor the same parcel of water for a given period of time, thus allowing for a more direct and easily quantifiable flux. However, the fact that they are enclosed prevents any determinations of exchanges between systems and places time constraints on the length of the incubation.

There was considerable difference in the patterns of flux between this study and the benthic flux study conducted just downstream in Taylor River. While I found net exports of $\mathrm{NO}_{3}{ }^{-} \mathrm{NO}_{2}{ }^{-}$and $\mathrm{NH}_{4}{ }^{+}$, Rudnick (unpublished data) found a consistent uptake of these two constituents at the same time. There are a few plausible explanations for this. First, these benthic chambers, like many others, contained no emergent vegetation and may or may not have contained submerged aquatic vegetation (SAV). Therefore, the benthic fluxes were mainly based on sediment-water column interactions. Since my goal was to directly determine wetland-water column exchanges, I included mangroves in the experimental units (enclosures). The presence of mangroves and the epibiont communities they support likely have a substantial effect on surface water chemistry (as shown by Ellison et al. 1996; Childers and Davis unpublished data). Next, the soils at 
these two sites are quite different from one another. The benthic chamber study was conducted in unconsolidated, organic-rich, subtidal sediment. In contrast, soils at the dwarf mangrove enclosure site were dense peats with little or no sediment layer. These differences in soil structure may also have accounted for some of the variability between these two sites.

The primary reasons for comparing studies using different flux techniques in different mangrove settings were 1) to get an idea of the possible ranges of constituent fluxes that existed on different ecological scales in this type of estuarine wetland, and 2) to demonstrate the efficacy of this method. My findings seemed to compare more favorably with those generated by techniques looking at within system exchanges rather than between system or whole estuarine exchanges and did not seem to be necessarily dependent upon similarities between sites. This reinforces the idea that the spatial and temporal scale of the question being asked should drive the choice of flux measurement techniques. This enclosure technique is appropriate for processes occurring within a small area $\left(5-15 \mathrm{~m}^{2}\right)$ of wetland with long residence times over relatively short time scales (6-12hr). Future study in other dwarf mangrove wetlands or functionally similar wetland types during the day or night will allow a further examination of the utility of this technique.

\section{$\underline{\text { Summary }}$}

I have presented a technique that allows for the quantification of nutrient exchange between a dwarf mangrove wetland and its associated water column. This particular usage was exercised in conjunction with standard water sampling procedures to 
quantify the seasonality in the fluxes of carbon, nitrogen, and phosphorus in an oligotrophic, perennially flooded, dwarf red mangrove wetland in Taylor River. This application provided an easily replicated and accurate means of determining nutrient dynamics over a short period of time. My findings suggest that the dwarf mangrove wetlands along Taylor River are a sink for TN, TP, and TOC and are a source of DOC and $\mathrm{NO}_{3}{ }^{-}+\mathrm{NO}_{2}{ }^{-}$. Nitrate+nitrite export was observed throughout the year intensifying during the dry season months, while the flux of $\mathrm{NH}_{4}{ }^{+}$appeared to be seasonal/temperature-related switching from export during the warmer months to import during the cooler months. Although it was designed for a specific mangrove system, this method could easily be adapted to fit other nontidal or microtidal, shallow water wetlands to address these or numerous other ecological questions. 


\title{
Chapter 3:
}

\section{Factors affecting the concentration and flux of carbon, nitrogen, and phosphorus in a non-tidal dwarf mangrove wetland}

\begin{abstract}
A two-year study was conducted to determine the influence of various factors on the concentration and flux of nutrients in a dwarf mangrove wetland of the southern Everglades. Triplicate dwarf mangrove island enclosures were sampled quarterly (August 96 - May 98) to quantify the wetland-water column exchanges of carbon, nitrogen, and phosphorus. Triplicate control chambers were added in Year 2 to help distinguish the influence of mangrove vegetation from sediment-water column processes on these exchanges. Only TN, DOC, and TOC showed an effect of season, with higher wet season concentrations than dry season. All nutrient concentrations, except SRP, had significant relationships with salinity or temperature. Many nutrient concentrations were significantly correlated with one another. Nutrient fluxes varied over the study period, however $\mathrm{NO}_{3}{ }^{-}+\mathrm{NO}_{2}{ }^{-}$and DOC were usually exported to the water column while $\mathrm{NH}_{4}{ }^{+}$, $\mathrm{TN}$, and TP were imported by the mangrove wetland. Nitrogen yielded significant flux relationships with temperature and salinity. Nitrate+nitrite flux was positively related to temperature, TN had a negative relationship with salinity, and ammonium flux showed negative relationships with both factors. Fluxes of $\mathrm{NO}_{3}{ }^{-}+\mathrm{NO}_{2}{ }^{-}, \mathrm{TN}$, and $\mathrm{TP}$ were also significantly related to their respective concentrations. Control fluxes paralleled whole wetland fluxes in direction but not in magnitude. In many instances, fluxes were several times greater in the absence of mangrove vegetation, suggesting an influence of the trees.
\end{abstract}


My findings also suggested that nutrient dynamics in this dwarf mangrove system were influenced by the aforementioned factors and may be affected by long-term changes in water delivery, climate, and sea-level rise.

\section{Introduction}

Studies of materials exchange in mangrove systems are becoming more prevalent in the estuarine literature. However, the forcing functions that regulate these exchanges are still poorly understood (Twilley 1998). Local hydrologic and geomorphologic characteristics are believed to play an important role in the flux of organic matter from estuarine wetlands (Odum et al. 1979). In fact, it is generally accepted that mangrove wetlands export organic matter in relation to tidal range (Twilley 1985; Lee 1995), although mangrove sediment may be an effective sink for DOC (Boto et al. 1989). At the present time, no such generalizations can be made for other ecologically important nutrients such as nitrogen and phosphorus. Consequently, there is a need for more mangrove research aimed at addressing these issues.

Nutrients can enter mangrove systems via a number of pathways (Boto 1982; Liebezeit 1985). Of these various pathways, precipitation, upland runoff, and tides are among the most important sources of organic and inorganic constituents to mangroves. In many areas, these sources are characterized by seasonal highs and lows, which often lead to seasonal patterns of nutrient concentrations and sometimes flux (Twilley 1985; Rivera-Monroy et al. 1995; Ohowa et al. 1997). Furthermore, in some estuarine systems, the direction and magnitude of nutrient flux has been shown to correspond to nutrient concentrations (Wolaver and Spurrier 1988; Whiting et al. 1989; Childers 1994). 
Therefore, an understanding of the factors that regulate nutrient concentrations in mangroves may yield valuable insight into the factors that govern mangrove nutrient fluxes.

Water temperature and salinity are two of the most important factors controlling the global and local distributions of mangrove ecosystems along the world's shorelines (Kuenzler 1974; Odum et al. 1982; Duke 1992). This control is manifested in the influence of these factors on the zonation and productivity of various mangrove species (Lugo and Snedaker 1974; Cintron et al. 1978; Ball 1988; Clough 1992). In tropical and subtropical areas, water temperatures typically indicate the season or time of year and may often reflect changes in air temperature and light intensity, while salinity is usually an indicator of season or physical position within an estuary. Fluctuations in either of these factors can have profound effects on forest and benthic productivity in mangrove wetlands (Alongi 1988; Alongi and Sasekumar 1992; Clough 1992). Therefore, they may be useful in explaining patterns of flux in mangrove systems. Similar effects have been observed in temperate saltmarsh systems, as phosphate uptake was shown to be positively related to salinity and temperature in a North Inlet, SC (Wolaver and Spurrier 1988).

Given the potential importance of these factors, such relationships may also exist for tropical mangrove systems. Thus, a study was conducted to determine the influence of seasonal factors on the concentration and flux of dissolved and total organic carbon (DOC and TOC), nitrogen $\left(\mathrm{NO}_{3}{ }^{-}+\mathrm{NO}_{2}{ }^{-}, \mathrm{NH}_{4}{ }^{+}\right.$, and TN), and phosphorus (SRP and TP) in a non-tidal, dwarf mangrove wetland of the southern Everglades. This area is currently experiencing a hydrologic restoration in the form of a systematic, long-term increase in freshwater delivery. Therefore, an understanding of the relationship between short-term 
nutrient dynamics and these seasonal factors may help predict the long-term effects of Everglades restoration on nutrient cycling. It was expected that season (wet vs. dry) and surface water salinity, temperature, and nutrient concentrations would all be useful in explaining nutrient dynamics in this system.

\section{Materials and Methods}

Site description

This study was conducted in a non-tidal dwarf mangrove wetland of Taylor Slough, Everglades National Park (Figure 2.1). The dwarf mangrove area of Taylor Slough is dominated by Rhizophora mangle $\mathrm{L}$. and is characterized by a distinct seasonal salinity pattern. Low salinity $(0-5 \%)$ persists in this area for much of the wet season (June-November), but in the dry season (December-May), salinity sometimes reaches above $30 \%$. This pattern is somewhat reflected in the daily salinity at the mouth of Taylor River, a major creek draining Taylor Slough into Florida Bay (Figure 2.2). Large fluctuations in salinity, independent of season, are also quite common in this area. These are often the result of irregular precipitation or wind events and do not persist for more than a week or two (Figure 2.2; personal observation).

The primary sources of wet season water and nutrients to this wetland are local precipitation and upland runoff from the freshwater Everglades marshes, whereas Florida Bay is typically the source during the dry season. These different sources have profound impacts on both the salinity and nutrient content of the surface water in wetlands of this area of the Everglades. Water temperature is also variable throughout the year as a result of air temperature, light intensity, and precipitation. Water temperatures in these dwarf 
mangrove wetlands generally peak during mid-summer and are lowest in early winter (Table 3.1).

Field, analytical and quantitative methods

Eight quarterly samplings of three dwarf mangrove island enclosures were carried out in order to quantify the fluxes of carbon, nitrogen, and phosphorus (refer to Chapter 2 for a detailed description of this method). Sampling dates were strategically planned to include four wet and four dry season incubations (Table 3.1). Sampling began in August 1996 and concluded in May 1998 (Table 3.1). Island enclosures were sampled initially before the walls were lowered, then at hourly intervals for six hours between midmorning and mid-afternoon hours (Table 3.1). Water samples were also collected from outside each enclosure during these same intervals to monitor ambient changes in nutrients. In August 1997 (beginning of Year 2), I added triplicate control chambers to this sampling protocol. Control chambers contained no mangrove vegetation and were added to differentiate the effects of the mangrove vegetation from those of the water column and sediment-water processes. Cylindrical control chambers made of clear, transparent Lexan ${ }^{\circledR}$ were placed over bare peat soil adjacent to each enclosure (Figure 2.3), and were sampled at the beginning and end of each six-hour incubation according to the same procedures used for the island enclosures.

All water samples were filtered (Whatman GF/F) immediately following each incubation and stored in HDPE sample bottles. Filtered samples were stored frozen and unfiltered samples were kept at $4^{\circ} \mathrm{C}$ until analyzed for nutrient content. All nutrient analyses were performed at the Southeast Environmental Research Center (SERC) 
Table 3.1 - List of seasons, dates, times, and hydrologic data for each sampling of the dwarf mangrove island enclosures in Taylor Slough.

\begin{tabular}{cccccc} 
season & $\begin{array}{c}\text { sampling } \\
\text { date }\end{array}$ & sampling time & $\begin{array}{c}\text { salinity } \\
\text { range (\%o) }\end{array}$ & $\begin{array}{c}\text { water level } \\
\text { change }(\mathrm{cm})\end{array}$ & $\begin{array}{c}\text { temperature } \\
\text { range }\left({ }^{\circ} \mathrm{C}\right)\end{array}$ \\
\hline wet & Aug. 18, 1996 & $11: 30-17: 30$ & 1.5 & 1 & $32.5-33$ \\
wet & Nov. 12, 1996 & $11: 00-17: 00$ & 0 & 1 & $27-28.5$ \\
dry & Jan. 13,1997 & $11: 00-17: 00$ & $2.5-3$ & 0 & $19-20$ \\
dry & May 11, 1997 & $11: 30-17: 30$ & $25-27$ & 0.5 & $28-30$ \\
wet & Aug. 1, 1997 & $11: 30-17: 30$ & 0 & 0.5 & $33-33.5$ \\
wet & Nov. 7, 1997 & $11: 00-17: 00$ & 0 & 1.5 & $26-27.5$ \\
dry & Jan. 10,1998 & $11: 30-17: 30$ & 0 & 0 & $17-19$ \\
dry & May 17, 1998 & $11: 00-17: 00$ & $14-15$ & 1 & $27-29$ \\
\hline
\end{tabular}


laboratory at Florida International University. Unfiltered water samples were analyzed for total phosphorus (TP) according to a modification of the dry ashing, acid-hydrolysis technique (Solorzano and Sharp, 1980), total nitrogen (TN) using an Antec 7000N total nitrogen analyzer, and total organic carbon (TOC) using a hot platinum catalyst, direct injection analyzer (Shimadzu model TOC-5000). Filtered water samples were analyzed for soluble reactive phosphorus (SRP), ammonium $\left(\mathrm{NH}_{4}{ }^{+}\right)$, nitrate+nitrite $\left(\mathrm{NO}_{3}{ }^{-}+\mathrm{NO}_{2}{ }^{-}\right)$, and nitrite $\left(\mathrm{NO}_{2}^{-}\right)$on a four-channel auto-analyzer (Alpkem model RFA 300), and for dissolved organic carbon (DOC) using the same method listed above for TOC.

Hourly measurements of salinity and temperature were made with an analog S-CT meter (YSI Model 33). Water level was also monitored inside each enclosure at hourly intervals, and used in conjunction with island survey data to track changes in enclosure volume over the course of the incubations (Chapter 2). To estimate the total mass of nutrients ( $\mu$ moles) in each enclosure at interval $=t$, nutrient concentrations were multiplied by island volume at interval $=t$. Mass estimates from each interval were then subtracted from the initial mass of nutrients (interval $=0$ ), normalized to enclosure wetland/island area $\left(\mathrm{m}^{2}\right)$, and regressed with time (hours) to track changes (i.e. fluxes) of nutrients (Figure 2.4). I considered the significant slopes $(\mathrm{p}<0.1)$ from these regressions as net areal fluxes ( $\mu$ moles $\mathrm{m}^{-2} \mathrm{hr}^{-1}$ ) and calculated standard errors of flux when more than one enclosure displayed a significant flux for a given constituent (Chapter 2). An alpha level of 0.1 was chosen for the flux regression procedure in order to compensate for the small sample size ( $\mathrm{n}=6$ for each enclosure incubation). When at least two enclosures yielded a significant flux of a given constituent, a one-sample t-test was used to test if the fluxes were significantly different from zero $(\mathrm{p}<0.05)$. 
I sampled control chambers only at the beginning and end of the incubations to prevent soil disturbance and to maintain a minimal head difference between the water level outside and inside the control. Triple rinsing of the sampling apparatus and the collection of one sample generally resulted in a lowering of the water level inside the control chamber by approximately $2-3 \mathrm{~cm}$. This difference was always negligible by the time the next sample was collected six hours later. Volume estimates of the control chambers were made by multiplying water level inside each chamber by the circular area of each cylinder. The total mass of nutrients for each sample was calculated as the product of the concentration and estimated control chamber volume. Net areal fluxes ( $\mu$ moles $\mathrm{m}^{-2} \mathrm{hr}^{-1}$ ) were calculated as the difference in mass of nutrients ( $\mu$ moles) between the initial $(t=1)$ and final $(t=6)$ sample, divided by the product of control chamber area $\left(0.102 \mathrm{~m}^{2}\right)$ and time (6 hours). Finally, the significance of control fluxes was determined using one sample t-tests, testing the hypothesis that the flux means $(\mathrm{n}=3)$ were significantly different (+or-) from zero.

Using ambient nutrient concentrations and significant fluxes for each enclosure/sampling event, one-factor ANOVAs were performed to test for year and season effects. Fisher's Pairwise Least Significant Differences test (Fisher's PLSD) was then used as a post-hoc test to determine differences in means following each significant ANOVA (StatView 5). Temperature and salinity data are presented as ranges (Table 3.1), but were averaged for each sampling and used as variables in a correlation matrix with mean nutrient concentrations for each enclosure/sampling. To test for correlation significance $(p<0.05)$, I used Fisher's $r$ to $z$ transformation to generate a $p$-value for each correlation (StatView 5). 
Temperature and salinity means were also used as independent variables in simple linear regressions to explore the relationships between these factors and nutrient fluxes. For all significant flux regressions $(\mathrm{p}<0.05)$, I estimated an import/export switch $(\mathrm{I} / \mathrm{E})$, after Childers (1994) and Childers et al. (1999), as a prediction of the point along the Xaxis (temperature or salinity) at which flux in this dwarf system shifted from import to export, or vice versa. Finally, I regressed concentration (independent variable) with significant fluxes (dependent variable) to determine the relationship between these two parameters. An $\mathrm{I} / \mathrm{E}$ switch was estimated for each significant $(\mathrm{p}<0.05)$ regression to indicate the predicted concentration at which flux shifted from import to export, or vice versa.

\section{Definitions}

In this manuscript, the terms "uptake" and "import" will always infer an uptake of nutrients by the wetland under investigation. Nutrient uptake is measured as a depletion of nutrients from the water column over time. The terms "export" and "release" will be used to infer a discharge of nutrients from the wetland into the overlying water column. This phenomenon is measured as an accumulation of nutrients in the water column over time. Since the mangrove wetland is the point of reference in this study, imports and exports will be presented graphically as positive and negative values, respectively. When explicitly defined as "exports" in the text, export fluxes will be presented as non-negative values to prevent any confusion. 


\section{Results}

\section{$\underline{\text { Surface water characterization }}$}

Surface water salinity and temperature in this dwarf mangrove showed little variability over much of the two years. Salinity remained between 0 and 3\%o during all wet season and early dry season (January 97 and 98) samplings (Table 3.1). Only during the late dry season (May 97 and 98) did salinity reach meso- to polyhaline conditions (Table 3.1). Water temperature fluctuated between $26-33.5^{\circ} \mathrm{C}$ for most of the study, but was considerably lower in January 97 and 98 than all other samplings $\left(17-20^{\circ} \mathrm{C}\right.$; Table 3.1). This is similar to the annual pattern in water temperature for mangroves in Laguna de Terminos, Mexico (Rivera-Monroy et al. 1995). Finally, water level change at the Taylor Slough dwarf mangrove site reflected the non-tidal nature of this region. Water level variability within a given sampling was trivial (usually $\leq 1 \mathrm{~cm}$; Table 3.1 ), and the range of water level change over the entire two-year study was only $0.16 \mathrm{~m}$.

Ranges of $\mathrm{NO}_{3}{ }^{-}+\mathrm{NO}_{2}{ }^{-}$and $\mathrm{NH}_{4}{ }^{+}$concentrations were similar to each other

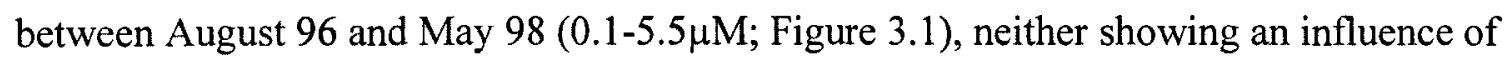
season. However, $\mathrm{NO}_{3}{ }^{-}+\mathrm{NO}_{2}{ }^{-}$concentrations were significantly higher during the first year of sampling (Table 3.2) and showed little within-sampling variability $(<1 \mu \mathrm{M})$, except for the dry season of 1997 (Figure 3.1). Ammonium, on the other hand, was more variable within a given sampling, and was always highest in the early dry season (up to $5.5 \mu \mathrm{M}$ ) and lowest in the late dry season (down to $0.1 \mu \mathrm{M}$; Figure 3.1 ). Wet season concentrations of $\mathrm{NH}_{4}{ }^{+}$were in between this range (1.2-4 $\mu \mathrm{M}$; Figure 3.1). Total nitrogen showed a significant influence of season (Table 3.2), with concentrations as high as $94 \mu \mathrm{M}$ during the early wet season and as low as $46 \mu \mathrm{M}$ in the late dry season (Figure 3.1). 

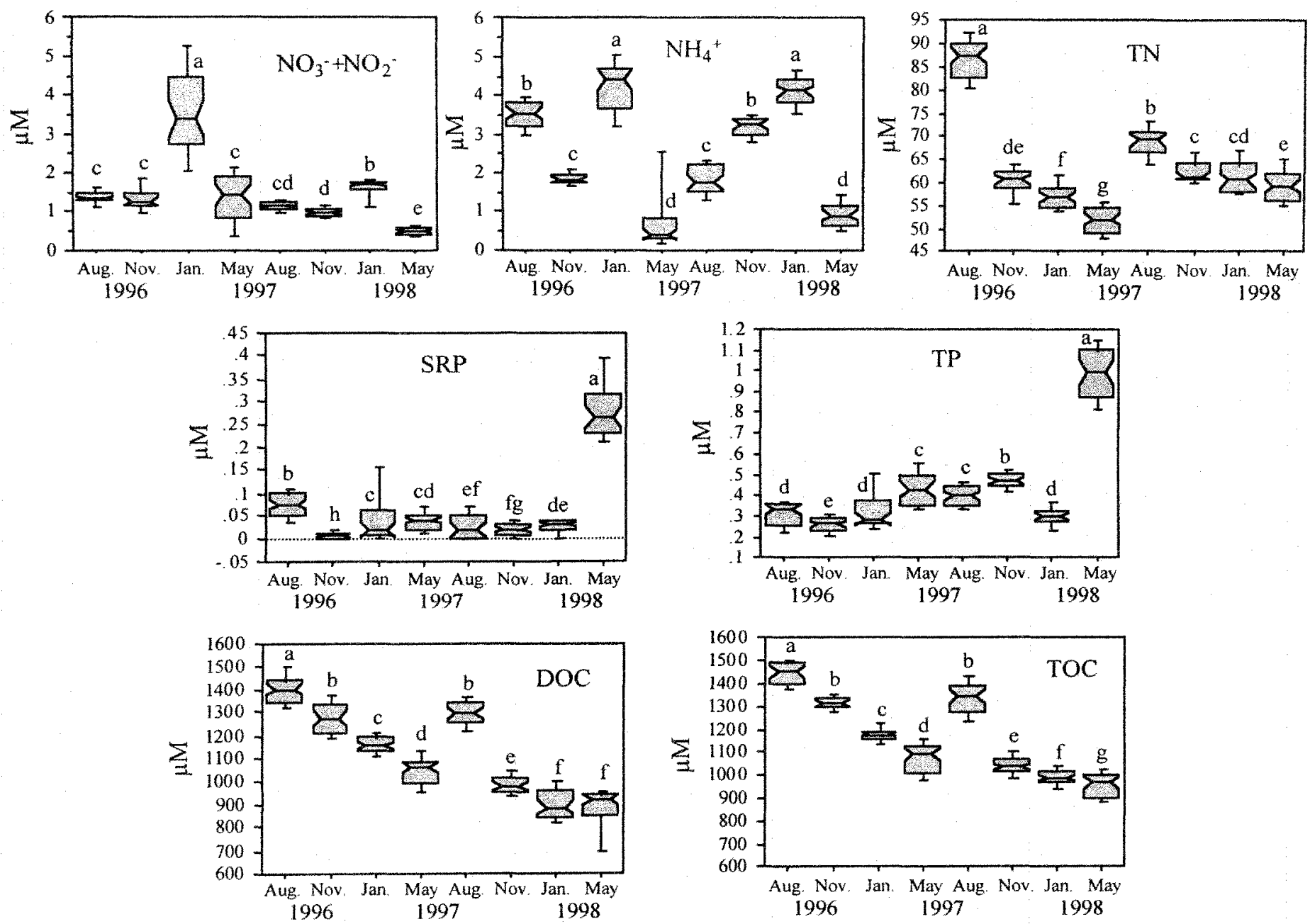

Figure 3.1- Box-and-whisker plots of ambient water column nutrient concentrations $(\mu \mathrm{M})$ at dwarf mangrove site during each sampling ( $n=36$ for all). Letters represent significant differences between samplings (ANOVA, $p<0.05$ ). 
Table 3.2- Results of one-factor ANOVA tests of concentration vs. Year and concentration vs. season from a Taylor Slough dwarf mangrove wetland.

\section{Concentration vs. Year}

\begin{tabular}{ccc} 
constituent & p-value & post-hoc results \\
\hline $\mathrm{NO}_{3}{ }^{-}+\mathrm{NO}_{2}{ }^{-}$ & $\mathrm{p}=0.0169$ & Year 1 > Year 2 \\
$\mathrm{TP}$ & $\mathrm{p}=0.0186$ & Year 1 < Year 2 \\
$\mathrm{DOC}$ & $\mathrm{p}=0.0046$ & Year 1 > Year 2 \\
$\mathrm{TN}: \mathrm{TP}$ & $\mathrm{P}=0.0264$ & Year 1 > Year 2 \\
\hline
\end{tabular}

\section{Concentration vs. Season}

\begin{tabular}{ccc} 
constituent & p-value & post-hoc results \\
\hline TN & $p=0.0012$ & wet $>$ dry \\
DOC & $p=0.0004$ & wet $>$ dry \\
TOC & $p<0.0001$ & wet $>$ dry \\
TN:TP & $P=0.012$ & wet $>$ dry \\
\hline
\end{tabular}


All samplings combined, dissolved inorganic nitrogen $\left(\mathrm{DIN}=\mathrm{NO}_{3}{ }^{-}+\mathrm{NO}_{2}{ }^{-}+\mathrm{NH}_{4}{ }^{+}\right)$made up $<10 \%$ of the total nitrogen content of the surface water in this mangrove wetland. The remainder of the TN fraction was likely dissolved organic in nature.

Phosphorus availability (especially SRP) in the Everglades and Florida Bay is extremely important, as it has been demonstrated to be the nutrient that limits primary production (Fourqurean et al. 1992) and microbial respiration (Amador and Jones 1993 and 1995). Soluble reactive phosphorus in the dwarf mangrove site was usually between 0.01 and $0.1 \mu \mathrm{M}$ (Figure 3.1), and in many samples was below the limit of detection $(<0.01 \mu \mathrm{M})$. However, SRP concentrations were abnormally high $(0.18-0.46 \mu \mathrm{M})$ during the May 98 sampling (Figure 3.1). Similarly, TP showed little variability throughout this study, aside from the high concentrations during May $98(0.74-1.32 \mu \mathrm{M}$; Figure 3.1). Combined with slightly elevated TP concentrations in August and November 97, this led to significantly higher mean TP concentration during Year 2 of this study (Table 3.2).

Soluble reactive phosphorus was usually $<10 \%$ of the total phosphorus in the surface water. However, this percentage jumped to $25 \%$ in August 96 and $>30 \%$ in May 98, demonstrating that labile SRP can be a substantial component of the surface water $P$ in this wetland. Furthermore, the DIN:DIP (SRP) molar ratios were quite low during these two samplings, ranging from 4.5 in May 1998 to 78 in August 1996 (Figure 3.2). All other samplings yielded DIN:DIP ratios between 53 and 491 (Figure 3.2). Total nitrogen:total phosphorus (TN:TP) ratios fluctuated over the same scale, varying between 55 and 286 (Figure 3.2), but displayed a significant seasonal trend (Table 3.2). These ratios were also much more stable within a given sampling than DIN:DIP ratios (Figure 3.2). Total nitrogen:total phosphorus ratios were also significantly higher during Year 1, 


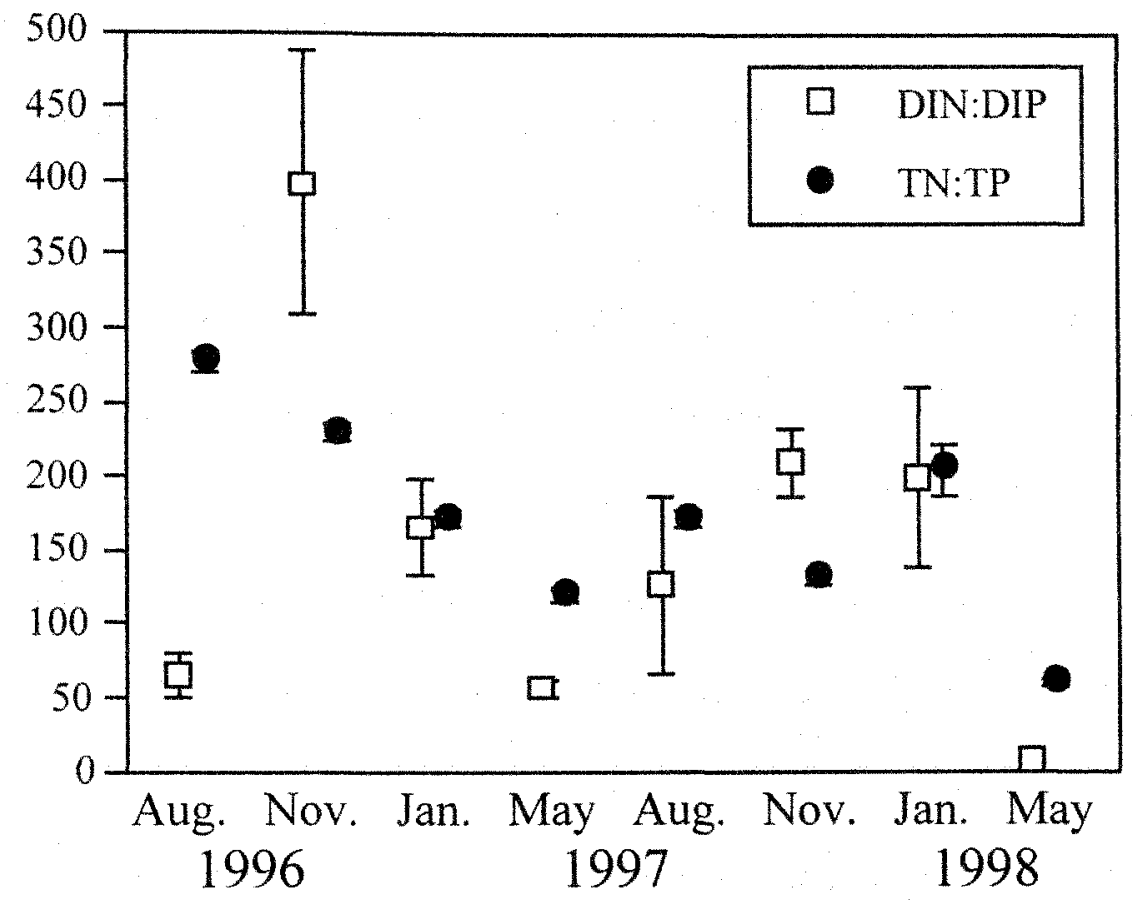

Figure 3.2- Plot showing mean DIN:DIP ( $\square$ ) and TN:TP (๑) molar ratios in the surface water of the dwarf mangrove site over the two-year study period. Error bars represent standard deviations. 
most likely as a combined result of the low Year 1 mean TP concentration and the high August 96 (Year 1) TN concentration range (Table 3.2 and Figure 3.1).

Concentrations of DOC and TOC in the dwarf mangrove were quite similar throughout this study (Figure 3.1). In fact, for all samplings, $>90 \%$ of the total organic carbon in the surface water was in the dissolved state, reflecting the low terrestrial sediment load common to carbonate settings (Woodroffe 1992). These constituents also displayed a similar seasonal pattern (Figure 3.1), with highest concentrations during the early wet season (August) and lowest concentrations during the late dry season (May; Table 3.2).

Many of these constituents showed significant correlation with salinity or temperature (Figure 3.3). Total nitrogen and organic carbon concentrations were both negatively linked to salinity and positively linked to temperature. Ammonium, on the other hand, showed a strong negative association with both factors (Figure 3.3). There were also many instances of concentration correlation between nutrients. Most notably, SRP and TP had strong positive correlation as did TN, DOC and TOC (Figure 3.3). Both DIN constituents also showed a fairly strong association with one another (Figure 3.3).

\section{$\underline{\text { Flux results }}$}

I had much success in measuring exchanges of nitrogen in this dwarf mangrove system. There were only two samplings in which significant net areal fluxes of TN were not measured in every enclosure and only one for $\mathrm{NO}_{3}{ }^{-}+\mathrm{NO}_{2}{ }^{-}$. Ammonium flux was measured in every enclosure during every sampling (Figure 3.4). Nitrate+nitrite export and $\mathrm{NH}_{4}{ }^{+}$and TN import occurred in six of eight samplings (Figure 3.4). Export of 


\begin{tabular}{|c|c|c|c|c|c|c|c|c|c|}
\hline \multirow{3}{*}{$\begin{array}{c}\text { salinity } \\
\text { temperature }\end{array}$} & salinity & temperatu & $\mathrm{O}_{3}-+\mathrm{NO}$ & $\mathrm{NH}_{4}{ }^{+}$ & SRP & $\mathrm{TP}$ & TOC & DOC & $\mathrm{TN}$ \\
\hline & - & & & & & & & & \\
\hline & & - & & & & & & & \\
\hline $\mathrm{NO}_{3}{ }^{-}+\mathrm{NO}_{2}^{-}$ & & -.573 & - & & & & & & \\
\hline $\mathrm{NH}_{4}{ }^{+}$ & -.606 & -.631 & .588 & - & & & & & \\
\hline SRP & .377 & & & -.427 & - & & & & \\
\hline $\mathrm{TP}$ & .436 & & -.477 & -.549 & .916 & - & & & \\
\hline TOC & -.383 & .631 & & & & -.445 & - & & \\
\hline DOC & & .504 & & & -.413 & -.581 & .916 & - & \\
\hline $\mathrm{TN}$ & -.477 & 430 & & & & & .826 & .634 & - \\
\hline
\end{tabular}

Figure 3.3- Matrix showing significant correlations $(\mathrm{p}<0.05)$ between salinity, temperature, and nutrient concentrations in a Taylor Slough dwarf mangrove wetland. 

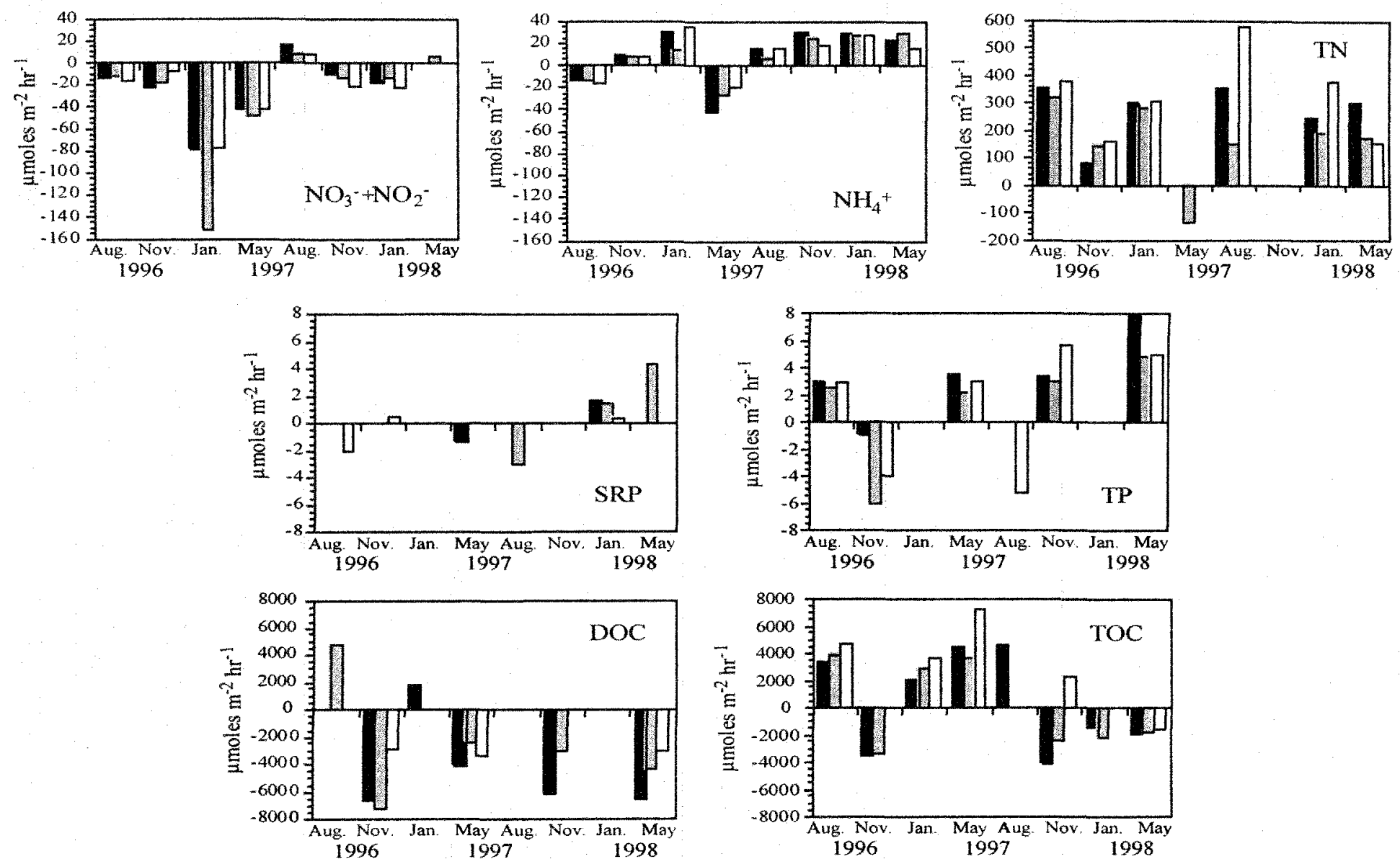

Figure 3.4- Bar charts showing significant net areal fluxes $\left(\mu\right.$ moles $\mathrm{m}^{-2} \mathrm{hr}^{-1}$ ) of nutrients in each replicate enclosure over the course of this study. Different colors represent each of three dwarf mangrove islands sampled in this study. Positive values indicate an uptake by the wetland and negative values signify an export to the water column. There was only one instance of disagreement in significant fluxes between replicate enclosures (TOC in November 1997). 
$\mathrm{NO}_{3}{ }^{-}+\mathrm{NO}_{2}{ }^{-}$ranged from 7.2 to $151.1 \mu$ moles $\mathrm{m}^{-2} \mathrm{hr}^{-1}$, while imports were only between 5.4 and $15.6 \mu$ moles $\mathrm{m}^{-2} \mathrm{hr}^{-1}$ (Figure 3.4). Ammonium fluxes were within a much narrower range, with uptakes only as high as $34.5 \mu$ moles $\mathrm{m}^{-2} \mathrm{hr}^{-1}$ and exports never exceeding $42.4 \mu$ moles $\mathrm{m}^{-2} \mathrm{hr}^{-1}$ (Figure 3.4). Total nitrogen import ranged from 79.2 to $575.8 \mu$ moles $\mathrm{m}^{-2} \mathrm{hr}^{-1}$ (Figure 3.4). Export of TN occurred only in May 97.

Measuring wetland-water column exchange of phosphorus proved to be more difficult as concentrations were often quite low (Figures 3.1 and 3.4). Soluble reactive phosphorus dynamics were highly variable with only one sampling yielding fluxes in all three enclosures (Figure 3.4). Overall, SRP flux ranged from -2.9 to $4.3 \mu$ moles $\mathrm{m}^{-2} \mathrm{hr}^{-1}$. Total phosphorus exhibited many more instances of measurable net areal flux. Four of these were uptakes ranging from 2.2 to $7.9 \mu$ moles $\mathrm{m}^{-2} \mathrm{hr}^{-1}$ (Figure 3.4). Export of TP was observed only in November 96 (all three enclosures) and August 97 (one enclosure; Figure 3.4).

The dynamics of TOC and DOC were expected to be similar to one another since much of the organic carbon in this system was in the dissolved form (Figure 3.1). This was true for the most part. When measurable, DOC tended to be exported. In fact, there were only two instances of DOC uptake in this dwarf mangrove (Figure 3.4). Total organic carbon fluxes were measured in at least two enclosures during every sampling, and shifted irregularly from uptake to export (Figure 3.4). Comparing these two constituents, I found that when fluxes were measured for each, TOC and DOC fluxes were similar in direction and magnitude for all samplings except May 98. During this particular sampling there was an overwhelming uptake of TOC with an export of DOC (Figure 3.4). 
Analyses of variance revealed that a few of these fluxes varied from one year to the next or from one season to the next. Nitrate+nitrite showed an influence of both, as exports were significantly greater in Year 1 and during the dry season (Table 3.3). Ammonium showed greater uptake during Year 1, while TOC uptake was greater during Year 2 (Table 3.3). Total phosphorus flux was also affected by season, with more uptake occurring in the dry season than the wet season (Table 3.3).

A number of significant regression relationships also existed between nutrient flux and salinity, temperature, or nutrient concentration. Fluxes of $\mathrm{NH}_{4}{ }^{+}$and $\mathrm{TN}$ showed negative linear relationships with salinity (Table 3.4). The concentrations of both these constituents were negatively correlated with salinity as well (Figure 3.3). Ammonium fluxes had a negative relationship with temperature, as did ammonium concentrations (Table 3.4 and Figure 3.3). Although $\mathrm{NO}_{3}{ }^{-}+\mathrm{NO}_{2}{ }^{-}$concentrations correlated negatively with temperature, the flux of this constituent was positively linked with temperature (Figure 3.3). Regression results also revealed a negative relationship between the concentration and flux of this constituent. Furthermore, as $\mathrm{NO}_{3}{ }^{-}+\mathrm{NO}_{2}{ }^{-}$concentrations increased to approximately $0.74 \mu \mathrm{M}$ in this dwarf mangrove, flux shifted from import to export (Table 3.4). Total nitrogen and phosphorus flux were also related to their respective concentrations, however these relationships were positive (Table 3.4). Given the importance of phosphorus availability in this system, I explored the possibility of similar relationships between nutrient fluxes and TN:TP or DIN:DIP ratios. No such relationships existed.

Flux measurements from the dwarf mangrove island enclosures and control chambers were tested for significance and averaged across replicates. Mangrove island 
Table 3.3- Results of one-factor ANOVA tests of flux vs. year and flux vs. season in a Taylor Slough dwarf mangrove wetland.

\section{Flux vs. Year}

\begin{tabular}{ccc} 
constituent & $\mathrm{p}$-value & post-hoc results \\
\hline $\mathrm{NO}_{3}{ }^{-}+\mathrm{NO}_{2}^{-}$ & $\mathrm{p}=0.01$ & greater export in Year 1 \\
$\mathrm{NH}_{4}{ }^{+}$ & $\mathrm{p}=0.0027$ & greater uptake in Year 2 \\
$\mathrm{TOC}$ & $\mathrm{p}=0.017$ & greater uptake in Year 1 \\
\hline
\end{tabular}

\section{Flux vs. Season}

\begin{tabular}{ccc} 
constituent & $\mathrm{p}$-value & post-hoc results \\
\hline $\mathrm{NO}_{3}{ }^{-}+\mathrm{NO}_{2}^{-}$ & $\mathrm{p}=0.0069$ & greater export during dry season \\
$\mathrm{TP}$ & $\mathrm{p}=0.0485$ & greater uptake during dry season \\
\hline
\end{tabular}


Table 3.4- Simple regressions of nutrient flux vs. salinity, temperature, and concentration. The r-squared, slope, and Y-intercept from all significant regressions is shown. $\mathrm{I} / \mathrm{E}$ switch indicates the predicted point along the $\mathrm{X}$-axis at which flux shifts from export to import or vice versa.

\section{Flux vs. Salinity}

\begin{tabular}{cccccc} 
constituent & r-squared & p-value & slope & Y-intercept & I/E switch \\
\hline $\mathrm{NH}_{4}{ }^{+}$ & 0.351 & 0.0023 & -1.318 & 16.845 & 12.6 \\
$\mathrm{TN}$ & 0.301 & 0.0151 & -11.066 & 294.81 & 26.3 \\
\hline
\end{tabular}

Flux vs. Temperature

\begin{tabular}{cccccc} 
constituent & r-squared & p-value & slope & Y-intercept & I/E switch \\
\hline $\mathrm{NO}_{3}{ }^{-}+\mathrm{NO}_{2}{ }^{-}$ & 0.259 & 0.0155 & 3.268 & -113.236 & 35.1 \\
$\mathrm{NH}_{4}{ }^{+}$ & 0.364 & 0.0018 & -2.278 & 69.621 & 30.7 \\
\hline
\end{tabular}

Flux vs. Concentration

\begin{tabular}{cccccc} 
constituent & r-squared & p-value & slope & Y-intercept & I/E switch \\
\hline $\mathrm{NO}_{3}{ }^{-}+\mathrm{NO}_{2}{ }^{-}$ & 0.644 & $<0.0001$ & -33.06 & 24.796 & 0.74 \\
$\mathrm{TN}$ & 0.346 & 0.008 & 9.037 & -330.09 & 36.4 \\
$\mathrm{TP}$ & 0.397 & 0.0089 & 9.674 & -2.789 & 0.29 \\
\hline
\end{tabular}


enclosure fluxes were nearly always the same direction as fluxes measured in the control chambers (Figure 3.5). However, the magnitude of flux between these methods was quite different. Whenever both were significant, the control chamber fluxes were significantly higher than those measured in the island enclosures (unpaired t-test, $p<0.05$ ).

Interestingly, all of these cases occurred during the same three samplings. They included $\mathrm{NO}_{3}{ }^{-}+\mathrm{NO}_{2}{ }^{-}$in August 97 and January 98 and $\mathrm{NH}_{4}{ }^{+}$in August 97 and January and May 98 (Figure 3.5).

The estimated annual fluxes of materials in this system varied somewhat between Years 1 and 2. During Year 1, total nitrogen was imported, but more than $1 / 4$ of this was exported back to the water column as DIN (Figure 3.6). Total phosphorus uptake $\left(0.08 \mu \mathrm{M} \mathrm{m}^{-2} \mathrm{yr}^{-1}\right)$ was balanced by SRP export $\left(0.11 \mu \mathrm{M} \mathrm{m}^{-2} \mathrm{yr}^{-1}\right)$, and over $25 \%$ of the TOC imported during Year 1 was exported as DOC (Figure 3.6). During Year 2, slightly more TN was imported, but a small fraction of this was associated with $\mathrm{NH}_{4}{ }^{+}$uptake (Figure 3.6). Total phosphorus was imported again, however more than half of the phosphorus taken up may have been in the soluble reactive form. Finally, there was a net export of organic carbon during Year 2, the majority of which was in the form of DOC (Figure 3.6).

\section{Discussion}

The results of this study indicate a consistent uptake of total nitrogen and total phosphorus by the dwarf mangrove wetland. Ammonium was also consistently imported, especially during Year 2, with a portion of this pool being transformed into an oxidized inorganic form $\left(\mathrm{NO}_{\mathrm{x}}{ }^{-}\right)$and released back into the water column. Other mangrove flux 

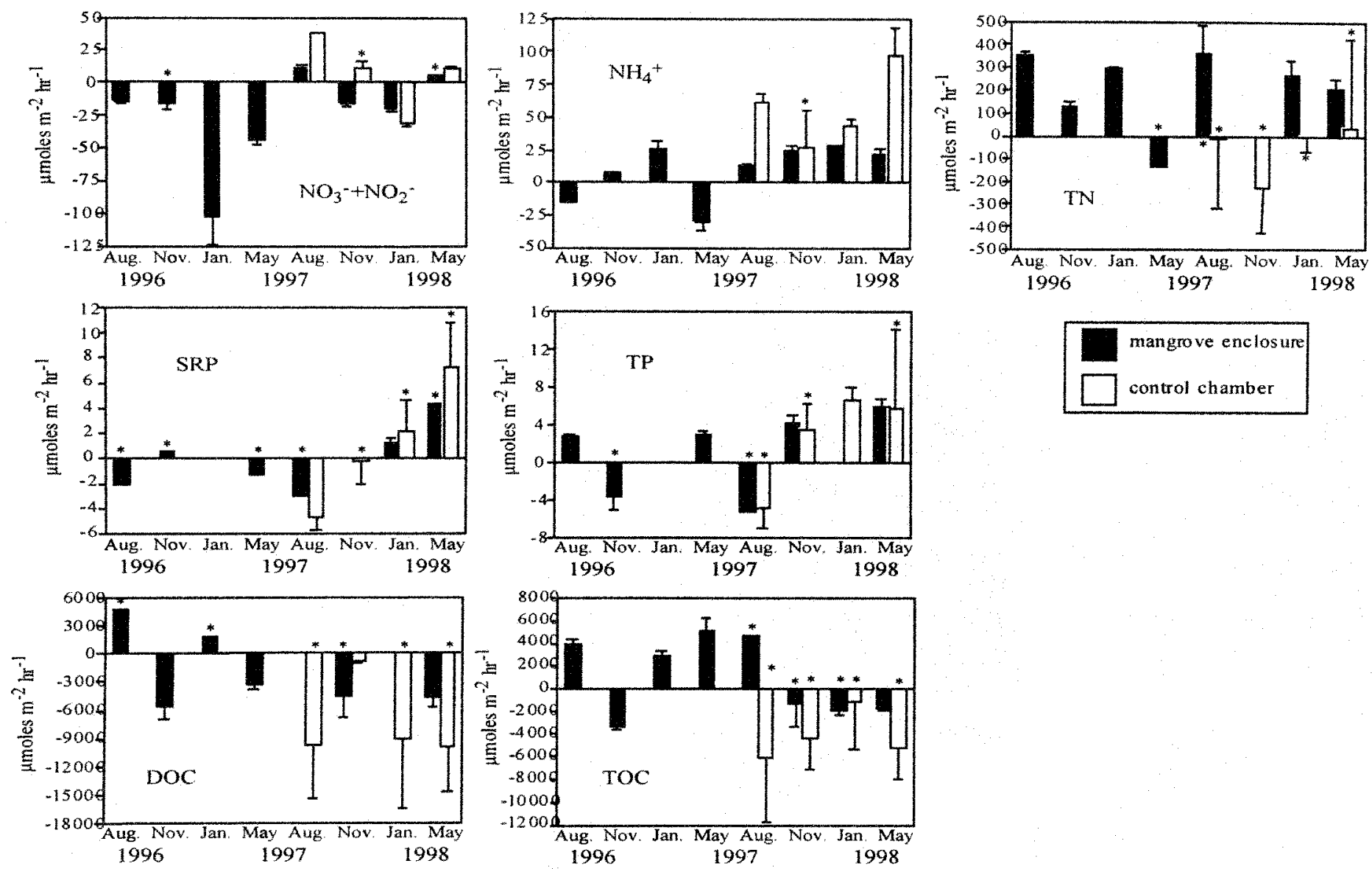

Figure 3.5- Bar charts showing average net areal fluxes $( \pm \mathrm{SE})$ of nutrients in dwarf mangrove island enclosures (black) and control chambers (white; year 2 only). Positive values indicate an uptake by the wetland and negative values signify an export to the water column. Note that different methods were used to calculate fluxes for each design. Asterisks indicate fluxes that are not significantly different from zero (one-sample t-test, $\mathrm{p}<0.05$ ). 


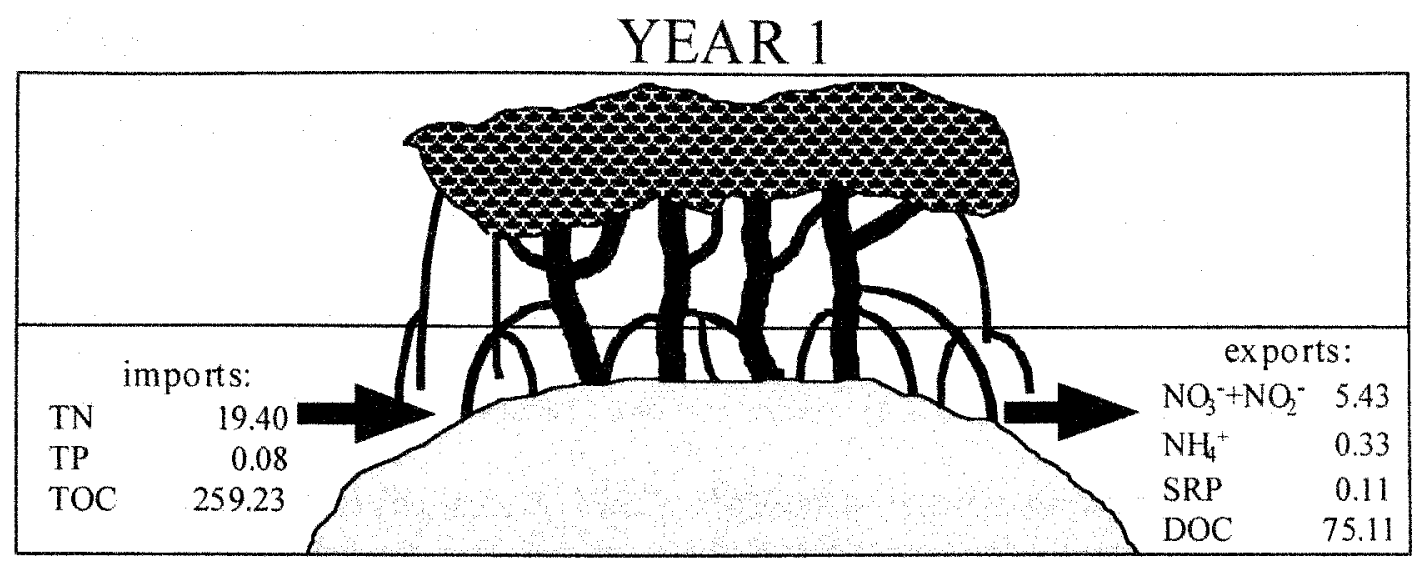

YEAR 2



Figure 3.6- Estimates of annual fluxes $\left(\mathrm{g} \mathrm{m}^{-2} \mathrm{yr}^{-1}\right)$ of nutrients in the dwarf mangrove wetland of Taylor Slough during Year 1 (top) and Year 2 (bottom) of this study. 
studies have shown consistent uptake of both DIN constituents (Kristensen et al. 1988; Rivera-Monroy et al. 1995). Total organic carbon flux was balanced between net uptake in Year 1 and net export during Year 2, while dissolved organic carbon was clearly exported over the two-year study. This pattern of DOC export is likely attributed to the leaching of plant tissues (i.e. leaves) and is contrary to what has been shown in a tidal mangrove in Australia (Boto et al. 1989). Patterns of reactive phosphorus dynamics were indecipherable, as measurable fluxes were few and far between.

Compared to other mangrove forest types, relatively little ecological work has been conducted in dwarf mangrove systems. The majority of this research has focused on dwarf mangrove seedling development (Koch and Snedaker 1997), litterfall (Twilley et al. 1986), herbivory (Feller 1995), or nutrient enrichment effects (Twilley 1995; Feller 1996; Koch 1997). My project is one of the first studies of nutrient dynamics in a dwarf mangrove. Consequently, it is difficult to compare the results of this study to other dwarf mangrove systems. The shallow, non-tidal nature of Taylor Slough allowed for the opportunity to enclose sufficiently large areas of dwarf mangrove for the purpose of measuring the wetland-water column exchanges of nutrients. Furthermore, the strong seasonal character of the mangrove transition area of Taylor Slough hinted at the possibility for seasonal controls on nutrient concentrations and fluxes. The relationships between these factors and nutrient dynamics allow for comparison with other mangrove and even other temperate estuarine systems. 


\section{Factors related to nutrient concentrations}

Many of the constituents examined in the present study showed significant correlation with water temperature or salinity (Figure 3.3). In this study, temperature was negatively related to DIN concentrations and positively related to TN, TOC, and DOC concentrations. Temperature relationships with concentration have been reported for other estuarine systems. For example, Wolaver and Spurrier (1988) found that particulate phosphorus and SRP concentrations in North Inlet, SC were positively correlated with water temperature. In Taylor Slough, SRP and TP concentrations were not correlated with temperature but instead with salinity (Figure 3.3). High SRP and TP concentrations were generally associated with high salinity (Figure 3.3). Nixon et al. (1984) found the opposite pattern for inorganic phosphorus in two Malaysian mangrove creeks. They also found a negative relationship between salinity and dissolved and organic nitrogen concentrations, similar to the pattern shown by $\mathrm{NH}_{4}{ }^{+}$and $\mathrm{TN}$ in the present study (Figure 3.3; Nixon et al. 1984).

Aside from temperature and salinity effects in Taylor Slough, there were also several constituents whose concentrations were correlated with those of other constituents. A high degree of correlation $(\mathrm{r}=0.916)$ existed between TP and SRP concentrations (Figure 3.3). This suggests that SRP availability is controlled by concentrations of $\mathrm{TP}$, much of which is likely in the dissolved organic form. Total and dissolved organic carbon and total nitrogen were positively correlated to each other, indicating that much of the $\mathrm{TN}$ in this dwarf mangrove may be organic in nature (Figure 3.3). Boto and Wellington (1988) found that DON and DOP were correlated with each other but not with DOC in Coral Creek. They concluded that the DOC in this system 
contained low amounts of $\mathrm{N}$ and $\mathrm{P}$, and instead was composed mostly of humic or polyphenolic compounds (Boto and Wellington 1988). These organic components are found in high concentrations in the leaf tissue of many mangrove species, especially in members of the Rhizophoraceae Family (Robertson et al. 1992).

Total and dissolved organic carbon and total nitrogen concentrations as well as TN:TP molar ratios in the Taylor Slough dwarf site were not only correlated, they also varied according to season (Figure 3.3 and Table 3.2). Assuming Boto and Wellington's (1988) conclusions are true for this Rhizophora-dominated system, then there must be a non-mangrove source of organic matter to this system producing the relationship between organic carbon and total nitrogen. The likely source is upland runoff from the freshwater Everglades marshes. During the wet season, high precipitation produces a net southerly flow of water (and nutrients) from the Everglades, through the mangrove transition zone, and out to Florida Bay. There was no such upland source of water and nutrients in Coral Creek, as it is a purely tidal-driven system.

Other studies have also reported seasonal relationships for these and other constituents in both mangrove and salt marsh systems. At a mangrove site near Laguna de Terminos, Rivera-Monroy et al. (1995) observed a seasonal pattern for DON and PN (DON $+\mathrm{PN} \approx \mathrm{TN}-\mathrm{DIN}$ ), with highest concentrations during the wet season (Table 3.2). The same investigators also measured the highest concentrations of $\mathrm{NH}_{4}{ }^{+}$and $\mathrm{NO}_{3}{ }^{-}+\mathrm{NO}_{2}{ }^{-}$ during the frontal season ('el Norte'; Rivera-Monroy et al. 1995). In Gazi Bay, Kenya, the highest concentrations of DIN and DIP were found during the wet season when seasonal rivers discharge into it (Ohowa et al. 1997). Finally, Wolaver et al. (1988) found highest concentrations of $\mathrm{NH}_{4}{ }^{+}$during the late summer and early fall in North 
Inlet, $\mathrm{SC} . \mathrm{High} \mathrm{NH}_{4}{ }^{+}$concentrations during that time of the year corresponded to the highest $\mathrm{NH}_{4}{ }^{+}$uptake rates (Wolaver et al. 1988).

\section{Factors related to nutrient fluxes}

Many of the aforementioned factors have also been linked to the flux of materials in tropical and temperate estuarine systems. For instance, exports of DOC and TOC on the west coast of Florida have been associated with seasonal patterns in precipitation and tide height (Twilley 1985). No seasonally related flux patterns were observed for either of these parameters in the Taylor Slough dwarf mangrove. Nevertheless, I found that the fluxes of the different nitrogen constituents $\left(\mathrm{NO}_{3}{ }^{-}+\mathrm{NO}_{2}{ }^{-}, \mathrm{NH}_{4}{ }^{+}\right.$, and $\left.\mathrm{TN}\right)$ were all related to changes in season, salinity, or temperature (Tables 3.3 and 3.4). Other studies have found similar relationships with nitrogen and even phosphorus dynamics. Nitrate + nitrite was usually exported from the wetland to the water column in the Taylor Slough system. These exports were greatest during the dry season (Table 3.3). Rivera-Monroy et al. (1995) measured $\mathrm{NO}_{3}{ }^{-}+\mathrm{NO}_{2}{ }^{-}$uptake in most of their flume samplings. However, a significant export of $\mathrm{NO}_{3}^{-}+\mathrm{NO}_{2}^{-}$was measured during the only dry season sampling (April 91; Rivera-Monroy et al. 1995). Boto and Wellington (1988) recorded 9 (out of 13) instances of significant $\mathrm{NO}_{3}{ }^{-}+\mathrm{NO}_{2}{ }^{-}$export from Coral Creek, Australia. These exports, however, were neither linked to season or any other environmental factor such as salinity or temperature.

Ammonium and TN fluxes in the island enclosures decreased with increasing salinity (Table 3.4), showing the same negative association with salinity as their respective concentrations (Figure 3.3). Wolaver and Spurrier (1988) observed that high 
ortho-phosphate uptake corresponded to high salinity at a creekside site along Bly Creek, North Inlet, SC. These fluxes also showed a positive correlation with temperature and ortho-phosphate concentrations (Wolaver and Spurrier 1988). At the same site and time, DIN uptake peaked during late summer and early fall and also corresponded to surface water concentrations (Wolaver et al. 1988; Whiting et al. 1989). In the present study, $\mathrm{NO}_{3}{ }^{-}+\mathrm{NO}_{2}{ }^{-}$uptake appeared to increase with temperature, however the predicted $\mathrm{I} / \mathrm{E}$ switch $\left(35.1^{\circ} \mathrm{C}\right)$ was above the highest measured temperature in this system. Also, $\mathrm{NO}_{3}{ }^{-}$ $+\mathrm{NO}_{2}{ }^{-}$exports were high when concentrations were high, and vice versa (Table 3.4). Similarly, Rivera-Monroy et al. (1995) observed some of their highest PN and DON exports when concentrations were highest. In Taylor Slough, high surface water concentrations of TN led to increased TN uptake. Additionally, as more TP became available, the import of it increased as well. The same trend was observed for particulate phosphorus in Bly Creek (Wolaver and Spurrier 1988).

\section{Conclusions}

My study indicates a moderate degree of variability in concentration and flux of nutrients in this dwarf mangrove. Some of this variance was explained by the factors investigated. However, the relationships between the actual processes controlling nutrient dynamics and the underlying forcing functions are still unknown. The potential influence of these seasonal factors on the concentrations or fluxes of nutrients are numerous, including the affect on microbial activity, enzyme-catalyzed reactions, diffusive fluxes, evapostranspiration rates, primary productivity, etc. I simply determined 
the presence of these relationships rather than the actual "cause and effect" of these seasonal factors.

In this non-tidal environment, seasons are determined mainly by precipitation patterns that result in different sources of water and, thus, nutrients and salinity to the mangrove wetlands throughout the year. Therefore, season alone can account for much of the variability in nutrient dynamics. Different seasons can also be characterized by differences in leaf litter turnover (Wafar et al. 1997), a potenitally large and instantaneous source of carbon, nitrogen, and phosphorus to the water column. Regardless, many potentially important relationships were revealed in this study. Some of which may lead to further research on the actual effects of these environmental factors on the biogeochemical processes controlling the cycling of nutrients.

The southeastern region of Everglades National Park (including Taylor Slough) is currently experiencing a hydrologic restoration. The goal of this restoration effort is to reestablish more "natural", pre-drainage conditions by diverting more freshwater back into Taylor Slough and the rest of the southern Everglades. This change will undoubtedly alter the long-term salinity and temperature patterns in this system. Therefore, it is necessary to generate a better understanding of the relationships between nutrient dynamics and these physical factors. Studies addressing these issues will lead to more insight concerning the long-term implications of this change. Furthermore, an approach such as the one taken in this study also allow one to make long-term predictions concerning the changes associated with global climate change and sea-level rise. 


\section{Chapter 4:}

Factors affecting the concentration and flux of nutrients in a southern Everglades fringe mangrove wetland - An application of a new flow-through flume design.

\section{Abstract}

Replicate, modified flow-through flumes were used to determine seasonal fluxes of carbon, nitrogen, and phosphorus in a creek-side fringe mangrove wetland of Taylor River, Everglades National Park, Florida. Consecutive days of sampling were conducted on a quarterly basis (beginning in November 1996 and ending in August 1998) to determine the factors that influenced the concentration and flux of materials such as salinity, season, water source, flume volume, and temperature. Only 66 significant fluxes out of a possible 224 ( 7 constituents x 16 sampling days $\times 2$ flumes) were observed. Ammonium concentrations were highest during the dry season, and total phosphorus concentrations were highest during the wet season. Nitrate+nitrite and SRP were highest when water was flowing north from Florida Bay. However, TN, TP, TOC, and DOC concentrations were highest when flow was towards Florida Bay. Neither season nor the direction of flow affected nutrient flux in lower Taylor River, as fluxes were highly variable from one sampling to the next. Also, there was no effect of salinity or temperature on nutrient concentrations or fluxes. However, there were strong relationships between the concentrations and fluxes of nitrate+nitrite and ammonium. In both cases, increased concentration coincided with increased uptake by the wetland. One possible explanation for the variability in these flux data may be the overriding influence of concentration fluctuations over time in Taylor River. There were multiple instances of 
large increases or decreases in concentration at the upstream sampling stations.

Phenomena such as these may have masked any influence of the areas of wetland isolated by the flumes. Estimations of annual flux for each constituent revealed uptake of nearly all constituents over the two-year study period. Nitrogen flux data from this study compare favorably with those of another mangrove flume study conducted in Mexico. Annual fluxes of phosphorus and organic carbon were also comparable to a creek flux study conducted in Australia. However, the lack of significant fluxes from many of the samplings makes it difficult to draw any definitive conclusions about this system.

\section{Introduction}

Ecologists have been speculating on and trying to quantify the exchanges of materials between coastal wetlands and near-shore waters for some 40 years now (Teal 1962; Nixon 1980; Childers et al.1999). The vast majority of these works were inspired by the Outwelling Hypothesis that was developed in the mid- to late 1960's (Odum and de la Cruz 1967). Although studies testing this concept have not actually proven the hypothesis, they have led to a better understanding of the influence of various factors on wetland-estuarine and estuarine-ocean interactions. Of these, tidal range, freshwater flow, and seasonal factors have been shown to among the more pervasive controls (Odum et al. 1979; Wolaver et al. 1983; Twilley 1985; Childers et al. 1999; Rivera-Monroy et al. 1995; Chapters 2 and 3).

Another outcome of these studies has been the advancement of a number of tools and sampling protocols for determining wetland-water column exchanges of materials. Among these, the flume technique has proven effective in a number of temperate 
estuarine wetland systems (Wolaver et al. 1983; Wolaver et al. 1985; Chalmers et al. 1985; Childers 1994; among others). Whether sampling is conducted at one end from an array of points or at both ends from a single point, this rather simple in situ technique allows for the direct quantification of the effect of a wetland on water column nutrient concentrations. While flume studies have frequented the body of literature from temperate estuaries for much of the past two decades, this technique has been utilized in tropical mangrove systems on just a few occasions (Twilley 1985; Rivera-Monory et al. 1995).

The number of mangrove flux studies in general has increased dramatically over the past fifteen years. This surge has most likely stemmed from the deterioration of water quality in many tropical coastal areas as a result of deforestation, freshwater diversion, coastal development, and oil spills (Twilley 1998). By and large, the focus of these studies has been on the exchange of organic matter between the mangrove and near-shore environment (Boto and Bunt 1981; Twilley 1985; Woodroffe 1985; Flores-Verdugo et al. 1987; Robertson 1988; among others). However, there have been a few studies that have quantified the exchange of nutrients within mangroves and between mangroves and nearshore environments (Boto and Wellington 1988; Kristensen et al. 1988; Rivera-Monroy et al. 1995; Chapter 2). While it is generally thought that mangroves export organic matter in relation to tidal energy (Odum et al. 1979; Lee 1995; Twilley 1995; Twilley 1998), the fate of nutrients in estuarine mangrove systems is still poorly understood (Rivera-Monroy et al. 1995). Furthermore, little is known about the exchanges of organic and inorganic nutrients (primarily carbon, nitrogen, and phosphorus) in non-tidal, seasonally driven mangrove systems. 
I developed and utilized modified, replicate, in-channel flow-through flumes in a non-tidal, creek-side fringe mangrove of the southern Everglades to quantify the fluxes of carbon, nitrogen, and phosphorus. The purpose of this study was not only to quantify nutrient exchange between the mangrove wetland and the water column but also to determine the factors that influence these exchanges. The hydrology of the southern Everglades is currently being restored to historical patterns through a systematic increase of freshwater flow in both the wet and dry seasons. This restoration is already resulting in more freshwater delivery to the mangroves of the southeast Everglades and to northeast Florida Bay. The communities that might be most affected by this change are the mangroves that lie at the interface of the mainland and Florida Bay.

In order to assess the long-term implications of increased freshwater to the mangroves of the southern Everglades, an understanding of the relationship between the potential factors affected by this change, and mangrove wetland-water column interactions is needed. Therefore, I sought to determine the factors influencing the concentrations and fluxes of these constituents, primarily season, water source, and salinity. As a number of salt marsh and mangrove flux studies have shown, I hypothesized that these factors would have a significant effect on nutrient and organic matter concentrations as well as the magnitudes and patterns (uptake or export) of flux of these constituents. This study was unique not only because it was the first application of the flume design in a non-tidal mangrove system, but also because it was the first use of side by side flumes within a creek channel. 


\section{Site Description}

This study was conducted in a mangrove creek draining Taylor Slough, southern Everglades National Park. Taylor Slough is the largest natural drainage for freshwater in the southern Everglades. It is located in the southeast corner of ENP and feeds numerous mangrove creeks that empty into northeastern Florida Bay. One of the most important of these channels is Taylor River (Figure 4.1).

Taylor River is a fairly small channel (approx. $10 \mathrm{~m}$ wide and $1-2 \mathrm{~m}$ deep) that links a number of small, shallow mangrove ponds along the north-south gradient of the salinity transition zone of the southern Everglades. Although it empties into Florida Bay via Little Madeira Bay, Taylor River is not significantly affected by tides. In fact, the direction and velocity of water flow in Taylor River is driven mostly by the interactions of precipitation, wind, and upland runoff (Sutula 1999). This produces a characteristic seasonal pattern in salinity and nutrients in this system (Figure 2.2). For Florida Bay, this salinity pattern combined with high evapotranspiration often results in the largest annual range in salinity (McIvor et al. 1994). Another outcome of the non-tidal character of this creek is cross-sectional homogeneity of nutrients, suspended solids, and chlorophyll $a$ throughout the year (Sutula 1999). Generally speaking, the upstream freshwater Everglades marshes are the source of water and materials to Taylor River during the wet season (south flow), whereas Florida Bay is typically the source during the dry season (north flow).

The lower stretch of Taylor River begins at a shallow mangrove pond and dissects the Buttonwood Ridge before emptying into Little Madeira Bay (Figure 4.1). This "ridge" is actually a carbonate sediment bank approximately $1 \mathrm{~m}$ above mean high water 


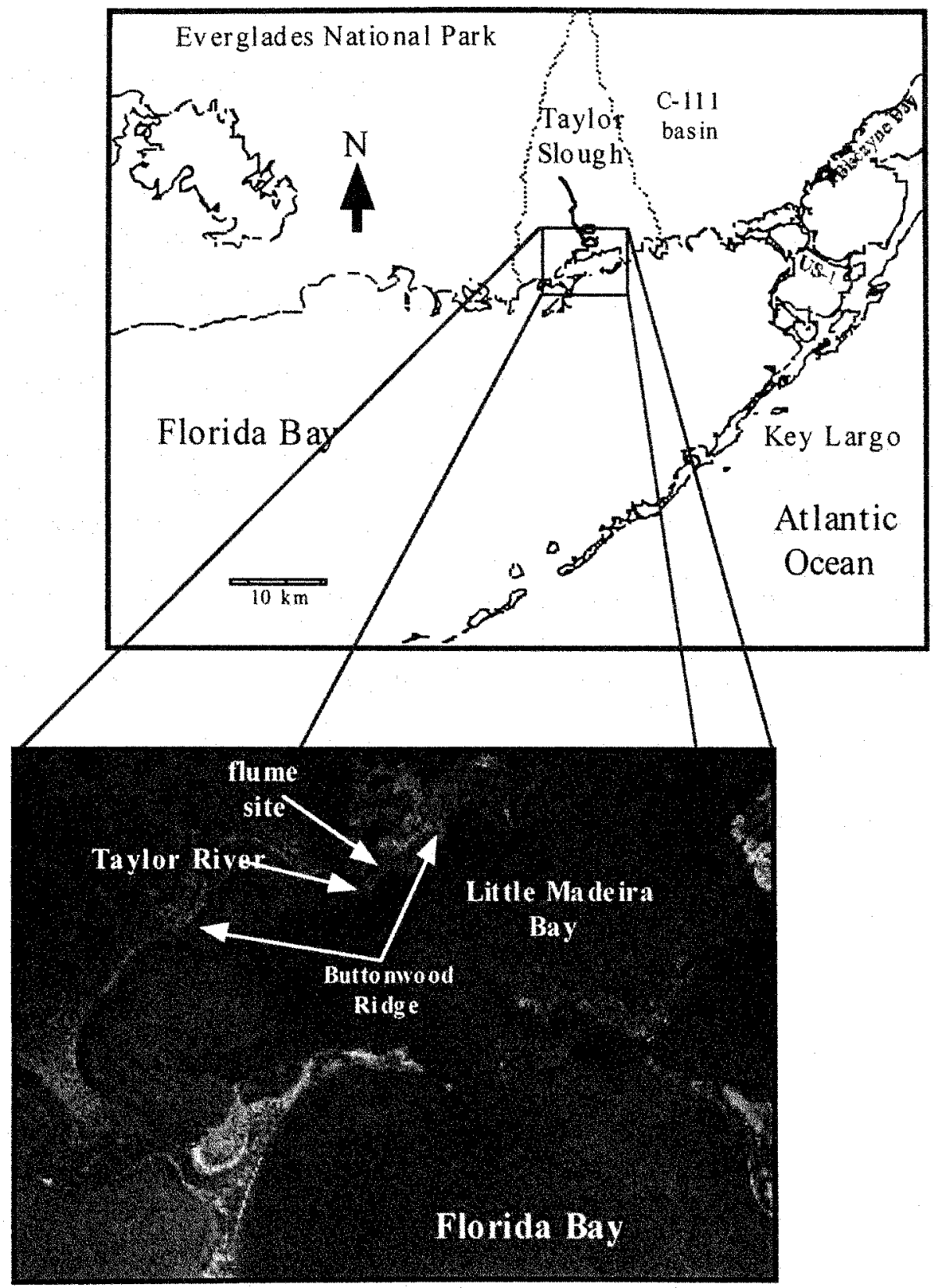

Figure 4.1- Map of south Florida showing Taylor Slough area. Enlargement highlights the lower, fringe mangrove-dominated stretch of Taylor River that dissects the Buttonwood Ridge. This is the area in which the flume study was conducted. 
and is believed to be the result of a past storm surge (Browder et al. 1994). Two mangrove forest types inhabit this area of Taylor River. First, a red mangrove-dominated (Rhizophora mangle L.), fringe forest lines both sides of the creek, as well as along the shore of Little Madeira Bay. This area is characterized by an abundance of epibiont covered prop roots that extend well into the creek channel. This matrix of roots and epibionts not only impedes flow but may also be an active zone of nutrient uptake and exchange (Childers and Davis, in prep). This fringe wetland is the primary focus of this study. Immediately behind this fringe forest, and slightly higher in elevation, is a rarely inundated, black (Avicennia germinans L.) and white (Laguncularia racemosa L. Gaertn.) mangrove-dominated basin forest. The basin forest runs parallel to Florida Bay along the Buttonwood Ridge and is roughly 0.5 to $1 \mathrm{~km}$ in width (Figure 4.1). Since Taylor River cuts through this feature, the channel is well delineated by high, steep sloping banks on either side.

\section{Materials and Methods}

Two, side by side, $14 \mathrm{~m}$ flumes were constructed parallel to the direction of flow in lower Taylor River for the purpose of enclosing the submerged mangrove vegetation on either side of the channel (Figure 4.2). This design utilized the steep sloping banks on either side of the channel as the lateral walls of the flumes along with fabricated medial walls (Figure 4.2). Medial walls were constructed of clear, 6 mil plastic film attached to aluminum fence posts via shower curtain rings. The use of flexible plastic walls allowed for a quick setup and takedown with minimal disturbance during each sampling. Fence 


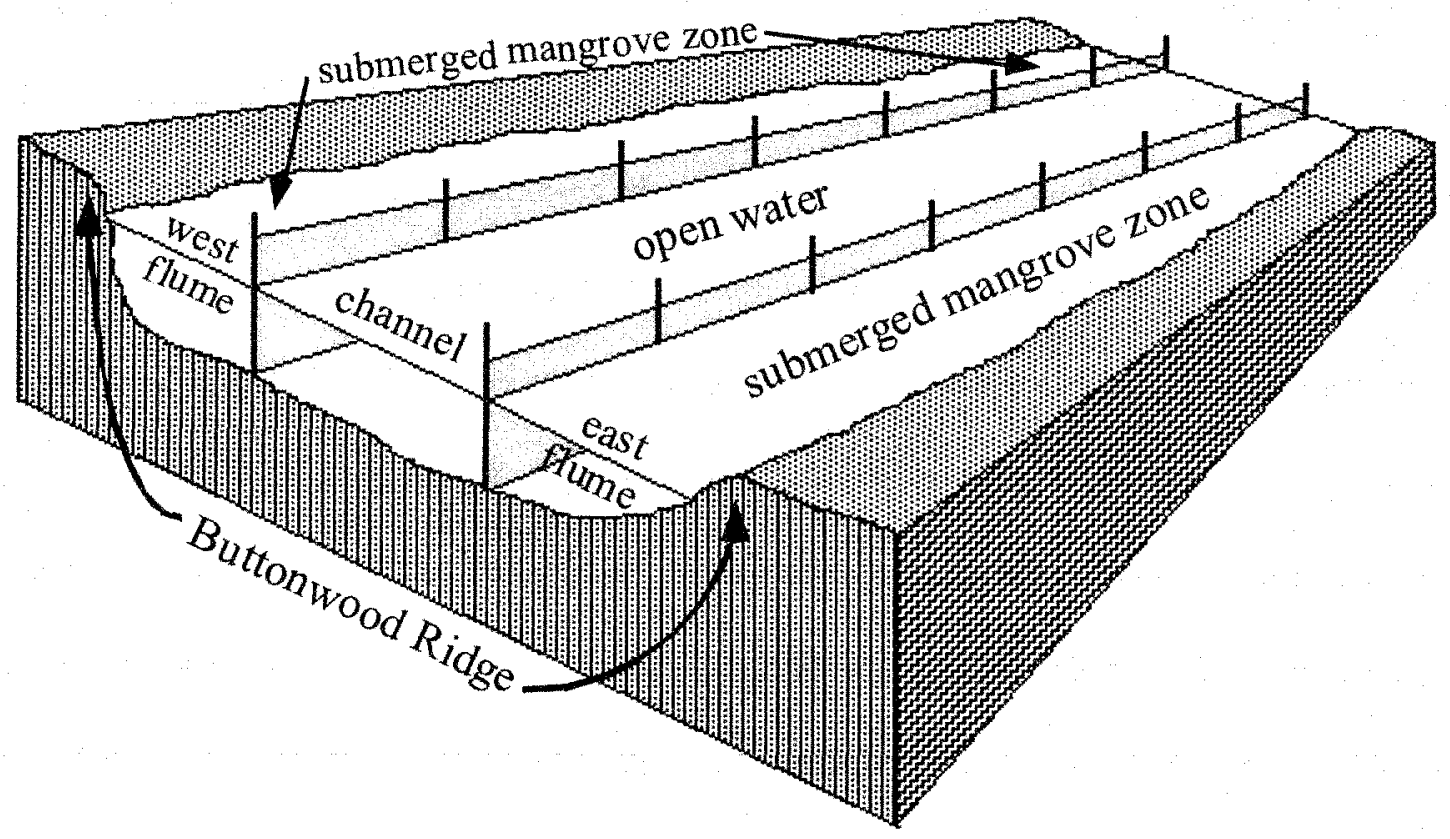

Figure 4.2- Illustration of side by side, in-creek flume design that utilizes the steep sloping banks on either side of the creek as lateral "walls" and flexible plastic as medial walls in order to isolate submerged mangrove vegetation. 
posts were spaced $2 \mathrm{~m}$ apart along the length of each wall. Since the bottom of Taylor River is mostly bare limestone, the posts were set into blocks of concrete to keep them in an upright position. An underwater lattice of cross poles also helped maintain the flume integrity during periods of high flow. The two flume (medial) walls were constructed parallel to one another separated by a distance of $2.9 \mathrm{~m}$. These walls prevented any lateral exchange of water with the unvegetated portion of the creek (Figure 4.2). The width of the vegetated areas and the distance between creek banks were not uniform resulting in varying widths along the length of each flume. In order to account for this variability, I conducted detailed surveys of depth and width profiles along each flume. An estimation of bottom surface area was then calculated from these surveys. These estimates also included the area of the creek bank submerged, as nutrient exchange may have occurred at the sediment-water interface during a given sampling. A water level meter was also established at one end of the flumes to monitor any change in water level over the course of a sampling. Survey data combined with water level were used to make estimates of wetland area inundated as well as flume volume.

Field and laboratory methods

I sampled both flumes quarterly for two years to investigate long-term variability in fluxes associated with season (Table 4.1). I also repeated samplings on consecutive days to account for any small-scale temporal variability (Table 4.1). Six pairs of upstream/downstream water samples were collected at regular intervals (usually $1 \mathrm{hr}$ ) from each flume on each sampling day as long as flow was measurable $\left(\geq 0.01 \mathrm{~m} \mathrm{sec}^{-1}\right)$ in a single direction. If flow stopped, I waited until flow resumed, and if flow switched 
Table 4.1 - List of seasons, dates, times, and hydrologic data for each sampling of the Taylor River flumes.

sampling sampling direction salinity water level temperature season date time of flow range $(\%)$ change $(\mathrm{cm})$ range $\left({ }^{\circ} \mathrm{C}\right)$

\begin{tabular}{ccccccc}
\hline late wet & Nov. 19, 1996 & $11: 00-18: 00$ & north & $8-10.5$ & 1.5 & $27-29$ \\
& Nov. 20, 1996 & $8: 00-16: 00$ & north & $8-10.0$ & 1.5 & $25.5-28$ \\
early dry Jan. 17, 1997 & $10: 00-15: 00$ & south & $1-1.5$ & 1.5 & $21-22$ \\
& Jan. 18, 1997 & $11: 00-16: 00$ & south & $1-1.5$ & 0 & $16.5-19$ \\
late dry & May 17, 1997 & $13: 00-16: 30$ & north & $27.5-29$ & 0.5 & $29-30$ \\
& May 18, 1997 & $11: 30-14: 30$ & south & 28 & 0.5 & $28-30$ \\
early wet & Aug. 6, 1997 & $12: 30-17: 30$ & north & 2 & 1 & $32-33.5$ \\
& Aug. 7, 1997 & $13: 00-18: 00$ & south & 2 & 1 & $31-32$ \\
late wet & Nov. 15, 1997 & $11: 00-16: 30$ & south & $11.5-13$ & 2 & $26-27.5$ \\
& Nov. 16, 1997 & $10: 30-15: 30$ & south & $7-8.5$ & 2 & $26-27$ \\
early dry Jan. 17, 1998 & $12: 00-17: 30$ & south & 0 & 2 & $16.5-18$ \\
& Jan. 18, 1998 & $11: 00-18: 00$ & south & 0 & 0.5 & $17-19.5$ \\
late dry & May 23, 1998 & $11: 00-15: 30$ & north & $15-17$ & 3 & $26-26.5$ \\
& May 24, 1998 & $11: 00-15: 30$ & north & $16.5-18$ & 2 & $25-27$ \\
early wet & Aug. 7, 1998 & $11: 30-15: 00$ & south & $5-8.5$ & 1 & $30-31.5$ \\
& Aug. 8, 1998 & $12: 00-15: 00$ & south & 4 & 1 & $29-31$ \\
\hline
\end{tabular}


directions in mid sampling, I collected a new set of six sample pairs for the new flow direction. Using a protocol similar to that of Childers and Day (1988) and RiveraMonory et al. (1995), water was collected from single, fixed points at the ends of each flume with a hand-pump and side-arm flask apparatus. Prior to each use, this apparatus was triple-rinsed with water from the station being sampled. Since cross-sectional homogeneity has been shown for this channel, single sampling points were sufficient to determine nutrient flux. Simultaneous current velocity readings were taken at each upstream and downstream sampling station with a Marsh-McBirney flow meter. Water level was recorded for every sampling interval. Salinity and temperature measurements were also taken during every sampling interval with an analog S-C-T meter (YSI Model 33). Water samples were temporarily stored in 1 liter, acid-rinsed, collapsible cubitainers and portions of each were immediately filtered (Whatman GF/F) at the conclusion of each sampling. Filtered samples were stored frozen and unfiltered samples were kept at $4^{\circ} \mathrm{C}$ until analyzed for nutrient content.

All nutrient analyses were performed at the Southeast Environmental Research Center (SERC) laboratory at Florida International University. Unfiltered water samples were analyzed for total phosphorus (TP) using a modified dry ashing, acid-hydrolysis technique (Solorzano and Sharp, 1980), total nitrogen (TN) using an Antec 7000N total nitrogen analyzer, and total organic carbon (TOC) using a hot platinum catalyst, direct injection analyzer (Shimadzu model TOC-5000). Filtered water samples were analyzed for soluble reactive phosphorus (SRP), ammonium $\left(\mathrm{NH}_{4}{ }^{+}\right)$, and nitrate + nitrite $(\mathrm{N}+\mathrm{N})$ on a four-channel auto-analyzer (Alpkem model RFA 300) and dissolved organic carbon (DOC) using the same method listed above for TOC. 


\section{Flux calculation and calibration}

I used a combination of equations from Childers and Day (1988) and RiveraMonroy et al. (1995) to calculate constituent fluxes (Table 4.2). Since Taylor River is non-tidal and water level change is minimal over short time intervals (Table 4.1), I used a velocity-area approach to calculate instantaneous water flux rather than a hypsometric method based on water level or flume volume change. This approach required a detailed understanding of the variability in cross-sectional discharge at either end of the flumes. Therefore, eight calibration samplings were conducted over the course of this study during three days of different flow characteristics. The purpose of these samplings was to generate relationships that could be used to predict cross-sectional discharge at the downstream end of each flume from a single current velocity measurement (Figure 4.3).

At the beginning of the study, current velocity measurements were taken at an array of equidistant points across the imaginary cross-section of the south end of the flumes over a 5 to 10 minute time period. Since the east flume was slightly wider, it had more calibration points than the west flume (Figure 4.3). These velocity measurements (in units of $\mathrm{m} \mathrm{sec}^{-1}$ ) were then used to calculate instantaneous water flux $\left(\mathrm{m}^{3} \mathrm{sec}^{-1}\right)$ according to a method similar to one presented in Kjerfve et al. (1981). Instantaneous water flux values (a.k.a. cross sectional discharges) from each calibration sampling were then regressed with the current velocity readings from a single fixed sampling station (Figure 4.3). These equations were then used to calculate instantaneous water fluxes (Y) from a single measure of water velocity (Figure 4.3). Since I assumed that the flux of water into the flumes equaled the flux of water out of the flumes, all instantaneous water 
Table 4.2- List of fluxes, units, and equations along with references used in this study.

\begin{tabular}{|c|c|c|c|}
\hline flux & units & equation & source \\
\hline instantaneous & $\mu \mathrm{M} \mathrm{sec}-1$ & $=\left[[\mathrm{X}]_{t} \times\left(\text { instantaneous } \mathrm{H}_{2} \mathrm{O} \text { flux }\right)_{t}\right]$ & Childers and Day 1988 \\
\hline total & $\mu \mathrm{M}$ & $=\sum_{t=1}^{n}\left[\frac{(\text { instantaneous flux })_{t}+(\text { instantaneous flux })_{t+1}}{2} \times\right.$ time $]$ & Childers and Day 1988 \\
\hline net areal & $\mu \mathrm{M} \mathrm{m}^{-2} \mathrm{hr}^{-1}$ & $=\frac{(\text { total flux })_{\text {upstream }} \cdot(\text { total flux })_{\text {downstream }}}{\text { flume area } \times \text { total time }}$ & $\begin{array}{l}\text { Childers and Day 1988; } \\
\text { Rivera-Monroy et al. } 1995\end{array}$ \\
\hline
\end{tabular}



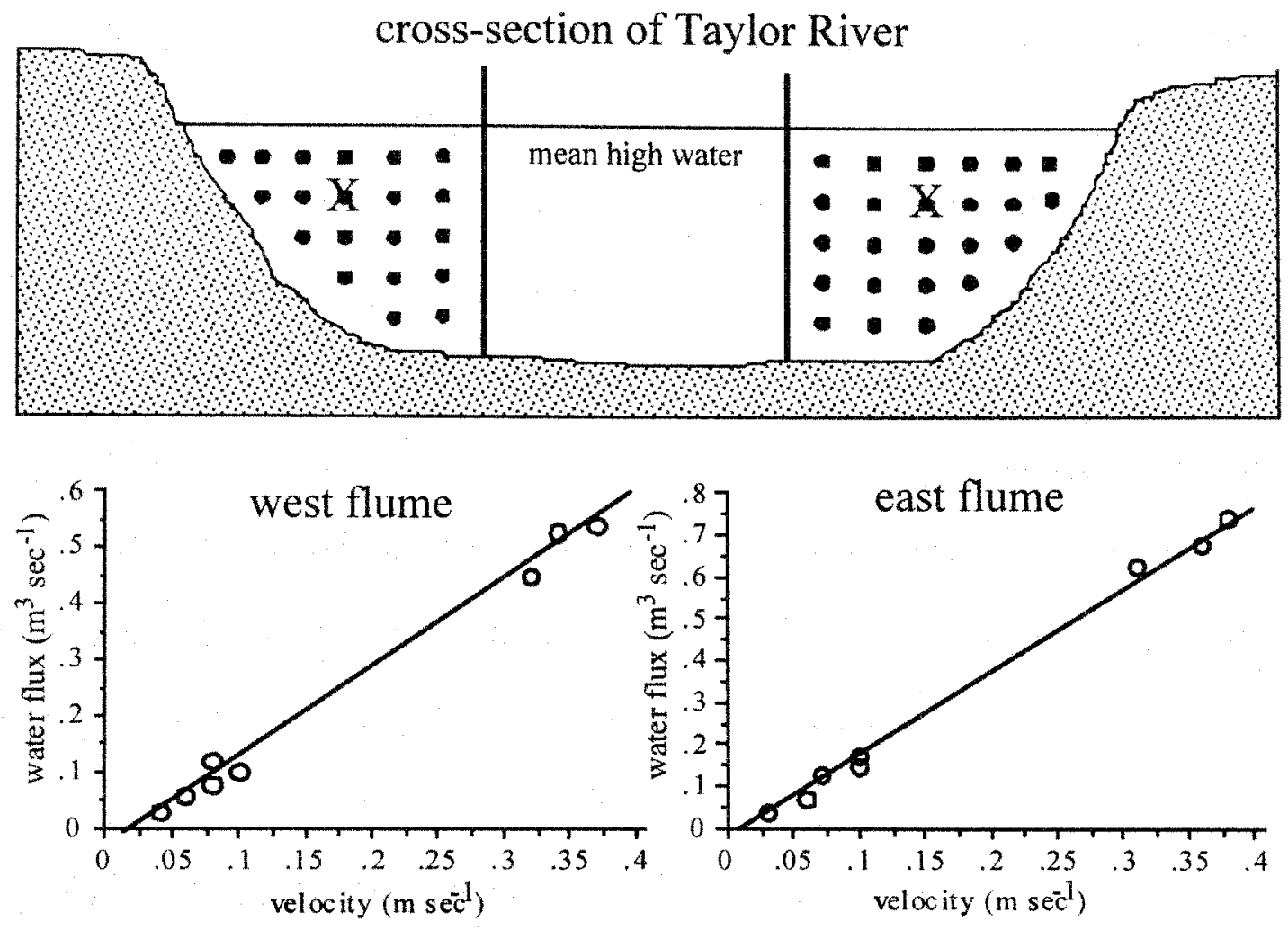

$\mathrm{Y}=-.037+1.604 * \mathrm{X} ; \mathrm{R}^{\wedge} 2=.993$

$$
\mathrm{Y}=-.032+2.002 * \mathrm{X} ; \mathrm{R}^{\wedge} 2=.997
$$

Figure 4.3- Illustration of Taylor River cross-section with flume sampling (X) and calibration points ( ). An array of current velocity measurements was taken along the downstream cross sections of both flumes at various times during the study. Each set of measurements was then used to calculate an instantaneous water flux. Regression analysis was used to model the relationship between current velocity at the fixed sampling point with the calculated water flux across each flume cross-section for all calibration samplings. The regression equation and r-squared for each flume are given. 
flux estimates were made from the current velocity readings taken at one end of the flumes, regardless of the direction of flow.

Instantaneous and total fluxes of nutrients were then calculated according to the equations used in Childers and Day (1988; Table 4.2). However, instantaneous flux in this study was calculated as the product of the constituent concentration (time $=t$ ) and instantaneous water flux (time $=t$ ) using a velocity-area estimate of water flux (Table 4.2). I calculated net areal flux according to the modified Childers and Day (1988) equation used in Rivera-Monroy et al. (1995) with "flume area" as the total benthic area of the flume, including bank area (Table 4.2). Net areal fluxes were either positive (indicating an uptake by the mangrove wetland), negative (indicating an export by the wetland), or zero (indicating no net flux) for a given sampling.

\section{Statistical methods and data analysis}

To determine if fluxes for a given flume were significant on a given day, I used a paired t-test (Statview 5) to test for a significant difference $(p<0.05)$ between pooled upstream and downstream concentrations $(\mu \mathrm{M})$ of a given constituent. Significant fluxes were then calculated for each flume and sampling day to show small scale spatial and temporal variability for a given constituent. However, to show overall patterns in the net movement of materials, I calculated average net areal fluxes for each constituent for each sampling. I did this by averaging all fluxes for each sampling ( 2 flumes $\mathrm{x} 2$ days) into a single value. All non-significant fluxes were treated as "no net flux" and were assigned a value of zero $\left(\mu \mathrm{mol} \mathrm{m} \mathrm{mr}^{-1}\right.$ ). These values were then extrapolated over 365 days, and 
converted to units of mass (mg) to get an estimated annual flux for each constituent for each year of this study.

Concentrations of nutrients at the upstream ends of the flumes were pooled by sampling or day and used in a number of analyses. These data were considered as "pretreatment", and could be used to determine the influence of seasonal factors. All statistical procedures were performed using StatView 5 for the Macintosh (SAS Institute, Inc., Cary, NC). First, box and whisker plots were generated for each constituent/sampling combination to show distributions of upstream nutrient concentrations. These plots show the $10^{\text {th }}, 25^{\text {th }}, 50^{\text {th }}, 75^{\text {th }}$, and $90^{\text {th }}$ percentiles, the $95 \%$ confidence range about the median, and the skewness of the distribution. I used a singlefactor analysis of variance to test for significant differences in concentrations among samplings. Single-factor analyses of variance were also used to determine the influence of season (wet vs. dry) and direction of flow or water source (north vs. south) on constituent concentrations. For all ANOVA tests, Fisher's Pairwise Least Significant Differences (PLSD) post-hoc tests were used to determine significant differences between treatment levels. In order to determine possible relationships between salinity and nutrient concentrations, I regressed mean salinity for each sampling with mean upstream nutrient concentration.

Flux data for each constituent were subjected to the same tests to determine the influences of these factors. However, I also regressed constituent fluxes with nutrient concentration and flume volume to determine any relationships between nutrient exchange and the availability (i.e. concentration) of nutrients or differences in the wetland:water ratio. Studies have shown that both of these factors can have significant 
impacts on the flux of nutrients in estuarine systems (Nixon 1980; Wolaver et al. 1983;

Whiting et al. 1989; Childers and Day 1990).

\section{Results}

Hydrologic data and nutrient concentrations

I expected to see a clear pattern of high salinity in the dry season and low salinity in the wet season. The combination of wind shifts associated with frontal passages and an extended wet season (January 1998) resulted in atypical salinity distributions for several samplings (Table 4.1). Salinity was always highest in May (late dry season) and lowest in January (early dry season; Table 4.1). The direction of flow was also altered by these factors, as sustained winds or rapid pulses of freshwater often reversed the direction of flow in Taylor River (personal observation). I anticipated southerly flow during the wet season samplings and northerly flow during the dry season samplings. For the most part, seasonal signals were fairly clear, especially in the case of temperature. Water temperatures were always highest in August and lowest in January (Table 4.1). Water level fluctuation within a sampling was minimal and did not appear to show any influence of season (Table 4.1).

Concentrations of most constituents were quite variable over the course of the study. Nitrate + nitrite concentrations ranged from a high of $5.75 \mu \mathrm{M}$ in November 96 to a low of $0.2 \mu \mathrm{M}$ in August 98 (Figure 4.4). Unlike ammonium, concentrations of nitrate+nitrite within a given sampling showed little variability. Nonetheless, ammonium displayed a similar overall range of concentration (0.1-6.3 $\mu \mathrm{M}$; Figure 4.4). Total nitrogen content ranged from $39 \mu \mathrm{M}$ in November 96 to $79 \mu \mathrm{M}$ in August 97 (Figure 4.4). 

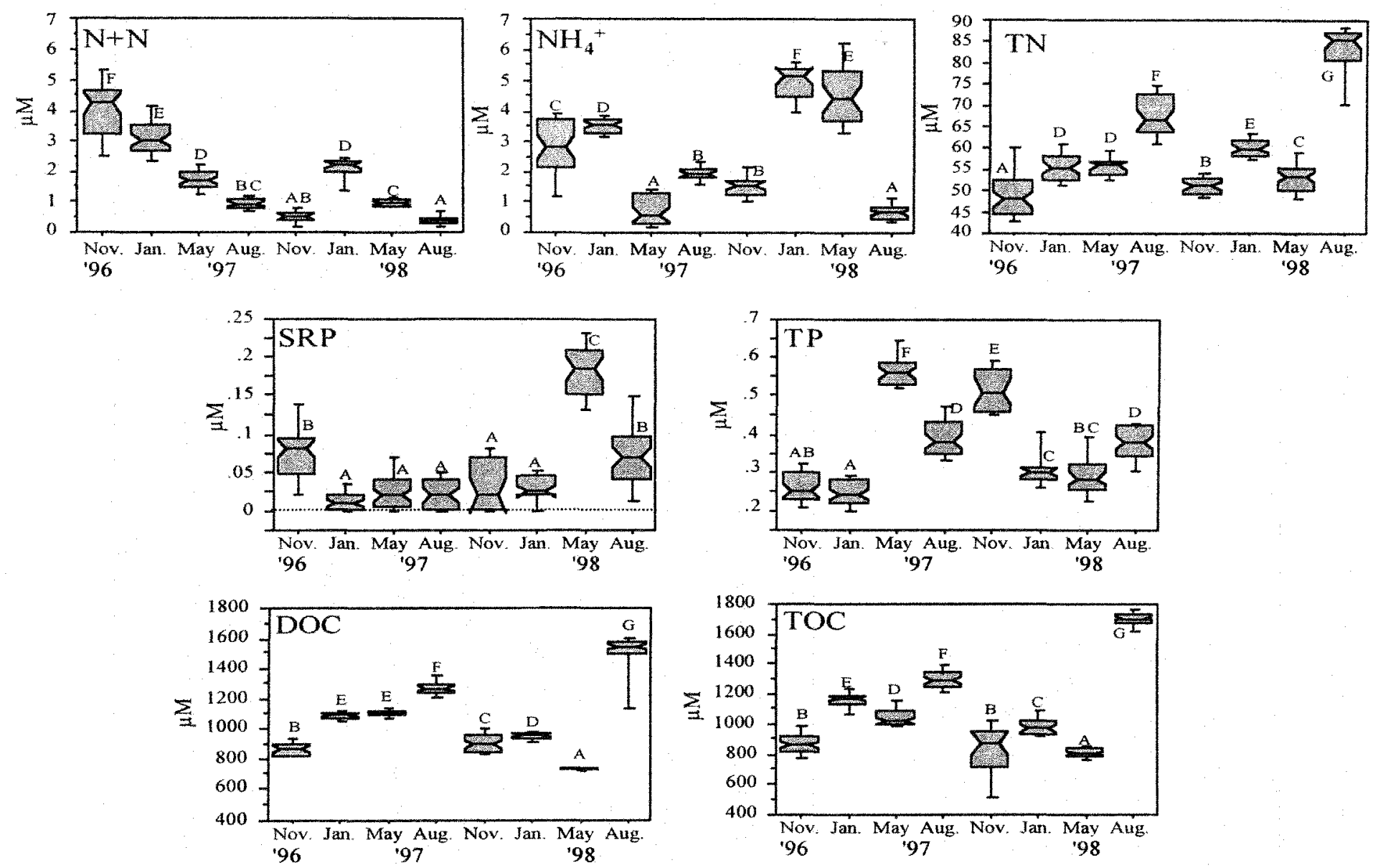

Figure 4.4- Box and whisker plots of nutrient concentration in the fringe zone of Taylor River during each flume sampling. Bottom and top whiskers demarcate the $10^{\text {th }}$ and $90^{\text {th }}$ percentiles, and the bottom the top lines of each box indicate the $25^{\text {th }}$ and $75^{\text {th }}$ percentiles, respectively. The middle line is the median and the notches represent the $95 \%$ confidence interval about the median. Different letters represent significant differences (ANOVA, $\mathrm{p}<0.05$ ) between samplings. 
Soluble reactive phosphorus concentrations were typically less than $0.1 \mu \mathrm{M}$ and, in many instances, were at or below the limits of detection $(0.01 \mu \mathrm{M}$; Figure 4.4$)$. However, concentrations of SRP were abnormally high during the May 98 sampling $(0.13-0.24 \mu \mathrm{M})$ making up roughly $45-50 \%$ of TP at that time (Figure 4.4). Typically SRP was 5-25\% of the total phosphorus in Taylor River that varied from $0.18-0.67 \mu \mathrm{M}$. Concentrations of dissolved and total organic carbon were similar in all samplings (Figure 4.4). In fact, roughly $95 \%$ of the TOC in Taylor River was in the dissolved form, reflecting the low suspended particulate load common to this creek. Concentrations of TOC and DOC ranged from lows of $800-850 \mu \mathrm{M}$ in May 98 to $1600-1700 \mu \mathrm{M}$ just three months later in August 98 (Figure 4.4).

Regression analysis revealed no direct relationship between salinity and nutrient concentrations in lower Taylor River. However, when testing for the effect of season on nutrient concentrations, analysis of variance yielded two significant constituents, $\mathrm{NH}_{4}{ }^{+}$ and TP (Table 4.3). Post-hoc results indicated that concentrations of $\mathrm{NH}_{4}{ }^{+}$were significantly higher during the dry season, whereas mean TP was higher during the wet season (Table 4.3). Direction of flow had a much greater influence on concentrations in Taylor River (Table 4.3). Fisher's PLSD showed that concentrations of nitrate+nitrite and SRP were significantly higher when flow was to the north while TN, TP, TOC, and DOC were all higher when flow was to the south (Table 4.3). These latter four constituents are all organically-dominated parameters and seem to reflect the influence of mangrove or freshwater marsh-derived organic matter. 
Table 4.3- ANOVA results showing the effects of season and direction of flow on nutrient concentrations in lower Taylor River.

\begin{tabular}{llcl} 
constituent & factor & p-value & post-hoc resutls \\
\hline $\mathrm{NH}_{4}{ }^{+}$ & season & $<0.0001$ & dry $>$ wet \\
$\mathrm{TP}$ & season & 0.01 & wet $>$ dry \\
$\mathrm{N}+\mathrm{N}$ & flow & $<0.0001$ & north $>$ south \\
$\mathrm{SRP}$ & flow & $<0.0001$ & north $>$ south \\
$\mathrm{TN}$ & flow & $<0.0001$ & south $>$ north \\
$\mathrm{TP}$ & flow & 0.03 & south $>$ north \\
$\mathrm{DOC}$ & flow & $<0.0001$ & south $>$ north \\
TOC & flow & $<0.0001$ & south $>$ north \\
\hline
\end{tabular}




\section{$\underline{\text { Flux results }}$}

Fewer than $1 / 3$ of a possible 224 fluxes ( 7 constituents $\times 8$ samplings $\times 2$ consecutive days $\times 2$ flumes) were significantly different from zero (Figure 4.5). Of these 66 significant fluxes, 35 were associated of nitrogen, 14 were of phosphorus, and 17 were of organic carbon (Figure 4.5). Broken down by season, 43 significant fluxes were measured during dry season samplings, while only 23 were measured during the wet season samplings (Figure 4.5). The majority of the significant fluxes measured were for dissolved inorganic nitrogen. Although there appeared to be little consistency in flux from one day or sampling to the next, there was considerable agreement between flumes when significant fluxes were observed for the same constituent on the same day. Of the 20 instances in which I observed significant fluxes of a constituent in both flumes on the same day, 16 were of the same magnitude and direction. Eleven of these cases were associated with either $\mathrm{NO}_{3}{ }^{-}+\mathrm{NO}_{2}^{-}$or $\mathrm{NH}_{4}^{+}$.

Consistently large uptakes of $\mathrm{NO}_{3}{ }^{-}+\mathrm{NO}_{2}{ }^{-}\left(1.55\right.$ to $5.61 \mu$ moles $\mathrm{NO}_{3}{ }^{-}+\mathrm{NO}_{2}{ }^{-} \mathrm{m}^{-2}$ $\mathrm{hr}^{-1}$ ) occurred during both November 96 and January 97 (Figure 4.6). A large uptake of $\mathrm{TN}\left(50 \mu\right.$ moles $\left.\mathrm{TN} \mathrm{m}^{-2} \mathrm{hr}^{-1}\right)$ coincided with $\mathrm{NO}_{3}{ }^{-}+\mathrm{NO}_{2}{ }^{-}$uptake during November 1996 (Figure 4.6). As the dry season of 1997 progressed into the early wet season, however, much smaller quantities of $\mathrm{NO}_{3}^{-}+\mathrm{NO}_{2}^{-}\left(-0.12\right.$ to $-1.13 \mu$ moles $\left.\mathrm{NO}_{3}^{-}+\mathrm{NO}_{2}^{-} \mathrm{m}^{-2} \mathrm{hr}^{-1}\right)$ were exported from the fringe mangrove wetland (Figure 4.7). This was followed by another net uptake in November 97 and more export in May 98 (Figure 4.6; Table 4.4). While $\mathrm{N}+\mathrm{N}$ was imported both days in January $97, \mathrm{NH}_{4}{ }^{+}$flux shifted from an uptake (0.94$1.27 \mu$ moles $\left.\mathrm{NH}_{4}{ }^{+} \mathrm{m}^{-2} \mathrm{hr}^{-1}\right)$ on the first day, to an export $\left(-0.48\right.$ to $-0.81 \mu$ moles $\mathrm{NH}_{4}^{+} \mathrm{m}^{-2}$ $\mathrm{hr}^{-1}$ ) on the second day. Export of $\mathrm{NH}_{4}{ }^{+}$occurred again in August 97 followed by net 


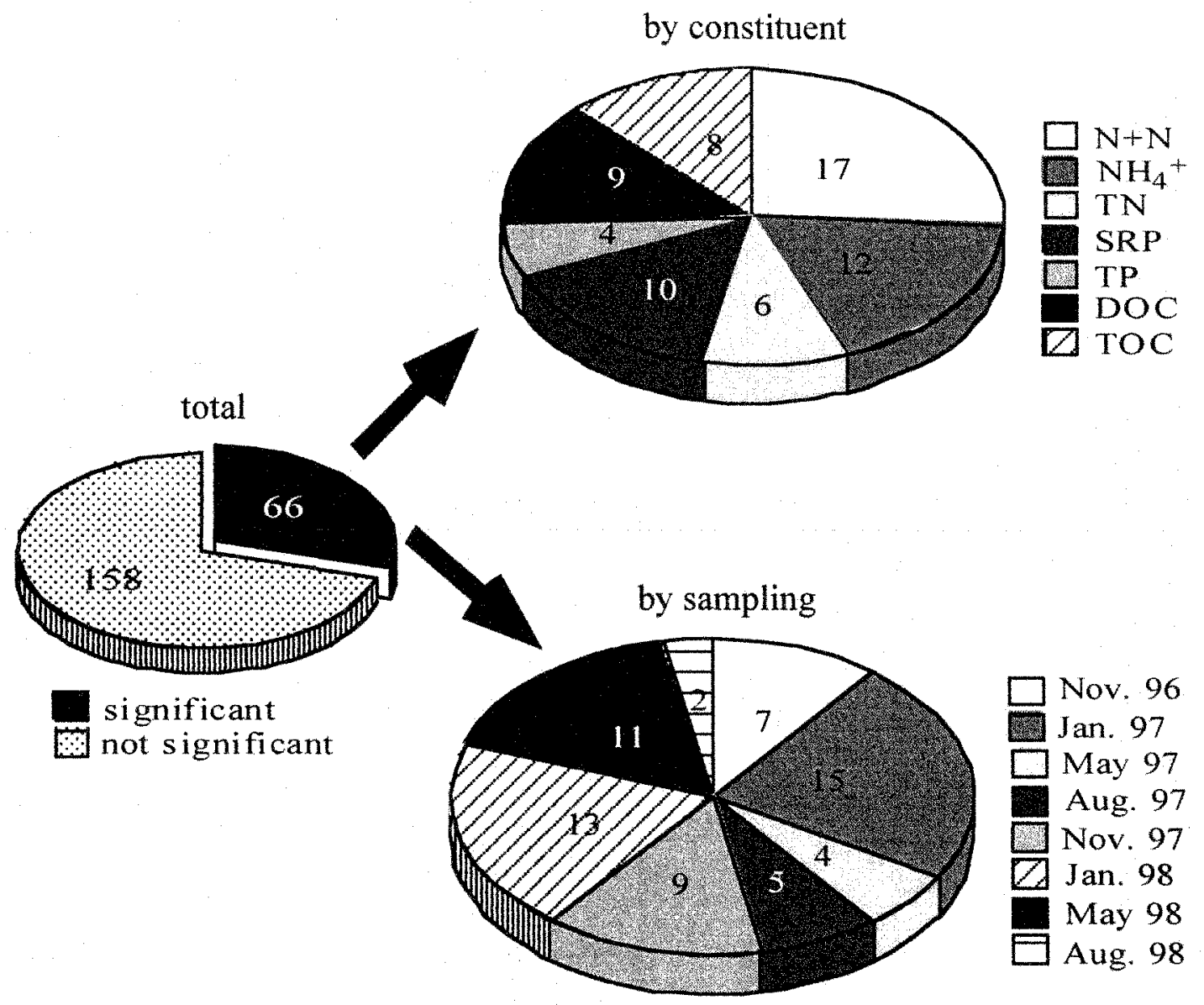

Figure 4.5- Pie charts showing breakdown of significant fluxes measured in lower Taylor River by constituent and sampling. 

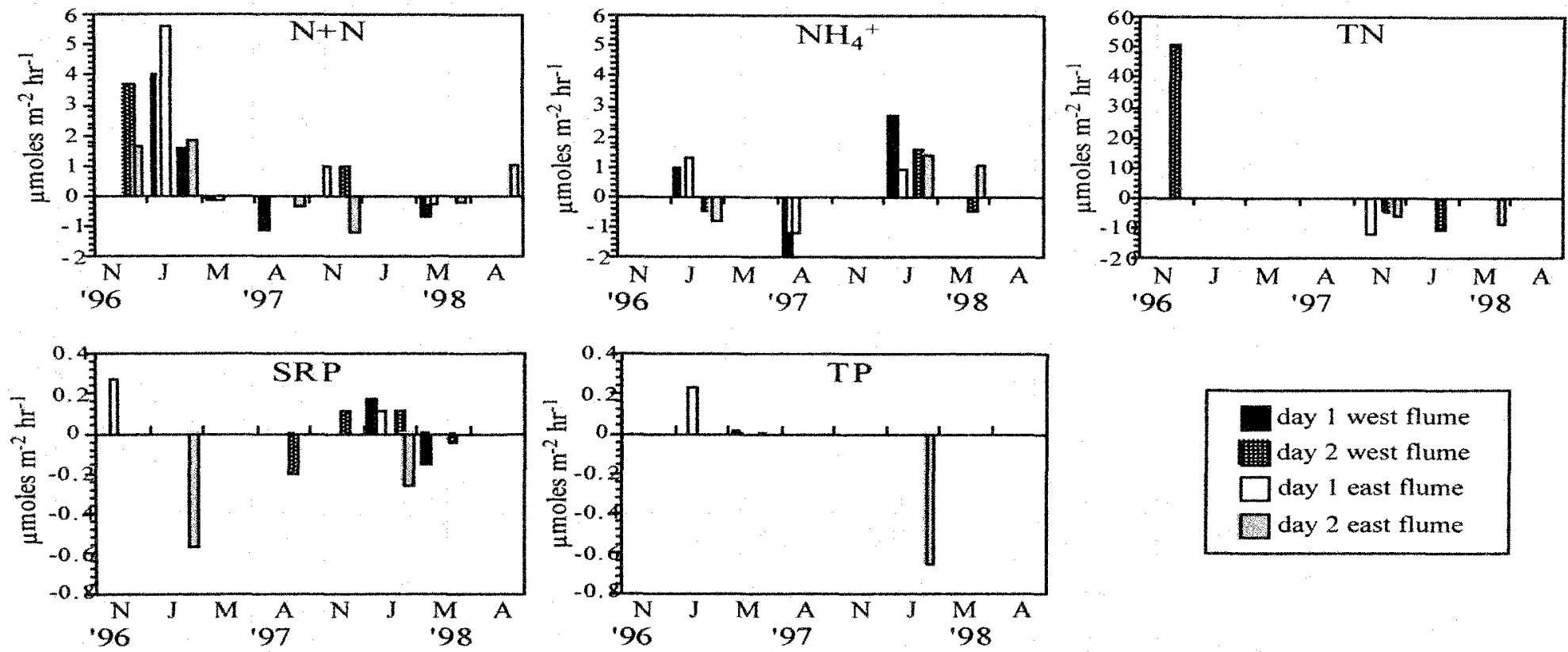

day 1 west flume day 2 west flume $\square$ day 1 east flume $\square$ day 2 east flume


Figure 4.6- Bar graphs showing significant fluxes of N, P, and C measured in the Taylor River fringe mangrove flumes. Values above the zero line represent uptake by the wetland, and values below the zero line represent export from the wetland. 
Table 4.4- Averaged net areal fluxes of nutrients per sampling $\left(\mu \mathrm{M} \mathrm{m}^{-2} \mathrm{hr}^{-1}\right)$ and estimated annual fluxes for Years 1 and $2\left(\mathrm{mg} \mathrm{m}^{-2} \mathrm{yr}^{-1}\right)$.

\begin{tabular}{cccccccc} 
Sampling & $\mathrm{N}+\mathrm{N}$ & $\mathrm{NH}_{4}{ }^{+}$ & $\mathrm{TN}$ & $\mathrm{SRP}$ & $\mathrm{TP}$ & DOC & TOC \\
\hline Nov-96 & 1.32 & 0.00 & 12.59 & 0.07 & 0.00 & 183.19 & 0.00 \\
Jan-97 & 3.25 & 0.69 & 0.00 & -0.14 & 0.06 & 38.20 & 12.69 \\
May-97 & -0.07 & 0.00 & 0.00 & 0.00 & 0.00 & 0.00 & 0.00 \\
Aug-97 & -0.36 & -0.76 & 0.00 & -0.05 & 0.00 & 0.00 & 0.00 \\
\hline Year 1 flux estimate & 127 & -2.1 & 386 & -8.4 & 4.2 & 5818.1 & 333.5
\end{tabular}

\begin{tabular}{cccccccc} 
Sampling & $\mathrm{N}+\mathrm{N}$ & $\mathrm{NH}_{4}{ }^{+}$ & $\mathrm{TN}$ & $\mathrm{SRP}$ & $\mathrm{TP}$ & $\mathrm{DOC}$ & $\mathrm{TOC}$ \\
\hline Nov-97 & 0.19 & 0.00 & -5.49 & 0.03 & 0.00 & 58.29 & 0.00 \\
Jan-98 & 0.00 & 2.11 & -2.61 & 0.03 & 0.17 & -113.69 & 146.21 \\
May-98 & -0.30 & -0.34 & -2.17 & -0.05 & 0.00 & 270.68 & -6.18 \\
Aug-98 & 0.25 & 0.00 & 0.00 & 0.00 & 0.00 & 0.00 & 0.35 \\
\hline Year 2 flux estimate & 4.3 & 54.3 & -314.9 & 0.7 & 11.9 & 5657.6 & 3689.2 \\
& & & & & & & \\
$\begin{array}{c}\text { average annual flux } \\
\text { estimate }\end{array}$ & 65.6 & 26.1 & 35.6 & -3.9 & 8.1 & 5737.9 & 2011.4
\end{tabular}


uptake in January and May 98 (Figure 4.6). Overall, total nitrogen exhibited little significant flux. However, there was a clear pattern of TN export from this mangrove in November $97\left(-4.41\right.$ to $-11.91 \mu$ moles $\left.\mathrm{TN} \mathrm{m}^{-2} \mathrm{hr}^{-1}\right)$ with evidence of this export continuing into the dry season of 1998 (Figure 4.6).

Phosphorus exhibited the fewest instances of significant flux, the majority of which were attributed to SRP (Figures 4.5 and 4.6). I observed net imports of SRP by the mangrove wetland in both November samplings as well as January 98 (0.11 to 0.27 4moles SRP $\left.\mathrm{m}^{-2} \mathrm{hr}^{-1}\right)$ and net exports in January 97, August 97, and May 98 (-0.04 to $-0.57 \mu$ moles SRP $\mathrm{m}^{-2} \mathrm{hr}^{-1}$; Figure 4.6; Table 4.4). Total phosphorus was taken up by the fringe mangrove wetland in January 97 and exported in January 98 (0.23 and -0.66 $\mu$ moles $\mathrm{TP} \mathrm{m}^{-2} \mathrm{hr}^{-1}$, respectively; Figure 4.6). A considerably smaller, but significant, uptake and export of TP occurred during the May 97 sampling $(0.01$ and $-0.01 \mu$ moles TP $\mathrm{m}^{-2} \mathrm{hr}^{-1}$; Figure 4.6).

The fluxes of DOC and TOC showed no pattern over the two years of this study. Still, there were four instances of agreement between both flumes for these two constituents, suggesting a consistent flux pattern in the fringe wetland. Although the bulk of TOC was in the dissolved form, these constituents had somewhat different flux patterns. Dissolved organic carbon was imported by the mangrove during November 96 , January 97, and May 98 (62.26 to $726.38 \mu$ moles $\left.\mathrm{m}^{-2} \mathrm{hr}^{-1}\right)$ and exported in November 97 and January 98 (-385.65 to $-454.74 \mu$ moles $\mathrm{m}^{-2} \mathrm{hr}^{-1}$; Figure 4.6). Total organic carbon was exported in both flumes on the first sampling day of May 97 (-234.09 to -434.17 $\mu$ moles $\mathrm{m}^{-2} \mathrm{hr}^{-1}$ ) and taken up in both on the next day (135.24 to $434.17 \mu$ moles $\mathrm{m}^{-2} \mathrm{hr}^{-1}$; 
Figure 4.6). There was also a small, but significant, uptake of TOC in August 98 (1.39 $\mu$ moles $\mathrm{m}^{-2} \mathrm{hr}^{-1}$; Figure 4.6).

Nutrient flux was not significantly affected by season, salinity, direction of flow, flume volume, or temperature. However, for both DIN constituents there was a significant relationship between upstream concentration (i.e. nutrient availability) and flux (Figure 4.7). In both instances, as the concentrations of $\mathrm{NO}_{3}{ }^{-}+\mathrm{NO}_{2}{ }^{-}$and $\mathrm{NH}_{4}{ }^{+}$ increased, uptake increased as well (Figure 4.7). Furthermore, the predicted concentrations at which export shifted to import were nearly the same for both flumes. For $\mathrm{NO}_{3}{ }^{-}+\mathrm{NO}_{2}{ }^{-}$in the west flume the predicted shift occurred around $1.25 \mu \mathrm{M}$, whereas the east flume shift occurred at around $0.75 \mu \mathrm{M}$ (Figure 4.7). Similarly, the shift for $\mathrm{NH}_{4}{ }^{+}$ occurred at 3.6 and $3.3 \mu \mathrm{M}$ in the west and east flumes, respectively (Figure 4.7). No such relationships existed for any other constituent. Perhaps this was due to the low number of significant fluxes observed for all other constituents.

When averaged for each sampling and extrapolated over each year, the flux results indicated an uptake of nearly every constituent by the mangrove over the course of this study (Table 4.4). Only $\mathrm{NH}_{4}{ }^{+}$and SRP were exported during Year 1 (Table 4.4). During Year 1 there was a large import of $\mathrm{NO}_{3}^{-}+\mathrm{NO}_{2}^{-}\left(127 \mathrm{mg} \mathrm{NO}_{3}^{-}+\mathrm{NO}_{2}^{-} \mathrm{m}^{-2} \mathrm{yr}^{-1}\right)$ that was reflected in the large uptake of $\mathrm{TN}\left(386 \mathrm{mg} \mathrm{NO}_{3}{ }^{-}+\mathrm{NO}_{2}^{-} \mathrm{m}^{-2} \mathrm{yr}^{-1}\right.$; Table 4.4). During Year 2 there was a noticeable shift. Ammonium was imported $\left(54.3 \mathrm{mg} \mathrm{NH}_{4}^{+} \mathrm{m}^{-2} \mathrm{yr}^{-1}\right)$ as was $\mathrm{N}+\mathrm{N}\left(4.3 \mathrm{mg} \mathrm{N}+\mathrm{N} \mathrm{m}^{-2} \mathrm{yr}^{-1}\right)$, but to a much lesser extent, and $\mathrm{TN}$ was exported (-314.9mg TN m $\left.\mathrm{m}^{-2} \mathrm{yr}^{-1}\right)$. Both forms of organic carbon as well as TP were also imported in relatively large amounts over both years (Table 4.4). 

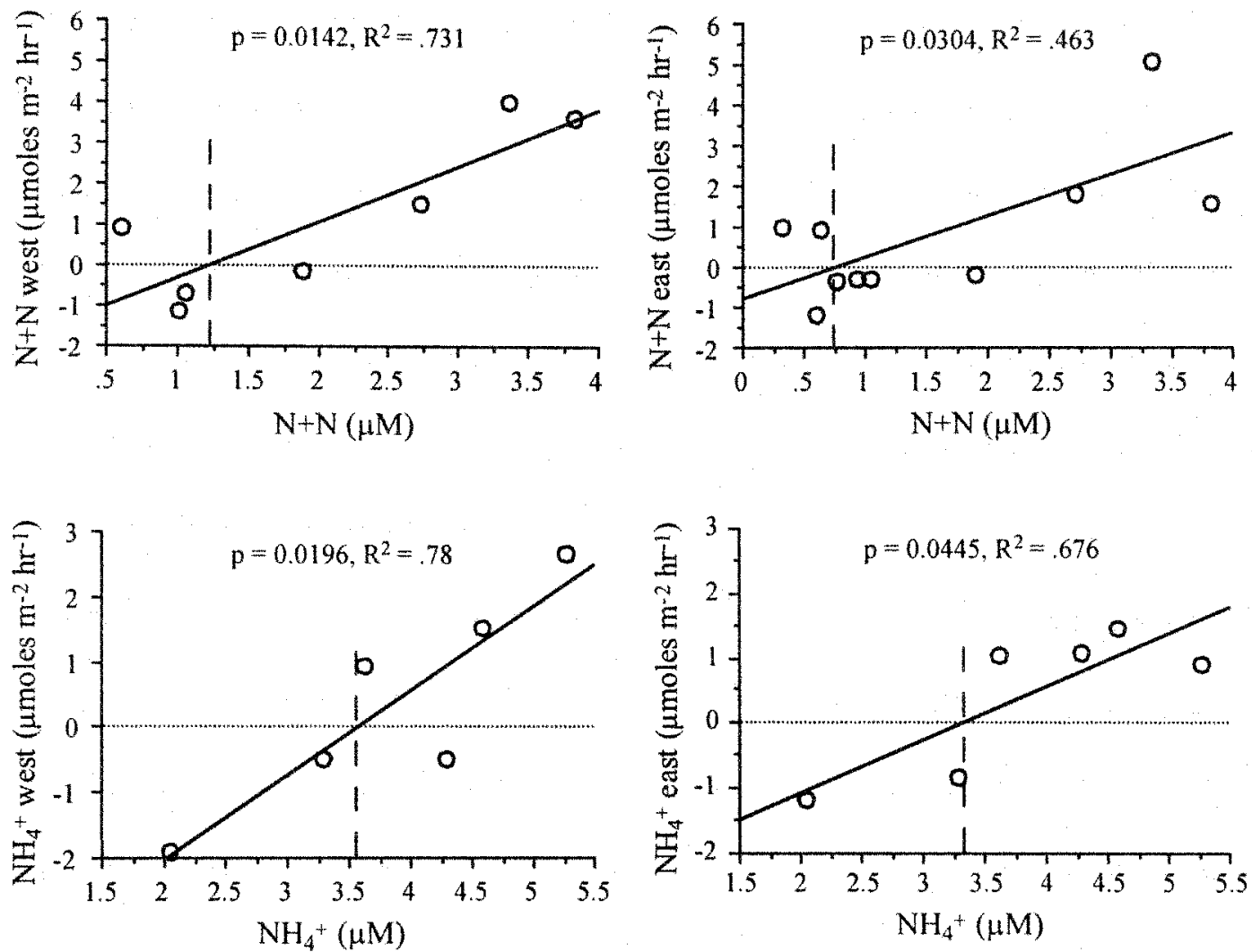

Figure 4.7- Regression plots showing the relationship between $\mathrm{N}+\mathrm{N}$ and $\mathrm{NH}_{4}{ }^{+}$ concentrations and $\mathrm{N}+\mathrm{N}$ and $\mathrm{NH}_{4}{ }^{+}$flux in each flume. Vertical dashed line represents the predicted concentration at which flux switches from export to uptake, or vice versa. 


\section{Discussion}

Presently, there are few studies of nutrient (nitrogen and phosphorus) flux in mangrove systems. Of these, Boto and Wellington (1988) and Rivera-Monroy et al. (1995) are among the few to conduct direct, in situ measurements of nutrient flux. Many such studies have been conducted in temperate salt marsh systems (see Nixon 1980; Childers et al. 1999 for reviews). A substantial number of these have used the flume technique to quantify wetland-water column exchanges (Childers 1994). And a few have demonstrated the importance of season and degree of tidal influence on the fluxes of materials (Wolaver et al. 1983; Childers 1994).

In Taylor River, season is a surrogate for tidal influence. Seasonal winds and precipitation are the major forcing functions that move water masses, and probably drive salinity and nutrient patterns, throughout the southern Everglades mangrove zone. I found direct evidence of this in the concentration dynamics of a number of constituents. Ammonium was higher, on average, during the dry season (Table 4.3). Since water typically flows north during the dry season, this suggests the bay is the source of ammonium to the mangrove zone. Nitrate+nitrite displayed a similar pattern, however, the high concentrations in November 96 resulted in a non-significant difference between wet and dry season (Figure 4.4). Notably, the direction of flow during this wet season sampling was to the north, as strong southerly winds overcame the freshwater head and forced bay water into the mangrove zone (Table 4.1). Therefore, it appears that Florida Bay was the source of $\mathrm{NO}_{3}^{-}+\mathrm{NO}_{2}^{-}$to this system as well. This idea is also supported by the fact that $\mathrm{NO}_{3}{ }^{-}+\mathrm{NO}_{2}{ }^{-}$was significantly higher when flow was to the north (Table 4.3). Soluble reactive phosphorus concentrations showed no effect of season, yet 
concentrations of SRP were strongly tied to the direction of flow (Table 4.3). Florida Bay, again, seemed to be the source of SRP to the mangroves, however, this appears to have been influenced by the elevated SRP values measured in May 98 (Figure 4.4).

A number of other parameters were significantly affected by the direction of flow. Among them, the organic constituents (OC, N, and P), as well as DOC, all appeared to be derived from upstream freshwater Everglades and dwarf mangrove sources, as concentrations were significantly higher when flow was to the south (Table 4.3). I also found that total phosphorus concentrations were significantly higher during the wet season. Although the other constituents did not show the same effect of season, TN, TOC and DOC concentrations were always highest at the onset of the wet season, suggesting a flushing effect (Figure 4.4). These high concentrations of organicassociated parameters may reflect an export of organic matter from the freshwater marshes and dwarf mangrove wetlands of the southern Everglades early in the wet season.

Unlike nutrient concentrations, fluxes were much more variable within and between samplings. For every sampling, there was at least one constituent that showed no significant flux, and in several instances three or four. However, the significant fluxes measured in Taylor River were similar in magnitude to those measured in a fringe mangrove in Laguna de Terminos, Mexico (Rivera-Monroy et al. 1995). The Terminos Lagoon flux study is analogous to the Taylor River study because 1) both used flowthrough flumes to determine wetland-water column exchanges, and 2) both were conducted in a red mangrove-dominated, creek-side fringe mangrove wetlands. The fundamental differences between them are that Taylor River is a non-tidal, carbonate- 
dominated system, whereas the Mexican mangrove is a tidal, silicious system (RiveraMonroy et al. 1995).

Like Rivera-Monroy et al. (1995), I measured net uptakes of $\mathrm{NO}_{3}{ }^{-}+\mathrm{NO}_{2}{ }^{-}$and $\mathrm{NH}_{4}{ }^{+}$over the course of this study (65.6 and $26.1 \mathrm{mg} \mathrm{m}^{-2} \mathrm{yr}^{-1}$, respectively). There was also a net uptake of TN that was nearly balanced by a large uptake in Year $1\left(386 \mathrm{mg} \mathrm{m}^{-2}\right.$ $\left.\mathrm{yr}^{-1}\right)$ and a similarly large export in Year 2 (-314.9 $\mathrm{mg} \mathrm{m}^{-2} \mathrm{yr}^{-1}$; Table 4.4). RiveraMonroy et al. (1995) observed an export of TN similar to my Year 2 flux estimate (PN + DON flux $\left.=-550 \mathrm{mg} \mathrm{m}^{-2} \mathrm{yr}^{-1}\right)$. In Coral Creek, Australia, Boto and Wellington (1988) measured a much greater net uptake of DON, on the order of $1300 \mathrm{mg} \mathrm{m}^{-2} \mathrm{yr}^{-1}$.

Averaged over both years, all other constituents, except SRP, were imported by the fringe mangrove of Taylor River as well. A large export of SRP in Year 1 overshadowed a smaller import in Year 2 (Table 4.4). This is interesting, considering that this region is highly limited by phosphorus availability (Fourqurean et al. 1992; Amador and Jones 1995). Overall, phosphorus dynamics have been neglected in the handful of mangrove nutrient flux studies that have been conducted. Of those that have considered it, SRP uptake has typically been shown (Nixon et al. 1984; Boto and Wellington 1988). In Coral Creek, uptake of total dissolved phosphorus (500 $\mathrm{mg} \mathrm{m}^{-2} \mathrm{yr}^{-1}$ ) doubled the export of particulate organic phosphorus $\left(-250 \mathrm{mg} \mathrm{m}^{-2} \mathrm{yr}^{-1}\right.$; Boto and Bunt 1981; Boto and Wellington 1988). The reverse of this was seen in Taylor River, as the uptake of TP $\left(8.1 \mathrm{mg} \mathrm{m}^{-2} \mathrm{yr}^{-1}\right)$ was twice the export of SRP $\left(-3.9 \mathrm{mg} \mathrm{m}^{-2} \mathrm{yr}^{-1}\right)$.

Uptake of both organic carbon parameters occurred in the fringe mangrove wetland of lower Taylor River. A review by Lee (1995), however, shows that many mangrove systems are sources of detritus or organic carbon to near-shore environments. 
Among the works reviewed by Lee (1995) is an investigation of organic carbon exchange between a basin mangrove and Rookery Bay. In this study, Twilley (1985) found large, seasonally and tidally-influenced exports of TOC $\left(64 \mathrm{~g} \mathrm{~m}^{-2} \mathrm{yr}^{-1}\right)$ and DOC (75\% of TOC export) from the mangrove wetland. Few other mangrove studies have looked at TOC. Dissolved organic carbon fluxes reported for Coral Creek (7300 $\left.\mathrm{mg} \mathrm{m}^{-2} \mathrm{yr}^{-1}\right)$ were similar those measured in Taylor River (5738 $\mathrm{mg} \mathrm{m}^{-2} \mathrm{yr}^{-1}$; Boto and Wellington 1988). This was surprising considering the disparity in tidal influence between these two carbonate systems. The difference may be attributed to the large upland source of organic matter in the south Florida system compared to the Australian system, which receives considerably lower terrestrial upland inputs.

While my findings are comparable to other studies in the mangrove literature, it would be careless to make any generalizations about the nutrient dynamics in the fringe mangrove wetlands of Taylor River at this point in time. Available flux data and annual flux estimates show only potential ranges of flux magnitude. However, these data do provide a means of comparison to other systems. The variability in fluxes I observed from one sampling to the next combined with the lack of significant fluxes have made it difficult to discern the influence of season on these exchanges. Likewise, the fluctuations in concentration over time made it difficult to discern the effect of the wetland isolated by the flumes from the influence of forces upstream of the flumes.

There were several instances in which I observed a clear increase or decrease of a constituent's concentration over the course of a sampling day (Figure 4.8). These patterns reflected concentration across the channel of Taylor River at the upstream ends of the flumes at each sampling interval. Interestingly, a number of these trends 

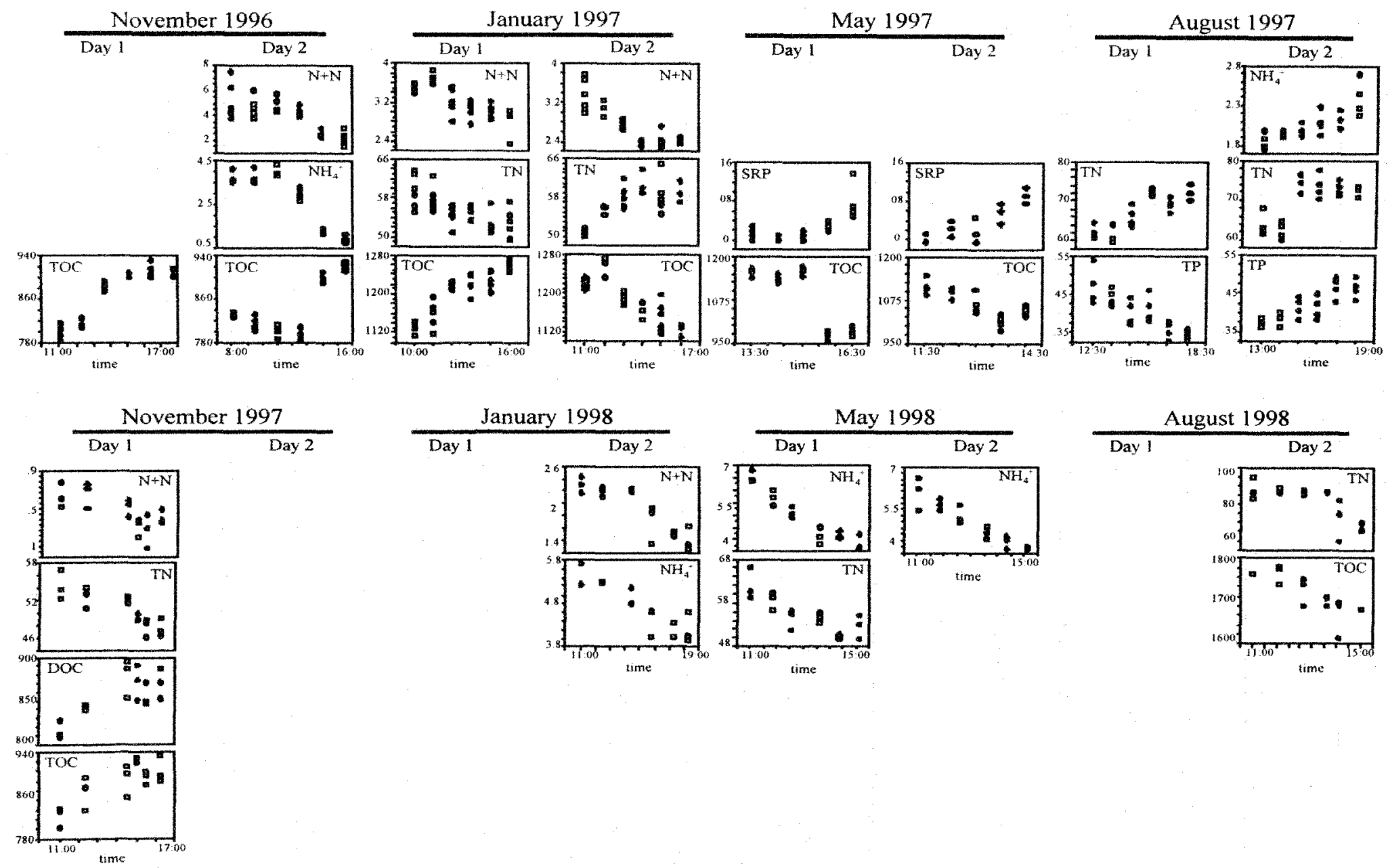

Figure 4.8- Time series plots of Taylor River nutrient concentrations from the upstream end of the flumes and channel from each sampling. Plots shown are for those constituents displaying a clear increasing or decreasing pattern of concentration over the course of a given sampling. All concentrations are in $\mu \mathrm{M}$. 
corresponded to measured fluxes. For example, the decrease in $\mathrm{NO}_{3}{ }^{-}+\mathrm{NO}_{2}{ }^{-}$at the upstream ends of both flumes during the January 97 sampling coincided with large uptakes of $\mathrm{NO}_{3}{ }^{-}+\mathrm{NO}_{2}{ }^{-}$measured within the flumes (Figures 4.6 and 4.8). These significant changes in $\mathrm{NO}_{3}{ }^{-}+\mathrm{NO}_{2}{ }^{-}$concentration over time may have transcended any signal given by the wetland. This brings up the question: Were the measured uptakes a function of the wetland effect, the decrease in the concentration of $\mathrm{NO}_{3}^{-}+\mathrm{NO}_{2}^{-}$delivered to the flumes, or both? It is difficult to say for certain at this time, however these are interesting, possibly diel, patterns that need to be investigated further.

I would argue that these fluxes are real and the concentration patterns are just background features that increase the difficulty of measuring a significant flux, hence the low number of significant fluxes measured in Taylor River. Of the 29 instances in which I observed an increasing or decreasing trend in nutrients, only ten corresponded to significant fluxes of nutrients (Figures 4.6 and 4.8). The coincidence of decreased concentration and nutrient uptake may also stem from the same phenomenon. In other words, as nutrients are taken up by the fringe wetland upstream, concentrations are lowered resulting in a decreasing trend and a flux that suggests uptake. Of the ten cases mentioned above, eight corresponded positively (uptake/decrease or export/increase; Figures 4.6 and 4.8). Only two instances of ammonium flux, which happened to occur in both flumes on the same day showed negative correspondence with concentration patterns (Day 2, May 98; Figure 4.8).

I found a clear relationship between the concentrations and fluxes of $\mathrm{N}+\mathrm{N}$ and $\mathrm{NH}_{4}{ }^{+}$on a seasonal time scale. Perhaps these small-scale (hourly) fluctuations result in the same relationship with fluxes on a small-scale. Further investigation of this 
phenomenon may provide valuable insight into the fluxes of nutrients and the factors that affect them. It might also provide an answer to the question: are the concentration patterns a result of wetland interactions or are they a result of shifting masses of water to which the wetlands are responding?

\section{Conclusion}

The wetlands of the southern Everglades are currently experiencing a change in the delivery of freshwater. These changes are expected to be more noticeable during the wet season, however the hydrologic patterns of the dry season may be affected as well. Mangrove wetlands comprise a large percent of the southern Everglades and little is presently known about the exchange of materials (i.e. nutrients and organic matter) in these systems. Moreover, the effect of increased freshwater flow on the cycling of materials in southern Everglades mangroves is not well understood. The goals of this study were to: 1) quantify fluxes of carbon, nitrogen, and phosphorus in the creek-side fringe mangrove wetlands of Taylor River over a two year period, and 2) relate concentrations and fluxes of nutrients to various hydrologic factors that may be affected by increased freshwater delivery (e.g. salinity, direction of flow, etc.).

I found that season (time of year) and direction of flow were both important factors in determining nutrient concentrations in lower Taylor River. These results suggest that Florida Bay is the source of dissolved inorganic nutrients, while the mangroves and freshwater Everglades are the major sources of total and dissolved organic carbon, total nitrogen and total phosphorus to the fringe mangrove wetlands of Taylor River. Although there were no relationships with seasonal factors, nutrient 
concentrations seem to be an important determiner of nutrient flux, especially in the case of $\mathrm{NO}_{3}{ }^{-}+\mathrm{NO}_{2}{ }^{-}$and $\mathrm{NH}_{4}{ }^{+}$. Evidence of increasing or decreasing concentrations over time complicates any conclusions of nutrient dynamics in this system. They do, however, bring up some interesting questions as to the factors behind these phenomena and how they are related to wetland-water column interactions in Taylor River. 


\title{
Chapter 5:
}

\section{Biotic and abiotic controls on mass loss and nutrient release from dwarf red mangrove leaf litter during the early phase of decomposition.}

\begin{abstract}
I conducted an experiment to determine the respective contributions of abiotic and biotic processes and the influence of salinity on the early decomposition of dwarf red mangrove leaves. I hypothesized that abioitc processes (i.e. leaching) would be responsible for more loss of mass and nutrients during the first three weeks of decomposition and that leaf mass and nutrient losses would be greatest in freshwater compared to 16 and $32 \%$ water. Yellow, nearly senesced leaves were collected from an oligotrophic, dwarf mangrove of the southern Everglades and incubated in clear glass bottles, with or without sodium azide (biocide). Substantial losses of dry mass associated with leaching occurred within the first 24 hours, with the greatest initial losses occurring in freshwater. The contribution of biotic processes to mass loss was trivial at first, but increased steadily over the three-week study period, especially in freshwater. Carbon and phosphorus losses from leaves were mainly attributed to leaching, showing no influence of biotic processes. Nitrogen, on the other hand, exhibited no net exchange from the leaves to the water as a result of leaching, but showed a significant increase in the water when biotic processes were present. Leaf $\mathrm{N}$ concentrations showed no net change from day 0 to day 21. Mean molar ratios of C:N in the water increased to a high of 158 and $\mathrm{N}: \mathrm{P}$ ratios decreased to a low of 75 by the end of the experiment. Carbon made up a minor percent of initial leaf losses, yet by the end of the study, nearly $30 \%$ of mass loss
\end{abstract}


was due to carbon. Nitrogen and phosphorus, combined, accounted for approximately $0.8 \%$ of leaf mass loss after 21 days of decomposition. Results of this experiment suggest that leaching and early leaf decomposition are important sources of carbon and phosphorus to the water column in this mangrove system. Phosphorus is of special interest considering the oligotrophic nature of this mangrove.

\section{Introduction}

Litterfall from deciduous and evergreen trees is the primary mechanism by which nutrients are returned to the forest floor. Accounting for approximately $70 \%$ of the dry mass of all aboveground litter in forested ecosystems, leaves are usually the most important litter component (O'Neill and DeAngelis 1981). Leaf litter represents a relatively large, labile pool of organic matter to soil decomposer communities. Although resorption, prior to leaf abcission, can be an effective means of conserving vital elements in many tree species, there is still a substantial outflow of organic and inorganic nutrients from trees via leaf litterfall (Tukey 1970; Fisher and Likens 1973; Aber and Melillo 1980; Aerts 1996; Killingbeck 1996). The release and availability of these nutrients are controlled by abiotic and biotic processes that are, in turn, regulated by the nature of the substrate and decomposer community as well as a number of environmental conditions (Tukey 1970; McClaugherty et al. 1985; Berg and Ekbohm 1990; Galliardo and Merino 1993; Vitousek et al. 1994).

The initial phase of leaf decomposition, as with all other litter types, is characterized by a rapid leaching of both soluble organic (sugars, organic acids, proteins, phenolic compounds, etc.) and inorganic ( $\mathrm{K}, \mathrm{Ca}, \mathrm{Mg}, \mathrm{Mn}$, etc.) matter. This is an abiotic 
process that has been defined as the removal of substances from plants or plant parts by the action of water (Tukey 1970). The initial leaching phase of leaves typically lasts no more than a few days, yet it is responsible for substantial losses of mass and of carbon, nitrogen, and phosphorus (Parsons et al. 1990; Chale 1993; Steinke et al. 1993; Taylor and Barlocher 1996; France et al. 1997). Furthermore, the rate of leaf litter leaching has also been shown to be sensitive to environmental factors such as temperature, sunlight, water availability, and salinity (Nykvist 1959; Nykvist 1961; Tukey 1970; Parsons et al. 1990; Chale 1993; Steinke et al. 1993). The bioitc contributions in this early stage of decomposition are usually minimal and are most often limited to microbial conditioning of the litter (Nykvist 1959; Cundell et al. 1979; France et al. 1997). However, it has been suggested that there is a possible interaction between the biotic and abiotic processes that result in the large, initial losses of leaf mass during this phase (Taylor 1997).

I conducted an experiment to determine the relative contributions of these abiotic and biotic processes in the early decomposition of dwarf red mangrove leaves immersed in water. I hypothesized that abiotic processes (i.e. leaching) would be responsible for more loss of mass and nutrients (carbon, nitrogen, and phosphorus) than biotic processes (i.e. microbial degradation) during the first three weeks of decomposition. However, I expected the contribution of the biotic processes to grow over the course of the experiment as microbial colonization increased and leaching slowed. I also determined the influence of the water's salinity in which the leaves were immersed on the loss of mass and nutrients. A similar study showed that both mass and nutrient losses were greater in Avicennia leaves immersed in water with a salinity of $16 \%$ versus $32 \%$ o (Steinke et al. 1993). Taking into consideration the findings of Steinke et al. (1993), I 
expected that these losses would be greatest in freshwater $(0 \%)$, moderate in water of mesohaline salinity $(16 \%)$, and lowest in water of polyhaline salinity $(32 \%)$.

\section{Site Description}

This experiment was conducted on leaves collected from an estuarine dwarf mangrove wetland in Taylor Slough, Everglades National Park. In most estuarine mangrove wetlands, the nutrients associated with leaf litter can either be recycled in situ or exported to adjacent systems depending upon the tidal range or the presence of litter consumers and processors (Robertson 1986; Twilley et al. 1986; Slim et al. 1997). When exported, mangrove-derived organic matter can fuel secondary production in adjacent offshore habitats (Odum and Heald 1972). However, the dwarf mangroves of the southern Everglades and Taylor Slough have neither influences of tide nor large macroinvertebrates, such as crabs or snails, which actively process leaf litter. In addition, rates of herbivory have been shown to be comparatively low in this type of mangrove wetland (Feller 1995). This suggests that in situ recycling of litter within the mangrove wetland is quite efficient, providing an important source of carbon, nitrogen, and phosphorus to this oligotrophic system.

The dwarf mangrove wetlands of the southern Everglades are dominated by a single species, Rhizophora mangle L. (red mangrove), and are characterized by persistent standing water. Therefore, when leaves fall from the trees, they almost inevitably hit the water and immediately sink to the bottom. Rhizophora leaves are rarely seen floating on the surface of the water (personal observation). The salinity of the water in this wetland varies seasonally, as the source of water shifts from the freshwater Everglades, during the 
wet season, to Florida Bay, during the dry season. Low salinity predominates during the wet season and high salinity characterizes much of the dry season. Refer to Chapter 3 for a more detailed description of the seasonal hydrology of this dwarf mangrove wetland. This experiment was conducted during May 1998 (late dry season).

\section{Materials and Methods}

I collected fresh, nearly-senesced, yellow leaves from dwarf red mangrove trees along Taylor River, Everglades National Park for use in this experiment (see Chapter 2 for full description of dwarf mangrove site). The experimental leaves were not dried, as drying has been shown to significantly affect rates of leaching and decomposition in many species (Taylor and Barlocher 1997; Taylor 1998). Individual fresh leaves were incubated in $250 \mathrm{ml}$, clear, square, glass bottles containing $242 \mathrm{ml}$ of water for up to 21 days (Figure 5.1). Incubations were conducted in the field under ambient temperature and sunlight conditions. Following incubation, leaves were removed from the bottles and rinsed with deionized water to remove any surficial bacterial layer and dried to a constant weight at $70^{\circ} \mathrm{C}$ (final dry mass $=\mathrm{DM}_{t}$ ).

Since I chose to use fresh material, an accurate means of estimating initial dry weight was needed in order to determine mass loss. To accomplish this, 75 nonexperimental, nearly-senesced leaves were collected from the same site, at the same time, and measured for maximum blade width $\left(\mathrm{W}_{\max }\right)$, maximum blade length $\left(\mathrm{L}_{\max }\right)$, and fresh mass (FM; Figure 5.1). Next, the leaves were dried at $70^{\circ} \mathrm{C}$ for 72 hours then re-weighed to get an initial dry mass $\left(\mathrm{DM}_{0}\right)$ for each leaf. Then, using $\mathrm{W}_{\max }, \mathrm{L}_{\max }$, and $\mathrm{FM}$ as independent variables and $\mathrm{DM}_{0}$ as the dependent variable, I generated a multiple 
A.

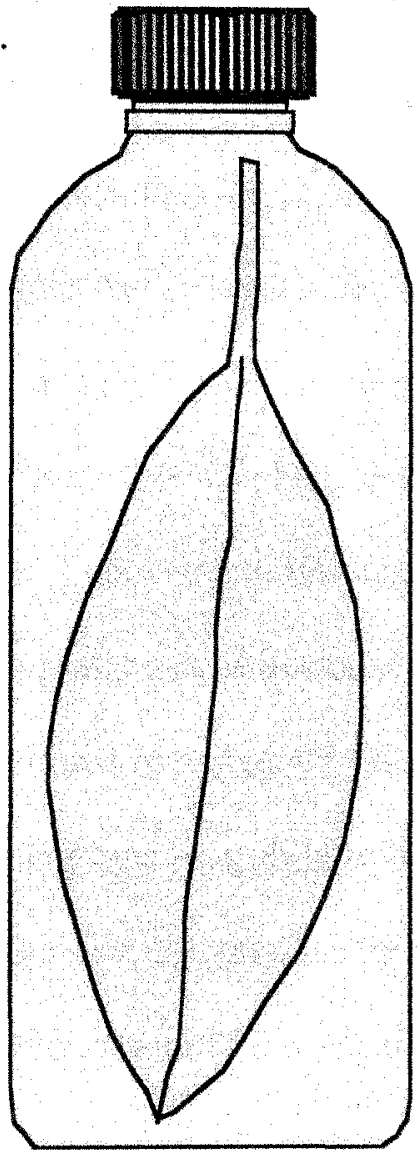

B.

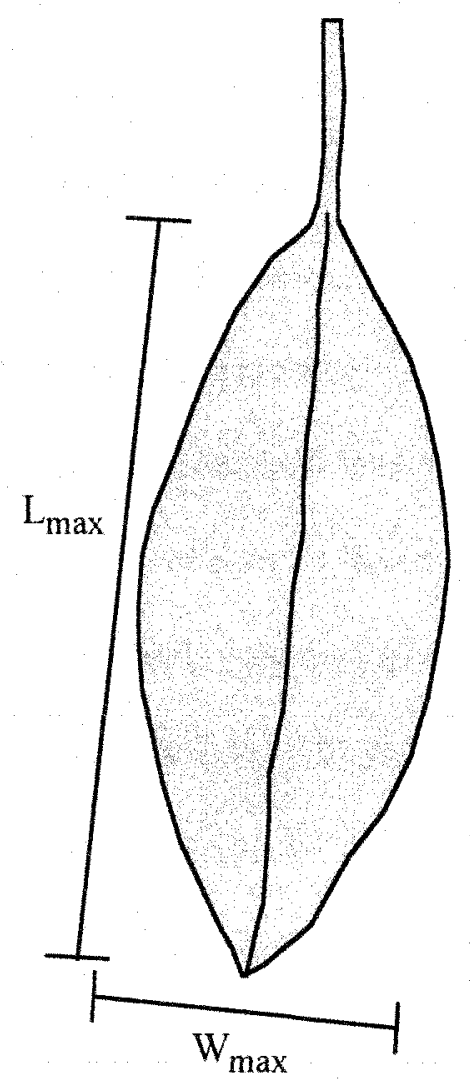

Figure 5.1 - A. Illustration of experimental unit with incubation bottle containing water $(0 \%, 16 \%$, or $32 \%)$ plus or minus $\mathrm{NaN}_{3}$ and mangrove leaf. $\mathrm{B}$. Illustration of leaf measurements (maximum width; $\mathrm{W}_{\max }$ and maximum length; $\mathrm{L}_{\max }$ ) taken on nonexperimental leaves along with fresh mass (FM) in order to estimate initial dry mass $\left(\mathrm{DM}_{0}\right)$. 
regression relationship that could be used to predict $\mathrm{DM}_{0}$ for each experimental leaf. In this case, only $\mathrm{W}_{\max }$ and $\mathrm{FM}$ were significant $(\mathrm{p}<0.05)$ model components, accounting for most of the total variability associated with $\mathrm{DM}_{0}$ (adj. R-squared=0.971; Figure 5.2). At the conclusion of the experiment, I calculated percent dry mass remaining (\%DMR) for each leaf by dividing $\mathrm{DM}_{t}$ by $\mathrm{DM}_{0}$. This regression approach was selected over the typical wet:dry weight ratio technique because it does not assume homogeneity of structural tissue content among leaves nor does it assume that each leaf is in the same stage of senescence. In other words, a leaf in a later stage of senescence may have a higher dry:wet weight ratio than a leaf in an early stage of senescence.

Following initial leaf measurements, 100 fresh experimental leaves were individually stored in sterile plastic bags at $4^{\circ} \mathrm{C}$ for no more than 24 hours. As the experiment commenced, 90 individual leaves were randomly assigned to treatment combinations according to the experimental design (Figure 5.3). The remaining 10 leaves were analyzed for initial concentrations of leaf nutrients. The treatments included water treatment ( 2 levels), water salinity ( 3 levels), and day (5 levels). All treatment combinations were triplicated (Figure 5.3).

In order to quantify the abiotic contributions to mass and nutrient loss, $2 \mathrm{ml}$ of a $1 \% \mathrm{NaN}_{3}$ (sodium azide) solution was added to half of the experimental units as a biocide (Figure 5.3). The remaining half of the bottles received $2 \mathrm{ml}$ of deionized water. Next, the effect of salinity on the early phase of leaf decomposition was determined by incubating leaves in waters of different salinity (Figure 5.3). The fixed levels of this treatment were chosen to represent the annual range of salinity common to this dwarf mangrove wetland. To mimic the wet season effects on leaf decomposition, water from 
Regression Summary:

$\mathrm{DM}_{0}$ vs. 2 Independents

\begin{tabular}{l|r|} 
Count & 75 \\
Num. Missing & 0 \\
\hline R & .986 \\
\hline R Squared & .972 \\
\cline { 2 - 2 } Adjusted R Squared & .971 \\
\hline RMS Residual & .036 \\
\hline
\end{tabular}

ANOVA Table

\begin{tabular}{l|r|r|r|r|r|}
\multicolumn{2}{c}{} & \multicolumn{2}{c}{ DF Sum of Squares Mean Square } & \multicolumn{2}{c|}{ F-Value P-Value } \\
\cline { 2 - 7 } $\begin{array}{l}\text { Regression } \\
\text { Residual }\end{array}$ & 2 & 3.343 & 1.671 & 1259.806 & $<.0001$ \\
\cline { 2 - 6 } & 72 & .096 & .001 & & \\
\hline 74 & 3.438 & & & \\
\hline
\end{tabular}

Regression Coefficients:

\begin{tabular}{l|r|r|r|r|r|} 
& \multicolumn{1}{c}{ Coefficient Std. Error } & \multicolumn{3}{c}{ Std. Coeff. $t$-Value } & P-Value \\
Intercept & -.100 & .021 & -.100 & -4.766 & $<.0001$ \\
\cline { 2 - 6 }$W_{\max }$ & .007 & .001 & .280 & 6.558 & $<.0001$ \\
\cline { 2 - 7 } FM & .243 & .014 & .729 & 17.044 & $<.0001$ \\
\cline { 2 - 6 }
\end{tabular}

Regression Equation:

$\mathrm{DM}_{0}=-0.1+\left(0.007 * \mathrm{~W}_{\text {max }}\right)+(0.243 * \mathrm{FM})$

Figure 5.2- Multiple regression statistics, ANOVA table, and model for the relationship between maximum width $\left(\mathrm{W}_{\max }\right)$, fresh mass $(\mathrm{FM})$, and initial dry mass $\left(\mathrm{DM}_{0}\right)$. 


\begin{tabular}{|c|c|c|c|c|c|c|c|}
\hline & water & $\operatorname{lini}$ & & coll & ction & ays & \\
\hline & treatment & $(\%)$ & 1 & 2 & 5 & 10 & 21 \\
\hline & & 0 & $\mathrm{XXX}$ & XXX & X X X & $\mathrm{X} \mathrm{X} \mathrm{X}$ & $\mathrm{XXX}$ \\
\hline$\stackrel{0}{0}$ & with $\mathrm{NaN}_{3}$ & 16 & X X X & X X X & X X X & $\mathrm{XXX}$ & X X X \\
\hline$\stackrel{0}{2} \stackrel{0}{=}$ & & 32 & X X X & X X X & $\mathrm{XXX}$ & $\overline{X X X}$ & $\mathrm{X} \mathrm{X} \mathrm{X}$ \\
\hline 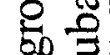 & & 0 & $\overline{X X X}$ & X X X & X X X & $\overline{X X X}$ & $\mathrm{XXX}$ \\
\hline & without $\mathrm{NaN}_{3}$ & 16 & X X X & X X X & X X X & X X X & X X X \\
\hline & & 32 & X X X & X X X & X X X & X X X & X X X \\
\hline & & 0 & & & & & X X X \\
\hline & with $\mathrm{NaN}_{3}$ & 16 & & & & & $\mathrm{XXX}$ \\
\hline & & 32 & & & & & $\mathrm{XXX}$ \\
\hline 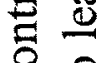 & & 0 & & & & & $\mathrm{XXX}$ \\
\hline g & without $\mathrm{NaN}_{3}$ & 16 & & & & & X X X \\
\hline & & 32 & & & & & X X X \\
\hline
\end{tabular}

Figure 5.3- Experimental design of leaf decomposition study, with 2 water treatment levels $\left( \pm \mathrm{NaN}_{3}\right), 3$ salinity levels $(0,16$, and $32 \%)$, and 5 collection day levels $(1,2,5,10$, and 21 days). All experimental units were triplicated. 
the freshwater Everglades marshes was used in $1 / 3$ of the incubations. Another $1 / 3$ of the bottles contained water of $16 \%$ salinity that was collected from within the mangrove wetland. The remaining bottles, representing the high end of the salinity range in this wetland, contained 32\%o water collected from Florida Bay (Figure 5.3). All water was pre-filtered (Whatman GF/F) to reduce variability between different waters, to remove large particulate matter that may have affected leaching rates, and to reduce variability in densities of waterborne microbes. Finally, collections of experimental units were made after 1,2, 5, 10, and 21 days of incubation (Figure 5.3). This sampling protocol allowed for the observation of rapid losses due to leaching (1-2 days) as well as longer term, biotically-associated losses (1-3 weeks).

During each sampling, leaves were removed from the bottles and water samples were collected. Water samples were stored in $125 \mathrm{ml}$, HDPE bottles at $4^{\circ} \mathrm{C}$ until analyzed for nutrients. All water nutrient analyses were conducted at the Southeast Environmental Research Center's laboratory at Florida International University. Samples were analyzed for total phosphorus (TP) according to a modification of the dry ashing, acid-hydrolysis technique (Solorzano and Sharp, 1980), total nitrogen (TN) using an Antec 7000N total nitrogen analyzer, and total organic carbon (TOC) using a hot platinum catalyst, direct injection analyzer (Shimadzu model TOC-5000). After final dry weight $\left(\mathrm{DM}_{t}\right)$ measurements were taken, all leaves were ground to a fine powder with a mortar and pestle and stored in $7 \mathrm{ml}$, borosilicate scintillation vials. Leaf material was analyzed for carbon and nitrogen content using a Carlo Erba 1500-N CHN analyzer and phosphorus content using the aforementioned method of Solorzano and Sharp (1980). 
To ensure that changes in water nutrients were solely due to the leaves, control bottles containing only water or water $+\mathrm{NaN}_{3}$ were incubated for the entire 21-day length of the experiment (Figure 5.3). Nutrient concentrations from the control bottles were compared with initial concentrations (post-filtration) to determine changes in total $\mathrm{C}, \mathrm{N}$, and $\mathrm{P}$ associated with water column or photochemical processes. Paired t-tests were used to determine significant differences between initial and final concentrations $(p<0.05)$. Since $\mathrm{NaN}_{3}$ was selected as the biocide in this experiment, TN concentrations were more than an order of magnitude higher in the bottles containing $\mathrm{NaN}_{3}$. However, I still anticipated observable water TN concentration changes in bottles containing leaves and $\mathrm{NaN}_{3}$ as a result of leaching.

\section{$\underline{\text { Statistical Methods }}$}

The changes in nutrients and leaf mass were considered to be the result of "abiotic processes" for those experimental units containing $\mathrm{NaN}_{3}$ and "biotic+abiotic processes" for those without $\mathrm{NaN}_{3}$. I used a one factor ANOVA to determine the effect of water treatment on \%DMR. This was followed by two-factor ANOVAs to determine the effect of salinity and collection day on \%DMR within each water treatment level. Finally, I used two-factor ANOVAs to investigate the effect of water treatment and collection day on \%DMR within each salinity level. Accordingly, similar approaches were used to determine the effects of these treatments on $\% \mathrm{C}, \mathrm{N}$, and $\mathrm{P}$ content of the leaves as well as the TOC, TN, and TP content of the water. For all analyses, Fisher's Pairwise Least Significant Differences (PLSD) post-hoc tests were used to determine differences 
between treatment means of significant ANOVAs $(\mathrm{p}<0.05)$. When appropriate, regressions were used to model changes in leaf mass or nutrients over time.

\section{Results}

Although no quantitative means were used determine the potency of the bioicide, a few qualitative observations were made over the course of the experiment in support of its effectiveness. For instance, after five days of incubation, the bottles containing 16 or $32 \%$ water without $\mathrm{NaN}_{3}$ had a strong sulfide odor that intensified by day 10 and 21 , suggesting the occurrence of biotic sulfate reduction. Non-azide bottles containing $0 \%$ water also had a strong odor between days 5 and 21, but it was not sulfidic in nature. Such odors were not present in any of the incubations containing $\mathrm{NaN}_{3}$. Also, after five days of incubation, leaves immersed in water not treated with $\mathrm{NaN}_{3}$ had a thick, surficial mucous layer likely of bacterial derivation. This feature persisted in these bottles through day 21. Leaves immersed in water containing $\mathrm{NaN}_{3}$ had no surficial mucous. Based on these observations, I concluded that the biocide and the concentration used were sufficient for this experiment.

\section{$\underline{\text { Losses of dry mass }}$}

Rapid losses of mass occurred in each water treatment level, as $10-20 \%$ of the initial dry mass was lost after 24 hours (Figure 5.4a). After day 1, changes in percent dry mass remaining (\%DMR) from one sampling to the next were more gradual. Overall, mean \%DMR was significantly higher when associated with abiotic processes only (Table 5.1). For the most part, early differences in \%DMR between water treatment 
A.
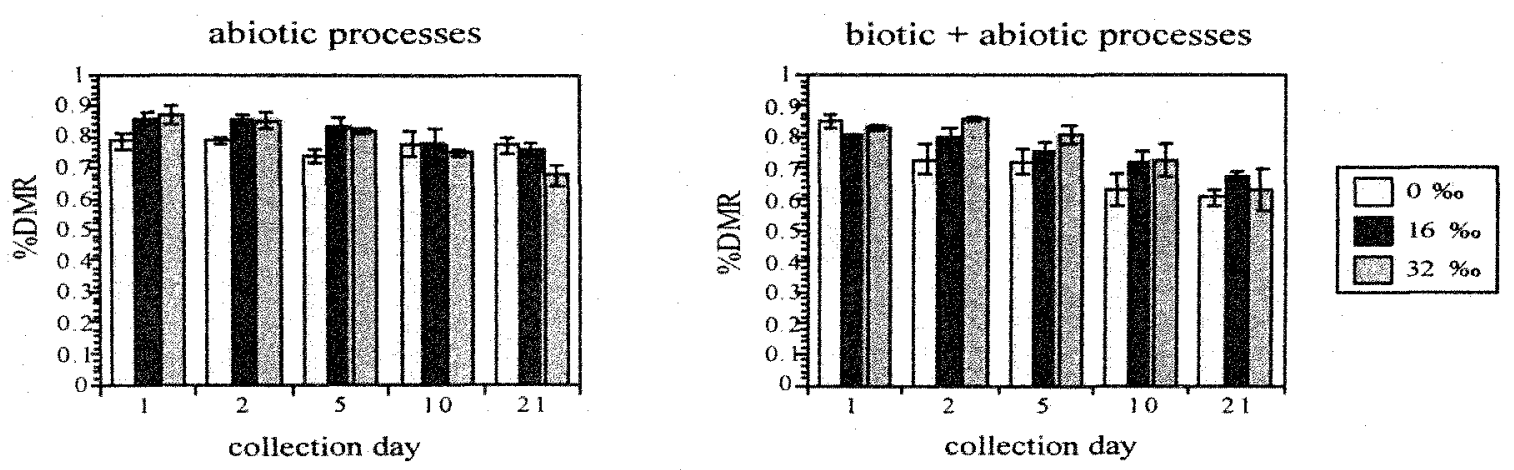

B.

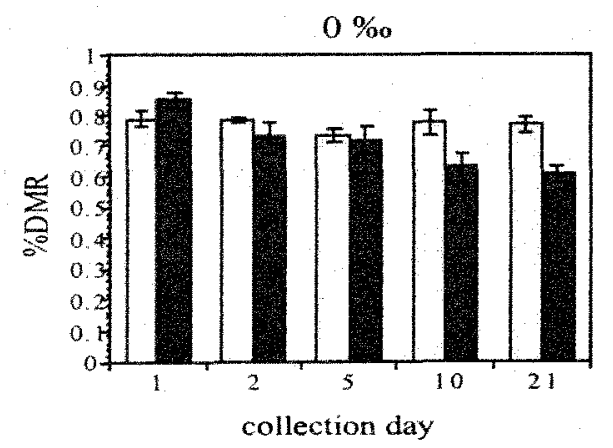

abiotic processes

biotictabiotic processes
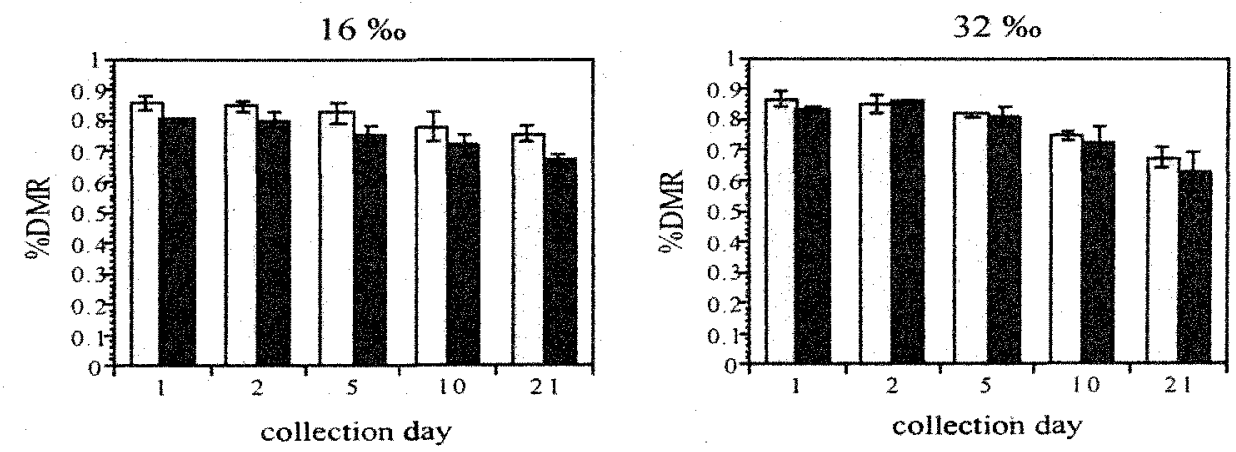

Figure 5.4- A. Mean change in percent dry mass remaining (\%DMR; \pm std. err.) over time for each salinity level, grouped by water treatment level. B. Mean change in \%DMR ( \pm std. err.) over time for each water treatment level, grouped by salinity level. 
levels were negligible. However, after five days of incubation, the differences between bottles with and without $\mathrm{NaN}_{3}$ became more noticeable (Figure 5.4a; Table 5.1). The effect of water treatment on mean \%DMR was further elucidated when broken down by salinity level.

I observed a difference in mean \%DMR between water treatment levels only in $0 \%$ and $16 \%$ water (Table 5.2; Figure 5.4b). The 32\%o salinity level yielded little or no difference in \%DMR between water treatment levels during all collection days (Table 5.2; Figure 5.4b). In all three salinity levels, the differences between the two water treatment levels tended to increase over the course of the experiment. Furthermore, these differences seemed to follow a salinity gradient, with the greatest discrepancy in $0 \%$ water, followed by $16 \%$, and then $32 \%$ (Figure $5.4 \mathrm{~b}$ ). Finally, an overall effect of salinity on mean \%DMR was detected only in leaves immersed in water containing $\mathrm{NaN}_{3}$ (Table 5.1). Percent dry mass remaining associated with abiotic processes was significantly higher in $16 \%$ water $(81.4 \%)$ than in freshwater $(76.7 \%)$, and $\% \mathrm{DMR}$ in $32 \%$ water $(79.1 \%)$ could not be statistically differentiated from either (Table 5.1).

Regression analyses revealed significant $(p<0.001$ for all) logarithmic relationships between \%DMR and collection day for both water treatment levels within each salinity level (Figure 5.5). These curves indicate the rapid, initial losses of mass during the first 24 hours, regardless of treatment (Figure 5.5). An average of about 16$17 \%$ of the initial dry mass of each leaf was lost during this brief period of time (Table 5.1). Although the contribution of biotic processes increased over time, abiotic processes accounted for more loss of mass after 21 days of leaf decomposition. 
Table 5.1- Treatment means ( \pm stdev) for $\%$ dry mass remaining. Different letters represent significant differences between treatment means (ANOVA, Fisher's PLSD; $\mathrm{p}<0.05$ ).

I. Water treatment

\begin{tabular}{cc} 
abiotic processes $^{\mathrm{a}}$ & biotic + abiotic processes $^{\mathrm{b}}$ \\
\hline $0.792 \pm 0.065$ & $0.740 \pm 0.102$
\end{tabular}

II. Salinity (within each water treatment level)

\begin{tabular}{cccccc} 
& abiotic processes & \multicolumn{3}{c}{ biotic + abiotic processes } \\
$0 \%{ }^{\mathrm{b}}$ & $16 \%^{\mathrm{a}}$ & $32 \%^{\mathrm{ab}}$ & $0 \%^{\mathrm{a}}$ & $16 \%^{\mathrm{a}}$ & $32 \%^{\mathrm{a}}$ \\
\hline $0.767 \pm 0.041$ & $0.814 \pm 0.060$ & $0.791 \pm 0.082$ & $0.708 \pm 0.107$ & $0.749 \pm 0.063$ & $0.763 \pm 0.124$
\end{tabular}

III. Collection Day (within each water treatment level)

abiotic processes

biotic + abiotic processes

\begin{tabular}{ccccccccccc} 
day $1^{\mathrm{a}}$ & day $2^{\mathrm{ab}}$ & day $5^{\mathrm{bc}}$ & day $10^{\text {cd }}$ & day $21^{\mathrm{d}}$ & & day $1^{\mathrm{a}}$ & day $2^{\text {ab }}$ & day $5^{\mathrm{b}}$ & day $10^{\mathrm{c}}$ & day $21^{\mathrm{d}}$ \\
\hline 0.838 & 0.829 & 0.793 & 0.767 & 0.727 & & 0.827 & 0.796 & 0.761 & 0.692 & 0.625 \\
\pm 0.052 & \pm 0.044 & \pm 0.055 & \pm 0.059 & \pm 0.053 & & \pm 0.031 & \pm 0.076 & \pm 0.066 & \pm 0.083 & \pm 0.095
\end{tabular}


Table 5.2- Water treatment and collection day treatment means ( \pm stdev) for $\%$ dry mass remaining within each salinity level. Different letters represent significant differences between treatment means (ANOVA, Fisher's PLSD; $\mathrm{p}<0.05$ ).

I. $0 \%$

\begin{tabular}{|c|c|c|c|c|}
\hline & abiotic processes $^{\mathrm{a}}$ & & biotic + abiotic processes ${ }^{b}$ & \\
\hline & $0.771 \pm 0.043$ & & $0.708 \pm 0.107$ & \\
\hline day $1^{\mathbf{a}}$ & day $2^{\text {ab }}$ & day $5^{\mathrm{bc}}$ & day $10^{\mathrm{c}}$ & day $21^{\mathrm{c}}$ \\
\hline $0.819 \pm 0.049$ & $0.757 \pm 0.065$ & $0.729 \pm 0.054$ & $0.703 \pm 0.106$ & $0.689 \pm 0.098$ \\
\hline
\end{tabular}

II. $16 \%$

\begin{tabular}{|c|c|c|c|c|}
\hline & abiotic processes $^{\mathrm{a}}$ & & biotic + abiotic processes ${ }^{b}$ & \\
\hline & $0.814 \pm 0.060$ & & $0.749 \pm 0.063$ & \\
\hline day $1^{a}$ & day $2^{\mathrm{a}}$ & day $5^{\text {ab }}$ & day $10^{b}$ & day $21^{b}$ \\
\hline $842 \pm 0.043$ & $0.834 \pm 0.045$ & $0.799 \pm 0.053$ & $0.748 \pm 0.061$ & $0.701 \pm 0.055$ \\
\hline
\end{tabular}

III. $32 \%$

abiotic processes $^{\mathrm{a}}$

$0.791 \pm 0.082$

\begin{tabular}{ccccc} 
day $1^{\mathrm{a}}$ & day $2^{\mathrm{a}}$ & day $5^{\text {ab }}$ & day $10^{\mathrm{b}}$ & ${\text { day } 21^{\mathrm{c}}}^{\mathrm{b}}$ \\
\hline $0.850 \pm 0.038$ & $0.855 \pm 0.034$ & $0.811 \pm 0.037$ & $0.736 \pm 0.058$ & $0.634 \pm 0.119$
\end{tabular}

biotic + abiotic processes ${ }^{\mathrm{a}}$

$0.763 \pm 0.124$ 


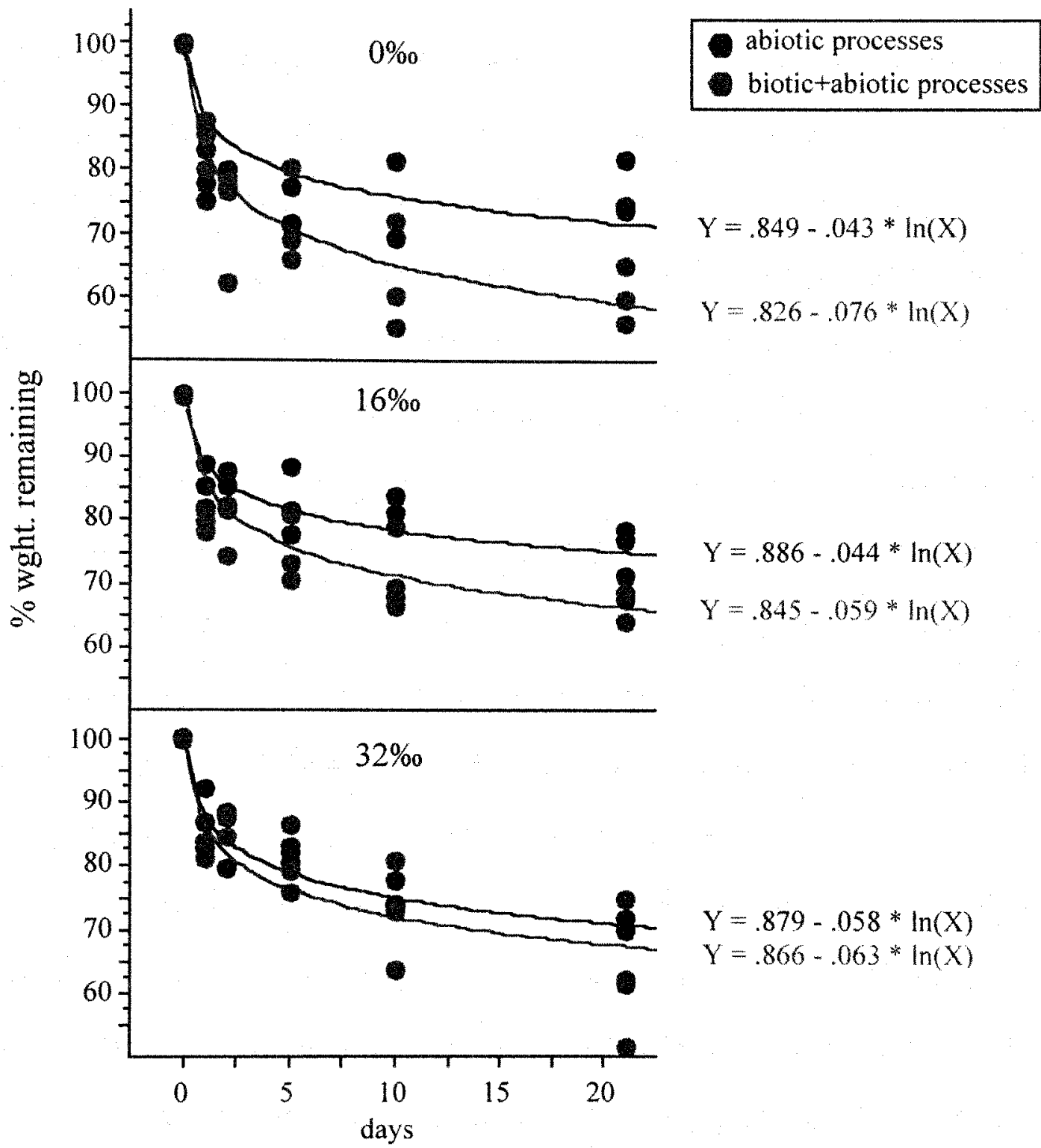

Figure 5.5- Logarithmic regression plots and equations for \%DMR versus time for each salinity/water treatment combination. Changes associated with abiotic processes are in blue, while changes associated with the combination of biotic and abiotic processes are in red. The contribution of just biotic processes can be interpreted as the difference between the blue and red lines. All regressions were significant with all p-values less than 0.001 . 


\section{$\underline{\text { Leaf Nutrients }}$}

The carbon content of yellow, nearly-senesced leaves from two dwarf mangrove sites near Taylor River ranged from 46-50\% (dry weight; Figure 5.6). This range did not differ from the $\% \mathrm{C}$ content of green leaves from the same sites (46-49\%; Figure 5.6). However, I found a large discrepancy between the $\mathrm{N}$ and $\mathrm{P}$ content of dwarf green and yellow leaves. The $\mathrm{N}$ content of green and yellow, dwarf mangrove leaves ranged from $0.75-1.3 \%$ and $0.4-0.65 \%$, respectively (Figure 5.6). Similarly, the P content of green, dwarf leaves was much higher (0.05-0.1\%) than yellow, dwarf leaves $(0.02-0.04 \%$; Figure 5.6). To relate these leaf concentrations of $C, N$, and $P$ to another, perhaps more productive, mangrove system I collected 20 leaves from a fringe mangrove site further downstream. There was no apparent difference in carbon content between the fringe and dwarf site (Figure 5.6). However, the $\mathrm{N}$ and $\mathrm{P}$ content of green and yellow, fringe leaves exceeded that of green and yellow, dwarf leaves (Figure 5.6).

Mean percent carbon content of the experimental leaves gradually increased over the course of the experiment. For both water treatment levels, relative (\%) carbon concentrations increased from a low of approximately $46 \%$, after one day, to more than $53 \%$ after 21 days (Figure 5.7). Mean $\% \mathrm{C}$ also showed a significant effect of salinity in each water treatment level. In both cases, mean relative carbon concentrations were highest in $0 \%$, followed by $16 \%$, and lowest in $32 \%$ (Figure 5.7 ). Increases in $\% \mathrm{C}$ content over time were also more noticeable in 0 and $16 \%$ than in $32 \%$ (Figure 5.8). However, absolute $\mathrm{C}$ concentrations (mass) were much more variable over time (Figure 5.8). For the most part, rapid, initial losses of carbon mass (1-5 days) were followed by little change in absolute $\mathrm{C}$ throughout the remainder of the experiment (Figure 5.8). 

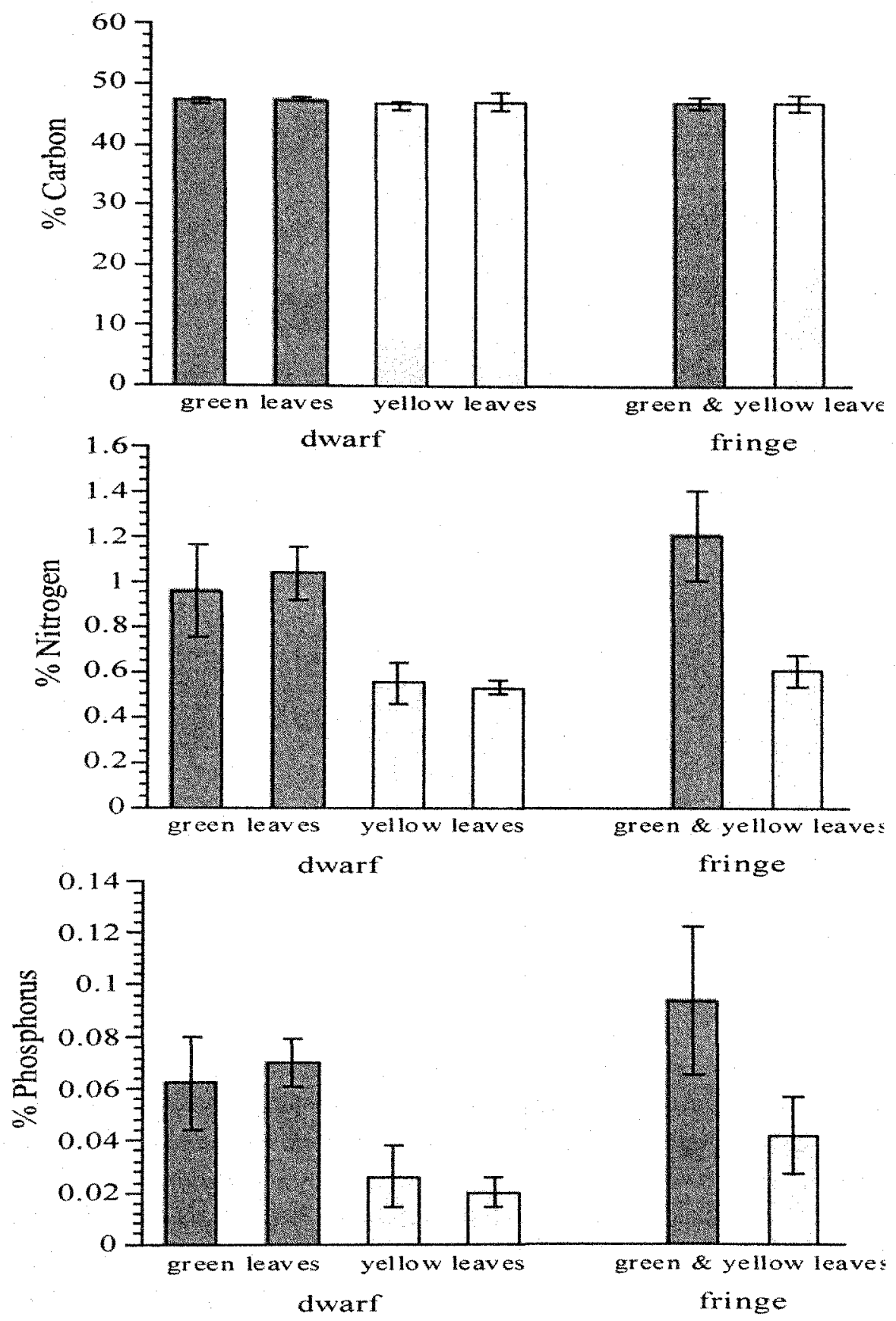

Figure 5.6- Initial concentrations (\% of dry mass) of carbon (C), nitrogen $(\mathrm{N})$, and phosphorus (P) in green and yellow, Rhizophora leaves collected from proximal dwarf sites in Taylor Slough. Also, C, N, and P data from Rhizophora leaves collected from a nearby fringe mangrove system. 

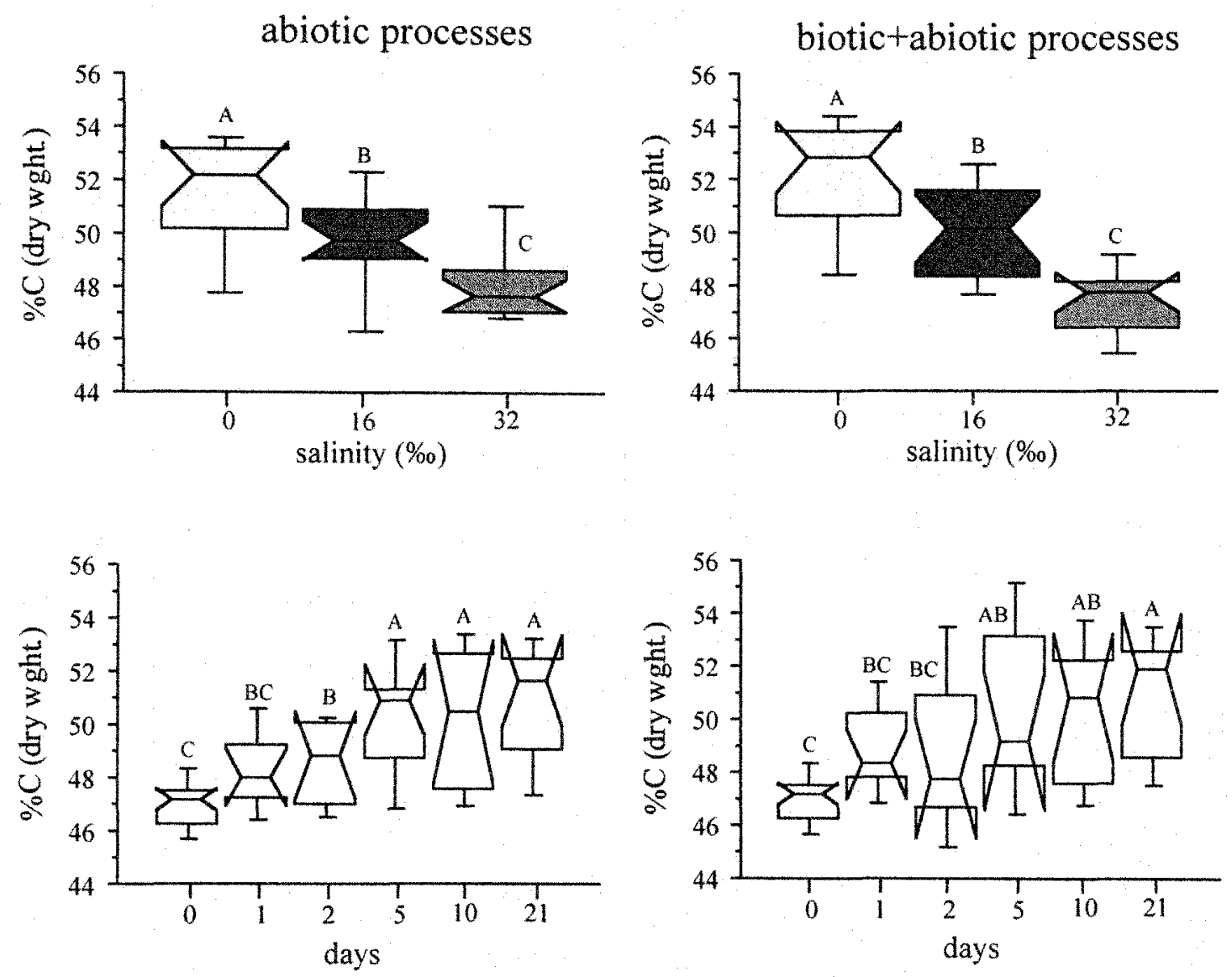

Figure 5.7- Box-and-whisker plots of leaf $\mathrm{C}$ content illustrating the differences in distributions between salinity levels and collection days under each water treatment level. For each plot, the center line marks the median, the notches indicate the $95 \%$ confidence interval about the median, the bottom and top line of each box represent the $25^{\text {th }}$ and $75^{\text {th }}$ percentiles, and the bottom and top line of the whiskers indicate the $10^{\text {th }}$ and $90^{\text {th }}$ percentiles, respectively. Letters represent significant differences between distributions (Fisher's PLSD, $\mathrm{p}<0.05$ ). 


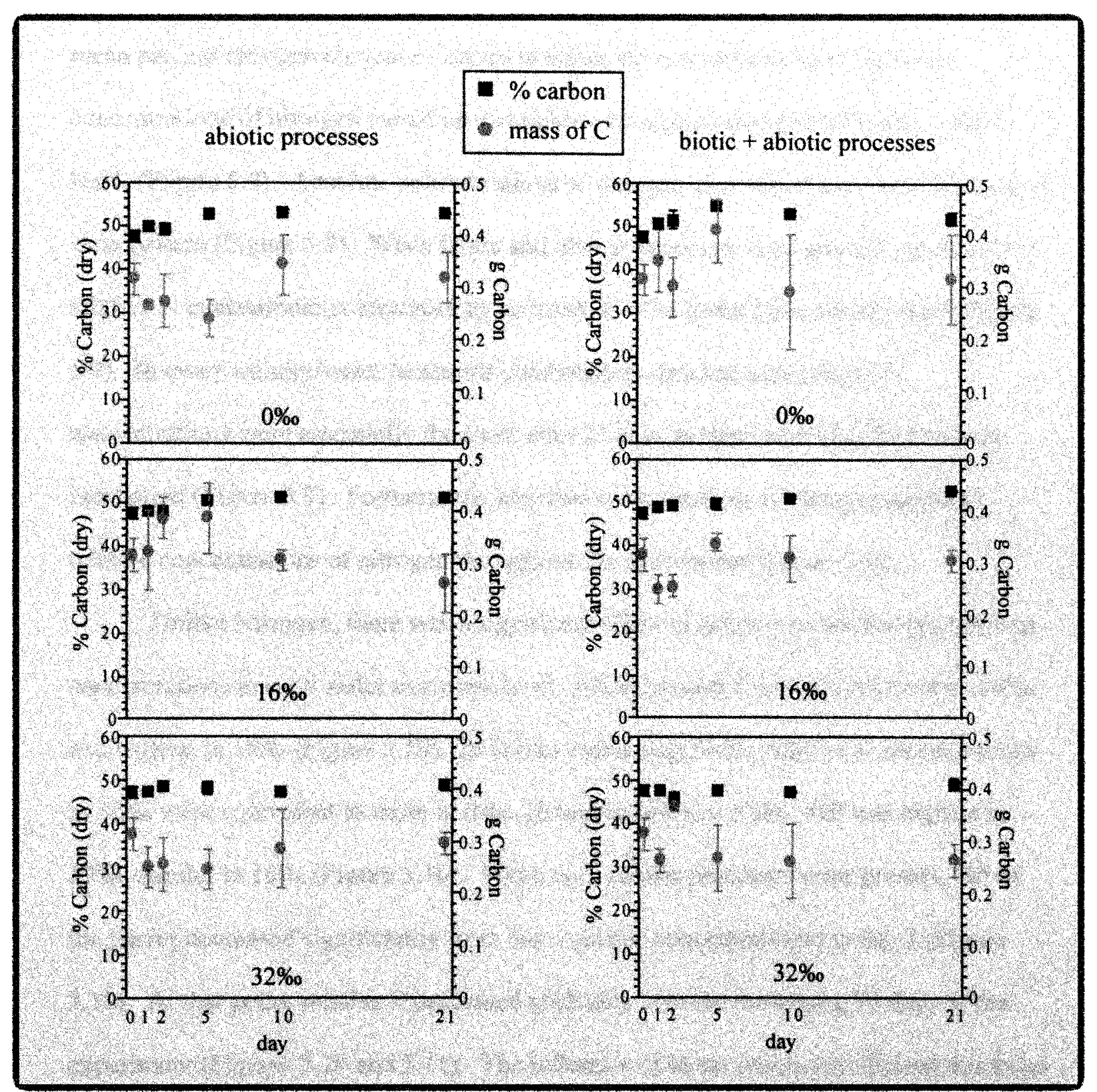

Figure 5.8- Plots showing mean change in relative (\%) and absolute $(\mathrm{g})$ concentrations of leaf $\mathrm{C}( \pm$ std. err.) over time in each salinity level, within each water treatment level. 
Analysis of variance revealed no effect of salinity or difference between days on mean percent nitrogen content of leaves in either water treatment level. Relative concentrations of nitrogen varied considerably over time, especially in bottles without $\mathrm{NaN}_{3}$ (Figure 5.9). Absolute concentrations of nitrogen also varied over time showing no clear pattern (Figure 5.9). When biotic and abiotic processes were present, absolute and relative $\mathrm{N}$ concentrations increased by as much as $50 \%$ in the $32 \%$ salinity level (Figure 5.9). In every salinity/water treatment combination, absolute and relative $N$ concentrations were essentially the same after 21 days as they were after 24 hours of incubation (Figure 5.9). Furthermore, absolute concentrations of nitrogen mirrored relative concentrations of nitrogen throughout the experiment (Figure 5.9).

Unlike Nitrogen, there was a significant effect of salinity on relative phosphorus concentrations in each water treatment level. Mean percent $P$ was always lowest in $0 \%$ o and highest in $16 \%$ (Figure 5.10). In bottles containing $\mathrm{NaN}_{3}$, relative $\mathrm{P}$ concentrations in $32 \%$ were equivalent to those in $0 \%$. However, without $\mathrm{NaN}_{3}, \% \mathrm{P}$ was highest in $32 \%$, similar to $16 \%$ (Figure 5.10 ). When only abiotic processes were present, $\% \mathrm{P}$ of the leaves decreased significantly from day 0 (initial concentrations) to day 1 (Figure 5.10). At that point, relative $P$ decreased gradually over the remaining 20 days of the experiment (Figures 5.10 and 5.11). The influence of biotic processes affected this trend by delaying the large decrease in \%P until the second day of the experiment (Figures 5.10 and 5.11). Biotic processes also produced an increase in $\% \mathrm{P}$ by day 10 that was again depleted after three weeks (Figure 5.11). These changes in relative $\mathrm{P}$ concentrations were also reflected in absolute $\mathrm{P}$ concentrations (Figure 5.11). 


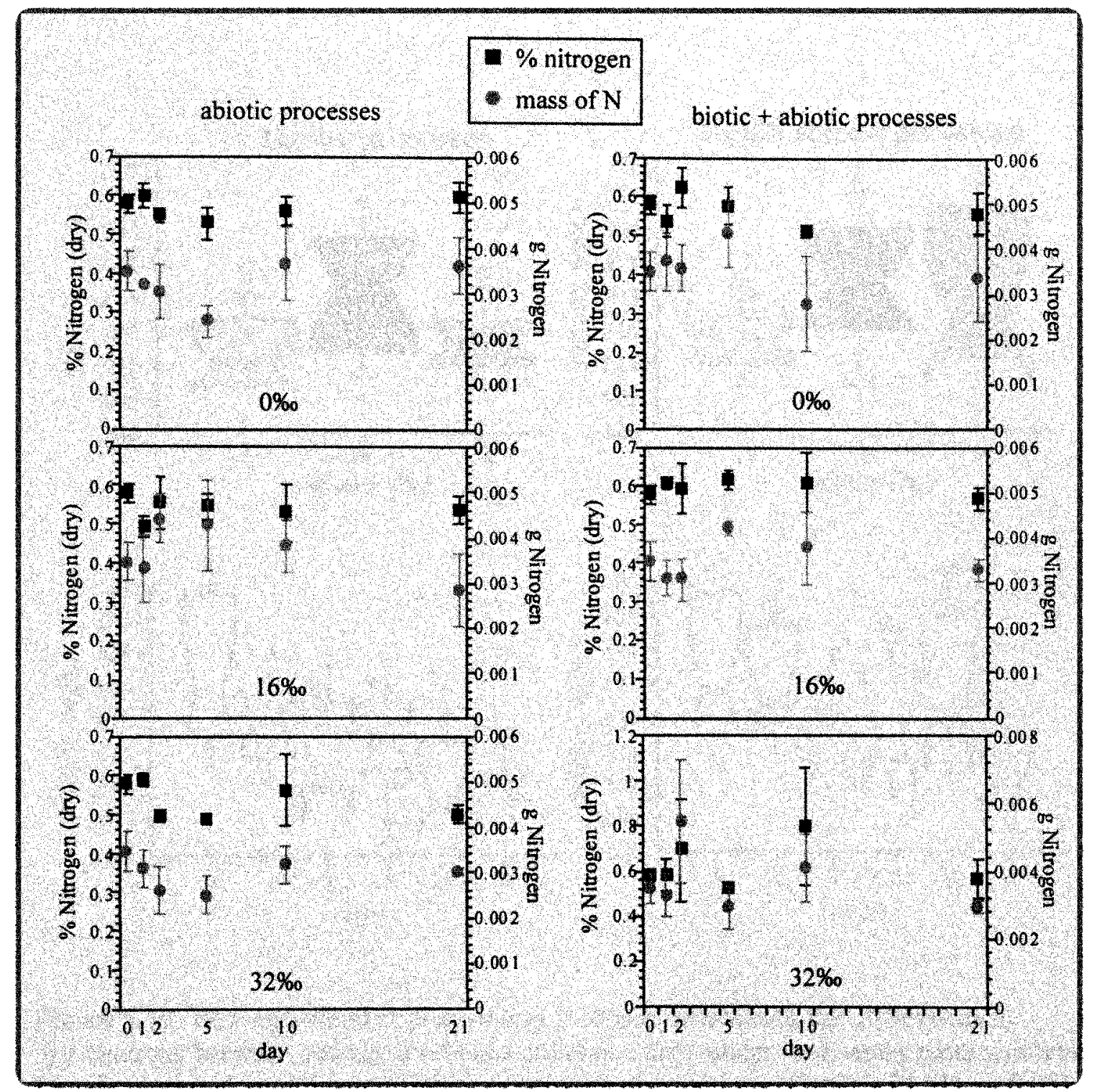

Figure 5.9- Plots showing mean change in relative $(\%)$ and absolute $(\mathrm{g})$ concentrations of leaf $\mathrm{N}( \pm$ std. err.) over time in each salinity level, within each water treatment level. 

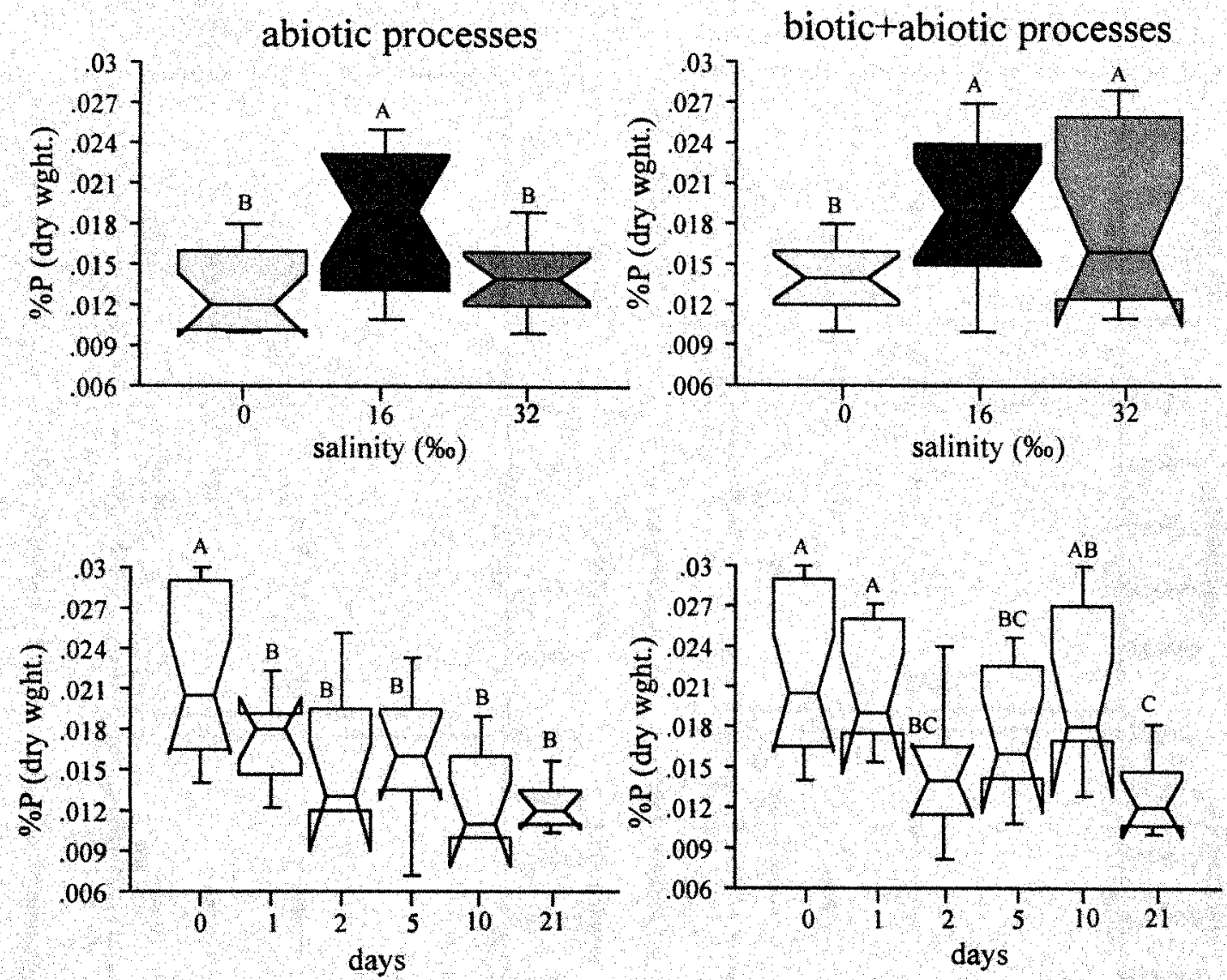

Figure 5.10- Box-and-whisker plots of leaf $P$ content illustrating the differences in distributions between salinity levels and collection days under each water treatment level. Letters represent significant differences between distributions (Fisher's PLSD, $\mathrm{p}<0.05$ ). 


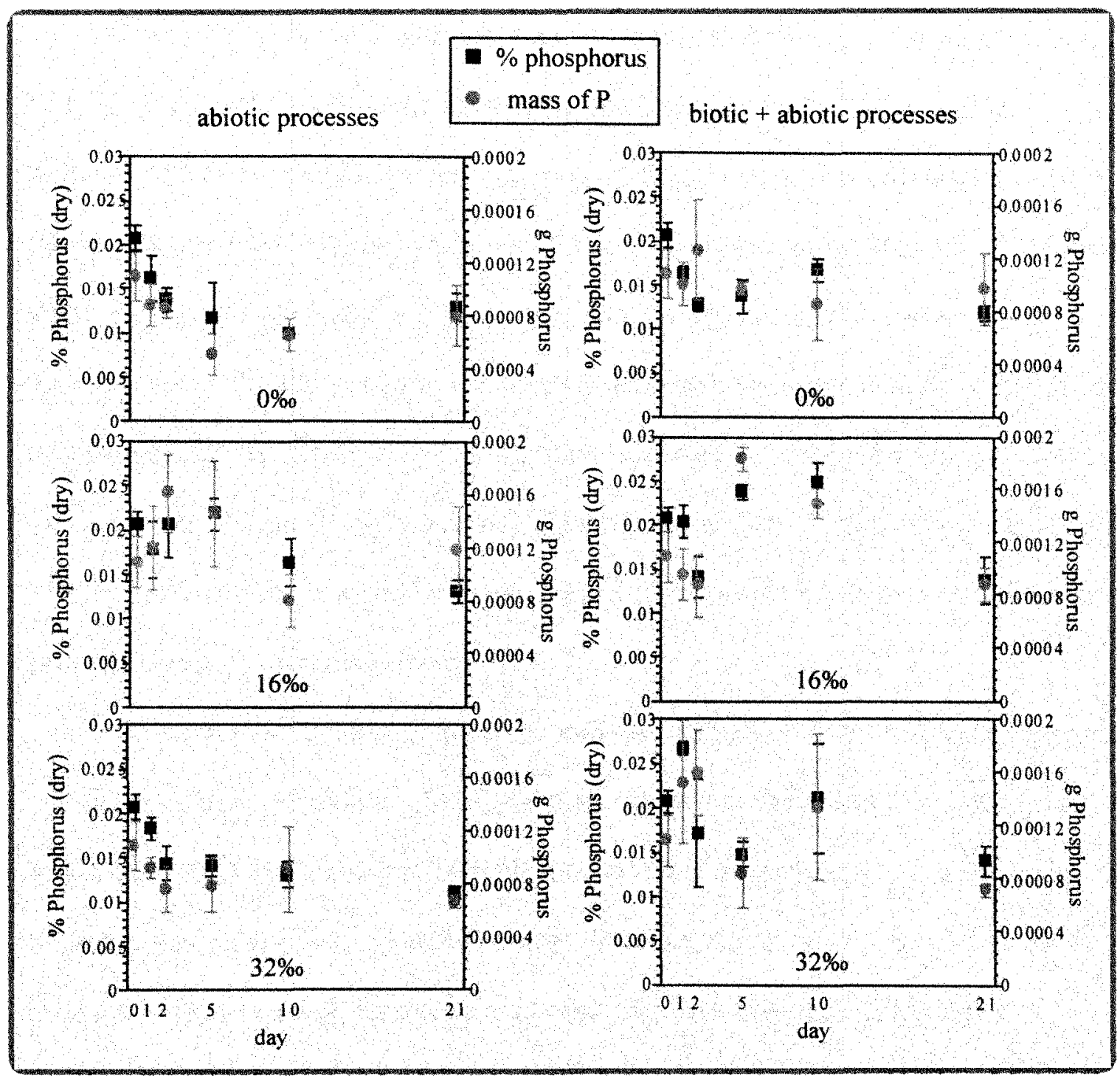

Figure 5.11- Plots showing mean change in relative $(\%)$ and absolute $(\mathrm{g})$ concentrations of leaf $\mathrm{P}( \pm$ std. err.) over time in each salinity level, within each water treatment level. 


\section{Water Nutrients}

The use of water from different sources resulted in differing initial concentrations of TOC, TN, and TP for the different salinity levels (Figure 5.12). However, the difference never exceeded a factor of two (Figure 5.12). Control bottles (without leaves) showed no significant change in TOC or TP concentrations from day 0 to day 21 in either water treatment level (Figure 5.12). As expected, the addition of $\mathrm{NaN}_{3}$ significantly increased water $\mathrm{TN}$ concentrations, so much so that there were no noticeable differences between salinity levels (Figure 5.12). Total nitrogen concentrations in the control bottles showed no significant change when only abiotic processes were active. Likewise, without sodium azide, water TN concentrations in the control bottles showed little change over the 21-day study period (Figure 5.12).

Water nutrient content at each time step was normalized to the initial dry mass of the leaf in each bottle $\left(\mu\right.$ moles $\left.\mathrm{g}^{-1}\right)$. Non-linear regressions were used to fit normalized concentrations of TOC, TN, and TP with collection day for each water level treatment. All were highly significant ( $<<0.001$ ) except TN under abiotic conditions (Figure 5.13). In an analysis of variance, the normalized values for each constituent indicated a significant time effect when biotic and abiotic processes were active. The trend for each was an initial, rapid increase in normalized concentrations followed by more gradual increases over the latter half of the three week study (Figures 5.13 and 5.14). However, TP concentrations fell slightly between day 10 and 21 (Figures 5.13 and 5.14). Sodium azide produced the same increasing pattern for TOC and TP (Figures 5.13 and 5.14). No temporal pattern was observed for TN under abiotic conditions, as normalized concentrations were high and variable. Total phosphorus was the only constituent to 


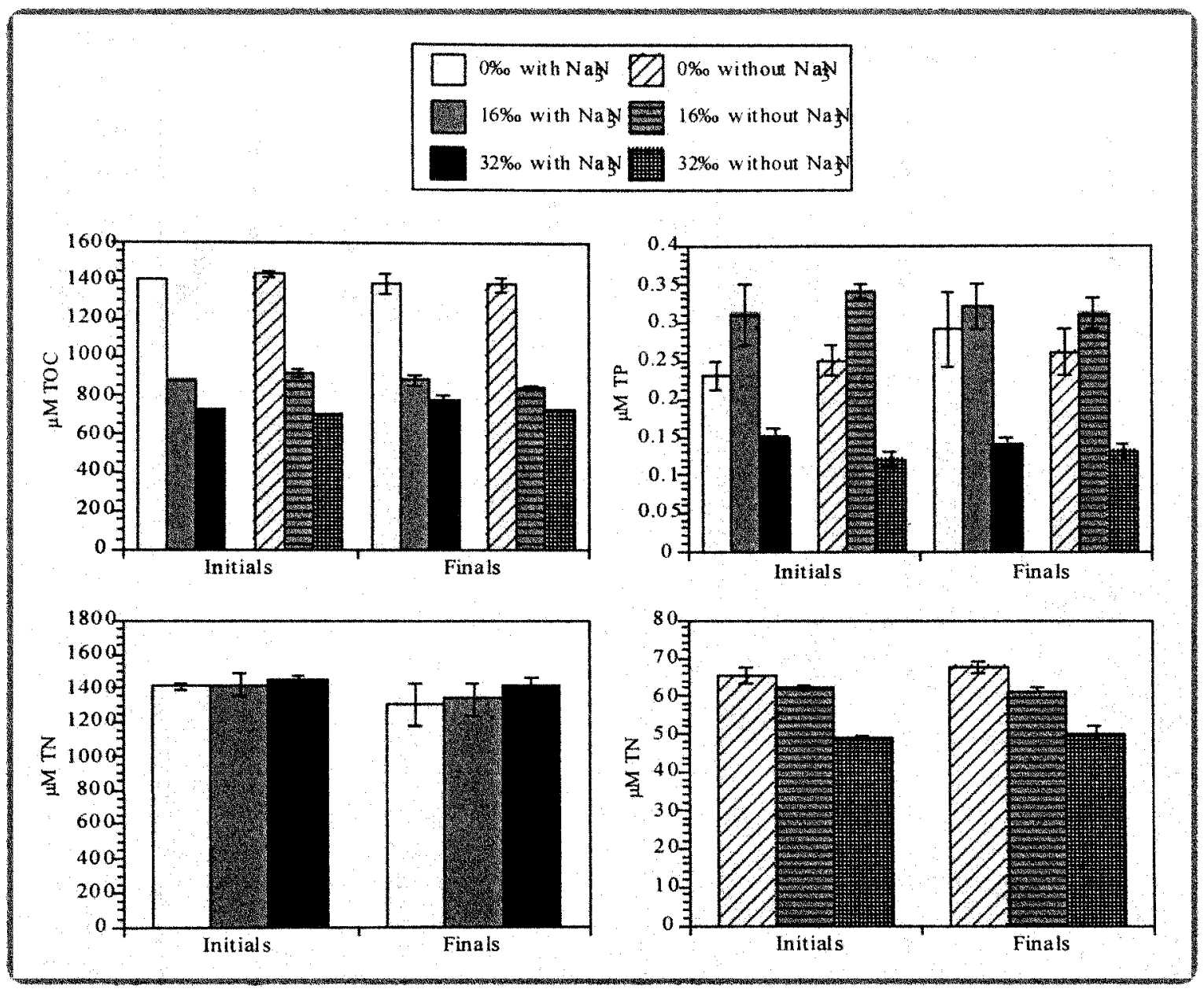

Figure 5.12- Initial and final (day 21) mean water concentrations ( \pm std. err.) of total organic carbon (TOC), total nitrogen (TN), and total phosphorus (TP) in control bottles with and without $\mathrm{NaN}_{3}$. 


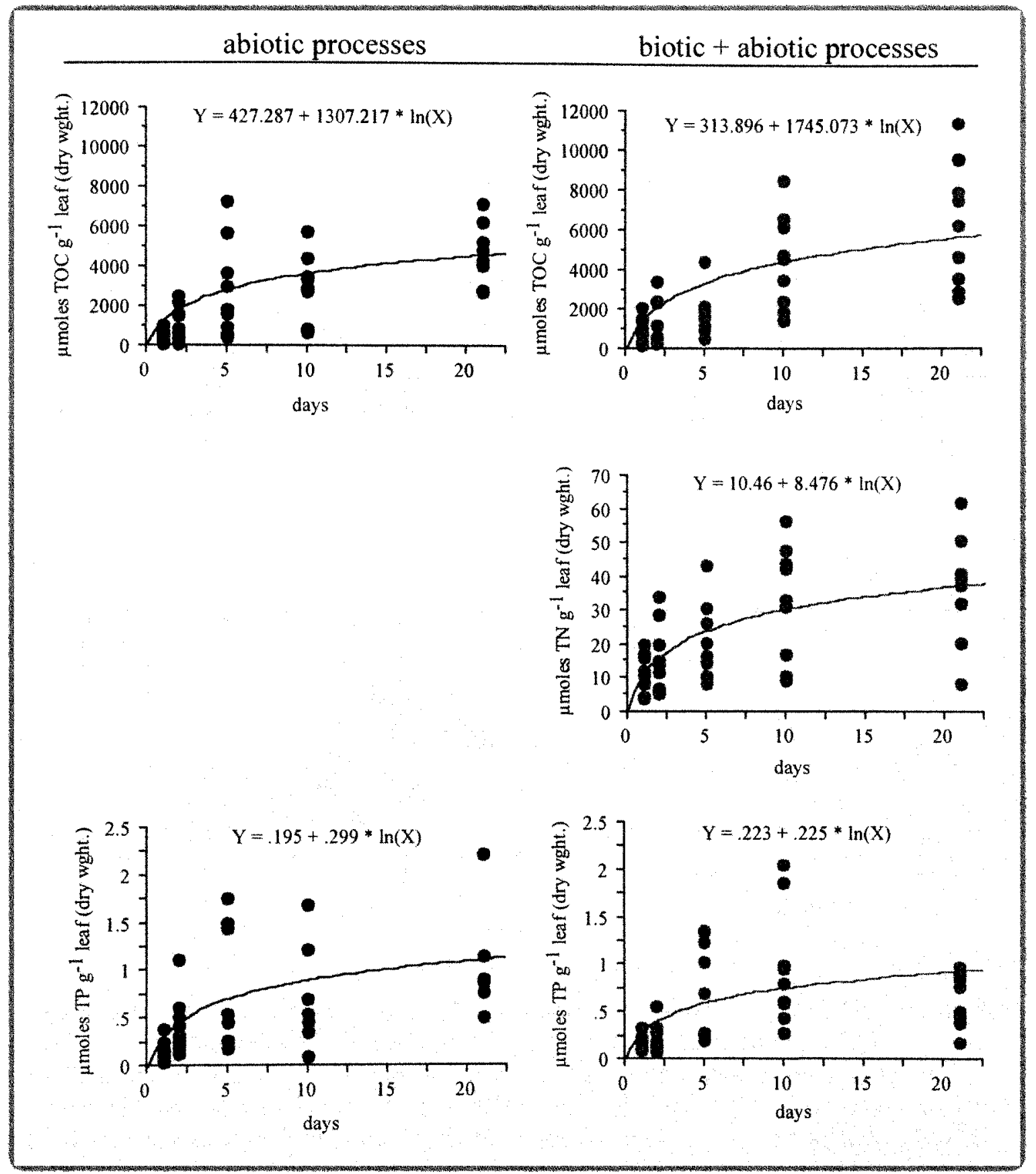

Figure 5.13-Logarithmic regression plots and equations for normalized water concentrations of TOC, TN, and TP in each water treatment level. Abiotic processes are shown in blue and the combination of biotic and abiotic processes are shown in red. All regressions shown were significant with p-values less than 0.001 . 


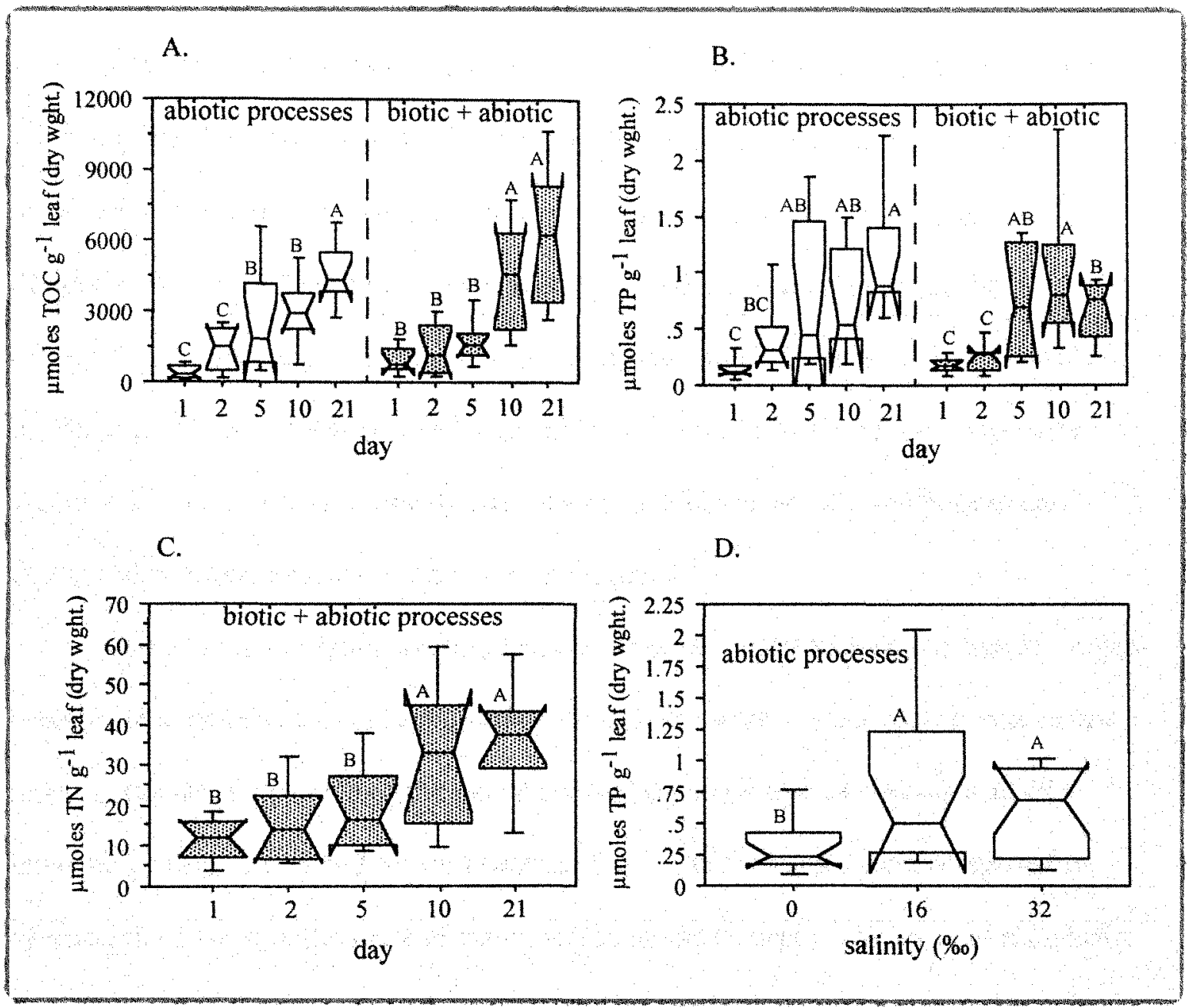

Figure 5.14- Boxplots showing normalized water concentrations of TOC (A.) and TP (B.) over time in each water treatment level. C. Boxplots showing normalized water concentrations of TN over time in the presence of biotic and abiotic processes. D. Boxplots showing distributions of normalized concentrations of TP in each salinity level. Letters represent significant differences between distributions (Fisher's PLSD, $\mathrm{p}<0.05$ ). 
show a significant effect of salinity. Mean TP concentrations were significantly higher in 16 and $32 \%$ water than in $0 \%$ (Figure 5.14).

Congruent with normalized water concentrations, molar ratios of $\mathrm{C}, \mathrm{N}$, and $\mathrm{P}$ also followed clear temporal patterns. Increasing TOC concentrations brought about increased C:N ratios in the water, regardless of water level treatment (Figure 5.15). Similarly, increased TP resulted in decreased N:P ratios that leveled off by day 21 (Figure 5.15). Although nitrogen concentrations increased with time in the non-azide bottles (Figure 5.14), they were outweighed by increases in TOC and TP. After three weeks, C:P molar ratios increased under abiotic conditions, yet showed little overall change when biotic processes were present (Figure 5.15).

Of the three nutrients investigated, carbon made up the majority of leaf dry weight (nearly 50\%) and had the highest concentrations in the water. Since carbon was such a major component, I calculated the percent of leaf dry mass loss associated with this element for each day in both water treatment levels. These values were calculated by dividing the change in the mass of water carbon by the change in dry mass of each leaf from time $=0$ to time $=t$. In both water treatment levels, there was a significant increase in the losses associated with carbon over the course of the experiment (Figure 5.16). However, the pattern was more regular when only abiotic processes were operating (Figure 5.16). Carbon apparently made up a very small percent $(<1 \%)$ of the initial losses yet, after three weeks, as much as $30 \%$ of dry mass losses were associated with carbon (Figure 5.16). By comparison, the combination of nitrogen and phosphorus accounted for less than $1 \%$ of dry mass losses after 21 days. 


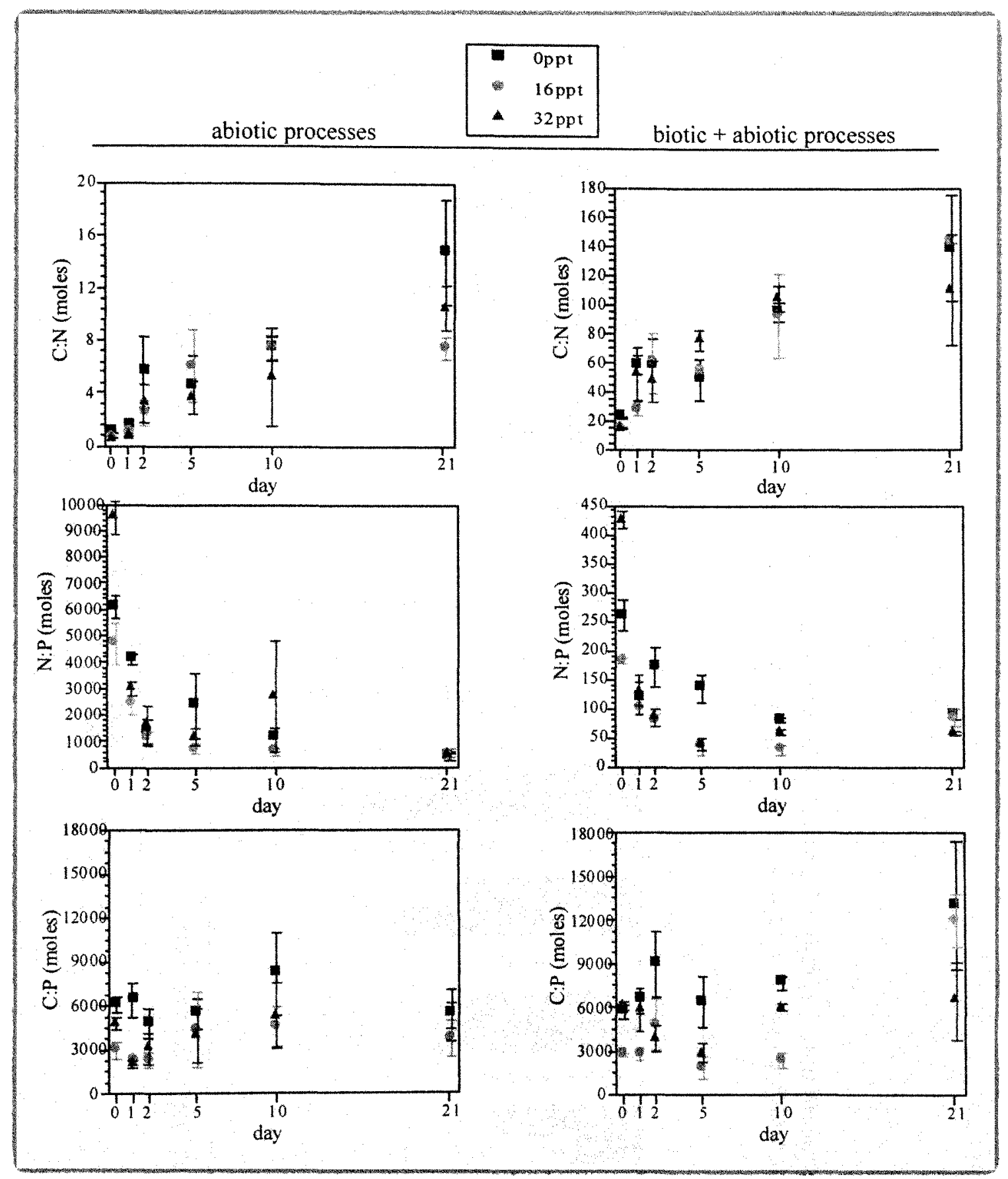

Figure 5.15- Temporal changes in mean molar ratios of $C: N, N: P$, and $C: P( \pm$ std. err.) in waters of different salinity. Plots are grouped according to water treatment level. 


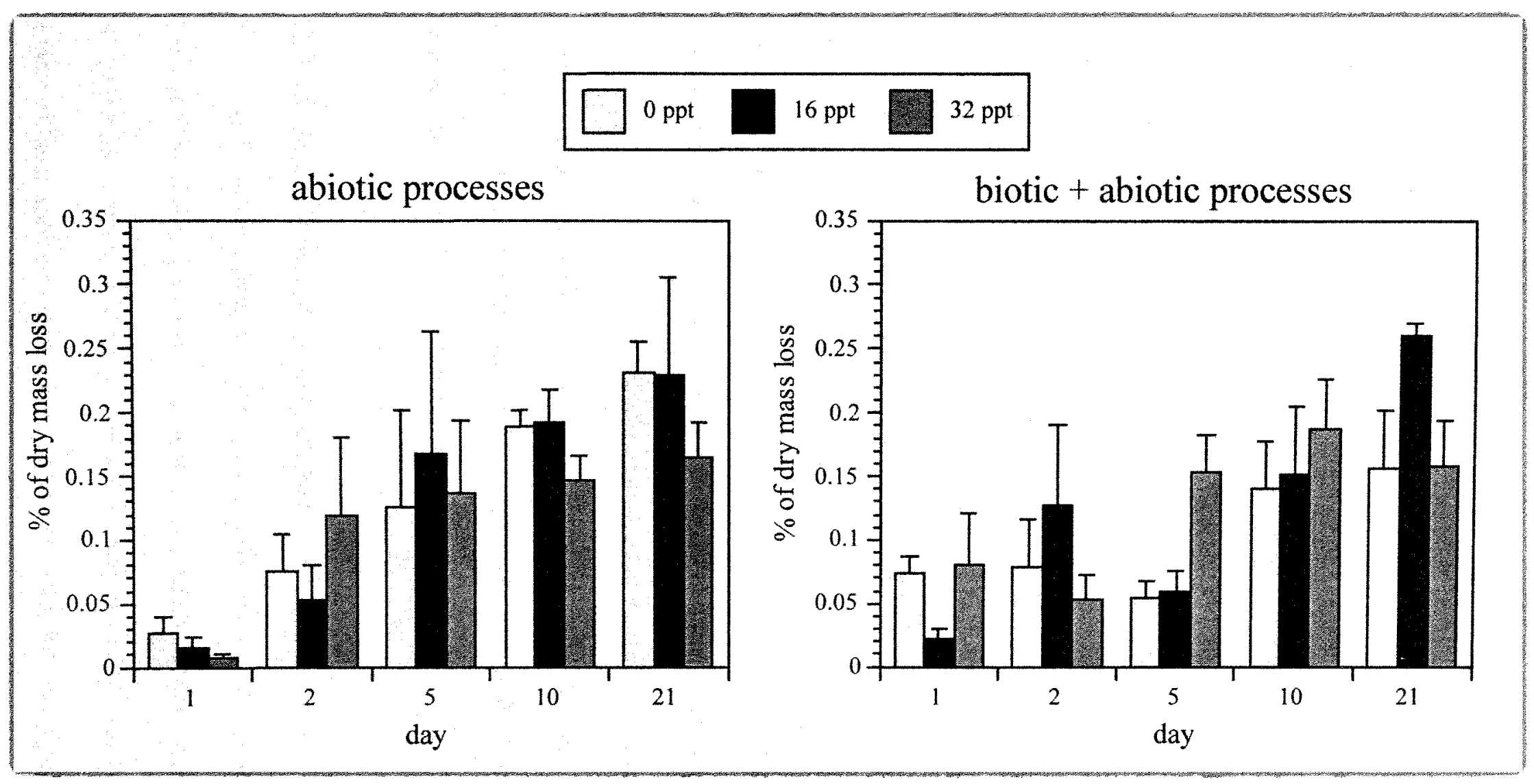

Figure 5.16- Bar charts showing the temporal change in mean percent of dry mass loss attributed to carbon ( \pm std. err.). Salinity levels are indicated by different shades of gray and plots are separated by water treatment level. 


\section{Discussion}

The benefits of this type of design are numerous. First, the use of a sealed container with little headspace allowed for an easily quantifiable exchange of nutrients from the leaves to the water, or vice versa. These calculations were facilitated by knowledge of initial leaf and water nutrient concentrations and by being able to accurately estimate the initial dry mass of each leaf. This allowed me to construct simple nutrient budgets for each incubation bottle. Next, even though the experiment was conducted outside the laboratory, there were very few sources of variability using this design. The major source of variability in this experiment was associated with differences among leaves. I was able to eliminate some of the variability due to differences in leaf mass by normalizing water concentrations to initial dry mass. However, I was unable to account for differences in initial leaf nutrient content, hence the need for triplicates of each treatment combination. Finally, as simple and easily replicated as this design was, it still mimicked the actual conditions (temperature, light, water salinity, etc.) under which leaves decompose in this system. Therefore, the data collected in this experiment are realistic and can be used to describe much of the dwarf mangrove system of the southern Everglades.

\section{Abiotic versus Biotic Contributions to Mass Loss}

In this experiment, leaching (abiotic processes) produced mean losses of mass of around $18 \%$ after 2 days and up to $30 \%$ after 3 weeks. These losses were comparable to other similar studies on temperate deciduous and tropical mangrove leaf litter (Table 5.3). Many of these showed that leaching-associated mass loss, although rapid at first, tended 
Table 5.3- Mass loss from leaves of various temperate and tropical mangrove species attributed to leaching. Time intervals of incubations are given as well as an indication of whether the leaves were immersed in water during incubation.

temperate species $\%$ dry mass loss time immersed source from leaching interval (d) in water?

\begin{tabular}{ccccc}
\hline Populus tremuloides & $5 \%$ & 7 & no & Taylor 1998 \\
Alnus crispa & $9 \%$ & 7 & no & Taylor 1998 \\
Populus tremuloides & $12 \%$ & 14 & yes & France et al. 1997 \\
Thuja occidentalis & $15 \%$ & 14 & yes & France et al. 1997 \\
Betula papyrifera & $16 \%$ & 14 & yes & France et al. 1997 \\
Alnus rugosa & $18 \%$ & 14 & yes & France et al. 1997 \\
Castanea sativa & $3 \%$ & 1 & yes & Ibrahima et al. 1995 \\
Fagus sylvatica & $6 \%$ & 1 & yes & Ibrahima et al. 1995 \\
\hline
\end{tabular}

mangrove species \% dry mass loss time immersed source from leaching interval (d) in water?

\begin{tabular}{ccccc}
\hline Avicennia marina & $18 \%^{\mathrm{a}}$ & 13 & yes $^{\mathrm{b}}$ & Tam et al. 1990 \\
Aegieeras corniculatum & $7 \%^{\mathrm{a}}$ & 13 & yes $^{\mathrm{b}}$ & Tam et al. 1990 \\
Kandelia candel & $15 \%^{\mathrm{a}}$ & 13 & yes $^{\mathrm{b}}$ & Tam et al. 1990 \\
A. marina & $24 \%$ & 7 & yes & Steinke et al. 1993 \\
Bruguiera gymnorrhiza & $21 \%$ & 7 & yes & Steinke et al. 1993 \\
A. marina & $19 \%$ & 1 & yes & Chale 1993 \\
Rhizophora mangle & $18 \%$ & 2 & yes & this study \\
\hline
\end{tabular}

${ }^{a}$ Litterbag study did not exclude biotic components that may have had an effect on mass loss. Also weight loss data were presented as $\%$ ash free dry weight remaining rather than $\%$ dry mass loss or $\%$ dry mass remaining.

${ }^{b}$ Litterbags were decomposed on an intertidal mudflat that was submergerd twice each day. 
to level off within a few weeks (Rice and Tenore 1981; Steinke et al. 1993; Ibrahima et al. 1995; France et al. 1997). However, some have claimed that leaching may be an important part of the decomposition of mangrove leaf litter for up to a month (Cundell et al. 1979; Tam et al. 1990).

In the present study, the biotic contributions to mass loss were minimal at first but gradually increased over the three-week study period. After 21 days, biotic processes accounted for approximately $4-14 \%$ of dry mass loss. These biotically-associated losses followed a salinity gradient with highest values for freshwater and lowest values for $32 \%$ water (Figure 5.5). I expect that the salinity-related gradient in the biotic contributions to mass loss were the result of differences in the initial organic carbon content of the different waters (Figure 5.12). Thus, the waters with highest $\mathrm{OC}$ concentrations may have also had the highest initial bacterial densities at the beginning of the experiment. Unfortunately, no quantitative steps were taken to verify this speculation. However, a study conducted on red mangrove leaves immersed in seawater $(33.5 \%)$ found that bacterial colonization of the leaves was not noticeable until after 28 days of submergence (Cundell et al. 1979). Furthermore, the investigators suggested that the leaching of tannins combined with the thick epidermis and waxy cuticle of $R$. mangle leaves could prevent mass colonization of bacteria for up to a month (Cundell et al. 1979). Perhaps, if the study of Cundell et al. (1979) had been conducted using freshwater from the Everglades, this colonization time might have been significantly lower. 


\section{Influence of Abiotic and Biotic Processes on Leaf and Water Nutrients}

I also found that leaching accounted for more of the leaf and water nutrient dynamics after three weeks than did biotic processes. The carbon content of leaves in this study increased in both water treatment levels, reaching their respective peaks after five days (Figure 5.7). The temporal patterns and final concentrations for each level were nearly identical, suggesting that abiotic processes were the predominant factor controlling relative leaf $\mathrm{C}$ concentrations. In a decomposition study of $R$. mangle leaf discs, Fell et al. (1975) noted similar patterns of carbon increase. They found that the relative concentration of leaf carbon increased from $42 \%$ to approximately $48 \%$ after 15 days in the field (Fell et al. 1975). Contrary to this, other investigations of leaf decomposition have shown significant decreases in leaf carbon over time. For example, Ibrahima et al. (1995) showed that the \%C content of three Mediterranean species decreased significantly over a ten-day incubation. Four other species showed no significant change over this time period (Ibrahima et al. 1995). Using the same species as the present study, Fell and Master (1980) reported a 50\% reduction in leaf C between 6-15 weeks, more than half of which was lost during the first 15 days. In addition, Rice and Tenore (1981) and Cundell et al (1979) noted sizable decreases in the carbon content of $R$. mangle leaves after 10 and 70 days, respectively.

Although I did not observe any significant decrease in leaf \%C over time, I did measure more increase in leaf \% $\mathrm{C}$ over time as salinity decreased (Figures 5.7 and 5.8). In fact, $\% \mathrm{C}$ in the $32 \%$ salinity level showed little observable change over time, and overall mean $\% \mathrm{C}$ was significantly lower in the $32 \%$ salinity level than in the others (Figure 5.7). I am unable to explain this "salinity effect" on leaf $\% \mathrm{C}$, but it seems to be 
related to abiotic processes, as the temporal patterns were nearly the same for both water treatment levels (Figure 5.8).

The temporal changes in relative leaf $\mathrm{P}$ concentrations also seemed to be mainly controlled by abiotic processes, as daily mean concentrations were quite similar between water level treatments (Figure 5.10). Nevertheless, biotic processes resulted in a brief increase in leaf $\mathrm{P}$ that was most pronounced in the 16 and 32\%o salinity levels (Figures 5.10 and 31 ). In either water level treatment, relative leaf $P$ concentrations after 21 days were basically the same (Figures 5.10 and 5.11). The overall result was an approximate loss of about $60 \%$ of the initial leaf $P$ after three weeks, much of which could be explained by abiotic processes. Other studies have shown similar trends for leaf $\mathrm{P}$ concentrations. For example, France et al. (1997) showed that nearly all leaf TP was leached from deciduous leaves after 7 days. And, Meyer (1980) found that the \%P content of various temperate deciduous leaves decreased by approximately $63 \%$ (from $0.035 \%$ to $0.022 \%$ ) after just 48 hours. A few mangrove studies have observed this same scenario for leaf $\mathrm{P}$. After only 3 days of submergence, $A$. marina leaves lost approximately $20 \%$ of their original phosphorus content (Steinke et al. 1993). Chale (1995) found a similar, although much more gradual, pattern of decreasing $\mathrm{P}$ in $A$. marina leaves.

The temporal pattern for leaf nitrogen was much less clear. In fact, I found no significant increase or decrease in relative leaf $\mathrm{N}$ concentrations, regardless of water treatment level (Figure 5.9). Evidence from a few other short-term decomposition studies supports this finding, while others do not. In a study of seven deciduous species common to the Mediterranean, Ibrahima et al. (1995) found no significant change in relative $\mathrm{N}$ 
concentrations after 10 days of leaf submergence. Similar findings were observed in a Tanzanian mangrove, as it took more than 6 weeks for nitrogen levels in Avicennia marina leaves to show any noticeable change (Chale 1993). Most other studies of leaf decomposition have noted clear, often rapid, temporal increases in leaf nitrogen. For example, Steinke et al. (1983) observed consistent increases in the $\mathrm{N}$ content of $A$. marina leaves over a three-week period of time, contrary to Chale's (1993) findings. Fell et al. (1975) measured no net change in the absolute $\mathrm{N}$ content of $R$. mangle leaves after 24 days. However, they did document a large increase in the relative $\mathrm{N}$ content over the same period of time (Fell et al. 1975). Cundell et al. (1979) noted that nitrogen concentrations increased nearly $60 \%$ (from $0.51 \%$ to $0.89 \%$ ) in the same species after 70 days of submergence.

\section{The Importance of C, N, and P in Early Leaf Decomposition}

Changes in leaf nutrients in the present study did not always correspond to changes in water nutrients. Relative concentrations of leaf carbon increased while absolute concentrations showed little or no net change (Figure 5.8). However, TOC concentrations in the water increased by as much as an order of magnitude. I believe that this can be explained by the relatively large concentration difference between the leaves and the water, where small, undetectable changes in leaf $\mathrm{C}$ may yield a sizable increase in water $\mathrm{C}$ concentrations. Although much of the carbon content Rhizophora leaves is likely associated with structural tissue, the tannin content in the leaves of this genera is fairly high (5-8\% of leaf mass; Cundell et al. 1979; Robertson 1988). Furthermore, these tannins as well as carbohydrates, proteins, and various inorganic elements are leached 
after a few weeks (Cundell et al. 1979; Benner et al. 1986; Steinke et al. 1993). The end result was a relative increase in structural tissue that appeared, in this instance, as an increase in the relative carbon content of the leaves. On the other hand, phosphorus concentrations in the water mirrored changes in concentrations of leaf P (Figures 5.11 and 5.13). Considering that leaf $P$ concentrations were relatively small $(\approx 0.035 \%)$ and much of the leaf $\mathrm{P}$ has been shown to be leachable, decreases in leaf $\mathrm{P}$ were directly observed as increases in water $P$.

Since nitrogen exhibited no net change under abiotic conditions, water molar ratios of $\mathrm{C}: \mathrm{N}$ increased and $\mathrm{N}: \mathrm{P}$ ratios decreased, regardless of the high, azide-induced nitrogen concentrations. And, even though TN increased when biotic processes were present (Figure 5.14), $\mathrm{C}: \mathrm{N}$ ratios in the water still increased over time, reaching an overall mean of about 148 after three weeks. More than a quarter of that increase was reached after 2 days when $\mathrm{C}: \mathrm{N}$ ratios of the water increased from an initial mean of 19 to 59. As a comparison, Benner et al. (1986) noted a C:N ratio of red mangrove leachate of approximately 83 after 48 hours. I also found that N:P ratios of the water decreased over time, leveling off after ten days. Based on these findings, it appears that the effluxes of carbon and phosphorus from Rhizophora leaves transcended any efflux of nitrogen.

I have demonstrated the behavior of carbon in the early degradation of $R$. mangle leaves as temporal changes in both tissue and water nutrients. I have also shown that carbon loss accounted for as much as $30 \%$ of the mass loss associated with leaching after three weeks of decomposition. By comparison, Ibrahima et al. (1995) found that carbon accounted for $50-80 \%$ of mass loss from deciduous leaves after 10 days of decomposition. Benner et al. (1986) have shown that this carbon-rich leachate can be 
rapidly and efficiently utilized by bacteria, thus serving as a potenitally important basis for the estuarine food web.

Further examination of my results indicates that carbon accounted for a small percent of leaf mass losses after one day. This was the period of time in which the greatest, single loss of mass occurred. Considering that the contribution of carbon to mass loss was delayed and the mass loss attributed to phosphorus and nitrogen was trivial, I searched the literature for clues as to the major contributors to initial mass loss from mangrove leaves. Evidence from these studies suggested that most of the initial losses I observed in this study were likely attributable to elements such as potassium, calcium, magnesium, and manganese (Steinke et al. 1983; Tam et al. 1990; Chale 1993; Steinke et al. 1993).

Although phosphorus was a minor component in terms of mass loss, the process of leaching appears to be a major source of $\mathrm{P}$ to a system considered to be limited by phosphorus availability (Feller 1995; Koch 1997). Regardless of the water treatment level, water concentrations of TP increased three-fold and N:P ratios decreased by as much as an order of magnitude from initial values after just five days. This rapid source of P may contribute to sustaining levels of productivity in such a relatively unproductive mangrove system. In contrast, nitrogen did not appear to have as important a role in the early degradation of dwarf Rhizophora leaf litter as carbon or phosphorus.

\section{Conclusion}

Leaching accounted for the largest losses of mass from dwarf red mangrove litter during the first three weeks of decomposition. Initial leaching losses and mean \%DMR 
were highest in freshwater. These losses in freshwater leveled off in less than a week, whereas leaching losses in 16 and $32 \%$ water continued throughout the remainder of the experiment. The contribution of biotic processes to mass loss was trivial at first, but steadily increased over the three-week study period. There was also an apparent influence of salinity on the disparity between biotic and abiotic processes. As salinity decreased, the biotic contributions over time increased. However, this "salinity effect" may have merely been an artifact of the differences in the organic carbon content and microbial densities of the different waters.

Carbon and phosphorus losses from Rhizophora leaves were also mainly attributed to leaching, showing no net difference between water treatment levels. At the same time, absolute and relative concentrations of leaf carbon were static while leaf $\mathrm{P}$ decreased over the three-week study period. Nitrogen, on the other hand, exhibited no net exchange from the leaves to the water due to leaching, but showed a significant increase in the water when biotic processes were present. Leaf $\mathrm{N}$ concentrations showed no net change from day 0 to day 21 . Perhaps, a longer period of decomposition was necessary to observe the temporal increase in leaf $\mathrm{N}$ that so many other studies have observed. Finally, carbon made up a minor percent of initial mass losses, yet by the end of the study, nearly $30 \%$ of mass loss was due to carbon. Nitrogen and phosphorus, combined, accounted for approximately $0.8 \%$ of leaf mass loss after 21 days of decomposition.

Future work in this area should focus on the short-term decomposition dynamics of the different south Florida mangrove species (Rhizophora mangle, Avicennia germinans, and Laguncularia racemosa) as well as the different forest types (e.g. dwarf 
vs. fringe vs. basin). There is also a need for more research on the influence of salinity and season on the degradation of mangrove litter in south Florida. In Taylor Slough these factors are interrelated (Chapters 2-4) and likely affect both the timing and quality of litter. Also, there is a need for research comparing the short and long-term leaf decomposition of mangrove litter. Such a study would certainly aid in the understanding of large-scale nutrient cycling in a system where litter recycling is a perpetual energy and nutrient source to the estuarine food web. 


\section{Chapter 6:}

Exploring the effects of an altered hydrologic regime on the subsystem exchange of nitrogen in the southern Everglades salinity transition zone through the use of a dynamic budget.

\section{Abstract}

I developed a dynamic budget to track the subsystem exchange of total nitrogen in the surface water of the salinity transition zone of Taylor Slough, Everglades National Park for one year. The salinity transition zone is a non-tidal, red mangrove-dominated system located between the freshwater Everglades (to the north) and Florida Bay (to the south). During the wet season, flow from the Everglades controls salinity and nutrient concentrations in this area, whereas the bay typically determines the salinity and nutrient profiles during the dry season. Calibration and validation of the model was accomplished with field data collected between 1996 and 1998. The simulated net annual export of TN to Florida Bay was $3.11 * 10^{4} \mathrm{~kg}$, with highest export during the wet season. Comparisons with field data indicated that the model satisfactorily predicted total nitrogen concentrations, total monthly fluxes at the interface with Florida Bay, and net areal fluxes in the dwarf subsystem. Month-for-month comparisons between model output and actual data necessitated similar hydrologic conditions (i.e. mean monthly salinity) in order to yield parity. Following validation, the model was used to simulate conditions of seasonal increases or decreases in freshwater flow. The results of these exercises indicated that both scenarios could lead to a reduction in the amount of total nitrogen exported to Florida Bay. However, further work needs to be conducted on determining actual 
subsystem dimensions and contributions of precipitation and evapotranspiration in order to refine the model.

\section{Introduction}

The ecological significance of mangrove wetlands as sources, sinks, or transformers of materials is not well understood at the present time. However, as these systems become more affected by human-related impacts, such as coastal development, freshwater diversion and nutrient enrichment, there will be an increased need for empirical data on the biogeochemical properties of these wetlands. While some investigators have shown that mangroves contribute a great deal of energy (in the form of fixed carbon) to offshore systems (Odum and Heald 1972), others have maintained that such contributions, especially to seagrass beds or coral reefs, are localized (Fleming et al. 1990; Hemminga et al. 1994). The general consensus emerging from much of the mangrove outwelling work is that the relative amount of export and spatial extent to which mangrove-derived organic matter penetrates offshore food webs is mainly a function of tidal characteristics (Odum et al. 1979; Boto and Bunt 1981; Twilley 1985; Lee 1995). Concurrent with organic matter export, mangrove systems also often function as sinks for suspended sediment and dissolved inorganic nutrients (Boto and Wellington 1988; Woodroffe 1992; Rivera-Monroy et al. 1995).

A further extension of this type of biogeochemical work has been to look at subsystem exchanges in order to quantify the relative contributions of different habitats within a system as well as their differential responses to forcing functions (e.g. tide, salinity, temperature, etc.; Rivera-Monroy et al. 1995). As with most estuarine wetlands, 
mangroves and adjacent aquatic systems are linked by surface and subsurface water connections, thus allowing for interactions at various spatial and temporal scales (Childers et al. 1993a). These interactions are often quantified as exchanges of materials or nutrients between estuarine habitats (e.g. oyster bed, Spartina marsh, mangrove wetland, etc.) and the water column (Wolaver and Spurrier 1988; Dame et al. 1989; Childers and Day 1990a; Childers and Day 1990b; Chapters 3 and 4). Given sufficient knowledge of subsystem fluxes of materials and hydrologic patterns, mathematical models can be useful tools to generate whole-system, dynamic nutrient budgets (Childers et al. 1993b). These models are beneficial because they aid in understanding the coupling of subsystems and how this coupling controls nutrient variability through space and time. They can also be used as the backbone for spatially articulate mechanistic models. Furthermore, dynamic budgets can be used to make predictions concerning future system states as well as to generate hypotheses. I developed a dynamic total nitrogen budget for a non-tidal estuarine mangrove system of the oligotrophic southern Everglades primarily for these reasons.

The model presented here was designed to track the movement of surface water total nitrogen (TN) within the salinity transition zone (STZ) of Taylor Slough, Everglades National Park and exchange between the STZ and Florida Bay. The model is based on intensive subsystem flux study (Chapters 3 and 4), extensive system exchange monitoring, and basic hydrological and geomorphological information. Given the nontidal nature of this system, the movement of water and TN between habitats is driven by freshwater flow in the wet season and wind-driven forcing in the dry season. Since this is merely a budget and not a simulation model, I made no attempt to model specific 
biogeochemical processes, only net exchanges of water and TN between the model components. The budget output was examined from both a temporal and spatial perspective to determine the intra-annual variability in TN dynamics within and between subsystems. Flux and exchange data not used for the purpose of model development were used to validate the effectiveness and accuracy of the dynamic budget. In situations where model output did not correspond with the validation data, weaknesses of the model were exposed and hypotheses were offered. Finally, in order to demonstrate the impacts of the past and future changes in freshwater delivery to this system, I ran the model under a few different scenarios of decreased freshwater flow during the wet season and increased freshwater flow during the dry season.

\section{Materials and Methods}

\section{$\underline{\text { Site Description }}$}

Taylor Slough is located along the eastern margin of Everglades National Park (Figure 6.1). Historically, it was considered the major overland source of freshwater to Florida Bay. However, the diversion of freshwater from Taylor Slough for urban use and flood control has changed the natural volume and timing of delivery through this system, sometimes leading to prolonged hypersalinity in Florida Bay (McIvor et al. 1994). Despite these changes in freshwater delivery, Taylor Slough is still one of the most important sources of freshwater driving seasonal salinity patterns in northeastern Florida Bay (McIvor et al. 1994). Recently, there has been a push to restore natural, premanaged freshwater delivery into the freshwater wetlands of the $\mathrm{C}-111$ basin and the 


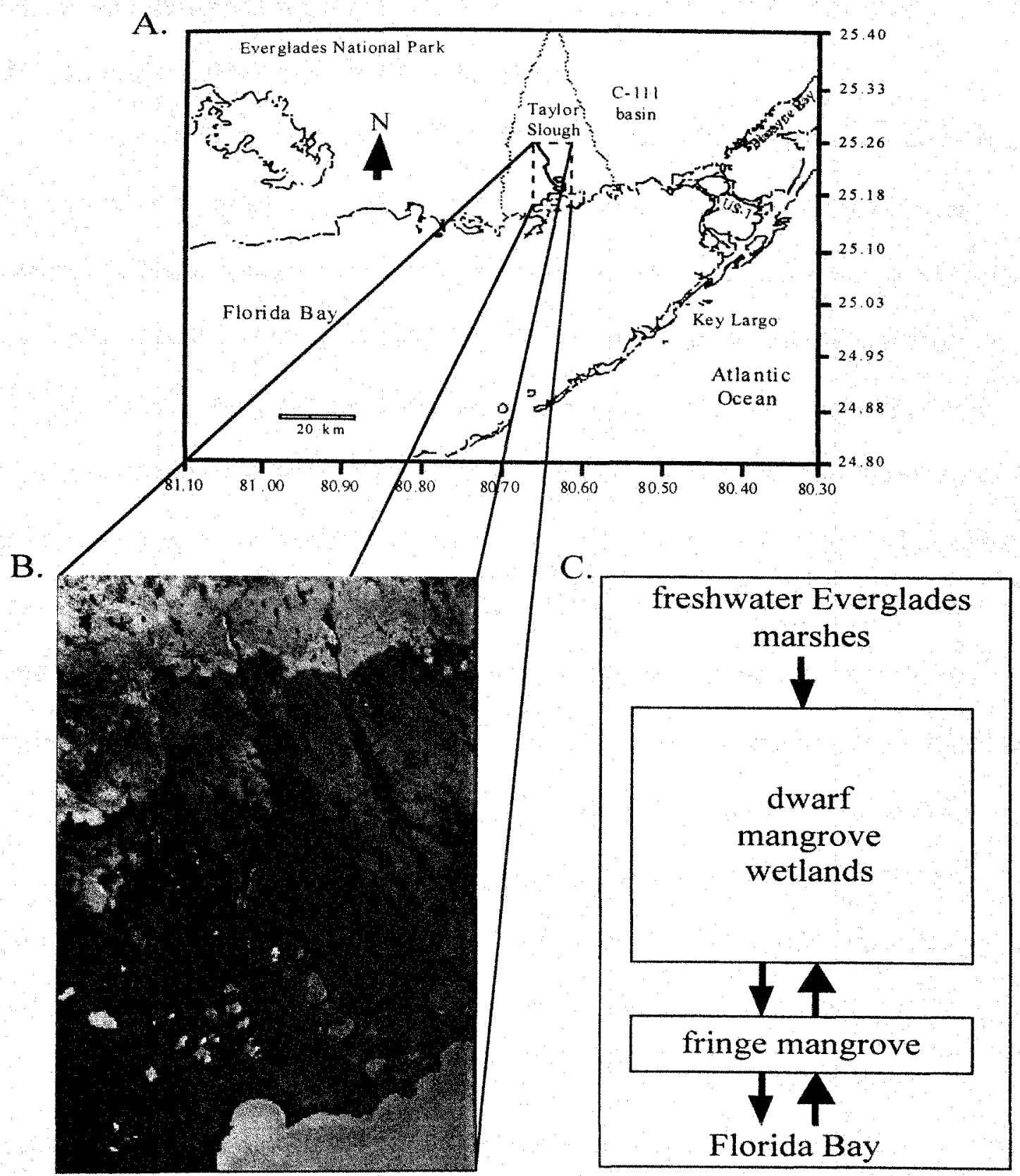

Figure 6.1- A. Map of eastern Florida Bay and the southern Everglades highlighting the approximate boundary of Taylor Slough and location of the salinity transition zone (STZ; dashed line). B. Aerial photo showing the STZ of Taylor Slough between the freshwater Everglades marshes and Florida Bay (note the numerous ponds and lakes along the southern end of the dwarf mangrove zone). C. The conceptual model of water dynamics in the STZ used to develop the dynamic budget. Freshwater flow, during the wet season, originates from the Everglades, flows through the STZ, and empties into Florida Bay. Inputs from the bay are limited to strong wind events and late dry season. 
salinity transition zone of Taylor Slough (Figure 6.1; see web site for Southern Everglades Restoration; www.serestoration.org).

The salinity transition zone (STZ) of Taylor Slough (Figure 6.1) is bordered by the freshwater Everglades marshes, to the north, and Florida Bay, to the south. It is composed of three mangrove communities, two of which (dwarf and fringe) are directly linked via surface water flow (Figure 6.1). The dwarf mangrove wetland covers a vast area just south of the freshwater Everglades and represents the northernmost extent of bay water (salinity) intrusion (Figure 6.1). The hydrology of this area is characterized mainly by precipitation-driven sheet flow. However, there are numerous shallow ponds linked by distinct channels at the southern end of this wetlandscape (Figure 6.1). The fringe wetland occupies much less area, bordering the lower stretch of Taylor River, a major distributary of Taylor Slough (Figure 6.1). Taylor River empties into Florida Bay, thus providing a direct surface water linkage between the Everglades and Florida Bay.

The dwarf and fringe wetlands of Taylor Slough are dominated by different growth forms of the red mangrove (Rhizophora mangle L.). Although, these wetland types are both typical of oligotrophic environments, they are quite different in their structural development, hydrologic characteristics, and relative rates of primary production (Cintron et al. 1985). Dwarf mangrove wetlands are generally shallow water environments with long hydraulic residence times (Cintron et al. 1985). They are also short in stature $(<1.5 \mathrm{~m}$ in height $)$ and the least productive mangrove wetland-type, most likely as a result of nutrient limitation (Cintron et al. 1985; Feller 1995; Twilley 1995; Koch 1997). On the other hand, fringe mangroves, having moderately high rates of 
production, are substantially taller $(\approx 10 \mathrm{~m}$ in height $)$ and have much shorter hydraulic residence times (Cintron et al. 1985).

The subsystem exchange of water in the salinity transition zone of Taylor Slough is mostly driven by upland runoff during the wet season (June-November). High rains at the onset of the wet season create a large freshwater head in the Everglades marshes, resulting in a rapid pulse of water through the STZ and into Florida Bay (Figures 6.1 and 6.2). This seasonal event results in a system-wide reduction of surface water salinity that persists for much of the remainder of the year (Figure 6.2). However, as the wet season gives way to the dry season (December-May), evaporative losses in the dwarf mangrove and freshwater marshes exceed freshwater inputs producing a much weaker hydraulic head in the opposite direction (Figure 6.1). This leads to increased bay water intrusion in the STZ and, thus, increased surface water salinity (Figures 6.1 and 6.2).

\section{Model Calibration Data}

The field data supporting this modeling effort came from a few different sources. First, the daily exchange of water, salinity, and nutrients (TN and TP) between Taylor River and Florida Bay (via Little Madeira Bay) has been monitored since early 1996 (Table 6.1). The United States Geological Survey (USGS) maintains a doppler, areavelocity gauge at the mouth of Taylor River to measure daily discharge into and out of the creek (E. Patino, USGS). A joint effort by investigators from Louisiana State University and Florida International University has monitored the daily exchange of total nitrogen, total phosphorus, and salinity at the same location as the USGS flow gauge since April 1996. Because 1997 was the first full year that these two datasets overlapped, 


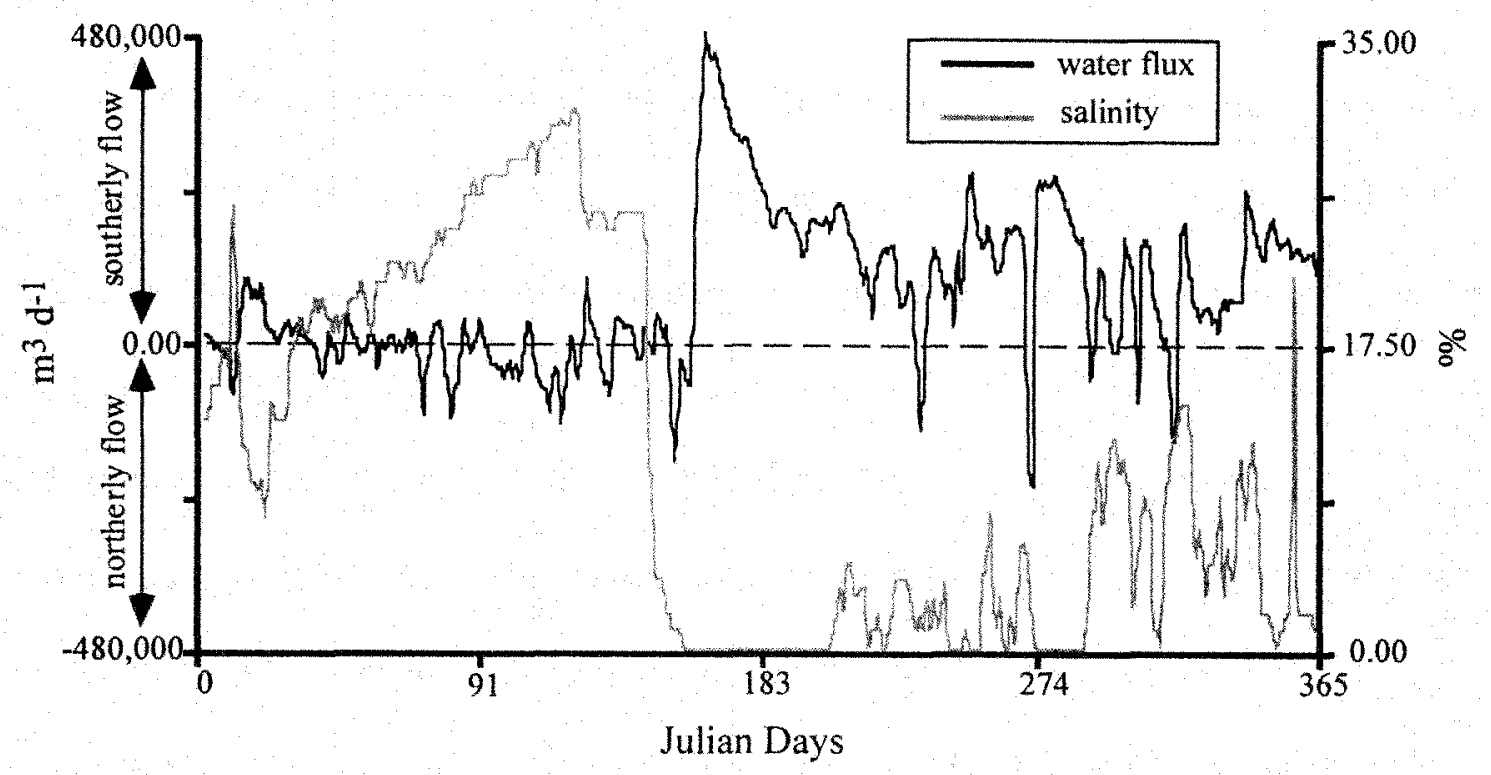

Figure 6.2- 1997 USGS hydro data from the mouth of Taylor River showing a time series of direction and magnitude of water flux as well as salinity. These data were used to drive subsystem water exchange in the dynamic budget. 
I chose to use flow and salinity data from 1997 to calibrate the dynamic budget (Figure $6.2)$.

Data on subsystem fluxes were taken from studies of wetland-water column exchanges of nutrients in dwarf and fringe mangrove sites in Taylor Slough STZ (Table 6.1; Chapters 3 and 4). In order to maintain consistency and reduce sources of variability in the model, only dwarf mangrove flux data from 1997 were used in the model calibration process. In contrast, all available flux data were used for the fringe component, as significant fluxes of nutrients were infrequently measured from 1996 to 1998 (Chapter 4). Other parameters from these flux studies such as nutrient concentrations, salinity, water level change, and flow measurements were also used in model development (Table 6.1).

\section{Model Description and Construction}

The dynamic budget was designed as an accounting exercise to keep track of total nitrogen in the surface water of the Taylor Slough STZ. Total nitrogen exchange was modeled for a few reasons. First, there were existing data on TN and salinity exchange between Taylor River and Florida Bay (Table 6.1). Although these TN data were not used for model calibration, they were an important first step in the validation process (Table 6.1). Next, the relationship between TN concentrations and salinity at the mouth of Taylor River suggested the potential importance of the mangrove subsystems in controlling TN dynamics, instead of simple dilution processes (Figure 6.3a). This 
Table 6.1- Sources of data used in the calibration or validation process of the dynamic total nitrogen budget.

\begin{tabular}{|c|c|c|c|c|c|}
\hline site & method & dates & parameters quantified & purpose & source \\
\hline \multirow{2}{*}{$\begin{array}{l}\text { Taylor Slough } \\
\text { dwarf } \\
\text { mangrove }\end{array}$} & $\begin{array}{l}\text { dwarf mangrove } \\
\text { enclosures }\end{array}$ & $\begin{array}{l}\text { Jan., May, Aug. and } \\
\text { Nov. } 97\end{array}$ & $\begin{array}{c}\text { net areal flux of TN, salinity, } \\
\text { and water level }\end{array}$ & calibration & Chapters 1 and 3 \\
\hline & & $\begin{array}{l}\text { Aug. and Nov. } 96 \text { and } \\
\text { Jan. and May } 98\end{array}$ & $\begin{array}{l}\text { net areal flux of TN and } \\
\text { salinity }\end{array}$ & validation & Chapters 1 and 3 \\
\hline $\begin{array}{l}\text { Taylor River } \\
\text { fringe } \\
\text { mangrove }\end{array}$ & in-channel flumes & $\begin{array}{l}\text { quarterly, from Nov. } \\
96 \text { - Aug. } 98\end{array}$ & $\begin{array}{c}\text { net areal flux of TN, salinity, } \\
\text { water level, and current } \\
\text { velocity }\end{array}$ & calibration & Chapter 2 \\
\hline \multirow{2}{*}{$\begin{array}{l}\text { Taylor River } \\
\text { mouth }\end{array}$} & $\begin{array}{l}6 \mathrm{hr} \text {. integrated } \\
\text { daily water sample, } \\
\text { fixed point }\end{array}$ & Jan. 1 - Dec. 31, 1997 & salinity & calibration & $\begin{array}{c}\text { Childers and } \\
\text { Davis unpublished } \\
\text { data }\end{array}$ \\
\hline & & $\begin{array}{l}\text { May } 96 \text { - Dec. } 96 \text {, Jan. } \\
98 \text { - April } 98\end{array}$ & TN concentration & validation & $\begin{array}{c}\text { Childers and } \\
\text { Davis unpublished } \\
\text { data }\end{array}$ \\
\hline \multirow{2}{*}{$\begin{array}{l}\text { Taylor River } \\
\text { mouth }\end{array}$} & $\begin{array}{l}\text { doppler, area- } \\
\text { velocity gauge }\end{array}$ & Jan. 1 - Dec. 31, 1997 & $\begin{array}{c}\text { daily flux of water at the } \\
\text { Taylor River-Florida Bay } \\
\text { interface }\end{array}$ & calibration & E. Patino, USGS \\
\hline & & $\begin{array}{l}\text { May } 96 \text { - Dec. } 96 \text {, Jan. } \\
98 \text { - April } 98\end{array}$ & $\begin{array}{c}\text { daily flux of water at the } \\
\text { Taylor River-Florida Bay } \\
\text { interface }\end{array}$ & validation & E. Patino, USGS \\
\hline
\end{tabular}



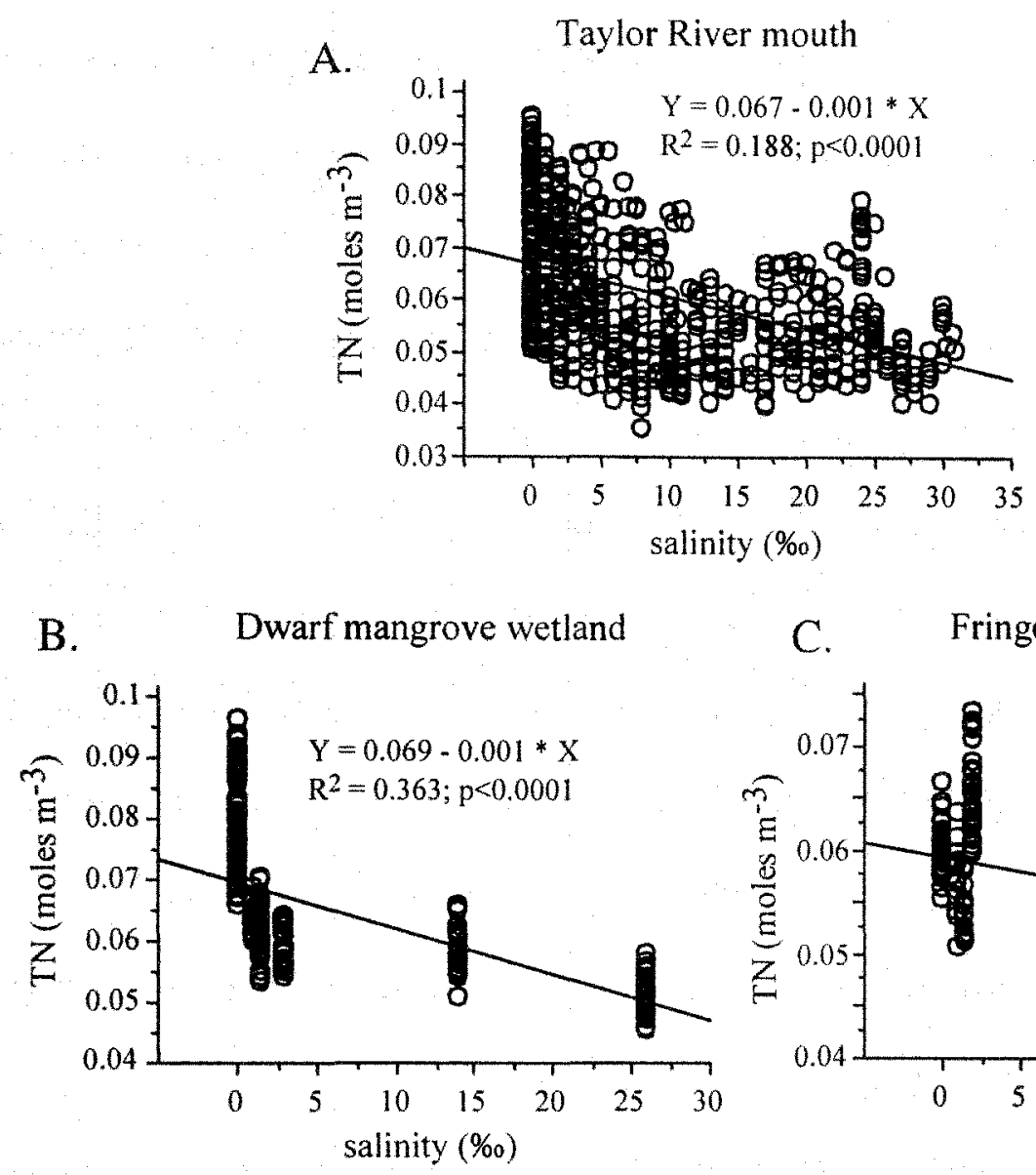

C. Fringe mangrove wetland

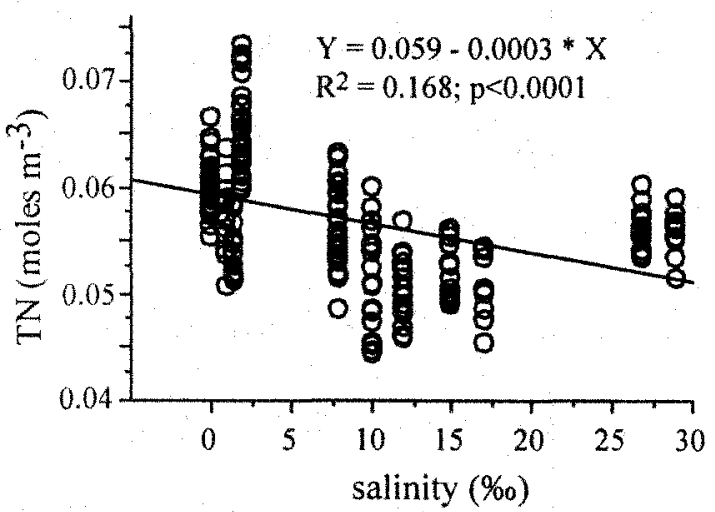

Figure 6.3- Relationships between salinity and total nitrogen concentrations at the mouth of Taylor River (A), in the dwarf wetland (B), and in the fringe wetland (C). 
concept was further supported by the presence of similar relationships within each subsystem (Figure $6.3 \mathrm{~b}$ and $\mathrm{c}$ ). Next, total nitrogen fluxes in the dwarf and fringe wetlands appeared to show opposite relationships with respect to ambient TN concentrations in the surface water, indicating a possible difference in the way these two subsystems cycle nitrogen (Figure 6.4). The use of a dynamic budget would show how TN exchange in one subsystem might affect TN exchange in another. Finally, nitrogen is an ecologically important macro-nutrient that often limits primary production (Boto and Wellington 1983; Smith 1984; Howarth 1988). An understanding of the subsystem exchange of TN within the STZ of Taylor Slough may provide vital insight into the seasonal exchanges of TN between the nutrient poor Everglades and Florida Bay.

The dynamic TN budget was constructed according to the conceptual model in Figure 6.1 using STELLA Research v. 4.02 modeling software for the Power Macintosh (High Performance Systems, Inc.). The model was designed to simulate 365 days (1 year) with a 1-day time step using Euler's integration method. Total nitrogen was tracked in units of moles and concentrations were kept in moles $\mathrm{m}^{-3}$. Figure 6.5 provides a graphical display of the base model's structure showing the flows between stocks as well as the numerous factors used to convert units and to regulate the flows of water and nitrogen. A description of each of these model components as well as initial values, equations, or relationships used is given in Table 6.2.

Julian day (time) was used as both a counter and an engine to drive the flux of water into and out of the southern end of the system according to the 1997 data (Figure 6.5). Assuming that the flux of water out of the system was equivalent to the flux of water into the system, I also used water flux to drive the input of water into the 


\section{Dwarf mangrove wetland}

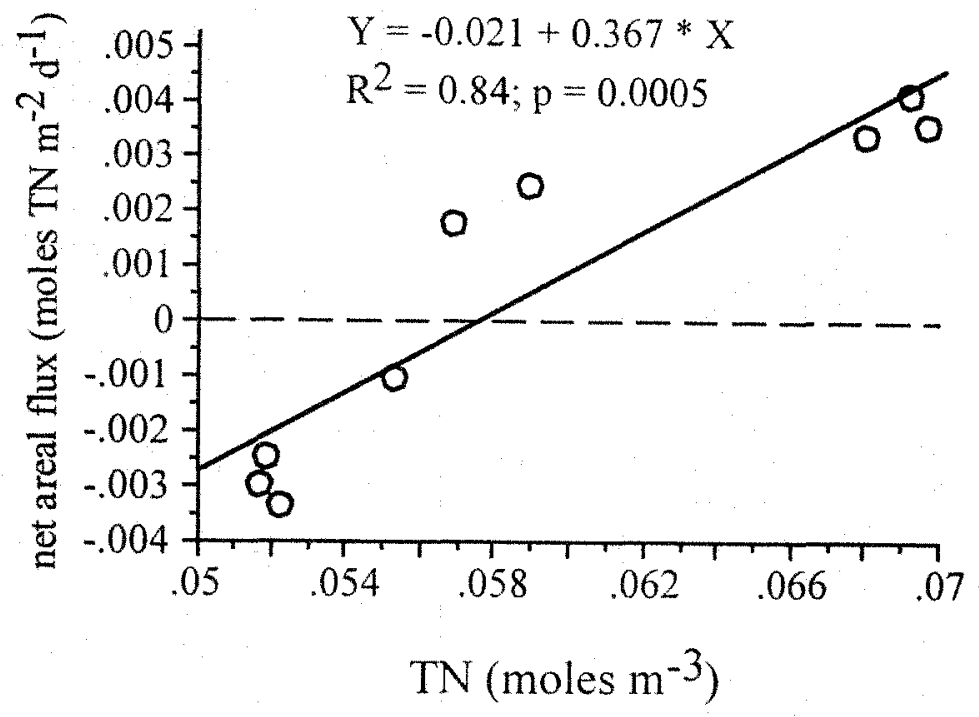

Fringe mangrove wetland

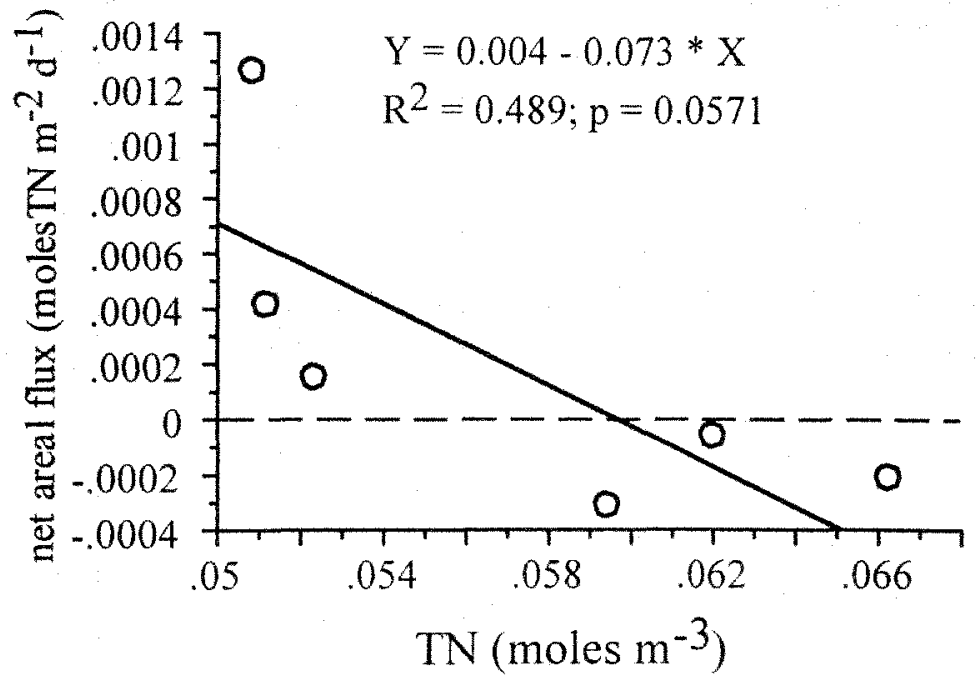

Figure 6.4- Relationships between total nitrogen concentrations and net areal fluxes of total nitrogen in each subsystem. 

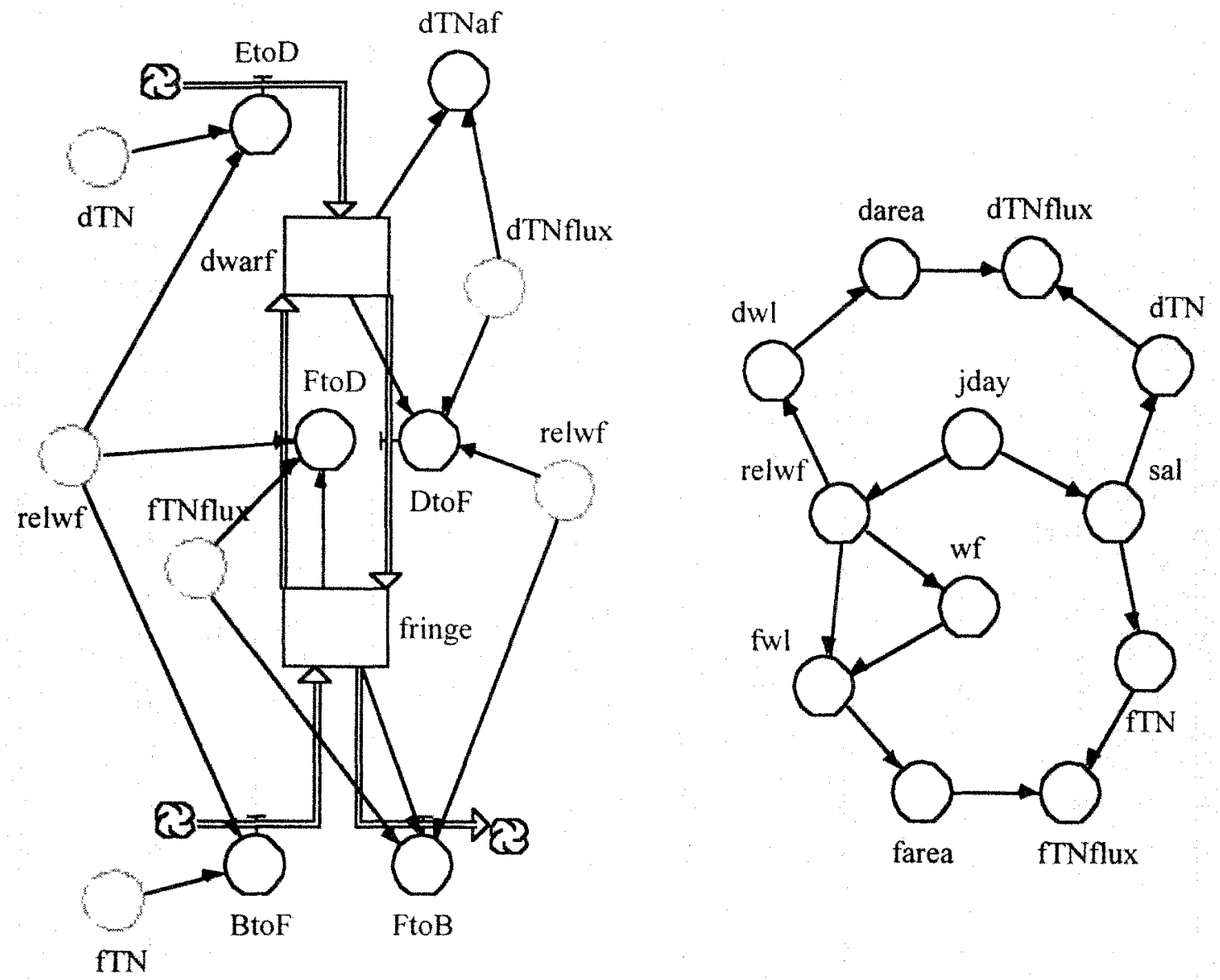

Figure 6.5- Illustration of dynamic budget model in STELLA symbols. Rectangles indicate subsystems, hollow arrows represent flows, and circles are used to convert units and drive flows. 
Table 6.2- List of model components, descriptions, units, and initial values or equations for Taylor River TN dynamic budget.

\begin{tabular}{|c|c|c|c|}
\hline components & description & units & value or equation \\
\hline $\begin{array}{l}\text { Stocks } \\
\text { dwarf }\end{array}$ & mass of TN in surface water & moles & initial value $=0$ \\
\hline fringe & $\begin{array}{l}\text { of dwarf mangrove wetland } \\
\text { mass of TN in surface water } \\
\text { of fringe mangrove wetland }\end{array}$ & moles & initial value $=0$ \\
\hline \multicolumn{4}{|l|}{ Flows } \\
\hline EtoD & $\begin{array}{c}\text { flow of } \mathrm{TN} \text { from freshwater } \\
\text { Everglades to dwarf } \\
\text { mangrove }\end{array}$ & moles d-1 & IF $($ relwf $>0) T H E N\left(w f^{*}\right.$ dTN $) \operatorname{ELSE}(0)$ \\
\hline DtoF & $\begin{array}{l}\text { flow of TN from dwarf } \\
\text { mangrove to fringe } \\
\text { mangrove }\end{array}$ & moles d-1 & IF $($ relwf $>0)$ THEN (dwarf-dTNflux) ELSE $(0)$ \\
\hline FtoB & $\begin{array}{l}\text { flow of TN from fringe } \\
\text { mangrove to Florida Bay }\end{array}$ & moles d-1 & IF (relwf $>0)$ THEN(fringe-fTNflux)ELSE $(0)$ \\
\hline BtoF & $\begin{array}{l}\text { flow of TN from Florida } \\
\text { Bay to fringe mangrove }\end{array}$ & moles d-1 & $\operatorname{IF}($ relwf $<0)$ THEN $\left(-1 * w f^{*}\right.$ fTN $) \operatorname{ELSE}(0)$ \\
\hline FtoD & $\begin{array}{l}\text { flow of TN from fringe } \\
\text { mangrove to dwarf } \\
\text { mangrove }\end{array}$ & moles d-1 & $\operatorname{IF}(w f<0) T H E N($ fringe-fTNflux $) \operatorname{ELSE}(0)$ \\
\hline \multicolumn{4}{|l|}{ Convertors } \\
\hline jday & Julian day & day & 1 to 365 \\
\hline sal & surface water salinity & $\%$ & actual values from 1997 -- Fig. 6.2 \\
\hline relwf & $\begin{array}{l}\text { relative flux of water from } \\
\text { one component to another }\end{array}$ & $\%$ & $\begin{array}{l}\text { actual values representing the percentage of } \\
\text { maximum water flux into (negative) and out } \\
\text { of (positive)Taylor River each day (1997) }\end{array}$ \\
\hline
\end{tabular}


Table 6.2- continued from previous page

\begin{tabular}{|c|c|c|c|}
\hline components & description & units & value or equation \\
\hline$\overline{w f}$ & $\begin{array}{l}\text { flux of water from one } \\
\text { component to another }\end{array}$ & $\mathrm{m} 3 \mathrm{~d}-1$ & $\begin{array}{c}\text { actual water fluxes into (negative) and out of } \\
\text { (positive) Taylor River during } 1997 \text {-- } \\
\text { Fig. } 6.2\end{array}$ \\
\hline dwl & $\begin{array}{l}\text { mean water level in dwarf } \\
\text { mangrove wetland }\end{array}$ & $\mathrm{m}$ & $\begin{array}{l}\text { estimated from min. (0) and max. }(0.2) \text { water } \\
\text { levels measured in dwarf mangrove wetland } \\
\text { from 1996-1998 related to water flux }\end{array}$ \\
\hline fwl & $\begin{array}{l}\text { mean water level in fringe } \\
\text { mangrove wetland }\end{array}$ & $\mathrm{m}$ & $\begin{array}{l}\text { IF }(\text { relwf }>0) \text { THEN }\left(0.874-\left(5.599 \mathrm{E}-7^{*} \text { wf }\right)\right) \\
\text { ELSE }\left(0.762+\left(1.075 E-6^{*} \text { wf }\right)\right)-- \text { Fig. } 6.6\end{array}$ \\
\hline dTN & $\begin{array}{l}\text { concentration of TN in } \\
\text { surface water of dwarf } \\
\text { mangrove wetland }\end{array}$ & moles $\mathrm{m}-3$ & $0.069-0.0007 * X$-- Fig. 6.3 \\
\hline fTN & $\begin{array}{l}\text { concentration of TN in } \\
\text { surface water of fringe } \\
\text { mangrove wetland }\end{array}$ & moles $\mathrm{m}-3$ & $0.059-0.0003 * X$-- Fig. 6.3 \\
\hline darea & $\begin{array}{l}\text { area of dwarf mangrove } \\
\text { wetland inundated }\end{array}$ & $\mathrm{m} 2$ & $\begin{array}{c}\text { max. darea estimated from max. dwl divided } \\
\text { by max. wf }\end{array}$ \\
\hline farea & $\begin{array}{l}\text { area of fringe mangrove } \\
\text { wetland inundated }\end{array}$ & $\mathrm{m} 2$ & $\begin{array}{l}\text { length of fringe zone estimated to be } 1000 \mathrm{~m} \text {. } \\
\text { Avg. width of fringe area inundated ranges } \\
\text { from } 3 \text { to } 6 \mathrm{~m}\end{array}$ \\
\hline dTNflux & $\begin{array}{l}\text { net areal flux of } \mathrm{TN} \text { in } \\
\text { dwarf mangrove wetland }\end{array}$ & $\begin{array}{l}\text { moles } \mathrm{m}-2 \\
\quad \mathrm{~d}-1\end{array}$ & $-0.021+0.367^{*} X-$ Fig. 6.4 \\
\hline fTNflux & $\begin{array}{l}\text { net areal flux of } \mathrm{TN} \text { in } \\
\text { dwarf mangrove wetland }\end{array}$ & $\begin{array}{l}\text { moles m-2 } \\
\quad \mathrm{d}-1\end{array}$ & $0.004-0.074 * X$-- Fig. 4 \\
\hline dTNaf & change in dwarf TN & moles & dwarf-dTNflux \\
\hline
\end{tabular}


Everglades end of the model during periods of southerly flow (Figure 6.5). A systemwide salinity regulated TN concentrations in the different subsystems according to the observed subsystem-specific relationships (Figure 6.3; Table 6.2). Water level in each subsystem, a function of water flux, determined the area of wetland inundated. These area values were then used to extrapolate area-specific mangrove fluxes to each subsystem. The fluxes of TN in either subsystem were also a function of surface water TN concentrations (Figure 6.4; Table 6.2).

Maximum $(0.2 \mathrm{~m})$ and minimum $(0 \mathrm{~m})$ water level values in the dwarf subsystem were taken from previous work in this wetland (Chapters 2 and 3). High water levels in the dwarf wetland typically corresponded with high freshwater flow events, while low water levels were usually measured during the dry season when flow freshwater flow was non-existent (personal observation). I discovered a different trend for the fringe wetland, in which water levels were generally lower when freshwater (southerly) flow was highest (Figure 6.6). However, when flow shifted directions, a frequent dry season phenomenon (Figure 6.2), water levels increased along with the flux of water (Figure 6.6).

The area of wetland inundated, a function of water level, was estimated for each subsystem from empirical data and anecdotal evidence. For the dwarf mangrove, an estimate of the total land area inundated for one day was first made by dividing the maximum daily flux of water $\left(480,732 \mathrm{~m}^{3} \mathrm{~d}^{-1}\right)$ by the maximum water level measured $(0.2 \mathrm{~m})$. This value was considered the potential area of land that could affect the TN content of the surface water exchanged between subsystems on a given day. However, a substantial percent of this wetlandscape is open water (ponds or channels) and the subsystem fluxes used in this budget were mangrove-specific (Figure 6.1). Therefore, I 


\section{Southerly flow}

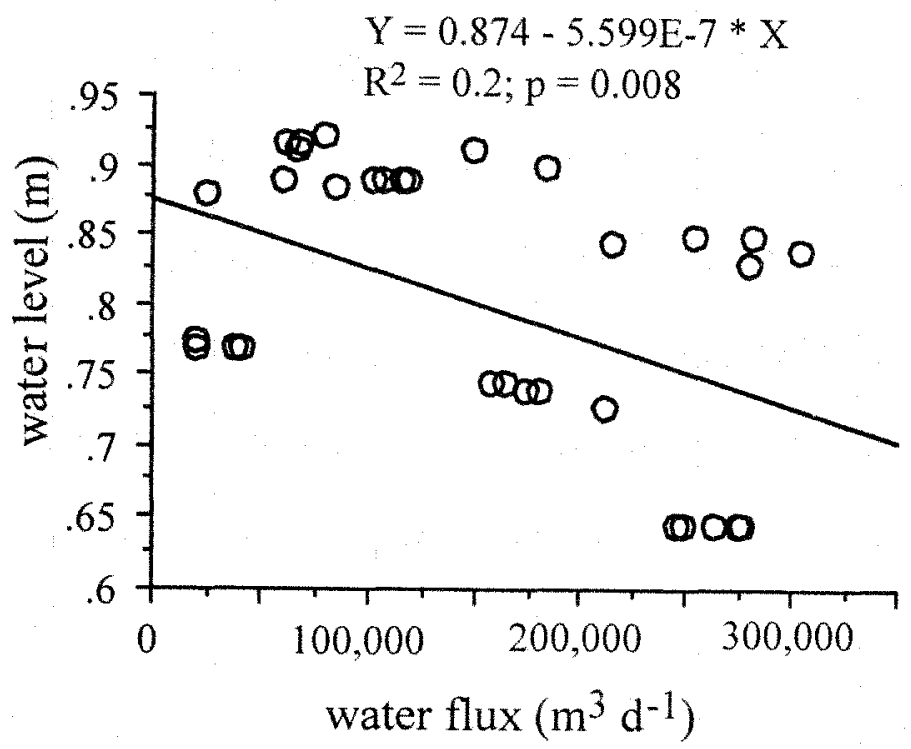

Northerly flow

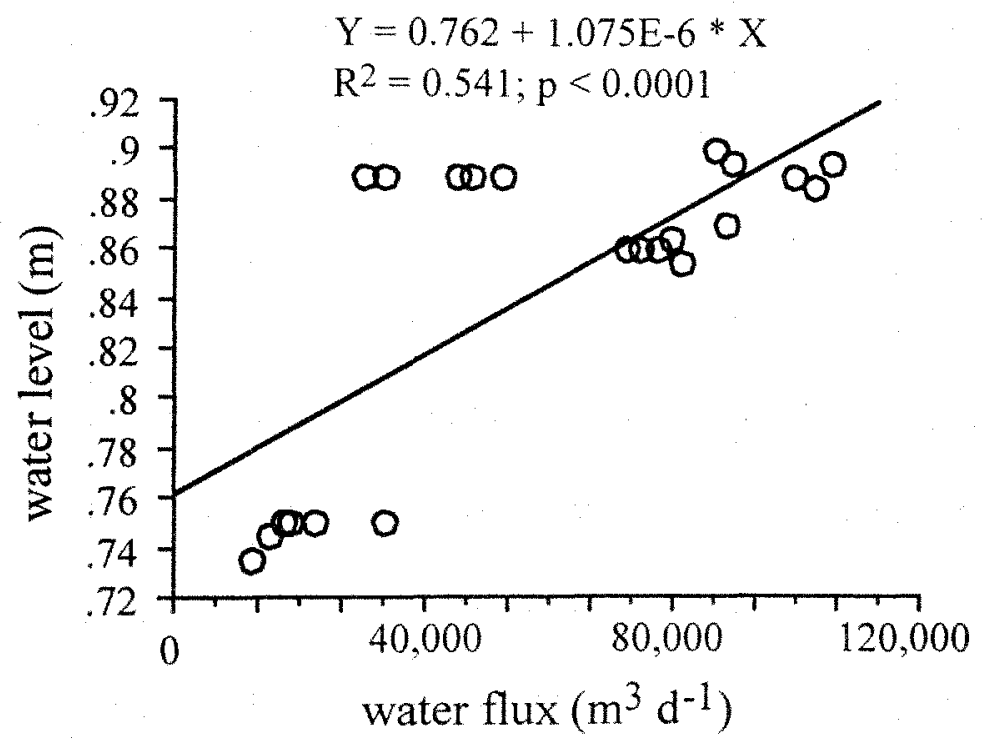

Figure 6.6- Relationships between water flux and water level in the fringe subsystem during southerly flow and northerly flow events. 
divided this potential area in half to get a conservative estimate of the maximum area of dwarf wetland that could treat one day's worth of surface water TN. The minimum value, when water level was zero, was set at $5 \%$ of the maximum in order to maintain model stability and to account for possible mangrove-independent exchanges of TN. Considering the topography of south Florida, I expected that small increases $(0.02-$ $0.05 \mathrm{~m}$ ) in water level above zero would inundate much of the dwarf wetland. Therefore, I used a graph function to calculate the area of dwarf wetland inundated, whereby area of wetland inundated increased rapidly with water level then gradually approached the maximum (Figure 6.7a).

A different approach was taken to estimate area of fringe mangrove inundated. This subsystem occupies both banks of the lower stretch of Taylor River and is characterized by numerous prop roots extending into the channel. The banks along this channel are relatively high and steep. Consequently, I expected increases or decreases in water level to have a minimal effect on wetland area. The range of water level measured in the fringe wetland was $0.66-0.94 \mathrm{~m}$ (Figure 6.6), and the width of the submerged mangrove zone one either side of the channel was estimated from past survey data to be between 3 and $6 \mathrm{~m}$ (S. Davis unpublished data). Finally, I estimated the length of this lower stretch to be $1000 \mathrm{~m}$. This produced a potential range of fringe area inundated from $6,000-12,000 \mathrm{~m}^{2}$. I entered the relationship between fringe water level and fringe area into STELLA as a positive linear function as shown in Figure 6.7b.

Finally, the flux of water at the mouth of Taylor River determined the direction and magnitude of water flux into and out of each subsystem. If there was a net southerly flux of water at the interface of the fringe mangrove and Florida Bay, then there was also 
A.

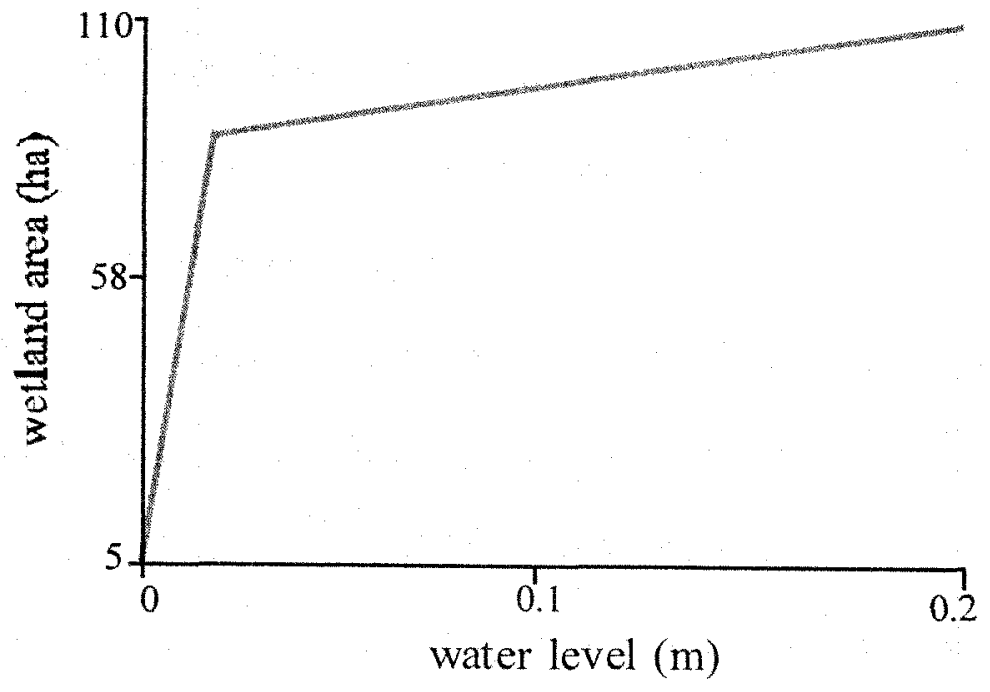

B.

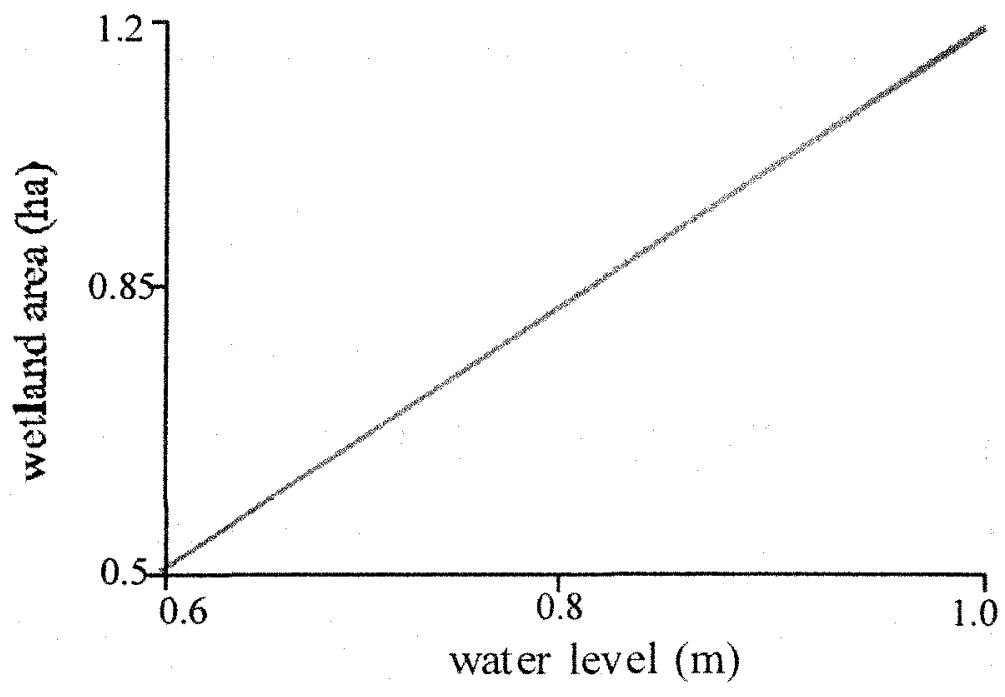

Figure 6.7- Hypothesized relationships between water level and area of wetland inundated in the dwarf (A.) and fringe (B.) subsystems. 
a southerly water flux, of equivalent magnitude, between all other components, and vice versa. Southerly flow originated from the freshwater Everglades marshes and ended in Florida Bay. Northerly flow, on the other hand, originated from Florida Bay but ended in the dwarf mangrove subsystem, as this was considered to be the northernmost point of baywater intrusion (Figures 6.1 and 6.5).

After the base model was completed and validated with data other than those used for calibration (Table 6.1), four simulations were run to predict the effects of a variable hydrologic regime on the exchange of TN between the STZ of Taylor Slough and Florida Bay (Table 6.3). In order to simulate the relative effects of past freshwater diversions, freshwater flow was first reduced by $10 \%$ then again by $40 \%$ throughout the entire wet season. Equivalent increases in freshwater flow during the dry season were made to predict the outcome of increased freshwater delivery on TN exchange (Table 6.3).

\section{Results}

Normal run - 1997 conditions

The daily water flux and salinity data used to drive the budget were considered typical for this system (Figure 6.2). Water flux was minimal and shifted frequently at the beginning of the year. In response to this, salinity gradually increased to a maximum of about $31 \%$ by Julian day 128 (Figure 6.2 ). By about Julian day 150 , salinity began to decrease at the mouth. By the time salinity reached $0 \%$, the flux of water out of the mouth of Taylor had reached its maximum discharge for the year $\left(480,732 \mathrm{~m}^{3} \mathrm{~d}^{-1}\right.$; Figure 6.2). This was followed by an extended period of freshwater conditions and a gradually decreasing out flux of water (Figure 6.2). The latter half of the wet season was also 
A.

Dwarf mangrove

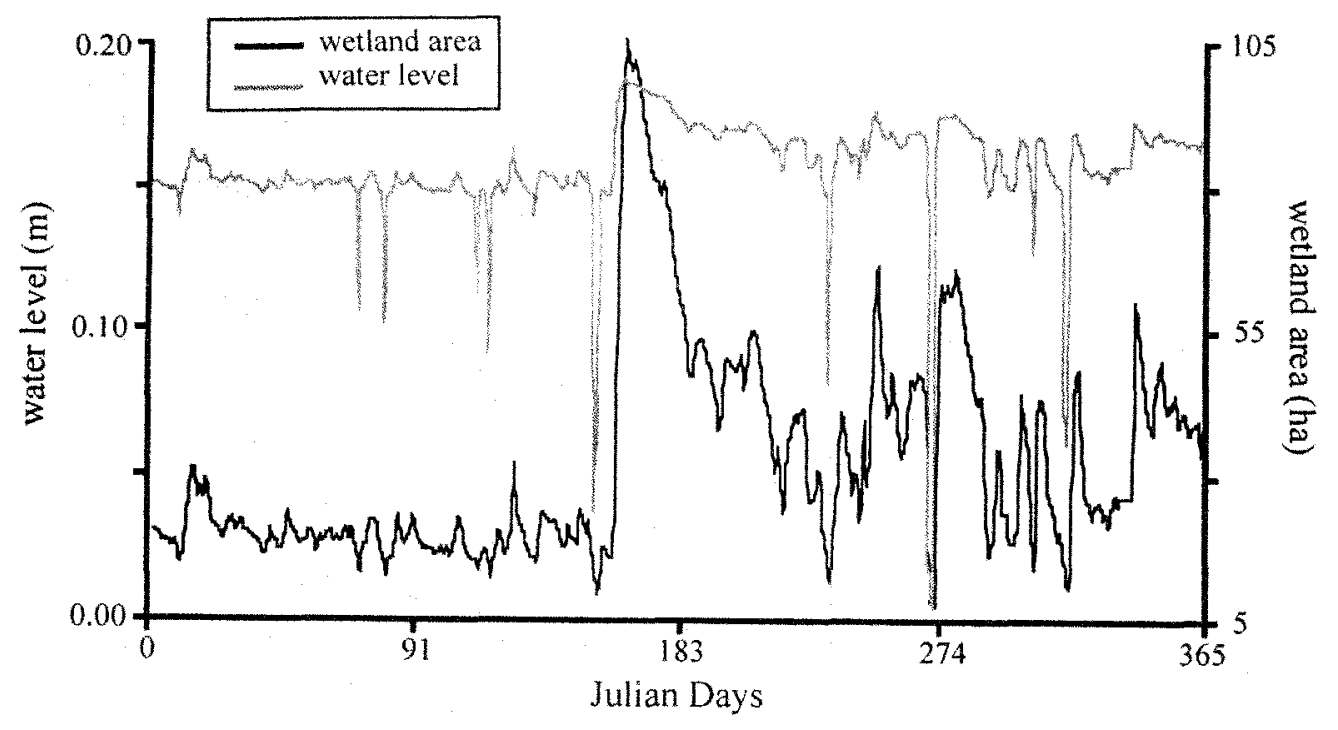

B.

Fringe mangrove

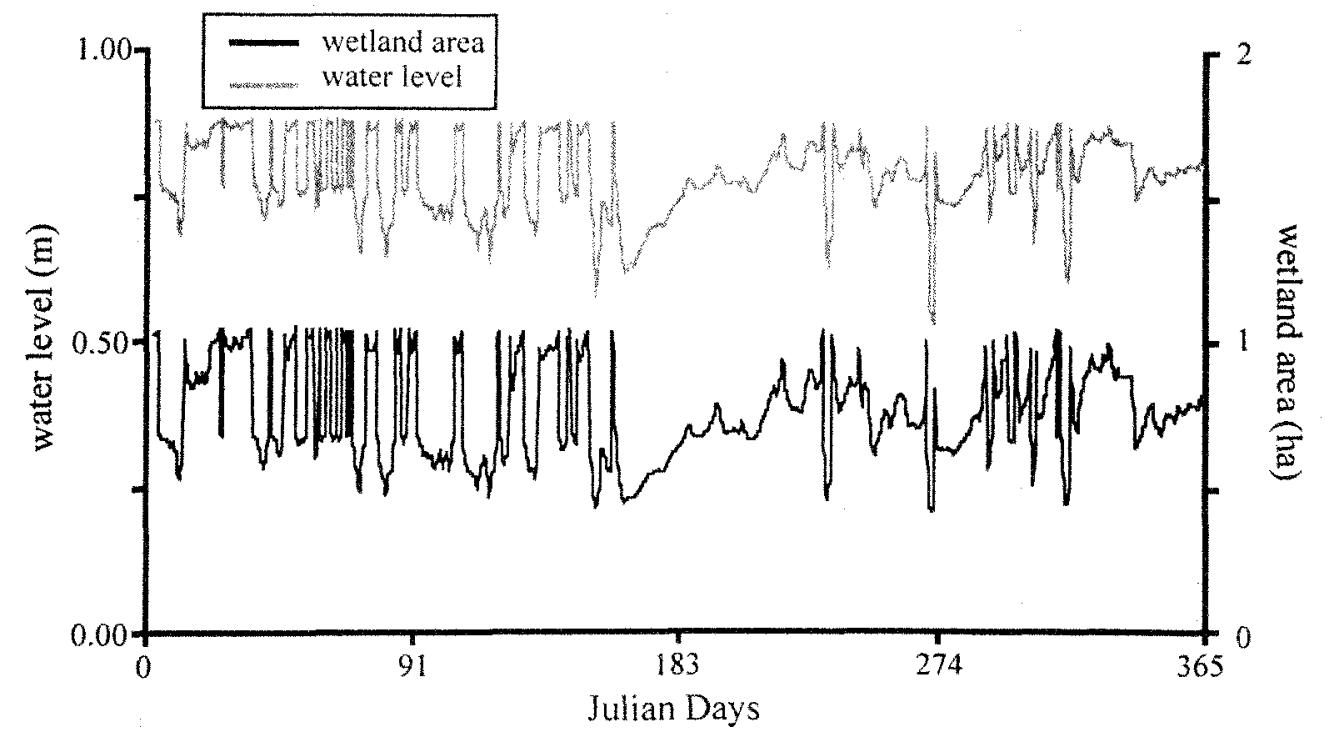

Figure 6.8- Time series plots of water level and wetland area in each mangrove subsystem. A two-step function was used to calculate dwarf wetland area, whereas a linear relationship was used for the fringe wetland. 
Table 6.3- List of different scenarios employed to determine the effect on TN exchange between subsystems in Taylor Slough.

\begin{tabular}{ccc} 
exercise \# & scenario & relative change \\
\hline 1 & $\begin{array}{c}\text { decreased freshwater flow } \\
\text { during wet season } \\
\text { decreased freshwater flow } \\
\text { during wet season }\end{array}$ & $10 \%$ increase \\
2 & $\begin{array}{c}40 \% \text { increase } \\
\text { increased freshwater flow } \\
\text { during dry season } \\
\text { increased freshwater flow } \\
\text { during dry season }\end{array}$ & $10 \%$ increase \\
4 & $40 \%$ increase \\
\hline
\end{tabular}


characterized by periodic, large shifts in water flux, probably in response to strong winds associated with frontal passages (Figure 6.2).

Water level in the dwarf subsystem was low, between 2 and $5 \mathrm{~cm}$, for much of the first five months of the simulation (Figure 6.8a). The area of dwarf wetland inundated during this same period of time fluctuated around 80ha, except for a few dry-down events when the water levels dropped below $2 \mathrm{~cm}$ (Figure $6.8 \mathrm{a}$ ). When the dry season gave way to the wet season, dwarf water levels increased dramatically, but did not have a substantial affect on wetland area, as much of the wetland was already flooded (Figure 6.8a). During the dry season, the fringe wetland experienced daily oscillations in water level that were directly reflected in the area of wetland inundated (Figure 6.8a). These oscillations were much less frequent in the early wet season because hydrologic conditions were more stable during this period of time (Figures 6.2 and 6.8b).

Total nitrogen concentrations in each subsystem approximated the actual range of concentrations at the mouth of Taylor River (Figure 6.9). However, given that salinity was the only variable used to predict TN concentrations, much of the variability was left unaccounted for. Concentrations in the dwarf zone often exceeded fringe concentrations, sometimes by as much as $10 \mu \mathrm{M}$ (Figure 6.9). Nevertheless, fringe TN concentrations remained consistently higher than those in the dwarf for the entire latter half of the dry season did (Figure 6.9). Since these two subsystems displayed opposite patterns in net areal flux with respect to total nitrogen concentration (Figure 6.4), the daily areal and total fluxes of TN within each subsystem were mirror images of one another, although on much different scales (Figure 6.10). For the most part, the dwarf wetland exported TN 


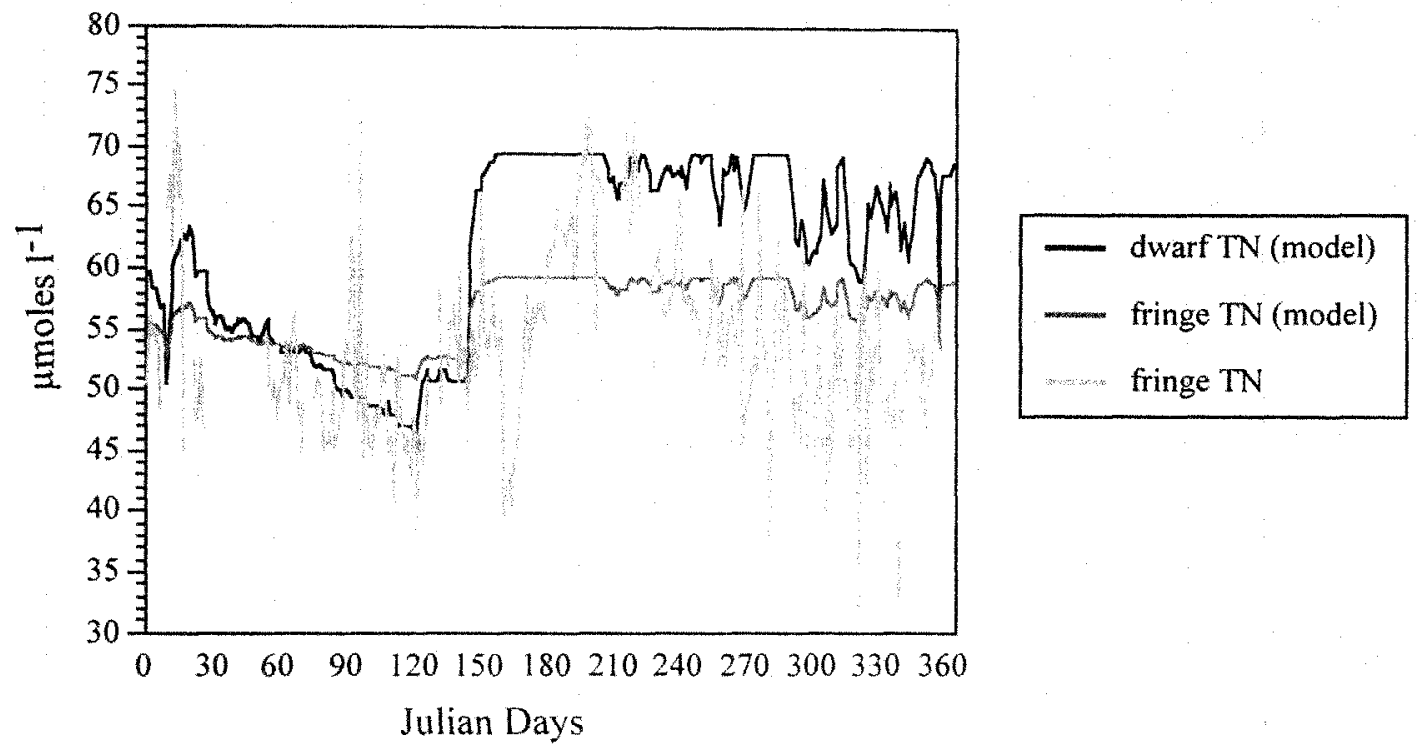

Figure 6.9- Time-series plots of daily total nitrogen concentrations in the modeled subsystems and at the mouth of Taylor River during 1997. 
Net Areal Flux

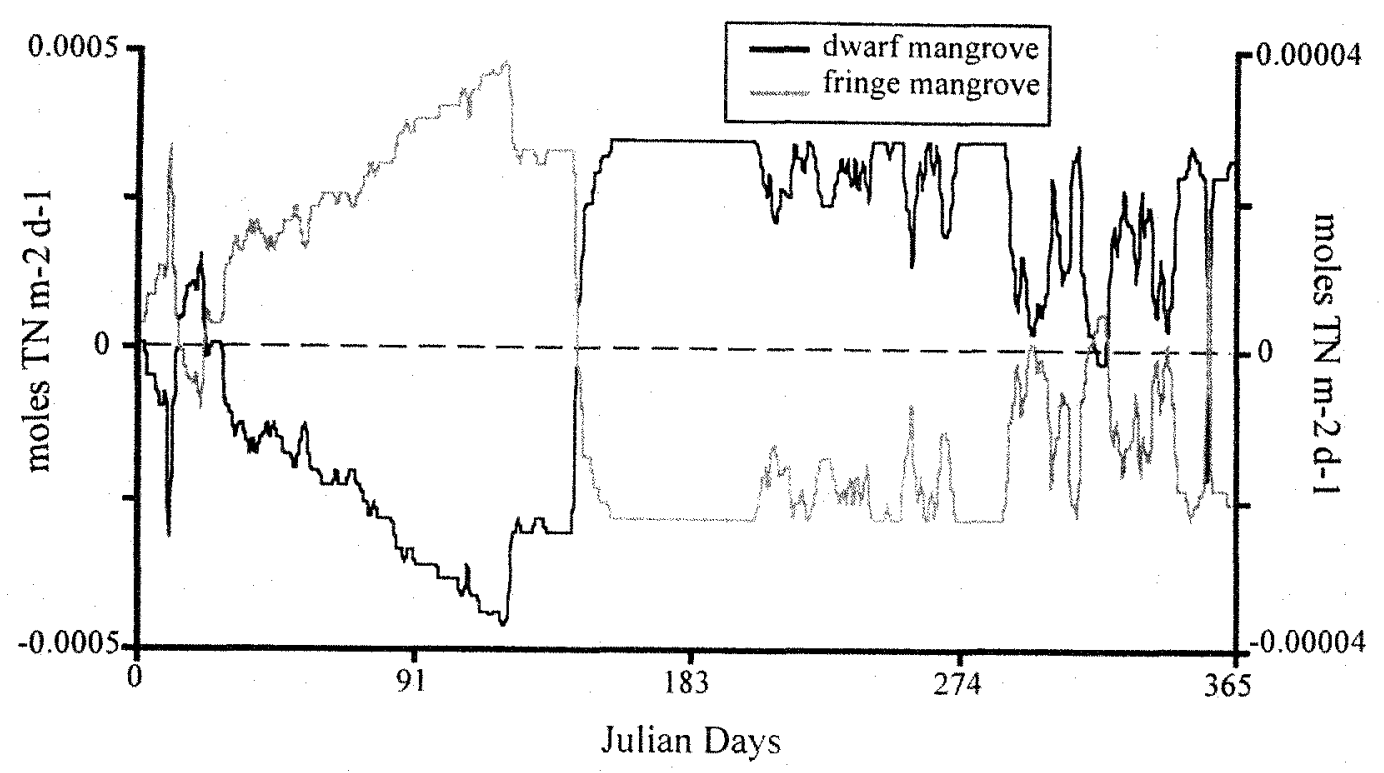

Net Areal Flux

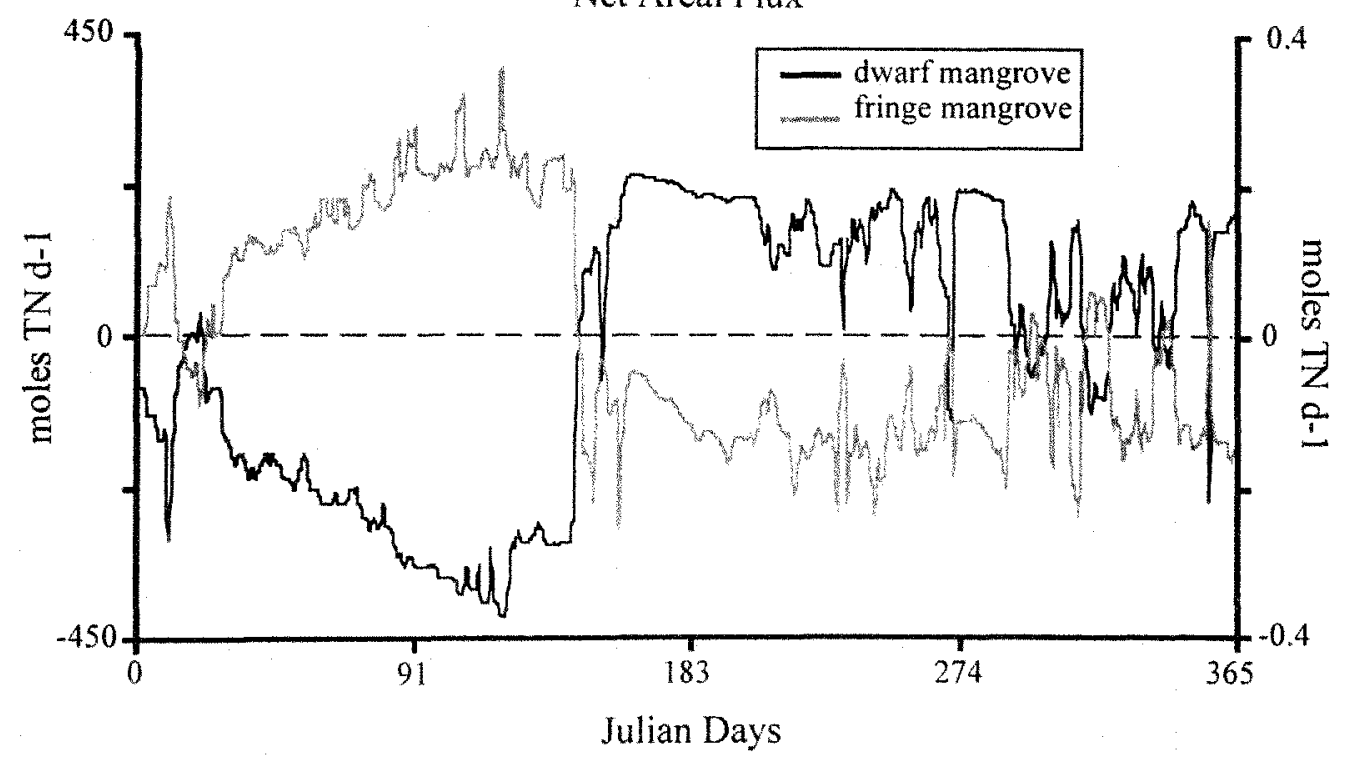

Figure 6.10- Time-series plots of daily net areal fluxes and total daily fluxes of TN in each subsystem. The opposing patterns are a result of the different relationships between $\mathrm{TN}$ concentration and net areal flux for each subsystem. 
into the water column during the dry season and imported it during the wet season. The opposite was true for the fringe subsystem (Figure 6.10).

\section{Model Validation}

In addition to verifying the ability of the model to predict 1997 total nitrogen concentrations (Figure 6.9), I compared the dynamic budget's monthly exchange of TN at the STZ-Florida Bay interface with actual 1997 exchange data (Table 6.4). These values were computed by mutliplying daily (1997) TN concentrations from the autosampler dataset by water fluxes from the USGS gauge (the same water fluxes used to calibrate the budget) and summing over each month (Table 6.1 ). The dynamic budget simulated the exchanges of TN at this interface with a fair degree of accuracy, as the two datasets produced fluxes that were of the similar direction and magnitude in most months (Table 6.4). Furthermore, the months showing the largest disparity between these two were likely a result of data missing from the 1997 dataset (e.g. February, May, July, and December; Table 6.4). An overall flux, calculated for each, revealed a much larger annual export of TN for the model output than the 1997 dataset (Table 6.4). Again, much of this may have been attributed to the fact that 71 days were missing from the 1997 dataset (Table 6.4).

A further step in the validation process was to validate total monthly fluxes of TN at the STZ-Florida Bay interface with total monthly fluxes from years other than 1997 (i.e. 1996 and 1998). Aside from 1997, there existed four months with sufficient data to do a comparison of this sort - January, February, and April 1998, and May 1996. Direct, month-for-month comparisons revealed disproportionate TN exchange between the 
Table 6.4- Comparison of model TN flux at mouth of Taylor River with actual flux data from 1997. The number of days missing from 1997 dataset are noted next to each month. Negative flux values indicate a net export of TN to Florida Bay, whereas positive $\mathrm{v}$

\begin{tabular}{ccccc} 
month & $\begin{array}{c}\text { mean monthly } \\
\text { salinity }\end{array}$ & $\begin{array}{c}\text { model flux (moles } \\
\text { TN mo-1) }\end{array}$ & $\begin{array}{c}\text { actual flux (moles } \\
\text { TN mo-1) }\end{array}$ & $\begin{array}{c}\text { days } \\
\text { missing }\end{array}$ \\
\hline January & 14.1 & -50704.41 & -34406.36 & 9 \\
February & 19.5 & -4474.10 & 2362.16 & 22 \\
March & 23.4 & -14356.81 & 21154.22 & 3 \\
April & 28.5 & 43400.47 & 59280.54 & 0 \\
May & 20.2 & -65190.72 & -5308.46 & 8 \\
June & 0.1 & -512175.15 & -316405.92 & 3 \\
July & 0.8 & -428755.23 & -272793.51 & 9 \\
August & 2.1 & -208278.47 & -137109.15 & 4 \\
September & 1.9 & -267700.13 & -224102.04 & 0 \\
October & 4.4 & -308437.55 & -218822.40 & 0 \\
November & 7.3 & -122994.95 & -77560.42 & 0 \\
December & 4.8 & -281322.54 & -144640.89 & 13 \\
\hline \multirow{2}{*}{} & $\begin{array}{c}\text { annual flux of } \\
\text { total nitrogen } \\
\text { (kg TN) }\end{array}$ & $-3.11^{*} 10^{\wedge} 4$ & $-1.89^{*} 10^{\wedge} 4$ & 71 \\
& & & &
\end{tabular}

$(\mathrm{kg} \mathrm{TN})$ 
model's output and actual fluxes (Figure 6.11a). However, there was also a substantial difference in mean monthly salinity between these two datasets, suggesting that hydrologic conditions between modeled months and actual data were not analogous (Figure 6.11a). These discrepancies in salinity may have affected both the concentration and subsystem flux of total nitrogen (Figures 6.3 and 6.4), thereby resulting in a significant difference in the mass of TN exchanged between the STZ and Florida Bay. Therefore, in attempt to make the validation more relevant, I compared modeled fluxes of TN with mean salinities similar to the actual flux data (Figure $6.11 \mathrm{~b}$ ). These comparisons were much more favorable as the direction and magnitude of each were nearly identical (Figure 6.11b).

Semblance in mean monthly salinity was also an important factor in the comparison of modeled net areal flux in the dwarf subsystem with actual fluxes from 1996 and 1998. Month-for-month comparisons of these fluxes revealed the most agreement between August (model) and August 1996 and the least agreement between May (model) and May 1998 (Figure 6.12). Interestingly, these are also the same pairs that had the least and greatest amount of variance, with respect to mean monthly salinity (Figure 6.12).

\section{Budget Exercises}

Following model validation, I conducted four exercises to model the effects of a variable hydrologic regime on the exchange of total nitrogen between the STZ of Taylor Slough and Florida Bay. Simulating the outcome of past diversions of freshwater flow 


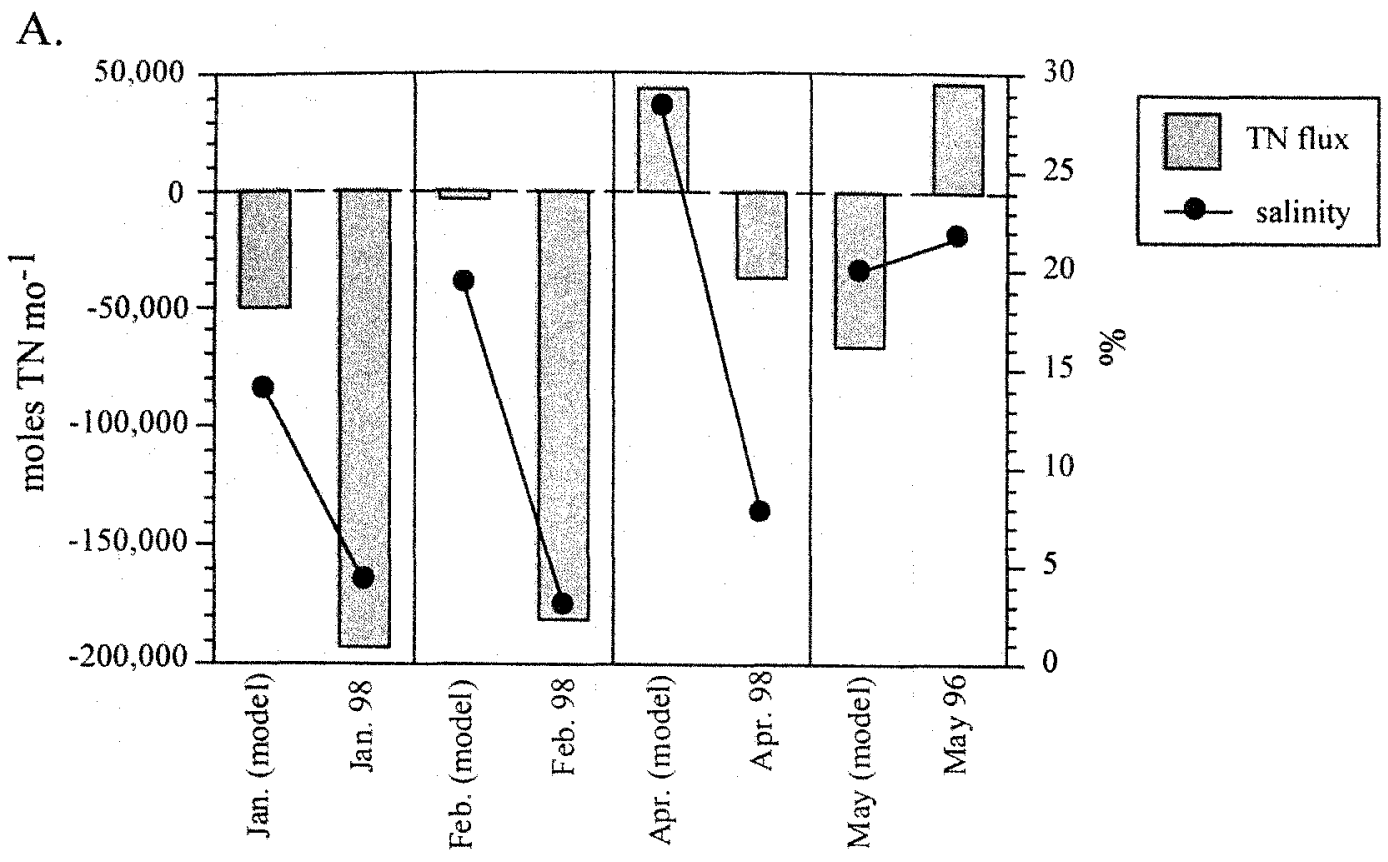

B.

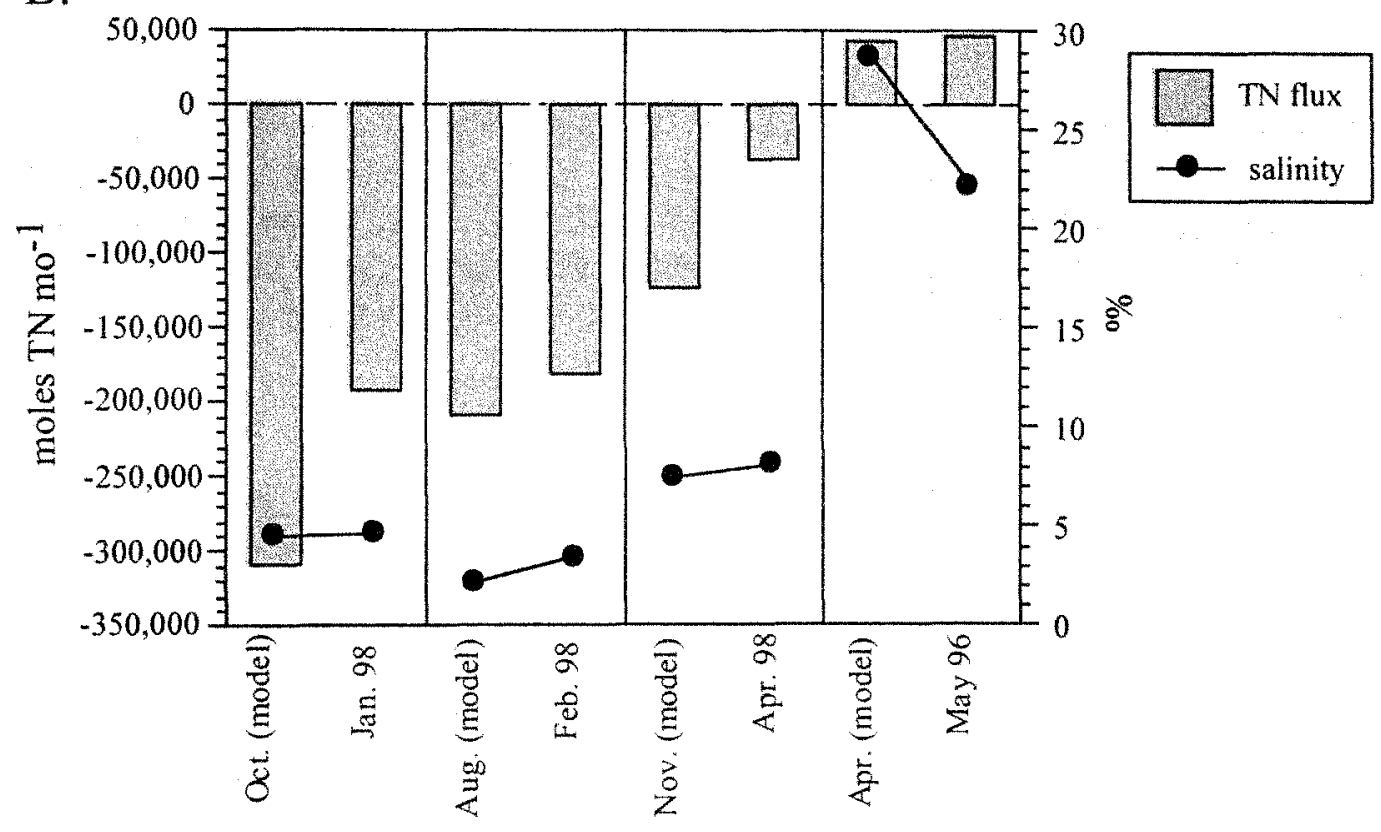

Figure 6.11- Bar charts comparing the total monthly flux of TN (gray bars) and mean salinity (black dots) at the mouth of Taylor River generated by the model with 1998 data. The top graph is a comparison of the same months, and the bottom graph is a comparison of different months with similar mean monthly salinity. 


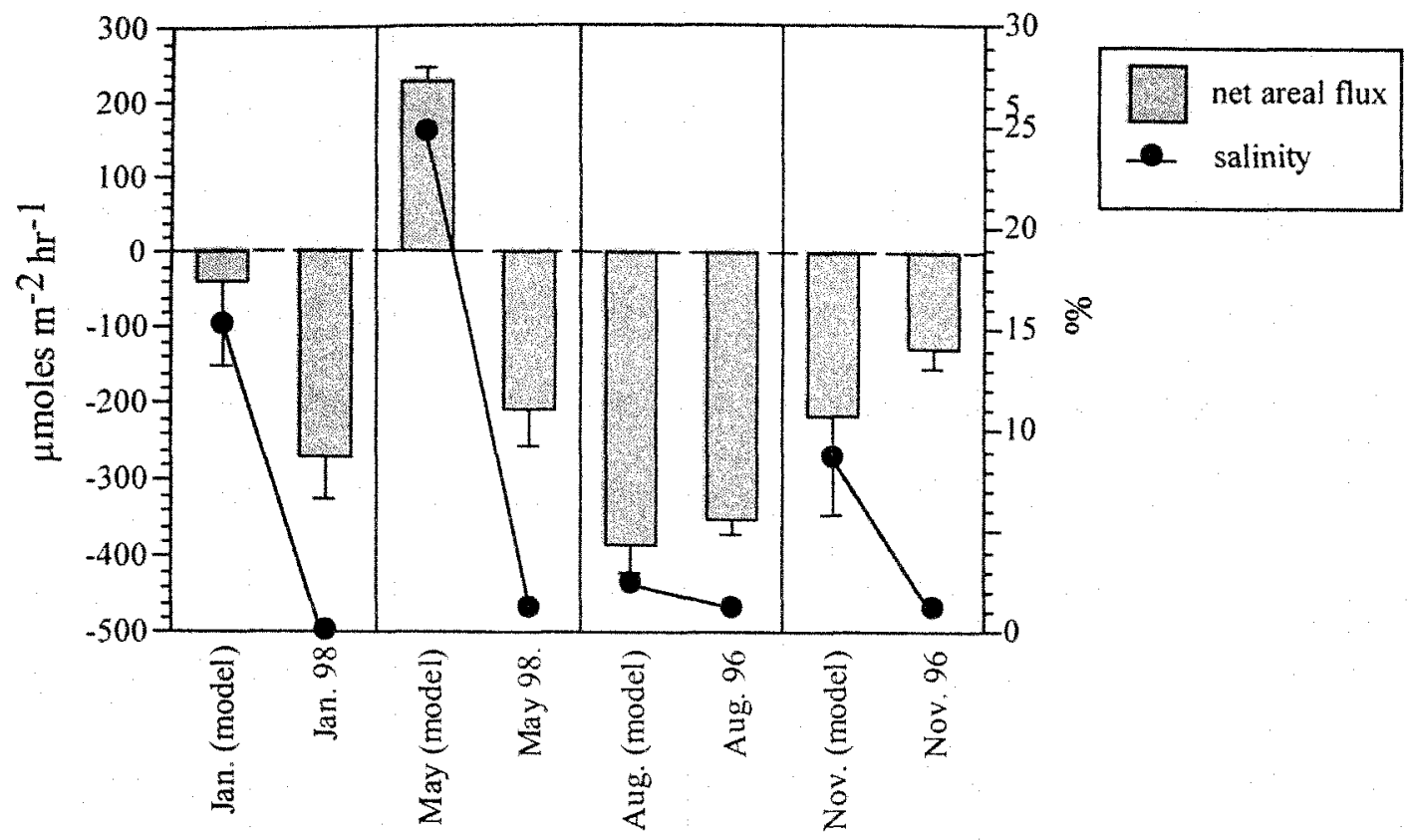

Figure 6.12- Bar chart comparing modeled net areal fluxes of TN (gray bars) and mean monthly salinity (black dots) of TN in the dwarf subsystem with dwarf TN fluxes and salinity measured in the field. Error bars for modeled fluxes represent standard deviations for days of the month, whereas error bars for actual fluxes represent standard errors of triplicate dwarf mangrove enclosures (Chapters 1 and 3). 
from the Taylor Slough basin, flow was reduced by $10 \%$ and $40 \%$ during the wet season (Table 6.3). These systematic reductions resulted in proportionate decreases in the amount of total nitrogen exported from the fringe to the bay because overall discharge was reduced (Figure 6.13a). Also, by decreasing wet season flow, salinity increased and total nitrogen decreased in both subsystems, resulting in reduced dwarf uptake and fringe export. Reduced wet season discharge had the opposite effect on imports from Florida Bay as shifts in the direction of water flux were more enhanced, leading to increased TN input (Figure 6.13b).

Finally, in attempt to model the effects of proposed hydrologic restoration on TN exchange at this same interface, I increased freshwater flow by $10 \%$ and $40 \%$ during the dry season (Table 6.3). Oddly enough, this had the same effect as reducing freshwater flow during the wet season (Figures 6.13a and 6.14a). Apparently, the increase in discharge boosted nitrogen concentrations and the area of dwarf wetland inundated thus substantially increasing total nitrogen uptake. The effect was similar for the imports from Florida Bay (Figure 6.14b). Increased discharge from the mouth of Taylor River prevented water from entering in from the bay. Therefore, total nitrogen input from the bay was proportionately reduced as freshwater flow increased in the dry season (Figure $6.14 b)$

\section{Discussion}

The dynamic budget presented here tracked the movement of total nitrogen within and between subsystems as well as the exchange between the salinity transition zone of 
A. Dry season flux of TN from fringe wetland to bay

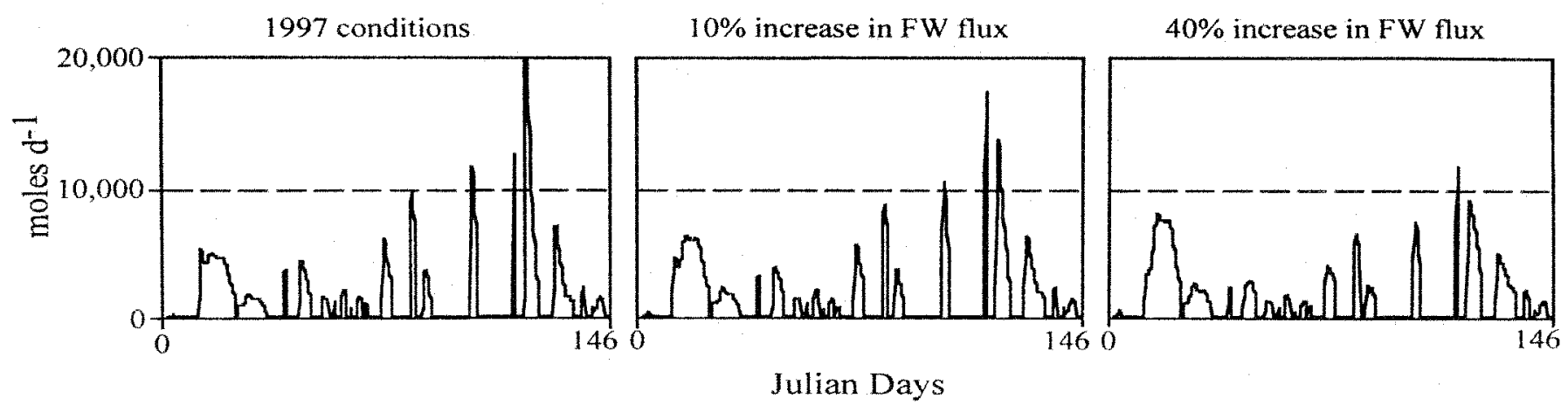

B. Dry season flux of TN from bay to fringe wetland

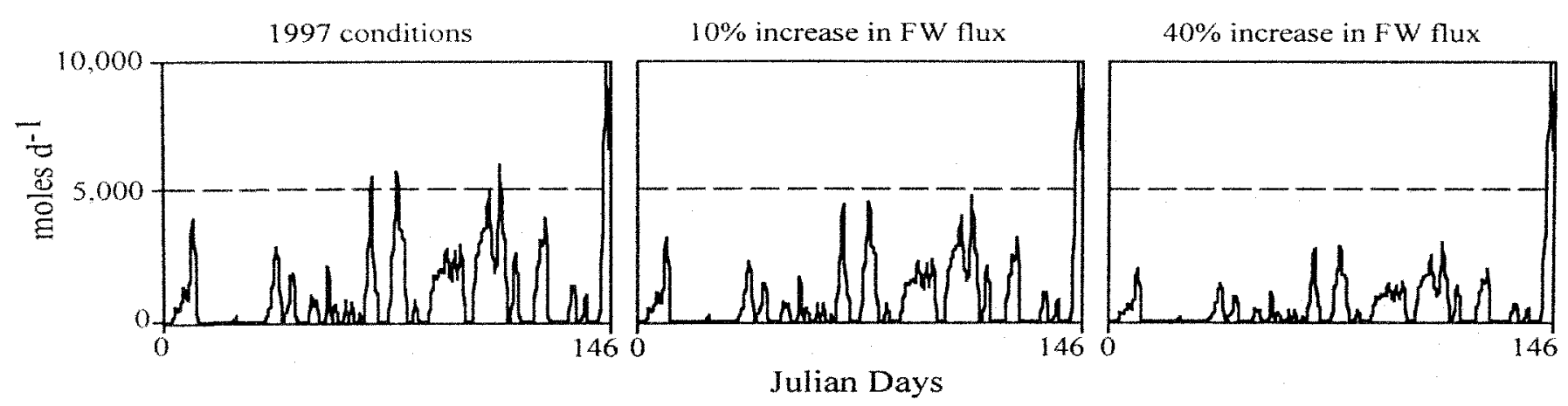

Figure 6.13- Time series plots showing the results of exercises \# 1 and 2. The top graphs represent the dry season flux of TN from the fringe wetland to Florida Bay during normal (1997) conditions (left graph), 10\% increased freshwater flow (middle graph), and $40 \%$ increased freshwater flow (right graph). The bottom graphs represent time series of TN flux from the bay to the fringe wetland during the dry season, with the bottom row reflecting the same model conditions as previously mentioned for the top row. 


\section{Wet season flux of TN from fringe wetland to bay}

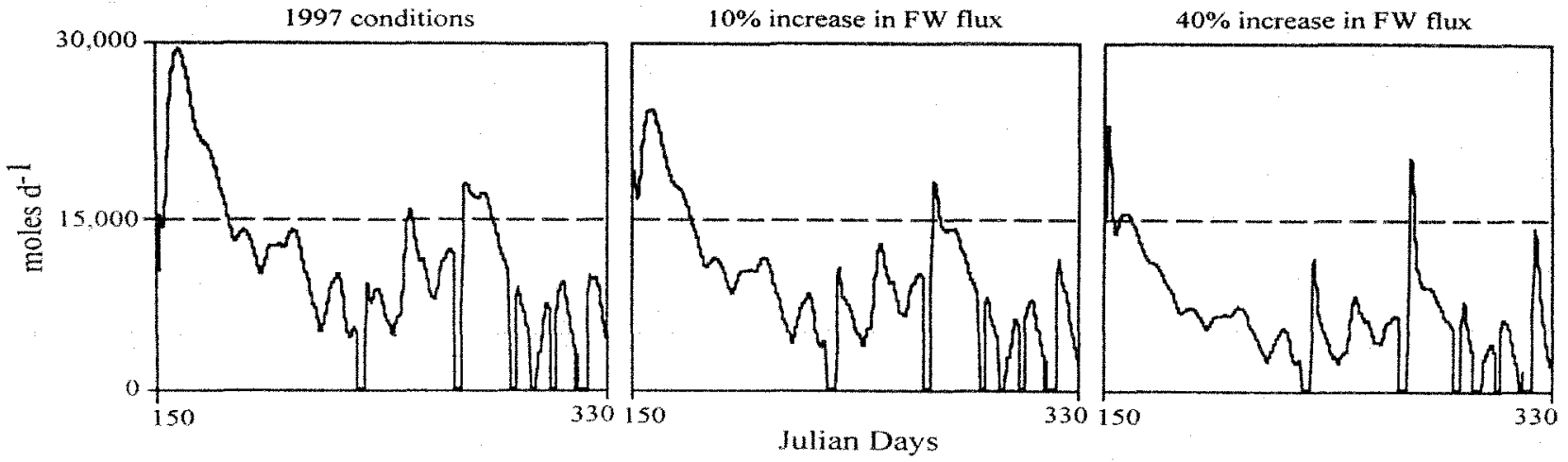

Wet season flux of TN from bay to fringe wetland

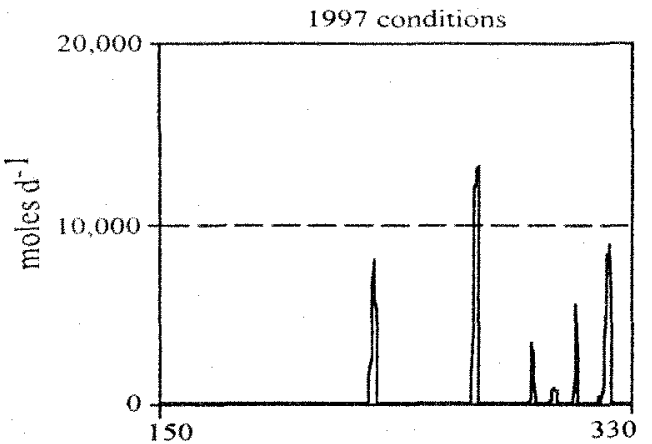

$10 \%$ increase in $\mathrm{FW}$ flux

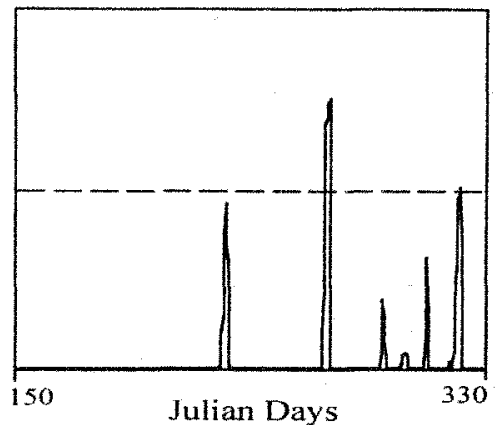

$40 \%$ increase in FW flux

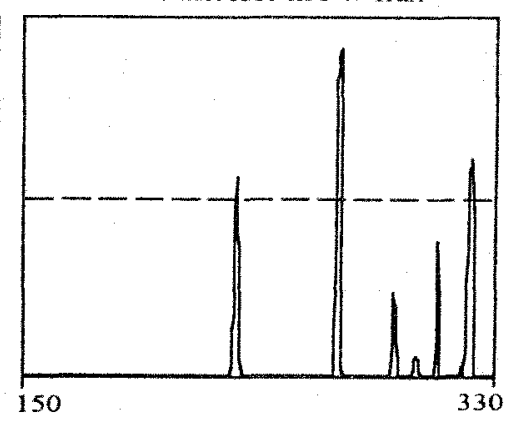

Figure 6.14- Time series plots showing the results of exercises \# 3 and 4. The top graphs represent the wet season flux of TN from the fringe wetland to Florida Bay during normal (1997) conditions (left graph), 10\% increased freshwater flow (middle graph), and $40 \%$ increased freshwater flow (right graph). The bottom graphs represent time series of $\mathrm{TN}$ flux from the bay to the fringe wetland during the wet season, with the bottom row reflecting the same model conditions as previously mentioned for the top row. 
Taylor Slough and Florida Bay. The model was run for 365 days to account for seasonal variability in hydrologic conditions (i.e. water flux and salinity), as they are believed to be major forcing functions in this ecosystem. Water flux, measured daily as discharge at the mouth of Taylor River in 1997, drove the model in terms of its control over wetland area and the lateral movement of total nitrogen. And, salinity determined total nitrogen concentrations and, thus, subsystem fluxes. Annual budgets of total nitrogen exchange between Taylor Slough and Florida Bay were calculated for the normal run (1997 conditions) and each of the four exercises. These budgets emphasized the importance of hydrologic conditions at both temporal (wet season and dry season) and spatial scales (subsystem and ecosystem level). The significance of hydrologic conditions was also evident in the validation process, as similarity in mean monthly salinity was an important consideration in comparing total monthly fluxes.

\section{Comparison with Other Flux Studies}

The Taylor Slough model generated an annual areal TN uptake of about $0.5 \mathrm{~g}$ TN $\mathrm{m}^{-2} \mathrm{y}^{-1}$ for the dwarf wetland and a net release of about $0.03 \mathrm{~g} \mathrm{~m}^{-2} \mathrm{y}^{-1}$ for the fringe wetland. Fluxes for each subsystem were ultimately a function of salinity, as salinity was used to predict concentration in the model. Other mangrove studies have shown a pattern of nitrogen dynamics similar to the dwarf mangrove. Rivera-Monroy et al. (1995) measured total nitrogen $\left(\mathrm{PN}+\mathrm{DON} \approx \mathrm{TN}\right.$ ) export on the order of $0.68 \mathrm{~g} \mathrm{~m}^{-2} \mathrm{y}^{-1}$ in a fringe forest at Laguna de Terminos. Interestingly, particulate nitrogen export from this Mexican mangrove forest was positively related to precipitation events (Rivera-Monroy et al. 1995). Much larger exports of DON were recorded in an Australian mangrove that 
receives no significant freshwater input. Boto and Wellington (1988), conducting a flux study in Coral Creek, measured an annual areal flux of $1.3 \mathrm{~g} \mathrm{DON} \mathrm{m}^{-2} \mathrm{y}^{-1}$. As a comparison of different systems, Wolaver et al. (1983) found an uptake of approximately $30 \mathrm{~g} \mathrm{TN} \mathrm{m}^{-2} \mathrm{y}^{-1}$ in an estuarine salt marsh system near Carter Creek, Virginia. This uptake was three orders of magnitude greater than that estimated for the fringe mangrove.

\section{Comparison with Other Nutrient Budgets}

According to this model, there was a large net annual export of total nitrogen from the salinity transition zone of Taylor Slough. Total nitrogen export was highest during the wet season months as a result of increased freshwater discharge (Table 6.4). Childers et al. (1993b) developed a similar dynamic budget for the North Inlet estuary and found approximately 3 times $\left(9.4^{*} 10^{4} \mathrm{~kg}\right)$ the annual export of total nitrogen from their system as I estimated for Taylor River $\left(3.11 * 10^{4} \mathrm{~kg}\right)$. The major differences between these two systems are that North Inlet is a tidal salt marsh system with little freshwater input and Taylor River is a non-tidal mangrove system fed by freshwater upland runoff for much of the year. Using a more comprehensive nutrient budget for the Chesapeake Bay estuary, Boynton et al. (1995) determined annual fluxes of TN and TP for each tributary. They generated exports of TN for each ranging from a high of 36.2 $\mathrm{kg}^{*} 10^{6} \mathrm{yr}^{-1}$ in the Maryland Mainstem Bay to $0.21 \mathrm{~kg}^{*} 10^{6} \mathrm{yr}^{-1}$ for the Patuxent River and an import of TN by the Choptank River $\left(-0.77 \mathrm{~kg}^{*} 10^{6} \mathrm{yr}^{-1}\right.$; Boynton et al. 1995). 


\section{Budget Exercises}

The four exercises were conducted as both a test for the sensitivity of water flow on the subsystem exchange of $\mathrm{TN}$ and to determine the possible changes associated with past decreases and proposed increases in freshwater delivery. Results from these simulations indicated consistent reductions in the amount of TN exported from Taylor River, regardless of the flow modification. Reductions in TN export for exercises 1 and 2 were associated with decreased discharge. For exercises 3 and 4, TN export to Florida Bay was reduced as a result of increased uptake by the dwarf wetland. This enhanced import of $\mathrm{TN}$ was a response to increased concentrations that were, in turn, a function of reduced salinity. Childers et al. (1993b) performed related exercises to discern the effect of incremental increases in sea level on nutrient exchange between North Inlet and the adjacent coastal zone. Their budget predicted that increased sea level (up to $20 \mathrm{~cm}$ ) would consistently yield decreased TN export from the estuary (Childers et al. 1993b).

\section{Model Weaknesses, Hypotheses and Management Implications}

The dynamic budget presented here is a barebones effort to account for TN exchange in the salinity transition zone of Taylor Slough with minimal field data. Although I had enough information on total nitrogen dynamics in the dwarf mangrove (Chapter 2 and 3), ambiguous TN flux data from the fringe subsystem (Chapter 4) and no data on benthic fluxes limited me. The relatively low chemical fluxes measured in this system did not reflect the physical differences between the dwarf and fringe subsystems (Chapters 3 and 4). Next, given the importance of areal fluxes to a budget such as this, accurate estimates of wetland area inundated are crucial in making accurate predictions of 
total subsystem flux (Childers et al. 1993b). Areal estimates in this account were made from water flux and survey data as well as past experience in these wetlands. Finally, the lack of data concerning water/nutrient input to the dwarf system, via upland runoff and precipitation, weakened the upstream end of this budget. Furthermore, the combination of these inputs and evaporative losses would have dramatically improved the model's ability to estimate surface water salinity during the dry season in this large, shallow wetland. Regardless of its weaknesses, the model still proved to be a satisfactory approximator of salinity in the STZ, net areal fluxes in the dwarf wetland, and the exchange of TN between Taylor River and Florida Bay.

Another role of this model was to test the sensitivity of TN exchange by varying the flow of water. Past and present water management strategies have resulted in a change in the natural timing and volume of freshwater delivery to Taylor Slough. According to this budget, those changes likely resulted in a reduction in the amount of nitrogen exported to Florida Bay each year, as freshwater discharge into the bay decreased. Since much of the total nitrogen was probably associated with organic matter, there may have also been a reduction in the amount of organic carbon and phosphorus exported from this system as well. However, these are unsubstantiated speculations. Future modifications to the model may aid in the understanding of past and present $\mathrm{C}$ and $\mathrm{P}$ dynamics in Taylor Slough. The reasons for restoring freshwater flow to this area are many, but the focus is mainly on nutrient supplies and offsetting hypersaline phenomena in eastern Florida Bay. While salinity reductions might occur as a result of increased freshwater flow, it is possible that the export of nutrients, especially TN, might not 
increase. The predictions of this budget suggest that TN uptake in the dwarf forest would increase, thereby reducing the amount of $\mathrm{TN}$ in the water column available for export. This concept of reduced TN export regardless of the change in freshwater flow is interesting given the goals of these restoration efforts. It not only casts a different light on the management strategies involved, but it also opens the door for further research on this and related nutrient issues. A recommended first step would be to further investigate the difference in the way these two mangrove systems cycle nitrogen. My dataset as well as nutrient data from autosamplers stationed at the northern and southern ends of the STZ suggest substantial removal of $\mathrm{TN}$ from the water column as it flows down slough (Childers and Davis, unpublished data). Ongoing research in Taylor Slough as well as in the panhandle wetlands of Everglades National Park will provide more insight into the changes in nutrient dynamics brought on by increasing freshwater delivery. 


\section{Chapter 7:}

\section{Summary}

Development in southeast Florida over the past $60+$ years has contributed to a change in the natural timing and a reduction in the volume of freshwater delivered to Taylor Slough and the $\mathrm{C}-111$ basin. These changes have gone essentially unchecked as little scientific research has been conducted to determine the long-term effect of this impact. Today we are faced with another change, as there is an effort to reestablish freshwater flow (both volume and timing) in this area to pre-management conditions.

In order to understand the potential ecological changes associated with this restoration, I conducted a study to assess the importance of season, water chemistry, and hydrologic conditions (temperature, water level, direction of flow, etc.) on the exchange of nutrients in two dominant mangrove wetland types along Taylor Slough. I also performed decomposition studies to determine the effect of water source (Everglades vs. Florida Bay), salinity, and season (wet vs. dry) on the processes controlling mass and nutrient loss from mangrove leaf litter, a potentially major source of nutrients to the water column. The results of my research indicated that these mangrove wetlands were sensitive to intra-annual changes in hydrologic parameters associated with season or water source. Furthermore, dwarf mangrove leaf decomposition appeared to be controlled by many of these parameters as well. Considering that current restoration will alter the present spatio-temporal patterns in many of these parameters, my results suggest that increased freshwater flow through this area has the potential to lead to long-term, system-level changes that may be as far reaching as eastern Florida Bay. 


\section{List of References}

Aber, J. D. and J. M. Melillo. 1980. Litter decomposition: measuring relative contributions of organic matter and nitrogen to forest soils. Canadian Journal of Botany. $58: 416-421$.

Aerts, R. 1996. Nutrient resorption from senescing leaves of perennials: are there general patterns? Journal of Ecology. 84:597-608.

Alongi, D. M. 1988. Bacterial productivity and microbial biomass in tropical mangrove sediments. Microbial Ecology. 15:59-79.

Alongi, D. M. and A. Sasekumar. 1992. Benthic communities. In A. I. Robertson and D. M. Alongi (Eds.), Tropical Mangrove Ecosystems. pp. 137-171. American Geophysical Union. Washington, D. C.

Amador, J. A. and R. D. Jones. 1993. Nutrient limitations on microbial respiration in peat soils with different total phosphorus content. Soil Biology and Biochemistry. 25(6):793801 .

Amador, J. A. and R. D. Jones. 1995. Carbon mineralization in pristine and phosphorusenriched peat soils of the Florida Everglades. Soil Science. 159(2):129-141.

Ball, M. C. 1980. Patterns of secondary succession in a mangrove forest of southern Florida. Oecologia. 44:226-235.

Ball, M. C. 1988. Ecophysiology of mangroves. Trees. 2:129-142.

Benner, R., E. R. Peele, and R. E. Hodson. 1986. Microbial utilization of dissolved organic matter from leaves of the red mangrove, Rhizophora mangle, in the Fresh Creek Estuary, Bahamas. Estuarine, Coastal and Shelf Science. 23:607-619.

Berg, B. and G. Ekbohm. 1991. Litter mass-loss rates and decomposition patterns in some needle and leaf litter types. Long-term decomposition in a Scots pine forest. VII. Canadian Journal of Botany. 69:1449-1456.

Boto, K. G. and J. S. Bunt. 1981. Tidal export of particulate organic matter from a northern Australian mangrove forest. Estuarine, Coastal, and Shelf Science. 13:247-255.

Boto, K. G. 1982. Nutrient and organic fluxes in mangroves. In B. F. Clough (Eds.), Mangrove ecosystems in Australia: structure, function and management. pp. 240-257. Australian National University Press. Canberra, Australia.

Boto, K. G. and J. T. Wellington. 1983. Phosphorus and nitrogen nutritional status of a northern Australian mangrove forest. Marine Ecology Progress Series. 11:63-69. 
Boto, K. G., D. M. Alongi, and A. L. J. Nott. 1989. Dissolved organic carbon-bacteria interactions at sediment-water interface in a tropical mangrove system. Marine Ecology Progress Series. 51:243-251.

Boto, K. G. and J. T. Wellington. 1988. Seasonal variations in concentrations and fluxes of dissolved organic materials in a tropical, tidally-dominated, mangrove waterway. Marine Ecology Progress Series. 50:151-160.

Boynton, W. R., J. H. Garber, R. Summers, and W. M. Kemp. 1995. Inputs, transformations, and transport of nitrogen and phosphorus in Chesapeake Bay and selected tributaries. Estuaries. 18:285-314.

Browder, J. A., P. J. Gleason, and D. R. Swift. 1994. Periphyton in the Everglades: spatial variation, environmental correlates, and ecological implications. in S. M. D. a. J. C. Ogden, ed. Everglades: The ecosystem and its restoration. p. 117-146. St. Lucie Press. Delray Beach, FL.

Chale, F. M. M. 1993. Degradation of mangrove leaf litter under aerobic conditions. Hydrobiologia. 257:177-183.

Chalmers, A. G., R. G. Wiegert, and P. L. Wolf. 1985. Carbon balance in a salt marsh: interactions of diffusive export, tidal deposition and rainfall-caused erosion. Estuarine, Coastal and Shelf Science. 21:757-771.

Chen, R. and R. R. Twilley. 1998. A gap dynamic model of mangrove forest development along gradients of soil salinity and nutrient resources. Journal of Ecology. $86: 37-51$.

Childers, D. L. and J. W. Day, Jr. 1988. A flow-through flume technique for quantifying nutrient and materials fluxes in microtidal estuaries. Estuarine, Coastal, and Shelf Science. 27:483-494.

Childers, D. L. and J. W. Day, Jr. 1990. Marsh-water column interactions in two Louisiana estuaries. I. Sediment dynamics. Estuaries. 13:393-403.

Childers, D. L. and J. W. Day, Jr. 1990. Marsh-water column interactions in two Louisiana estuaries. II. Nutrient dynamics. Estuaries. 13:404-417.

Childers, D. L., H. N. McKellar, R. F. Dame, F. H. Sklar, and E. R. Blood. 1993. A dynamic nutrient budget of subsystem interactions in a salt marsh estuary. Estuarine, Coastal, and Shelf Science. 36:105-131. 
Childers, D. L., S. Cofer-Shabica, and L. Nakashima. 1993. Spatial and temporal variability in marsh-water column interactions in a southeastern USA salt marsh estuary. Marine Ecology Progress Series. 95:25-38.

Childers, D. L. 1994. Fifteen years of marsh flumes: a review of marsh-water column interactions in southeastern USA estuaries, p. 277-293. In W. J. Mitsch (ed.), Global Wetlands: Old World and New. Elsevier, Amsterdam.

Childers, D. L., J. W. Day, Jr., and H. N. McKellar, Jr. 1999. Twenty more years of marsh and estuarine flux studies: revisiting Nixon (1980), In M. P. Weinstein and D. Q. Kreeger (eds.), Concepts and Controversies in Tidal Marsh Ecology.

Cintron, G., A. E. Lugo, D. J. Pool, and G. Morris. 1978. Mangroves of arid environments in Puerto Rico and adjacent islands. Biotropica. 10(2):110-121.

Cintron, G., A. E. Lugo, and R. Martinez. 1985. Structural and functional properties of mangrove forests, p. 52-66. In W. G. D'Arcy and M. D. Correa (eds.), The Botany and Natural History of Panama, IV Series: Monographs in Systematic Botany, vol. 10. Missouri Botanical Garden, St. Louis.

Clough, B. F. 1992. Primary productivity and growth of mangrove forests. In A. I. Robertson and D. M. Alongi (Eds.), Tropical Mangrove Ecosystems. pp. 225-250. American Geophysical Union. Washington, D. C.

Craighead, F. C. 1971. The Trees of South Florida. University of Miami Press, Coral Gables, Florida.

Cundell, A. M., M. S. Brown, and R. Stanford. 1979. Microbial degradation of Rhizophora mangle leaves immersed in the sea. Estuarine and Coastal Marine Science. 9:281-286.

Davis, J. H. 1940. The ecology and geologic role of mangroves in Florida, p. 303-412. Publication no. 517, Carnegie Institution, Washington.

Davis, S. M. 1989. Sawgrass and cattail production in relation to nutrient supply in the Everglades. In R. R. S. and J. W. Gibbons (Eds.), Freshwater Wetlands and Wildlife. pp. 325-341. U. S. Department of Energy. Charleston, S. C.

Duke, N. C. 1992. Mangrove floristics and biogeography. In A. I. Robertson and D. M. Alongi (Eds.), Tropical Mangrove Ecosystems. pp. 63-100. American Geophysical Union. Washington, D. C.

Egler, F. E. 1952. Southeast saline Everglades vegetation, Florida, and its management. Vegetatio Acta Botanica. 3:213-265. 
Elison, A. E., E. J. Farnsworth, and R. R. Twilley. 1996. Facultative mutualism between mangroves and root-fouling sponges in Belizean mangal. Ecology. 77(8):2431-2444.

Fell, J. W., R. C. Cefalu, I. M. Master, and A. S. Tallman (1975). Microbial activities in the mangrove (Rhizophora mangle) leaf detrital system. pp 661-679. In S. C. Snedaker, G. E. Walsh, and H. J. Teas (Eds.), Proceedings of the International Symposium on Biology and Management of Mangroves. Vol. 2. Gainesville, FL: Institute of Food and Agriculture, University of Florida.

Fell, J. W. and I. M. Master. 1980. The association and potential role of fungi in mangrove detrital systems. Botanica Marina. 23:257-263.

Feller, I. C. 1995. Effects of nutrient enrichment on growth and herbivory of dwarf red mangrove (Rhizophora mangle). Ecological Monographs. 65:477-505.

Feller, I. C. 1996. Effects of nutrient enrichment on leaf anatomy of dwarf Rhizophora mangle L. (red mangrove). Biotropica. 28(1):13-22.

Fisher, S. G. and G. E. Likens. 1973. Energy flow in Bear Brook, New Hampshire: an integrative approach to stream ecosystem metabolism. Ecological Monographs. 43:421439.

Fleming, M., G. Lin, and L. S. L. Sternberg. 1990. Influence of mangrove detritus in an estuarine ecosystem. Bulletin of Marine Science. 47:663-669.

Flores-Verdugo, F. J., J. W. Day, Jr., and R. Briseno-Duenas. 1987. Structure, litter fall, decomposition, and detritus dynamics of mangroves in a Mexican coastal lagoon with an ephemeral inlet. Marine Ecology Progress Series. 35:83-90.

Fourqurean, J. W., J. C. Zieman, and G. V. N. Powell. 1992. Phosphorus limitation of primary production in Florida Bay: Evidence from $\mathrm{C}: \mathrm{N}: \mathrm{P}$ ratios of the dominant seagrass Thalassia testudinum. Limnology and Oceanography. 37(1):162-171.

France, R., H. Culbert, C. Freeborough, and R. Peters. 1997. Leaching and early mass loss of boreal leaves and wood in oligotrophic water. Hydrobiologia. 345:209-214.

Gallardo, A. and J. Merino. 1993. Leaf decomposition in two Mediterranean ecosystems of southwest Spain: Influence of substrate quality. Ecology. 74(1):152-161.

Golley, F., H. T. Odum, and R. F. Wilson. 1962. The structure and metabolism of a Puerto Rican red mangrove forest in May. Ecology. 43:9-19.

Hemminga, M. A., F. J. Slim, J. Kazunga, G. M. Ganssen, J. Nieuwenhuize, and N. M. Kruyt. 1994. Carbon outwelling from a mangrove forest with adjacent seagrass beds and coral reefs (Gazi Bay, Kenya). Marine Ecology Progress Series. 106:291-301. 
Howarth, R. W. 1988. Nutrient limitation of net primary production in marine ecosystems. Annual Review of Ecology. 19:89-110.

Ibrahima, A., R. Joffre, and D. Gillon. 1995. Changes in leaf litter during the initial leaching phase: An experiment on the leaf litter of Mediterranean species. Soil Biology and Biochemistry. 27(7):931-939.

Killingbeck, K. T. 1996. Nutrients in senesced leaves: keys to the search for potential resorption and resorption proficiency. Ecology. 77(6):1716-1727.

Kjerfve, B., H. Stevenson, J. A. Proehl, T. H. Chrzanowski, and W. M. Kitchens. 1981. Estimation of material fluxes in an estuarine cross section: a critical analysis of spatial measurement density and errors. Limnology and Oceanography. 26:325-335.

Koch, M. S. 1997. Rhizophora mangle L. seedling development into the sapling stage across resource and stress gradients in subtropical Florida. Biotropica. 29(4):427-439.

Koch, M. S. and S. C. Snedaker. 1997. Factors influencing Rhizophora mangle L. seedling development in Everglades carbonate soils. Aquatic Botany. 59:87-98.

Kristensen, E., F. O. Andersen, and L. H. Kofoed. 1988. Preliminary assessment of benthic community metabolism in a south-east Asian mangrove swamp. Marine Ecology Progress Series. 48:137-145.

Kuenzler, E. J. 1974. Mangrove Swamp Systems. In H. T. Odum, B. J. Copeland, and E. A. McMahon (Eds.), Coastal Ecological Systems of the United States I. pp. 346-371. The Conservation Foundation. Washington, D. C.

Lee, S. Y. 1990. Primary productivity and particulate organic matter flow in an estuarine mangrove-wetland in Hong Kong. Marine Biology. 106:453-463.

Lee, S. Y. 1995. Mangrove outwelling: a review. Hydrobiologia. 295:203-212.

Liebezeit, G. 1985. Sources and sinks of organic and inorganic nutrients in mangrove ecosystems. In S. Cragg and N. Polunin (Eds.), Workshop on Mangrove Ecosystems Dynamics, 1. pp. 167-170. UNDP/UNESCO. Port Moresby, Papua New Guinea.

Lin, G. and L. S. L. Sternberg. 1992. Differences in morphology, carbon isotope ratios, and photosynthesis between scrub and fringe mangroves in Florida, USA. Aquatic Botany. 42:303-313.

Lugo, A. E. and S. C. Snedaker. 1974. The ecology of mangroves. Annual Review of Ecology and Systematics. 5:39-64. 
McIvor, C. C., J. A. Ley, and R. D. Bjork. 1994. Changes in Freshwater Inflow from the Everglades to Florida Bay Including Effects on Biota and Biotic Processes: A Review, p. 117-146. In S. M. Davis and J. C. Ogden (Eds.), Everglades: The ecosystem and its restoration. St. Lucie Press, Delray Beach, FL.

McClaugherty, C. A., J. Pastor, J. D. Aber, and J. M. Melillo. 1985. Forest litter decomposition in relation to soil nitrogen dynamics and litter quality. Ecology. 66(1):266-275.

McKee, K. L. 1993. Soil physicochemical patterns and mangrove species distribution reciprocal effects? Journal of Ecology. 81:477-487.

Meyer, J. L. 1980. Dynamics of phosphorus and organic matter during leaf decomposition in a forest stream. Oikos. 34:44-53.

Nixon, S. W. 1980. Between coastal marshes and coastal waters: a review of 20 years of speculation and research on the role of saltmarshes in estuarine productivity and water chemistry, p. 437-525. In P. Hamilton and K. B. McDowell (eds.), Estuarine and Wetland Processes. Plenum Press, New York.

Nixon, S. W., B. N. Furnas, V. Lee, N. Marshall, J. E. Ong, C. H. Wong, W. K. Gong, A. Sasekumar. 1984. The role of mangroves in the carbon and nutrient dynamics of Malaysia estuaries, p. 535-544. In E. Soepadmo, A. N. Rao, and D. J. Macintosh (eds.), Proceedings of the Asian Symposium on Mangrove Environment: research and management. Univ. of Malaya, Kuala Lumpur.

Nykvist, N. 1959. Leaching and decomposition of litter I. Experiments on leaf litter of Fraxinus excelsior. Oikos. 10:190-211.

Nykvist, N. 1961. Leaching and decomposition of litter III. Experiments on the leaf litter of Betula verrucosa. Oikos. 12:249-263.

Odum, E. P. and A. de la Cruz. 1967. Particulate organic detritus in a Georgia salt marshecosystem. American Association for the Advancement of Science Publication. 83:383388.

Odum, W. E. and E. J. Heald. 1972. Trophic analyses of an estuarine mangrove community. Bulletin of Marine Science. 22:671-738.

Odum, W. E., J. S. Fisher, and J. C. Pickral. 1979. Factors controlling the flux of particulate organic carbon from estuarine wetlands. In R. J. Livingstone (Ed.), Ecological Processes in Coastal and Marine Systems. pp. 69-80. Plenum Press. New York. 
Odum, W. E., C. C. Mclvor, and T. J. Smith, III. 1982. The ecology of mangroves of south Florida: A community profile. U.S. Fish and Wildlife Service. FWS/OBS-87/17. Washington, D.C. 177 pp.

Ohowa, B. O., B. M. Mwashote, and W. S. Shimbira. 1997. Dissolved inorganic nutrient fluxes from two seasonal rivers into Gazi Bay, Kenya. Estuarine, Coastal and Shelf Science. 45:189-195.

O'Neill, R. V. and D. L. DeAngelis. 1981. Comparative productivity and biomass relations of forest ecosystems, pp 411-449 in D. E. Reichle (ed.), Dynamic properties of forest ecosystems. Cambridge University Press, Cambridge, England.

Parsons, W. F. J., B. R. Taylor, and D. Parkinson. 1990. Decomposition of aspen (Populus tremuloides) leaf litter modified by leaching. Canadian Journal of Forest Research. 20:943-951.

Rice, D. L. and K. R. Tenore. 1981. Dynamics of carbon and nitrogen during the decomposition of detritus derived from estuarine macrophytes. Estuarine, Coastal, and Shelf Science. 13:681-690.

Rivera-Monroy, V. H., J. W. Day, R. R. Twilley, F. Vera-Herrera, and C. CoronadoMolina. 1995. Flux of nitrogen and sediments in Terminos Lagoon. Mexico. Estuarine, Coastal and Shelf Science. 40:139-160

Robertson, A. I. 1986. Leaf-burying crabs: their influence on energy flow and export from mixed mangrove forests (Rhizophora spp.) in northeastern Australia. Journal of Experimental Marine Biology and Ecology. 102:237-248.

Robertson, A. I., D. M. Alongi, and K. G. Boto. 1992. Food chains and carbon fluxes. In A. I. Robertson and D. M. Alongi (Eds.), Tropical Mangrove Ecosystems. pp. 293-326. American Geophysical Union. Washington, D. C.

Slim, F. J., M. A. Hemminga, C. Ochieng, N. T. Jannink, E. Cocheret de la Moriniere, G. van der Velde. 1997. Leaf litter removal by the snail Terebralia palustris L. and sesarmis crabs in an east African mangrove forest (Gazi Bay, Kenya). Journal of Experimental Marine Biology and Ecology. 215:35-48.

Smith, S. V. 1984. Phosphorus versus nitrogen limitation in the marine environment. Limnology and Oceanography. 29:1149-1160.

Solorzano, L, and J, H, Sharp. 1980. Determination of total dissolved phosphorus and particulate phosphorus in natural waters. Limnology and Oceanography. 25(4):754-758. 
Steinke, T. D., G. Naidoo, and L. M. Charles. 1983. Degradation of mangrove leaf and stem tissues in situ in Mgeni Estuary, South Africa. pp 141-149. In H. J. Teas (Ed.), Biology and Ecology of Mangroves. W. Junk Publishers, The Hague.

Steinke, T. D., A. J. Holland, and Y. Singh. 1993. Leaching losses during decomposition of mangrove leaf litter. South African Journal of Botany. 59(1):21-25.

Sutula, M. 1999. Processes controlling nutrient transport in the southeastern Everglades wetlands, Florida, USA. Louisiana State University, Department of Oceanography and Coastal Sciences. Ph.D. Dissertation.

Tam, N. F. Y., L. L. P. Vrijmoed, and Y. S. Wong. 1990. Nutrient dynamics associated with leaf decomposition in a small subtropical mangrove community in Hong Kong. Bulletin of Marine Science. 47(1):68-78.

Taylor, B. R. and F. Barlocher. 1996. Variable effects of air-drying on leaching losses from tree leaf litter. Hydrobiologia. 325:173-182.

Taylor, B. R. 1998. Air-drying depresses rates of leaf litter decomposition. Soil Biology and Biochemistry. 30(3):403-412.

Teal, J. M. 1962. Energy flow in the salt marsh ecosystem of Georgia. Ecology. 43:614624.

Thom, B. G. 1967. Mangrove ecology and deltaic geomorphology: Tabasco, Mexico. Journal of Ecology. 55:301-343.

Tukey, H. B. 1970. The leaching of substances from plants. Annual Review of Plant Physiology. 21:305-324.

Twilley, R. R. 1985. The exchange of organic carbon in basin mangrove forests in a southwest Florida estuary. Estuarine, Coastal and Shelf Science. 20:543-557.

Twilley, R. R., A. E. Lugo, and C. Patterson-Zucca. 1986. Litter production and turnover in basin mangrove forests in southwest Florida. Ecology. 67(3):670-683.

Twilley, R. R. 1988. Coupling of mangroves to the productivity of estuarine and coastal waters, p. 155-180. In B. O. Jansson (ed.), Coastal-Offshore Ecosystem Interactions. Springer-Verlag, Berlin.

Twilley, R. R. 1995. Properties of mangrove ecosystems related to the energy signature of coastal environments. in C. A. S. Hall, ed. Maximum Power: The ideas and applications of H. T. Odum. University Press of Colorado. Niwot, Colorado. p. 43-62. 
Twilley, R. R. 1998. Mangrove Wetlands. In M. G. Messina and W. H. Conner (Eds.), Southern Forested Wetlands: Ecology and Management. pp. 445-473. Lewis Publishers. Boca Raton, Florida.

Vitousek, P. M., D. R. Turner, W. J. Parton, and R. L. Sanford. 1994. Litter decomposition on the Mauna Loa environmental matrix, Hawaii: Patterns, mechanisms, and models. Ecology. 75(2):418-429.

Wafar, S., A. G. Untawle, and M. Wafar. 1997. Litter fall and energy flux in a mangrove ecosystem. Estuarine, Coastal and Shelf Science. 44:111-124.

Whiting, G. J., H. N. McKellar, Jr., J. D. Spurrier, and T. J. Wolaver. 1989. Nitrogen exchange between a portion of vegetated salt marsh and the adjoining creek. Limnology and Oceanography: 34(2):463-473.

Whiting, G. J. and D. L. Childers. 1989. Subtidal advective water flux as a potentially important nutrient import to southeastern U.S.A. saltmarsh estuaries. Estuarine, Coastal and Shelf Science. 28:417-431.

Wolaver, T. G. and J. D. Spurrier. 1988. The exchange of phosphorus between a euhaline vegetated marsh and the adjacent tidal creek. Estuarine, Coastal and Shelf Science. $26: 203-214$

Wolaver, T. G., J. C. Zieman, R. Wetzel, and K. L. Webb. 1983. Tidal exchange of nitrogen and phosphorus between a mesohaline vegetated marsh and the surrounding estuary in the lower Chesapeake Bay. Estuarine, Coastal and Shelf Science. 16:321-332.

Wolaver, T., G. Whiting, B. Kjerfve, J. Spurrier, H. McKellar, R. Dame, T. Chrzanowski, R. Zingmark, and T. Williams. 1985. The flume design-Methodology for evaluating material fluxes between a vegetated salt marsh and the adjacent tidal creek. Journal of Experimental Marine Biology and Ecology. 91:281-291.

Wolaver, T. G., G. J. Whiting, R. F. Dame, T. M. Williams, and J. D. Spurrier. 1988. Bly Creek ecosystem study - nitrogen exchange within a euhaline salt marsh basin of North Inlet, South Carolina. Marine Ecology Progress Series. 49:107-116.

Woodroffe, C. D. 1985. Studies of a mangrove basin, Tuff Crater, New Zealand: III. The flux of organic and inorganic particulate matter. Estuarine, Coastal and Shelf Science. 20:447-461.

Woodroffe, C. 1992. Mangrove sediments and geomorphology. In A. I. Robertson and D. M. Alongi (Eds.), Tropical Mangrove Ecosystems. pp. 7-42. American Geophysical Union. Washington, D. C. 


\section{Sources of Unpublished Materials}

Childers, D. L. and S. E. Davis, Department of Biological Sciences/Southeast Environmental Research Center, Florida International University, University Park, Miami, FL 33199.

Rudnick, D. T., South Florida Water Management District, Everglades Systems Research Division, 3301 Gun Club Road, West Palm Beach, FL 33416. 


\section{VITA}

\section{STEPHEN EDWARD DAVIS, III}

September 4,1970

1993

1994

1995-1998
Born, Dayton, Ohio

B.S., Biology

Georgetown College

Georgetown, Kentucky

M.S., Biology

Morehead State University

Morehead, Kentucky

Laboratory Teaching Assistant

Ecology and General and Human Biology

Florida International University

Miami, Florida

\section{PUBLICATIONS AND PRESENTATIONS}

Davis, S. E., D. L. Childers, J. W. Day, Jr., D. T. Rudnick, and F. H. Sklar. in review. An enclosure technique for quantifying wetland-water column exchange of nutrients in non-tidal dwarf mangrove wetlands. Estuaries.

Childers, D. L., S. E. Davis, III, R. Twilley, and V. Rivera-Monroy. 1999. Wetland-water column interactions and the biogeochemistry of estuary-watershed coupling around the Gulf of Mexico. pp. 211-235. In: T. S. Bianchi, J. R. Pennock, and R. R. Twilley (Eds.), Biogeochemistry of Gulf of Mexico Estuaries. John Wiley \& Sons, New York.

Davis, S. E., B. C. Reeder, and M. D Quillen. Sediment and Nutrient Considerations in Three Tidal Creeks of North Inlet, South Carolina. November 9, 1991 at the Annual Meeting of the Kentucky Academy of Sciences, Owensboro, Kentucky.

Davis, S. E., B. C. Reeder, and M. D Quillen. Nutrient Considerations in Tidal Creeks of North Inlet, South Carolina. April 10, 1992 at the Annual Meeting of the Association of Southeastern Biologists, Tuscaloosa, Alabama.

Davis, S. E., B. C. Reeder, and M. D Quillen. Advective Nutrient Flux in Tidal Creeks of North Inlet, South Carolina. April 16, 1993 at the Annual Meeting of the Association of Southeastern Biologists, Virginia Beach, Virginia. 
Davis, S. E. and B. C. Reeder. Water Quality Analysis of Eight Eastern Kentucky

Reservoirs. November 1, 1994 at the annual Scientific Symposium for the Ohio River Basin Consortium for Research and Education, Huntington, West Virginia.

Davis, S. E. and D. L. Childers. Two New Methods for Measuring Nutrient Flux in South Florida Mangrove Systems. May 13, 1996 at the Mangrove Modeling Workshop, South Florida Water Management District, West Palm Beach, Florida.

Davis, S. E. and D. L. Childers. Salinity and Organic Matter Transformations as Controls on Wetland-Water Column Interactions in a South Florida Mangrove. May 24, 1997 at the First Annual Walt Dineen Society for South Florida Ecosystems, Florida International University, Miami, Florida.

Davis, S. E. and D. L. Childers. Nutrient Flux and Organic Matter Transformations in Everglades Mangrove Wetlands. August 13, 1997 at the Annual Meeting of the Ecological Society of America jointly with The Nature Conservancy, Albuquerque, New Mexico.

Davis, S. E. and D. L. Childers. The Influence of Salinity on Carbon, Nitrogen, and Phosphorus Flux in Two South Florida Mangroves. October 13, 1997 at the 14th Biennial Estuarine Research Federation Conference, Providence, Rhode Island.

Davis, S. E. and D. L. Childers. Effect of Salinity on Wetland-Water Column Interactions in Taylor River Mangroves. January 7, 1998 at the Southeast Environmental Research Program, Florida International University, Miami, Florida.

Davis, S. E. and D. L. Childers. Seasonal Variation in Concentration and Fluxes of Carbon, Nitrogen, and Phosphorus in two South Florida Mangrove Forests. March 27, 1998 at the Gulf Estuarine Research Society's Spring Meeting, Galveston, Texas.

Davis, S. E. and D. L. Childers. Investigating the Influence of Season/Salinity on MangroveWater Column Interactions at two Spatial Scales in Taylor River (poster). May 12, 1998 at the 1998 Florida Bay Science Conference, Miami, Florida.

Davis, S. E. and D. L. Childers. The release of Carbon, Nitrogen, and Phosphorus via leaf leaching in an oligotrophic mangrove wetland of the southern Everglades - An experiment testing the effects of salinity and season. January 15,1999 at the $1^{\text {st }}$ Annual Biology Research Symposium, Florida International University, Miami, Florida.

Davis, S. E. and D. L. Childers. The release of Carbon, Nitrogen, and Phosphorus via leaf leaching in an oligotrophic mangrove wetland of the southern Everglades - An experiment testing the effects of salinity and season. March 26, 1999 at the annual meeting of the Gulf Estuarine Research Society. Louisiana State University, Baton Rouge, Louisiana. 
Davis, S. E. and B. C. Reeder. Water Quality Analysis of Eight Eastern Kentucky

Reservoirs. November 1, 1994 at the annual Scientific Symposium for the Ohio River Basin Consortium for Research and Education, Huntington, West Virginia.

Davis, S. E. and D. L. Childers. Two New Methods for Measuring Nutrient Flux in South Florida Mangrove Systems. May 13, 1996 at the Mangrove Modeling Workshop, South Florida Water Management District, West Palm Beach, Florida.

Davis, S. E. and D. L. Childers. Salinity and Organic Matter Transformations as Controls on Wetland-Water Column Interactions in a South Florida Mangrove. May 24, 1997 at the First Annual Walt Dineen Society for South Florida Ecosystems, Florida International University, Miami, Florida.

Davis, S. E. and D. L. Childers. Nutrient Flux and Organic Matter Transformations in Everglades Mangrove Wetlands. August 13, 1997 at the Annual Meeting of the Ecological Society of America jointly with The Nature Conservancy, Albuquerque, New Mexico.

Davis, S. E. and D. L. Childers. The Influence of Salinity on Carbon, Nitrogen, and Phosphorus Flux in Two South Florida Mangroves. October 13, 1997 at the 14th Biennial Estuarine Research Federation Conference, Providence, Rhode Island.

Davis, S. E. and D. L. Childers. Effect of Salinity on Wetland-Water Column Interactions in Taylor River Mangroves. January 7, 1998 at the Southeast Environmental Research Program, Florida International University, Miami, Florida.

Davis, S. E. and D. L. Childers. Seasonal Variation in Concentration and Fluxes of Carbon, Nitrogen, and Phosphorus in two South Florida Mangrove Forests. March 27, 1998 at the Gulf Estuarine Research Society's Spring Meeting, Galveston, Texas.

Davis, S. E. and D. L. Childers. Investigating the Influence of Season/Salinity on MangroveWater Column Interactions at two Spatial Scales in Taylor River (poster). May 12, 1998 at the 1998 Florida Bay Science Conference, Miami, Florida.

Davis, S. E. and D. L. Childers. The release of Carbon, Nitrogen, and Phosphorus via leaf leaching in an oligotrophic mangrove wetland of the southern Everglades - An experiment testing the effects of salinity and season. January 15,1999 at the $1^{\text {st }}$ Annual Biology Research Symposium, Florida International University, Miami, Florida.

Davis, S. E. and D. L. Childers. The release of Carbon, Nitrogen, and Phosphorus via leaf leaching in an oligotrophic mangrove wetland of the southern Everglades - An experiment testing the effects of salinity and season. March 26,1999 at the annual meeting of the Gulf Estuarine Research Society. Louisiana State University, Baton Rouge, Louisiana. 